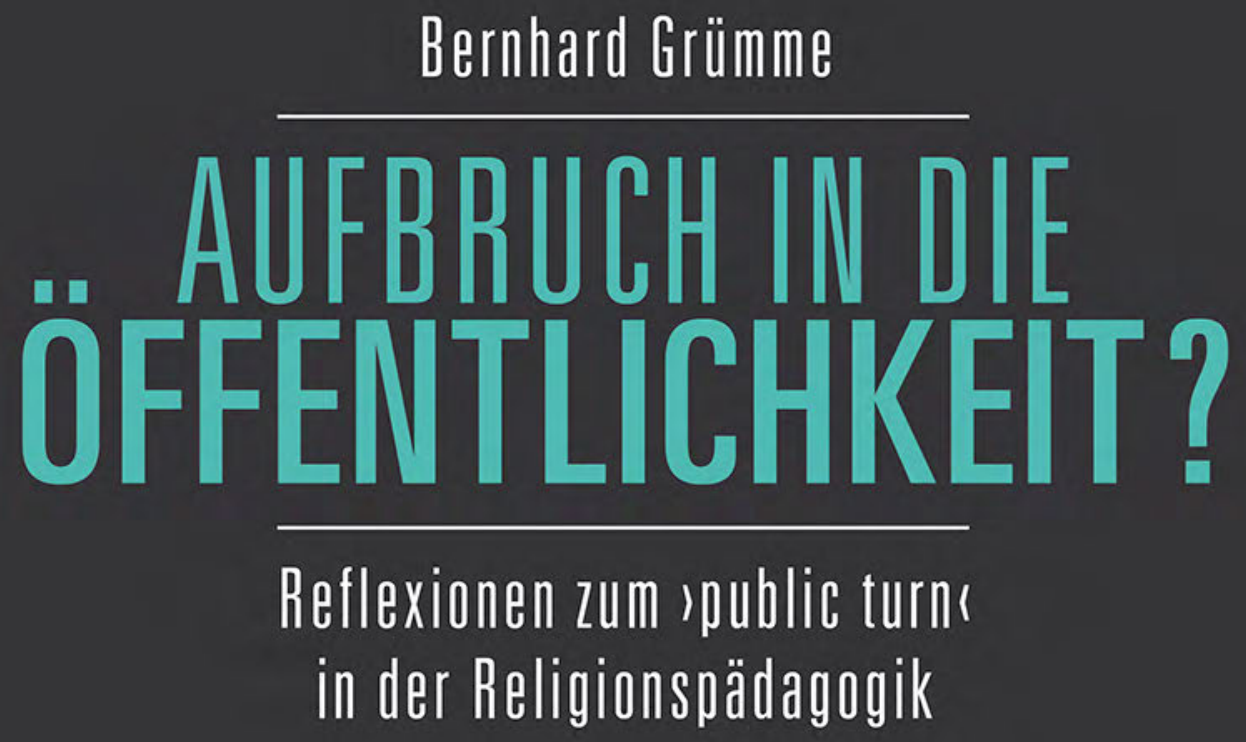

[transcript] Religionswissenschaft 
Bernhard Grümme

Aufbruch in die Öffentlichkeit?

Religionswissenschaft | Band 12 
Bernhard Grümme (Dr. theol. habil.), geb. 1962, ist Lehrstuhlinhaber für Religionspädagogik und Katechetik an der Katholisch-Theologischen Fakultät der Ruhr-Universität Bochum mit dem Schwerpunkt religionspädagogische Grundlagentheorie und Heterogenitätsforschung. 2015 und 2017 war er Gastwissenschaftler an der Universität PUCRS Porto Alegre (Brasilien). Er ist Mitglied der REA (Religious Education Association, USA). 
BERNHARD GRÜMME

\section{Aufbruch in die Öffentlichkeit?}

Reflexionen zum spublic turnı in der Religionspädagogik 


\section{(c)}

Dieses Werk ist lizenziert unter der Creative Commons Attribution 4.० (BY). Diese Lizenz erlaubt unter Voraussetzung der Namensnennung des Urhebers die Bearbeitung, Vervielfältigung und Verbreitung des Materials in jedem Format oder Medium für beliebige Zwecke, auch kommerziell. (Lizenztext: https://creativecommons.org/licenses/by/4.o/deed.de)

Erschienen im transcript Verlag 2018

(C) Bernhard Grümme

Bibliografische Information der Deutschen Nationalbibliothek

Die Deutsche Nationalbibliothek verzeichnet diese Publikation in der Deutschen Nationalbibliografie; detaillierte bibliografische Daten sind im Internet über http://dnb.d-nb.de abrufbar.

Umschlaggestaltung: Kordula Röckenhaus, Bielefeld Satz: Justine Buri, Bielefeld Druck: Majuskel Medienproduktion $\mathrm{GmbH}$, Wetzlar Print-ISBN 978-3-8376-4227-8

PDF-ISBN 978-3-8394-4227-2

Gedruckt auf alterungsbeständigem Papier mit chlorfrei gebleichtem Zellstoff. Besuchen Sie uns im Internet: http://www.transcript-verlag.de Bitte fordern Sie unser Gesamtverzeichnis und andere Broschüren an unter: info@transcript-verlag.de 


\section{Inhalt}

\section{A. Einleitung $\mid 9$}

\section{B. Aufbruch zu einer Öffentlichen Religionspädagogik $\mid 15$}

1. Kontextuelle Herausforderungen $\mid 15$

2. Erste Konturierungen $\mid 18$

3. Öffentliche Religionspädagogik zwischen public theology und Kritischer Theorie $\mid 21$

4. Eine defizitäre Begriffsbildung. Skizzen eines Desiderats $\mid 27$

5. Markierungen $\mid 29$

5.1 Annäherungen aus dem politikwissenschaftlichen Diskurs heraus: Judith Könemann | 30

5.2 Gesuchte Anschlussfähigkeit an sozialphilosophische Zugänge: Manfred Pirner $\mid 34$

5.3 Ein systematischer Entwurf öffentlicher Religionspädagogik: Bernd Schröder $\mid 39$

6. Auftrag zu einer Metatheorie Öffentlicher Religionspädagogik $\mid 43$

C. Konzepte der Öffentlichkeit $\mid 47$

1. Deliberative Öffentlichkeit: Jürgen Habermas $\mid 47$

1.1 Bürgerliche Öffentlichkeit $\mid 48$

1.2 Deliberation und Kommunikative Vernunft $\mid 49$

1.3 Öffentlichkeit und Religion. Ein Exemplum deliberativer Öffentlichkeitstheorie | 55

1.4 Debatten um den Öffentlichkeitsbegriff | 62

$1.5 \quad$ Kritik $\mid 64$

1.5.1 Universalität - Partikularität | 64

1.5.2 Religion $\mid 68$

1.5.3 Diskurstheorie $\mid 70$

2. Liberale Öffentlichkeit: Volker Gerhardt $\mid 74$

$2.1 \quad$ Systematisch-genetische Annäherungen 174

2.2 Profil $\mid 76$ 
2.3 Soziomorphes Bewusstsein als Grund der Öffentlichkeit | 79

2.4 Konsequenzen $\mid 81$

2.5 Kritik $\mid 83$

2.5.1 Kriterien $\mid 83$

2.5.2 Normativitätsschwäche $\mid 85$

2.5.3 Religionspädagogische Perspektive | 86

3. Öffentlichkeit zwischen System und Umwelt: Niklas Luhmann | 88

3.1 Systemlogik statt Subjekt. Von der Kultivierung

der Beobachterperspektive | 89

3.2 Implikationen $\mid 91$

3.3 Systemtheoretische Öffentlichkeit $\mid 93$

3.4 Kritik|96

3.4.1 Subjekt $\mid 97$

3.4.2 Differenz $\mid 97$

3.4.3 Wahrheit $\mid 98$

3.4.4 Luhmann und die Öffentliche Religionspädagogik | 99

4. Pragmatische Öffentlichkeitstheorie: Charles Taylor $\mid 102$

4.1 Anthropologie in modernekritischer Absicht | 104

4.2 Pathologien der Moderne 104

4.2.1 Atomismus $\mid 104$

4.2.2 Instrumentelle Vernunft $\mid 107$

4.2.3 Entpolitisierung $\mid 110$

4.3 Der Vorrang des Guten vor dem Gerechten | 113

4.4 Öffentlichkeit als Resultat moderner Transformationsprozesse | 115

4.5 Vernunftfähige Religion | 121

4.6 Hanan Alexanders Pädagogik als Konkretisierung | 125

4.7 Kritik $\mid 130$

5. Poststrukturalismus und Performative Öffentlichkeit: Judith Butler | 133

5.1 Poststrukturalistische Anbahnungen bei Foucault | 134

5.2 Subjektivierung und Identitätsbildung | 139

5.3 Entnormierte Vernunft? | 143

5.4 Sprache, Performativität, Widerstand $\mid 146$

5.5 Performative Öffentlichkeit $\mid 150$

5.5.1 Öffentlichkeit und Privatheit $\mid 150$

5.5.2 Öffentlichkeitstheoretische Ausweitung des Performativitätsbegriffs | 154

5.5.3 Religion als Index für Alterität | 157

5.6 Kritik $\mid 158$ 
6. Ertrag und Frageüberhang $\mid 165$

6.1 Vernunft $\mid 166$

6.2 Normativität 167

6.3 Verhältnis von Universalität und Partikularität $\mid 168$

6.4 Religion in der Öffentlichkeit $\mid 169$

\section{Skizze eines religionspädagogischen Öffentlichkeitsbegriffs | 171}

1. Anläufe $\mid 171$

2. Zuspitzung $\mid 173$

3. Alteritätstheoretische Vernunft $\mid 176$

4. Aufgeklärte Selbstreflexivität und Normativität $\mid 179$

5. Öffentlichkeit zwischen Universalität und Partikularität | 184

6. Religion als Bewährungsprobe $\mid 189$

7. Öffentliche Religion $\mid 193$

8. Konsequenzen $\mid 197$

E. Fazit und Ausblick. Religionspädagogische Implikationen | 201

1. Konturen eines alteritätstheoretisch strukturierten Öffentlichkeitsbegriffs | 201

2. Religionspädagogische Öffentlichkeiten $\mid 203$

2.1 Makroebene: Religionspädagogik in den diversen Öffentlichkeiten | 204

2.2 Mesoebene: Religionspädagogik in der Vielzahl ihrer Disziplinen | 205

2.3 Mikroebene: Religionsunterricht 205

2.3.1 Außerreligionsunterrichtliche Öffentlichkeit | 206

2.3.2 Innerreligionsunterrichtliche Öffentlichkeit $\mid 208$

3. Religion als conversation stopper? Horizonte $\mid 212$

Literatur | 217

Internetquellen | 243

Namensregister | 247 



\section{A. Einleitung}

Gibt es einen »public turn « in der Wissenschaft? ${ }^{1}$ Sehen sich Wissenschaftler mehr und mehr gezwungen, sich aus ihren Hörsälen, Laboratorien, ihren Büros und Studierstuben auf die Straße, auf die Plätze, in die Kirchen, die Bürgerversammlungen und Organisationen, die Parlamente zu begeben? Jedenfalls sieht vieles danach aus, wenn man Entwicklungen in verschiedenen Wissenschaften analysiert. Längst hat der Elfenbeinturm, ohnehin mehr Konstrukt als Realität, als vorrangiger Orientierungsrahmen wissenschaftlicher Selbstverständigungsprozesse ausgedient. Wissenschaftler arbeiten nicht in ihrem stillen Kämmerlein. Auch ein umgekehrter Blickwechsel ist zu vermelden. Man fordert gesellschaftlich Expertise, man fordert - gelegentlich unter Missverständnis des ureigenen Anspruchs der Forschungsfreiheit - wissenschaftliche Voten und wissenschaftliche Gutachten, deren Validität gleichzeitig in Zeiten von fake news und populistischen Verzerrungen massiv angefragt wird. Ein Trend der Wissenschaft zur Öffentlichkeit und der Öffentlichkeit zur Wissenschaft ist offensichtlich.

Der Aufbruch zu einem public turn findet sich auf verschiedenen Feldern der Wissenschaften, wie sich exemplarisch zeigen lässt:

Eine Öffentliche Soziologie, in den USA als Public Sociology entwickelt, wird inzwischen auch im deutschsprachigen Raum breit rezipiert. Für deren Erfolg ist einerseits die Erkenntnis federführend, dass es in der Logik der Soziologie selber liegt, sich nicht nur durch empirische Forschungen und Publikationen, sondern durch eigene Positionierungen publik zu machen. Andererseits zeigt sich in Zeiten von Pluralisierung und eskalierend beschleunigter Unübersichtlichkeit ein wachsender Bedarf an Orientierungen, an Selbst- und Fremddeutungen. Es charakterisiert eine Öffentliche Soziologie, darauf bis in

1 Aulenbacher, Dörre, Michael Burawoys 2015, 12. Vgl. Kreutzer, Politische Theologie für heute 2017, 7-30. 
die eigenen wissenschaftstheoretischen Grundlegungen konstruktiv zu reagieren. $^{2}$

Innerhalb der Erziehungswissenschaft, über ihre Beschäftigung mit privaten Instanzen wie der Familie hinaus ohnehin in ihrem Bezug auf Institutionen des Kindergartens, der Schule, Erwachsenenbildung oder auch Universität konstitutiv auf Öffentlichkeit ausgerichtet, artikulieren sich starke Stimmen, die für eine Öffentliche Erziehungswissenschaft plädieren. So wird angesichts eines sich historisch verändernden Verhältnisses von >privat< und >öffentlich und den wandelnden gesellschaftlichen, privaten und politisch-ökonomischen Formationen eine bewusste Positionierung der Erziehungswissenschaft im Öffentlichen vorgenommen. Vor dem Hintergrund der

"aktuellen, aktiven Umstrukturierung der Öffentlichkeit durch die Veränderung des Sozialen, durch die Privatisierung des Staatlichen und durch die Entprivatisierung des Privaten kann das Erziehungswesen den Blick auf vielfältige (Teil-/Gegen-)Öffentlichkeiten richten und sich selbst als Teil konstruktiver Öffentlichkeiten nach demokratischem Modell situieren. Das öffentliche Erziehungswesen ermöglicht somit die Kooperation von staatlicher und privater Souveränität. “ ${ }^{3}$

Wird so in einer genealogischen und zudem interkulturellen Perspektive der öffentliche Charakter der Erziehungswissenschaft anvisiert, werden darüber hinaus neuerdings auch erziehungswissenschaftliche Aspekte des Strukturwandels der Öffentlichkeit bedacht, die insbesondere mit einer Internet- und Medienöffentlichkeit im Zuge fortschreitender Digitalisierung zu tun haben, ${ }^{4}$ so finden sich daneben auch historische Forschungen zur erziehungswissenschaftlichen Relevanz von Öffentlichkeit. ${ }^{5}$

Profiliert und unter gesellschafts- wie kulturkritischen Aspekten spezifiziert wird dies im Programm einer Öffentlichen Erziehung.

"Das Thema ,Öffentliche Erziehung، fokussiert die gesellschaftliche Verortung von Schule, Unterricht und Bildung und greift damit eine der Schlüsselfragen erziehungswissenschaftlicher Reflexion auf. Es geht um den gesellschaftlichen Ort der Erziehung im Kontext der europäischen Aufklärung und der sozialen, ökonomischen, politischen und kulturellen Modernisierungsprozesse ab der zweiten Hälfte des 18. Jahrhunderts. Mit Blick auf den Entstehungszeitraum des Konzepts Öffentlicher Erziehung konzentriert sich die pädagogische Diskussion über Erziehung und Bildung vor allem auf die

2 | Vgl. Burawoy, Public Sociology 2015; Kreutzer, Politische Theologie für heute 2017, $7 f$.

3 | Kojima, Die Öffentlichkeiten der Erziehung 2015, 17.

4 | Vgl. Binder, Oelkers, Der neue Strukturwandel von Öffentlichkeit 2017.

5 | Vgl. Brüggen, Art. Öffentlichkeit 2010, 724-749. 
wechselseitigen Bedingungsverhältnisse von Bildung, Öffentlichkeit, Demokratie und Modernisierung. " 6

Die Rede ist von einem demokratischen »Habitus« in der Zivilgesellschaft, für dessen Genese Bildung und Erziehung elementar sind. »Bildung ist dabei nicht im Sinne eines akademischen Grades notwendig, sondern als Voraussetzung für intelligente Problemlösungen, die demokratisch ausgehandelt und an der Basis erzeugt wird, ohne die Komplexität der Probleme zu unterschätzen. $\ll^{7}$ Überraschenderweise gibt es freilich in der Allgemeinen Pädagogik eine interessante Perspektivenallianz, insofern im prominenten Entwurf Dietrich Benners die Öffentlichkeit der Schule mit der Öffentlichkeit von Religion und religiöser Bildung verbunden wird. ${ }^{8}$

Ebenfalls die Theologie ist öffentlich geworden, jedenfalls in Teilen. Die Neue Politische Theologie, weithin theologisch etabliert und profiliert, ohne doch an den Universitäten schulbildend geworden $\mathrm{zu}$ sein, fragt nach den gesellschaftlichen und politischen Implikationen des Glaubens in Geschichte und Gesellschaft. Sie will gegenüber allen Privatisierungstendenzen den Glauben im Lichte gesellschaftlicher, politischer und kultureller Selbstverständigungsprozesse in der Moderne als befreiendes Potential ausweisen und zugleich darin das öffentliche Potential des Glaubens in einer bestimmten, nämlich gesellschaftskritischen und prophetischen Weise in die gegenwärtigen Lebenswelten und Diskurse einbringen. Aus der eigenen Tradition wie aus der Gesellschaft heraus drängt in der Perspektive der Politischen Theologie der Glaube in die Öffentlichkeit. Er trägt Öffentlichkeitscharakter.9

Vergleichbar, doch mit anderem Akzent, profiliert sich eine Öffentliche Theologie im deutschsprachigen Raum, die in einer gewissen genealogischterminologischen Analogie zur public sociology aus der ebenfalls primär im angloamerikanischen Kontext situierten public theology hervorgeht. Während die Politische Theologie in der gegenwärtigen Wahrnehmung trotz beeindruckender Revitalisierungsversuche eher verblasst, ${ }^{10}$ drängt die Öffentliche Theologie über kirchliche und theologische Kreise in die allgemeine gesellschaftliche Öffentlichkeit. Programmatisch höchst aufschlussreich und deshalb als längeres Zitat wiedergegeben ist das mission statement des 2017 gegründeten Berlin-Institute for Public Theology.

6 | Amos u.a., Öffentliche Erziehung revisited 2011, 9.

7 | Oelkers, Öffentliche Bildung ohne Öffentlichkeit 2017, 114.

8 | Vgl. Benner, Bildung und Religion 2014, 127-141.

9 | Vgl. Metz, Zum Begriff der neuen Politischen Theologie 1997; Metz, Memoria passionis 2006; Schüssler Fiorenza u.a., Politische Theologie 2011; Manemann, Wacker, Politische Theologie - gegengelesen 2008.

10 | Vgl. Kreutzer, Politische Theologie für heute 2017. 
"Public Theology, understood as theologically informed interdisciplinary discourse on public issues and the scholarly reflexion thereof, is of paramount importance in modern societies which tend to be pluralistic in regard to religions and comprehensive worldviews. It involves the plural perspectives of faith into public debates and allows for a critical reflection of those perspectives. Thus it enables public scrutiny of those perspectives while enriching public discourse by the contribution of religious perspectives. As Public Theology is vitally interested in public discourse as part of a democratic and pluralistic culture, it tries to enable and further it wherever possible. By rendering the particular background perspectives transparent, Public Theology contributes to the clarification of normative issues, the formation of opinions and political deliberation. Even though originating in a Protestant Christian field of discourse, Public Theology as an academic endeavour aims at an horizon encompassing ecumenical, interreligious and other perspectives on comprehensive worldviews. "11

Öffentliche Theologie sieht demnach ihren Ort wesentlich in der Öffentlichkeit, lässt sich aus ihr herausfordern und bringt sich dort kritisch ein.

Damit lösen Politische wie Öffentliche Theologie je auf ihre Weise ein, was der Wissenschaftsrat von der gesamten Theologie nicht nur für den Bereich der Universitäten gefordert hat und worauf die Theologie in der Vielzahl ihrer Disziplinen inzwischen sensibel und differenziert reagiert. ${ }^{12}$

Innerhalb der Theologien gibt es nun auch in der Religionspädagogik Aufbrüche zu einer Öffentlichen Religionspädagogik. Diese wollen, je nach innertheologischen und interdisziplinären Referenzen, den Impulsen der Politischen und Öffentlichen Theologie sowie einer Öffentlichen Erziehungswissenschaft folgend, die Religionspädagogik als eine öffentliche Wissenschaft ausweisen und profilieren. Öffentlichkeit ist dort ein zentrales Forum, an dem, durch das und für das religiös gelernt wird. Öffentliche Religionspädagogik hat von verschiedenen Teilöffentlichkeiten zu sprechen gelernt. Religiöse Bildung will sich dementsprechend ausweisen, bewahrheiten und kritisch-produktiv einbringen in den verschiedenen Öffentlichkeiten der Schule, Universität, Kirche

11 | Berlin Institute for Public Theology, Mission Statement, https://www.theologie. hu-berlin.de/de/professuren/institute/bipt (3.8.2017, 17:09 Uhr).

12 | Vgl. Wissenschaftsrat, Empfehlungen zur Weiterentwicklung, https://www.wissen schaftsrat.de/download/archiv/9678-10.pdf (3.8.2017, 17:16 Uhr); Krieger, Zur Zukunft der Theologie 2017. 
und Gesellschaft. ${ }^{13}$ Auch diese Initiative hat, auf breiter Publikationsbasis, ${ }^{14}$ ihren vielversprechenden institutionellen Niederschlag gefunden. ${ }^{15}$

Doch so sehr sich auch die Religionspädagogik ihrerseits in diesem public turn artikuliert, so sehr dies zu begrüßen ist angesichts ihrer Geschichte, in der sie sich selber zu affirmierenden Tendenzen hat hinreißen und in der sie sich hat politisch instrumentalisieren lassen oder in der sie selber eine dunkle Geschichte schwarzer, dehumanisierender Pädagogik hat, ${ }^{16}$ so bleibt vor allem ein grundlegendes Desiderat. Die bisher vorgelegten Versionen Öffentlicher Religionspädagogik lassen - unbeschadet ihrer hohen Instruktionskraft, Kohärenz und Plausibilität - einen zentralen Aspekt außer Acht: Sie reflektieren nicht über den Öffentlichkeitsbegriff selber. Sie bedenken Öffentlichkeit als Gegenstand, reflektieren über interdisziplinäre Referenzen und Bezugsgrößen, aus denen heraus sich diese Öffentliche Religionspädagogik befruchten, korrigieren und inspirieren lassen könnte. Sie unterlassen es aber darüber nachzudenken, wie dieser Begriff selber gebildet wird, was seine semantischen, pragmatischen und vor allem performativen Implikationen sind. Damit aber zeigen sie nicht nur ein Defizit auf hermeneutischer wie grundlagentheoretischer Ebene. Nur mit einer präzisen Begrifflichkeit ist deren Anliegen bestimmt und kritisch-konstruktiv zu artikulieren. Das Problem ist zudem, dass durch diese Lücke potentiell ihr eigenes Anliegen gefährdet wird. Denn es könnte doch sein, dass Öffentliche Religionspädagogik mit ihrer Weise, Öffentlichkeit zu denken, ihre eigene Tradition und Wahrheit performativ unterläuft, ja vielleicht gar konterkariert. Das ist die These der folgenden Überlegungen.

Um dieses Desiderat analytisch-kritisch wie konstruktiv zu bearbeiten, gilt es, den Argumentationsgang in vier Schritten anzulegen:

Erstens muss dieses Desiderat erst einmal präzise aufgewiesen werden. Dazu dient ein kritischer Durchgang durch maßgebliche Versionen Öffentlicher Religionspädagogik (Teil B).

Zweitens wird dann interdisziplinär in einem noch zu begründenden Bezugsfeld nach weiterführenden Referenzen gesucht, die einen Öffentlichkeitsbegriff erst angemessen denkbar machen (Teil C). Damit ist einerseits

13 | Vgl. Grümme, Öffentliche Religionspädagogik 2015; Pirner, Öffentliche Religionspädagogik 2015, 62-81; Schlag, Öffentliche Kirche 2012; Schröder, Religionspädagogik 2012; Pirner, Lähnemann, Haussmann, Schwarz, Public Theology, Religious Diversity and Interreligious Learning 2018.

14 | Vgl. Themenheft Religionspädagogik und Öffentlichkeit 2015; Themenheft Öffentliche Religionspädagogik 2016.

15 | Vgl. Forschungsstelle für Öffentliche Religionspädagogik www.rupre.uni-erlangen. org (19.8.2017, 16:31 Uhr).

16 | Vgl. Sander, Politik in der Schule 2004; Paul, Antike und Mittelalter 1993; Paul, Barock und Aufklärung 1995; Weber, Aspekte zu einer Sozialgeschichte 1983, 108-176. 
die Anschlussfähigkeit an die theologische Tradition gemeint, andererseits die reflexive und praktische Ausweisbarkeit und Legitimierbarkeit im gegenwärtigen Kontext. Eine solche Kontextualität ist nach dem hier zu Grunde gelegten Verständnis geradezu von axiomatischer Qualität für den Öffentlichkeitsbegriff. Dieser Kontext ist in religionspädagogischer Hinsicht vor allem durch interdependente Faktoren geprägt wie die Pluralisierung, Säkularisierung und die zunehmende Ausdifferenzierung sozialer, kultureller, ökonomischer, religiöser Lebenswelten, die sich durch Globalisierung und Migration, durch fehlende Inklusion, Anerkennung und Gerechtigkeit noch intensiviert. All dies schlägt sich in den überkomplexen Diversitätserfahrungen bis in den konkreten Unterricht hinein nieder. Kurz: Die Gegenwart ist in einem eminenten Maße heterogen geworden, dass es zu den grundlegenden Anforderungen an die Religionspädagogik geworden ist, heterogenitätsfähig zu werden. ${ }^{17}$

Drittens liegt es insofern auf der Hand, dass die Konturierung und Begründung eines religionspädagogischen Öffentlichkeitsbegriffs sich vor diesem Anforderungsprofil ausweisen und bewähren muss. Hierbei wird eine alteritätstheoretische Vernunft eine erhebliche Begründungslast tragen (Teil D).

Und viertens wird schließlich die Perspektive auf Implikationen für die Religionspädagogik in ihren verschiedenen Öffentlichkeiten gewendet und damit das eingangs thematisierte Desiderat zu beseitigen versucht (Teil E).

17 | Vgl. Grümme, Heterogenität 2017. 


\section{B. Aufbruch zu einer Öffentlichen Religionspädagogik}

\section{Kontextuelle Herausforderungen}

Die Religionspädagogik kommt in Bewegung. ${ }^{1}$ Mit neu entflammter Leidenschaft wird über Formen des Religionsunterrichts nachgedacht, der der zunehmenden Säkularisierung und Pluralisierung von Religion gerecht zu werden und dabei die wachsende Zahl an nicht-konfessionell Gebundenen mit $\mathrm{zu}$ bedenken vermag. Kann Religionsunterricht noch im Binnenraum konfessioneller Selbstverständigungsprozesse angesiedelt sein, wenn die Voraussetzung einer wenigstens in Ansätzen christlich sozialisierten Schülerschaft kaum noch gegeben ist? Macht dieser Umstand nicht eher ein konfessionellkooperatives Setting erforderlich? Nur was ist dann mit den nicht-konfessionell, ja den nicht-religiös orientierten Heranwachsenden? Müsste dies nicht eher auf ein religionskundliches Lernen im Klassenverband hinweisen? Dort würden immerhin jene Fähigkeiten der Kommunikation und Verständigung eingeübt, die für heterogene Gesellschaften notwendig sind, dies allerdings um den Preis, dass die Kraft, die mit einer bezogenen Positionalität aus einer Teilnehmerperspektive heraus verbunden ist, dort gerade verloren geht. Doch wie geht man religionspädagogisch mit jenen Strömungen um, die - oft ihrerseits mit weltanschaulicher Aufladung - dem Religionsunterricht in der öffentlichen Schule das Existenzrecht verweigern? Denn Religion gehöre ins Private. Ein konfessionell verantworteter Religionsunterricht würde die Religionsgemeinschaften ungebührlich privilegieren und unter Verletzung der Errungenschaften der Aufklärung die Heranwachsenden mit unausgewiesenen und entmündigenden Traditionen konfrontieren.

Mehrere, zumindest kurz anzuspielende Gesichtspunkte wirken in diese unübersichtliche Lage religiösen Lernens und religiöser Bildung hinein:

1 | Zu Hintergründen als Überblick Riegel, Art.: Pluralisierung 2016; Gärtner, Religionsunterricht - ein Auslaufmodell? 2015; Grümme, Öffentliche Religionspädagogik 2015; Grümme, Heterogenität 2017. 
Nicht allein, dass unter diese komplexen Bedingungen von Säkularisierung und Pluralisierung erfahrungsbezogene Religionsdidaktiken eine Relevanz gewinnen, die Ästhetik und Performanz fruchtbar machen wollen. Wo religionssozialisatorisch Erfahrungen mit verfasster Religion außerschulisch nicht mehr wie selbstverständlich vorausgesetzt werden können, diese aber eine wesentliche Implikation religiöser Lern- und Bildungsprozesse sind, liegt es doch bereits intuitiv nahe, solche Erfahrungen innerschulisch, ja gar im Religionsunterricht selber zumindest anzubahnen. Doch ringt man gegenwärtig darum, diese Erfahrungsgegenwart so religionsdidaktisch zu inszenieren oder gar zu realisieren, dass die Grenzen zur Katechese nicht porös werden.

Nicht allein, dass sich überdies innerhalb der Religionsdidaktik eine überraschende wie inspirierende Konstellation herausgestellt hat. Einerseits gibt es vor dem Hintergrund der Kompetenzorientierung der Schule sowie eines religionspädagogischen Konstruktivismus das Bemühen, die Schülerinnen und Schüler in ihren Lernwegen zu stützen, zu ermutigen und zu den zentralen Agenten religiösen Lernens zu erheben. Kein festgelegter Bestand eines Kanons an Inhalten soll vermittelt werden, nicht die Institutionen der Kirche, des Staates, der Gesellschaft sollen die pädagogische wie religionspädagogische Dominanz beanspruchen dürfen. Es sind die Subjekte selber, deren Bedürfnisse im Hinblick auf Autonomie und Partizipation an Gesellschaft, Politik und Ökonomie in den Transformationsprozessen der Spätmoderne zum Ausgangspunkt wie Zielhorizont avancieren. Kompetenzen sollen jene anzubahnenden Voraussetzungen im Subjekt benennen, die dafür erforderlich sind. Der pädagogische Konstruktivismus will die Lernwege zeigen, die dies ermöglichen sollen. Nun macht die evidenzbasierte empirische Bildungsforschung mehr und mehr darauf aufmerksam, dass ein Moment, das im Zuge sich intensivierender pädagogischer Subjektorientierung zunehmend in den Hintergrund geriet, für die Lernprozesse eine ganz wesentliche Rolle spielt: die Lehrkraft. Gerade wenn Lernprozesse im Dienste der Subjekte stehen sollen, haben die Lehrerinnen und Lehrer hohe Bedeutung. Beeinflusst durch solche Ergebnisse evidenzbasierter Lehrerforschung in der Tradition John Hatties setzt die Religionslehrerprofessionalitätsforschung den Akzent auf der Seite der Lehrenden, wenn sie nach teacher beliefs und auch nach dem Beitrag der Lehrenden zu einem guten Religionsunterricht fragt. Dieser Zweig der Religionsdidaktik gewinnt aus dem interdisziplinären Dialog heraus prominente Relevanz, wobei sich als der vielleicht gegenwärtig virulenteste Brennpunkt der religionspädagogischen Debatten das Verhältnis der Lehrerforschung zu Kompetenzorientierung und Konstruktivismus herauskristallisiert.

Nicht allein, dass im Lichte globalisierter Migrationsströme das Bemühen um Interreligiöses Lernen enorm an Fahrt aufgenommen hat. Die Gegenwart von Schülerinnen und Schülern aus anderen Kontexten, anderen Kulturen, anderen Religionen ist eine inzwischen kaum noch zu bestreitende Realität. 
Gewiss muss kontextuell unterschieden werden. Aber in der Metropolregion des Ruhrgebietes haben an manchen Schulen Lernende mit Migrationshintergrund die Mehrheit. Die Herausforderungen für die Religionspädagogik sind eklatant. Beeindruckende Aufbrüche sind zu erkennen, die interkulturelle und interreligiöse Bildungsprozesse zusammenführen, auch wenn derzeit wohl noch zu wenig die Herausforderungen durch Flucht und Vertreibung traumatisierter Menschen und deren Religion reflektiert werden. Dies betrifft freilich nicht allein den Religionsunterricht, sondern auch die Lehrerbildung an den Universitäten. Denn jede Lehrkraft in allen Fächern hat mehr und mehr mit Geflüchteten zu tun. Wie aber kann die Universität Lehrerinnen und Lehrer wahrnehmungs-, sprach- und handlungsfähig machen bezüglich einer oft durch fürchterliche Leiderfahrungen geprägten Religion, wenn nach allen religionssoziologischen Forschungen eine Innenperspektive an Religion bei den meisten Heranwachsenden und so auch den Studierenden nicht mehr vorausgesetzt werden kann? Müsste dies nicht Konsequenzen für das Hochschulcurriculum haben?

Nicht allein, dass Bildungsungerechtigkeit ein wesentliches Moment auch des Religionsunterrichts darstellt. Dieser hat als ordentliches Unterrichtsfach in makro-, meso- und mikrosoziologischer Hinsicht teil an den Strukturen einer Schule, die ein Spiegelbild zunehmender gesellschaftlicher Spannungen und sozial-ökonomischer Disparitäten ist. Das Ringen um Identität, um Kultur, um Anerkennung muss deshalb zusammengebracht werden mit dem Ringen um Gerechtigkeit und Gleichheit.

Und schließlich nicht allein, dass Inklusion inzwischen einer der zentralen Ziel- und Orientierungshorizonte der Bildungspolitik, der Pädagogik und in einer gewissen nachholenden Ungleichzeitigkeit ebenso der Religionspädagogik geworden ist. An Inklusion in einem weiten Sinne halten alle mehr oder weniger fest. Gelegentlich scheint dies für manche vor allem deshalb möglich, weil dieses Postulat so abstrakt ist, dass es die eingespielten Praktiken vor Ort nicht gefährdet. Nur wenn es konkret wird, wenn es gilt, die Inklusion insbesondere von Menschen mit Behinderungen im Bildungssystem und im Unterricht der einzelnen Fächer (sogar von Lernbehinderten selbst am Gymnasium) $\mathrm{zu}$ verwirklichen, wird es problematisch. Hier spielen fehlende Ressourcen, mangelnde infrastrukturelle Unterstützungen, aber auch mentale Hindernisse und Überambitionen mancher Beteiligter eine Rolle. Als ordentliches Schulfach betrifft dies ebenfalls den Religionsunterricht, der bereits von seinem theologischen Hintergrund her inklusiv denken und handeln sollte, aber doch in den Mühen der Ebene verständlicherweise Schwierigkeiten und Hindernisse benennt und auf Differenzierungen besteht.

Nein, mit solchen Bemühungen, mit solchen Aufbrüchen, Retardierungen, Reflexionen und kritischen Interventionen gewinnt eine Perspektive an Bedeutung, die bislang in der Religionspädagogik zumeist außer Betracht 
blieb: die Perspektive der Öffentlichkeit. Auch wenn es Anbahnungen dazu bereits in der Problemorientierten Religionspädagogik gegeben hat, ja - auch dies muss gesagt werden - auch wenn bereits die Konzeptionen der Evangelischen Unterweisung sowie der Materialkerygmatik in dem Sinne öffentlich waren, als sie selber politisch funktionalisiert wurden oder sich gar in den Dienst des politischen, kirchlichen und gesellschaftlichen Status Quo stellten, ${ }^{2}$ auch wenn sich eine emanzipatorische oder auch konvergenztheoretische Religionspädagogik sich bewusst in die Gesellschaft und Geschichte eingeschaltet hat, so wird doch erst unter dem Eindruck der skizzierten Ausgangslage eine Öffentliche Religionspädagogik vollends virulent. Sie scheint deshalb gerade jetzt zu entstehen, weil erst durch eine sich dezidiert im Forum der Öffentlichkeit bewegende, sich dort artikulierende und von dort her angefragte und angereicherte Religionspädagogik die gegenwärtigen Herausforderungen in der angedeuteten Komplexität ihrer Momente wahrgenommen und zugleich als Erweis ihrer Wahrheit und sinnstiftenden Kraft kritisch-konstruktiv bearbeitet werden können.

\section{Erste Konturierungen}

Es sind demnach zunächst die Blicke von außen, die die Religionspädagogik mit dem Phänomen der Öffentlichkeit konfrontieren. Wenn auch das Leben in den Kirchengemeinden und mit Abstrichen in kirchlichen Akademien nur einen begrenzten öffentlichen Aufmerksamkeitsgrad haben, schwillt doch der Grad öffentlicher Erregung noch immer an, wenn es um Religionsunterricht in der öffentlichen Schule geht. Kann man bei ersten Phänomenen hier noch auf den privaten Charakter religiöser Traditionen verweisen, so sieht sich die Religionspädagogik auf dem Feld der Schule unter erheblichen Legitimationsdruck gesetzt. Warum soll eine weitgehend entkonfessionalisierte Gesellschaft für einen weitgehend konfessionell geprägten Religionsunterricht zahlen? Hingegen gibt es um den Zusammenhalt und das Gedeihen gesellschaftlichen Zusammenlebens besorgte Stimmen, die auf Wertevermittlung drängen. Man kann den Eindruck gewinnen, dass mit den eskalierenden Beschleunigungen und den damit verbundenen Erosionen überkommener Gefüge, Traditionen und Milieus die Anmutungen an den Religionsunterricht wachsen, seinen Beitrag zum Ganzen durch die Vermittlung verbindlicher sinnstiftender wie orientierender Angebote zu leisten. Offenkundig sind die Zeiten vorbei, in der Religionspädagogik meinte, sich nicht dem Forum der Öffentlichkeit aussetzen zu müssen.

2 | Vgl. Sander, Politische Bildung im Religionsunterricht 1980; Paul, Antike und Mittelalter 1993; Paul, Barock und Aufklärung 1995. 
Durchaus in Wechselwirkung mit solchen Anfragen von außen sind es aber zugleich Entdeckungen, Aufbrüche, hermeneutische und grundlagentheoretische Umorientierungen, die die Öffentlichkeit als Kategorie innerhalb der Religionspädagogik wichtig werden lassen. Vier exemplarische Einblicke zeigen dies eindrücklich:

1. Oft kritisch gegen privatisierende und entpolitisierende Untertöne performativer und ästhetischer Religionsdidaktiken gerichtet, wurde die politische Dimension als eine Dimension religiöser Bildung markiert. Dabei geht es um die präzise wie anspruchsvolle Positionierung zwischen zwei Extremen, die in gelegentlich massiver Form in der Geschichte der religiösen Erziehung und Bildung vorkommen: einerseits um die angedeutete politische Instrumentalisierung im Interesse von Herrschaftssicherung und Festigung gesellschaftlicher Strukturen, andererseits um die Beschwichtigung und Halbierung jener prophetischen Wucht und befreienden Kraft biblischer Traditionen, wie sie dem theologischen Impetus der Religionspädagogik innewohnen. Darum kann es nicht um eine schlichte Politisierung oder eine ästhetisierende Privatisierung gehen, sondern eben um eine politische Dimension. Die wird aber angesichts dessen nur recht verstanden, wenn sie in Wechselwirkung mit ästhetischen, pragmatischen und kognitiven Dimensionen des Religionsunterrichts steht. Vor diesem Hintergrund wird der Religionsunterricht sich seiner öffentlichen, d.h. gesellschaftlichen, politischen und durchaus ökonomischen Bedingungszusammenhänge bewusst. Die Religionspädagogik will sich dezidiert vor diesem Hintergrund im Lichte der eigenen theologischen wie humanwissenschaftlichen Traditionen formieren und sich aktiv in diesen Kontexten einbringen. So geht diese Entdeckung der politischen Dimension religiöser Bildung mit der Entdeckung der politischen Pointe der biblischen und kirchlichen Tradition einher. ${ }^{3}$

2. Substantiiert wie konkretisiert wird dieses Bemühen um den öffentlichen Rang der Religionspädagogik durch die Auseinandersetzungen um den Zusammenhang von Bildung und Gerechtigkeit. Dies ist bislang religionspädagogisch stark unterbelichtet worden, rückt aber zunehmend in den Fokus. Die prekären wie schillernden ökonomischen, bildungspolitischen und kulturellen Zusammenhänge von Bildung und Gerechtigkeit in Deutschland werden mit wachsender Intensität zum Gegenstand religionspädagogischer Selbstverständigungsprozesse. Umso bedrückender freilich wirkt angesichts solcher Aufbrüche die Erkenntnis, dass selbst der Religionsunterricht als ordentliches

3 | Vgl. Grümme, Religionsunterricht und Politik 2009; Schlag, Horizonte demokratischer Bildung 2010. Vgl. zu einer Genealogie der öffentlichen Religionspädagogik Pirner, Öffentliche Religionspädagogik 2015. 
Schulfach in der Öffentlichen Schule durch manche seine didaktischen Praktiken und durch die überwiegend am Niveau der Mittelschicht ausgerichtete Mentalität seiner Lehrkräfte seinen Beitrag liefert zu dem, was man in der Schulforschung institutionelle Diskriminierung nennt. Er trägt zur Perpetuierung dessen bei, was ihm von seiner Intention her widerspricht. ${ }^{4}$ Mehr noch: gegenwärtig arbeitet die Religionspädagogik an ihrer Heterogenitätsfähigkeit, weil ihr mehr und mehr klar wird, wie prekär eine einseitige Konzentration auf kulturelle Aspekte und Aspekte religiöser Identität wäre. Differenz und Gleichheit, Anerkennung und Gerechtigkeit, Unterschiedlichkeit und Ungleichheit sind in spannungsvoller wie konstruktiver Weise zusammenzudenken und unterrichtspraktisch zusammen zu halten. Gerade auf den Feldern der Inklusion, der Interreligiosität und der Genderfrage wird dies hoch virulent. ${ }^{5}$

3. Noch weitgesteckter wird der Öffentlichkeitsradius, wenn er im Weltmaßstab bedacht wird. Globalisierungsprozesse sind nicht nur über Glokalisierungszusammenhänge für konkretes schulisches Lernen relevant. Sie haben eminente religionspädagogische Relevanz. Oikologisches Lernen, ein Lernen von Gerechtigkeit, Frieden und Bewahrung der Schöpfung sind schon des Längeren Bestandteil religionspädagogischer Überlegungen. In dem Maße, wie das Ferne ganz nah rückt, in dem Maße, in dem die weltweiten Verflechtungen wirtschaftlicher und politischer Art zur Anfrage an die kontextuelle Wahrheitsfähigkeit des Evangeliums werden, in dem Maße, wie Religion aus unterschiedlichen kulturellen Verwurzelungen in der regionalen Übersichtlichkeit der Kommune und auch der eigenen Pfarrgemeinde präsent wird, drängen mit Macht Fragen weltweiter ökonomischer Verflechtungen noch des alltäglichen Konsumverhaltens, Fragen weltweiter Gerechtigkeit, Fragen der Öffentlichkeit der Religion oder auch Fragen kontextuell sehr unterschiedlicher Gestalten des Christentums in den Fokus der Religionspädagogik. So gesehen können die Anforderungen an eine globalisierte Religionspädagogik als Verdichtung ihres Ringens um Öffentlichkeit gedeutet werden. ${ }^{6}$

4. Jedoch gibt es innerhalb der Religionspädagogik noch eine andere Ebene der Auseinandersetzung mit Öffentlichkeit. Diese will die Anforderungen von außen und die - durchaus damit in Wechselwirkung stehenden - Neujustierungen im Inneren als Ansatz für eine kategoriale Neuausrichtung der Religionspädagogik überhaupt begreifen. Eine solche Religionspädagogik

4 | Vgl. Grümme, Sich aufs Spiel setzen 2014; Könemann, Mette, Bildung und Gerechtigkeit 2013; Grümme, Schlag, Gerechter Religionsunterricht 2016.

5 | Vgl. Grümme, Heterogenität 2017; aus erziehungswissenschaftlicher Sicht Bohl u.a., Umgang mit Heterogenität in Schule und Unterricht 2017.

6 | Vgl. Simojoki, Globalisierte Religion 2012. 
versteht sich wissenschaftstheoretisch als Öffentliche Religionspädagogik. Buchstabiert man dies auf den drei Ebenen wissenschaftstheoretischer Selbstkonzeptionalisierung will eine Öffentliche Religionspädagogik sich auf grundlagentheoretischer, auf kairologisch-kontextueller und auf praxeologischer Ebene profilieren. ${ }^{7}$ Dementsprechend finden sich unterschiedliche Anläufe oder gar Entwürfe einer Öffentlichen Religionspädagogik. ${ }^{8}$ Diese will religiöse Bildungs- und Tradierungsprozesse vor dem Forum der Öffentlichkeit ausweisen, verantworten, und sie - durchaus mit geltungstheoretischem Anspruch - kritisch wie produktiv einspielen. Dabei wird gleichermaßen der Anspruch vorausgesetzt wie zugleich als legitimationsbedürftig verstanden, dass die eigene Tradition einen weiterführenden Beitrag zum gesellschaftlichen und politischen Ringen um das gemeinsame Ganze darstellt. Öffentliche Religionspädagogik versteht sich in einem emphatischen Sinne als eine diskursive Wissenschaft, die sich mit dem Geltungsanspruch ihrer Tradition geradezu axiomatisch auf Entdeckungs-, auf Bewährungs-, auf Bewahrheitungs- und auf Übersetzungszusammenhänge einlässt. Wollte sie sich dem verweigern, wollte sie sich auf das Opake ihrer eigenen Überlieferungen und die Eigenlogik ihrer Pragmatiken, Institutionen und Referenzsysteme zurückziehen, würde sie in dieser Perspektive in einem performativen Selbstwiderspruch ihren eigenen Ansatz als Religionspädagogik konterkarieren. Religionspädagogik muss öffentlich sein - sonst wäre sie nicht.

\section{3. ÖfFEntliche ReligionsPÄdagogiK ZWISChEN PUBLIC THEOLOGY UND KRITISCHER THEORIE}

Doch was heißt öffentlich? Was sind die theologischen, was sind die philosophischen Referenzsysteme, in denen sich Öffentliche Religionspädagogik begriffsaxiomatisch verwurzelt? Nicht immer wird differenziert genug auf den Unterschied hingewiesen, der damit verbunden sein kann. ${ }^{9}$ Grundsätz-

7 | Vgl. Englert, Wissenschaftstheorie der Religionspädagogik 1995.

8 | Vgl. Grümme, Öffentliche Religionspädagogik 2015; Pirner, Öffentliche Religionspädagogik 2015; Schlag, Öffentliche Kirche 2012; Schröder, Religionspädagogik 2012.; Schluß, Religiöse Bildung im öffentlichen Interesse 2010; Themenheft Religionspädagogik und Öffentlichkeit 2015; Pirner, Lähnemann, Haussmann, Schwarz, Public Theology, Religious Diversity and Interreligious Learning 2018; Schweitzer, ZivilgesellschaftSchule-Religion 1999; Schweitzer, Mehr als eine Privatangelegenheit 2011; Wollbold, Religionsunterricht in der Bürgergesellschaft 2000.

9 | Vgl. Höhne, Öffentliche Theologie 2015; Höhne, Oorschot, Grundtexte Öffentliche Theologie 2015; Pirner, Lähnemann, Haussmann, Schwarz, Public Theology, Religious Diversity and Interreligious Learning 2018; Chung, Public Theology in an Age of World 
lich lassen sich in dieser Perspektive grob zwei Richtungen unterscheiden: 1. eine Öffentliche Religionspädagogik, verwurzelt in der public theology und 2. eine Öffentliche Religionspädagogik, verwurzelt in Traditionen der Kritischen Theorie.

1. Die größten, publizistisch und wissenschaftspraktisch ambitioniertesten Aufbrüche einer Öffentlichen Religionspädagogik verorten sich im weiten Rahmen einer Öffentlichen Theologie und damit der weltweit vernetzten public theology. ${ }^{10}$

Es ist schon richtig, dass der Begriff der Öffentlichen Theologie (public theology) so weit, so schillernd ist, dass die mit ihr in Verbindung gebrachten Sachverhalte so divers sind, dass dies zu Lasten der Präzision des Konzepts gehen kann. ${ }^{11}$ Florian Höhne hat in beeindruckenden Rekonstruktionen die außerordentlich komplexen Hintergründe dieses sehr weiten Begriffs aufgehellt. ${ }^{12}$ Insgesamt aber bleibt der konstitutive Öffentlichkeitscharakter dessen entscheidendes Signum. Der Begriff der Öffentlichen Theologie ruft in Erinnerung, dass das Thema der Theologie »keineswegs auf die Sphäre des Privaten beschränkt« ist. »Es richtet sich vielmehr auf das >öffentliche Leben< [...]. >Öffentliche Theologie< fragt sodann nach dem Ort der Kirche in der Öffentlichkeit, nach ihrer sozialen Gestalt und ihrer gesellschaftlichen Rolle. $\aleph^{13}$ Breit rezipiert und affirmiert wurde die Definition Wolfgang Vögeles:

"Öffentliche Theologie ist die Reflexion des Wirkens und der Wirkungen des Christentums in die Öffentlichkeiten der Gesellschaft hinein; das schließt ein sowohl die Kritik und die konstruktive Mitwirkung an allen Bemühungen der Kirchen, der Christen und Christinnen, dem eigenen Öffentlichkeitsauftrag gerecht zu werden, als auch die

Christianity 2010; Miggelbrink, Öffentliche Theologie 2011; Bedford-Strohm, Öffentliche Theologie in der Zivilgesellschaft 2008; Bedford-Strohm, Öffentliche Theologie als Befreiungstheologie 2009; Bedford-Strohm, Kirche in der Zivilgesellschaft 1998.

10 | Vgl. Pirner, Lähnemann, Haussmann, Schwarz, Public Theology, Religious Diversity and Interreligious Learning 2018; Sinner, Öffentliche Theologie 2011; Vögele, Zivilreligion 1994.

11 | Vgl. Höhne, Öffentliche Theologie 2015, 12; ferner Cady, H. Richard Niebuhr 1991; Arens, Kritisch, kirchlich, kommunikativ 2012; Bedford-Strohm, Poverty and Public Theology 2008; Große Kracht, Kirche in ziviler Gesellschaft 1997; Villagrán, The Future of Catholic Public Theology 2013; Theological Roundtable, Theology in the Public Sphere 2016.

12 | Vgl. Höhne, Öffentliche Theologie 2015, 77-101; Polke, Öffentliche Religion in der Demokratie 2009; Liedhegener, Werkner, Religion zwischen Zivilgesellschaft und politischem System 2011; Moltmann, Gott im Projekt der modernen Welt 1997.

13 | Huber, Vorwort 1993, 9; vgl. Höhne, Öffentliche Theologie 2015, 29. 
orientierend-dialogische Partizipation an öffentlichen Debatten, die unter Bürgerinnen und Bürgern über Identitäten, Ziele, Aufgaben und Krisen dieser Gesellschaft geführt werden. ${ }^{14}$

Danach muss Bildung »ein Thema öffentlicher Theologie werden, einer Theologie also, die aus der Sicht der jüdisch-christlichen Tradition Orientierungen in Fragen grundlegender Bedeutung zu geben versucht, die die Öffentlichkeit beschäftigen «. ${ }^{15}$

Es ist nun signifikant, welchen Rang gesellschaftliche, ökonomische und politische Strukturen sowie eine entsprechende Gesellschaftskritik in der public theology einnehmen. Sowohl der für die public theology in Deutschland prägende Heinrich Bedford-Strohm als auch Vögele sehen das Spezifische der Öffentlichen Theologie gegenüber der Politischen Theologie darin, einer fundamentalen gesellschaftskritischen Perspektive und der Reflexion in politischen Kategorien keine prinzipielle Bedeutung beizumessen. Sie sei nicht »auf die prinzipielle Kritik der gesellschaftlichen Verhältnisse « ausgerichtet. ${ }^{16} \mathrm{Im}$ Vordergrund stehen so Fragen der Kommunikabilität, der Übersetzbarkeit und Präsenz des Glaubens, der Theologie und der Kirchen im öffentlichen Raum einer liberalen Gesellschaft. ${ }^{17}$

Damit wird - um es hier zunächst sehr verallgemeinernd und ungeachtet innerer Differenzierungen zu sagen - ein Akzent beim Erbe liberaler Theologie, protestantischer Sozialethik sowie beim philosophisch-politischen Liberalismus gesetzt.

2. Eine andere Richtung der Öffentlichen Religionspädagogik verwurzelt sich in den Traditionen der Neuen Politischen Theologie und damit stärker in dem seinerseits umstrittenen Erbe einer differenziert angeeigneten Kritischen Theorie. In ihr spielen die Debatten um eine Öffentliche Religion eine zentrale

14 | Vögele, Zivilreligion 1994, 421f.; vgl. Höhne, Öffentliche Theologie 2015, 36.

15 | Bedford-Strohm, Bildung und Gerechtigkeit 2009, 14; vgl. Grümme, Menschen bilden 2012.

16 | Vögele, Zivilreligion 1994, 424; vgl. Bedford-Strohm, Öffentliche Theologie in der Zivilgesellschaft 2008; Bedford-Strohm, Poverty and Public Theology 2008; Höhne, Öffentliche Theologie 2015, 29.

17 | Vgl. Höhne, Öffentliche Theologie 2015, 125f. Webb, The Way Out of Darkness 2007; Graham, Rowlands, Pathways to the Public Square 2003; D'Costa, Theology in the Public Square 2005; Storrar, Morton, Public Theology for the 21st Century 2004; McDermott, One Holy and Happy Society 1992; Higton, Christ, Providence \& History 2004; Doak, Reclaiming Narrative for Public Theology 2004. 
Rolle. ${ }^{18}$ Sie artikuliert sich in gesellschaftlich-politisch sensiblen Kategorien, um genau darin die Würde des Subjekts theologisch wie religionspädagogisch zu markieren. Diese ist öffentlich, weil sie sich normativ auf eine diskursive Öffentlichkeit bezieht. Nicht alles Nicht-Private ist schon öffentlich. ${ }^{19}$ Öffentlichkeit ist für sie die Sphäre, auf der mit der Kraft des besseren Arguments um die Gestaltung der Gesellschaft gerungen wird. Auf dieser Ebene, die eben vor allem die Ebene der Zivilgesellschaft ist, will sich eine Öffentliche Religionspädagogik mit ihrem spezifischen, unvertretbaren Eigensinn der Gotteshoffnung im Interesse der Subjektwerdung und Autonomie aller Menschen einbringen. ${ }^{20}$ Dabei greift sie in ihrem kontextuell-kritischen Vernunftbegriff auf das kritisch angeeignete Erbe der Kritischen Theorie zurück.

Kritische Theorie nimmt in der Sicht des Sozialphilosophen Rainer Forst die Frage auf, »weshalb eine moderne Gesellschaft nicht dazu in der Lage ist, rationale Formen der gesellschaftlichen Ordnung hervorzubringen. Kritische Theorie ist der Versuch, an dieser Frage festzuhalten, dabei aber den verwendeten Begriff der Vernunft selbst kritisch auf seine >Unvernunft< und seine Herrschaftspotentiale zu befragen. $\ll^{21}$ Eine solche kritisch-theoretische Selbstreflexivität der Vernunft ist für eine Öffentliche Religionspädagogik elementar, und dies in zweierlei Hinsicht: 1. Sie muss sich über die machtförmigen, hegemonialen wie identitätslogischen Strukturen aufklären, in denen sie kontextuell je schon steht; 2. sie muss sich über jene Mechanismen der Exklusion, der Stigmatisierung, der Macht aufklären, die möglicherweise in ihr selber auch dann noch in ihrem Bemühen um Gerechtigkeit und Anerkennung der Subjekte in den verschiedenen Orten religiöser Erziehung und Bildung wirksam werden, wenn sie dem intentional widerspricht.

Insofern religiöse Bildung sich als kritische, transformatorische Bildung auch für deren geschichtlich-gesellschaftliche Ausgangsbedingungen verantwortlich verstehen muss, ${ }^{22}$ ist sie als Öffentliche Religionspädagogik beim Ringen um Bildungsgerechtigkeit, um Inklusion, um Anerkennung von Vielfalt und Differenz als einem Ringen um ein gutes Leben für alle bei ihrem eigenen Kern, wenn dabei auch über Fragen der strukturellen Bedingungen von Ungleichheit und über die Definitionsmacht des Rechts auf Rechtfertigung diskutiert wird.

18 | Vgl. Grümme, Öffentliche Religionspädagogik 2015; Arens, Gottesverständigung 2007; Casanova, Die religiöse Lage in Europa 2007; Arens, Hoping, Wieviel Theologie verträgt die Öffentlichkeit 2000; Arens, Vom Schrei zur Verständigung 2009.

19 | Vgl. Gerhardt, Der Sinn des Sinns 2014.

20 | Vgl. Grümme, Öffentliche Religionspädagogik 2015, 15-70.

21 | Forst, Kritik der Rechtfertigungsverhältnisse 2011, 18.

22 | Vgl. Dederich, Bildungsgerechtigkeit und Inklusion 2011, 51; Peukert, Die Frage nach der Allgemeinbildung 1987. 
Um dies exemplarisch anhand des derzeit besonders bedrückenden Themas der Bildungsgerechtigkeit etwas zu verdeutlichen:

Dieses Thema ergibt sich für diesen Ansatz

"aus diesem Bildungsverständnis selbst, nicht erst im nachträglichen Bezug auf die Problematik ungerechter Verhältnisse hinsichtlich des Zugangs zu Bildung etc. Und das Einklagen von Bildungsgerechtigkeit wird dann auch bereits in Bezug auf dieses Bildungsverständnis von religionspädagogischer Seite nicht nur möglich, sondern sogar dringend erforderlich, weil man ansonsten das intrinsische Verhältnis von Freiheit und Gleichheit ausblenden würde - mit entsprechender Verengung hin zu einem ,bürgerlichen، Verständnis von Bildung, das zwar Bildung für alle als Ideal vorschreibt, aber lediglich Bildung für Wenige realisiert. ${ }^{23}$

Religiöse Bildung bringt im Rahmen einer Öffentlichen Religionspädagogik die Option einer parteilichen Gottes-Gerechtigkeit als einer Gerechtigkeit für die Opfer ein. »Religionspädagogik ist gefordert, in die öffentliche Bildungsdebatte einzutreten, gesamtgesellschaftliche Diskurse aktiv zu begleiten, diese aus christlicher Perspektive kritisch zu hinterfragen und vor allem auch die Kirche für den bildungspolitischen Streit wachzurütteln, Herrschafts- und Ideologiekritik zu betreiben beispielsweise in der hartnäckigen Frage nach Verteilungsgerechtigkeit, und dies immer unter der Maßgabe, wie solidarisches Leben für alle möglich ist. « ${ }^{24}$ Die Sensibilität für Ungerechtigkeit, für die Ausgeschlossenen und Leidenden zu einer religionspädagogischen Sache zu machen und so in den Bildungsdiskurs einzutragen, erfordert eine politisch sensible, in sich komplexe Religionspädagogik. Pointiert gesagt: Um Exklusionen zu vermeiden, muss diese Religionspädagogik in Kategorien gedacht werden, die universal ausgerichtet sind, ohne Alterität zu relativieren; die geschichtlich-gesellschaftlich strukturiert und gesellschaftskritisch angelegt ist, ohne zu politisieren; die gerechtigkeitstheoretisch Aspekte von Verteilungsgerechtigkeit, Befähigungsgerechtigkeit und Anerkennungsgerechtigkeit so miteinander vermittelt, dass die Grundsätze egalitärer Gerechtigkeit gewahrt und doch die Würde und die Andersheit der jeweiligen Subjekte zur Geltung gebracht und die befreiende bildende Macht einer unbedingten, Gerechtigkeit stiftenden Liebe bezeugt und bewahrheitet wird. In genau diesem Sinne müsste die Religionspädagogik als eine alteritätstheoretisch fundierte politisch sensible Religionspädagogik ihrerseits einen genuinen Begriff von Bildungsgerechtigkeit entwickeln. ${ }^{25}$

23 | Könemann, Bildungsgerechtigkeit 2013, 50; vgl. Marx, Zierer, Glaube und Bildung 2013, 62-67.160.

24 | Pirker, Wer hat dem wird gegeben 2013, 82-83.

25 | Vgl. Grümme, Öffentliche Religionspädagogik 2015, 5-100. 
Hier ist nicht der Ort einer kritischen Diskussion beider Ansätze, galt es doch nur, auf das Spektrum öffentlicher Religionspädagogik zumindest aufmerksam zu machen. Aber zumindest die Brisanz dieser divergenten Rückgründung und Formung Öffentlicher Religionspädagogik soll markiert werden. Denn aus dieser Konstellation kommen Fragen auf: Kann in den Bahnen der public theology die Radikalität der christlichen Botschaft wirklich angemessen erfasst werden, deren Option für die Ausgeschlossenen, deren Parteilichkeit? Zeigt nicht gerade das von mir exemplarisch herangezogene Ringen um Bildungsgerechtigkeit, dass kulturelle und soziale, religiöse wie gesellschaftliche, individuelle wie intersubjektiv-strukturelle Aspekte ineinandergreifen? Sind vielleicht trotz gegenteiliger Strömungen auch in der public theology die Anleihen an liberaler Theologie, ${ }^{26}$ an einem nur oberflächlich durch sozialethische Kategorien gebrochenen Kulturchristentum sowie die Rezeptionen zivilreligiöser Begründungen zu stark, um tatsächlich auch die Strukturen und damit die politischen Dimensionen von Theologie und Religionspädagogik angemessen zu denken? Es sollte doch zu denken geben, wenn BedfordStrohm Öffentliche Theologie als »Befreiungstheologie für eine demokratische Gesellschaft« anlegt. ${ }^{27}$ Wo bleibt der dynamische, kategorial verankerte Impuls der Theologie für die Veränderung der Gesellschaft, bei der man eben nicht je schon von einer demokratischen Gesellschaft ausgehen kann? Aus befreiungstheologischer Perspektive wie aus demokratietheoretischen Debatten um »Postdemokratie « (Colin Crouch) wirkt dieser vorausgesetzte Rahmen als eine Setzung, die alles andere als selbstverständlich ist. Sie muss gegen ökonomische Kolonisierungsmechanismen oder demokratiedestruktive Tendenzen teilweise erst noch errungen oder verteidigt werden. Hier liegt wohl ein kategoriales hermeneutisches wie analytisches Defizit der public theology. Jedenfalls könnte ein kritischer Dialog mit der Diskursanalyse Foucaults wie mit den sozialtheoretischen Ansätzen in der Tradition der Kritischen Theorie auf blinde Flecken und übersehene Mechanismen von Macht, Exklusion und Hegemonie in der religionspädagogischen Praxis und Theoriebildung hinweisen. Aber, wie gesagt: hier soll keine detaillierte Diskussion erfolgen. Hier soll vor allem auf eine offene Flanke der Öffentlichen Religionspädagogik aufmerksam gemacht werden.

26 | Vgl. etwa Stackhouse, Public Theology and Political Economy 1987; BedfordStrohm u.a., Kommunikative Freiheit 2014.

27 | Vgl. Bedford-Strohm, Vorrang für die Armen 2009, 167-182. 


\section{Eine defizitäre Begriffsbildung. SKIZZEN EINES Desiderats}

Diese offene Flanke, so die hier vertretene Position, hat im Wesentlichen mit der Begriffsbildung innerhalb der Öffentlichen Theologie zu tun. In folgenden Fragen wird dies manifest: Inwiefern nämlich prägen die unterschiedlichen Referenzen im Feld der Öffentlichen Religionspädagogik ihr Design, ihren Anspruch und ihre Begriffslogik? Lassen sich an dieser Stelle gar konfessionelle Distinktionen in der Referenz aufweisen - eher protestantisch die erste (public theology), eher katholisch die zweite (Neue Politische Theologie) -, die sonst im Alltagsgeschäft der Religionspädagogik nicht unbedingt eklatant sichtbar werden? Und gibt es Bezüge zu dem jeweils in den diversen Ansätzen Öffentlicher Religionspädagogik artikulierten und in Anspruch genommenen Öffentlichkeitsbegriff? Lassen sich Differenzen, Anspielungen, Wechselwirkungen aufweisen? Die Öffentliche Religionspädagogik scheint insgesamt bislang zu wenig reflektiert $\mathrm{zu}$ haben, was sie eigentlich meint, wenn sie diesen Öffentlichkeitscharakter beansprucht. Es gibt bisher nur rudimentäre semantische und begriffslogische Klärungen des Öffentlichkeitsbegriffs aus religionspädagogischer Perspektive, die aber dem aufkommenden Fragebedarf nicht entsprechen. ${ }^{28}$ Was bedeutet >Öffentlichkeit<? Ist nicht bereits der Singular verfehlt, weil es in einer funktional ausdifferenzierten Wirklichkeit distinkte Teilöffentlichkeiten gibt, die sich überlappen, die im Widerstreit stehen, die isoliert voneinander existieren? Politikwissenschaftliche wie soziologische Theorien betonen in einem zunehmenden Maße eine Heterogenität von Öffentlichkeiten. So wird etwa kultursoziologisch der Strukturwandel der Moderne zur Spätmoderne in der Ausdifferenzierung einer allgemeinen Öffentlichkeit hin zu einer Vervielfältigung von singulären Öffentlichkeiten gesehen, die sich um das emphatische Postulat von Kreativität, erfahrungsbezogener Authentizität und Beheimatung herum gruppieren. Darüber sei aber die in modernen Selbstverständigungsprozessen anvisierte Vermittlung des Besonderen mit einem übergreifenden Allgemeinen in Vergessenheit geraten. ${ }^{29}$ Genau darin freilich liege die Hauptwurzel für die derzeit grassierenden Krise der Öffentlichkeit in der Spätmoderne.

"Im Selbstverständnis der klassischen Moderne kam dem Politischen die herausgehobene Rolle zu, das Allgemeine zu fördern und zu vertreten. Das politische System sollte eine Steuerungskraft für die gesamte Gesellschaftsentwicklung entfalten; und die allgemeine Öffentlichkeit in den Massenmedien und Volksparteien hatte eine sozialintegrative Funktion. Die Parzellierung der politischen Öffentlichkeit in diverse Communities,

28 | Vgl. Pirner, Öffentliche Religionspädagogik 2015.

29 | Vgl. Reckwitz, Die Gesellschaft der Singularitäten 2017, 371-420. 
auch das Erstarken der insbesondere ethnischen und religiösen Partikularismen des Kulturessentialismus sowie der partielle Rückzug des Staates können dann als Ausdruck eines Verschwindens des Allgemeinen aus der Politik interpretiert werden. “30

Nähert man sich nun dem Öffentlichkeitsbegriff, so ist zunächst eine Differenzierung grundlegend. >Öffentlichkeit< beruht traditionell auf der binären Unterscheidung von >öffentlich $<$ und >privat $<.{ }^{31}$ Damit ist vor allem die Zurückdrängung des Staates aus der Sphäre des Privaten verbunden. Das Private ist Reservat, Schutzraum lebensweltlicher Ressourcen und Vollzüge von Freiheiten. Der Grad seiner Realisierung ist Index für die Rechtstaatlichkeit des Gemeinwesens, ohne dass damit die Relevanz des Öffentlichen für das Private marginalisiert werden dürfte. »Bürgerliche Freiheit im liberalen Rechtsstaat bedeutet die Zurückdrängung des Staates aus der Privatsphäre des Lebens und des Wirtschaftens, heißt Freiräume für bürgerliches Leben und die individuelle Sphäre zu schaffen, in die der Staat nicht eindringen darf. « ${ }^{32}$ Diese negativen Freiheiten, unbeeinflusst durch staatlichen Zwang, sich selbst autonom artikulieren zu können, hängen aber zugleich eng mit der positiven Entfaltung von Freiheit zusammen. Frei gesetzt von staatlichem Einfluss wird der Mensch frei, sich selber in den Dienst von Demokratie und Öffentlichkeit zu stellen. »Das Private ist damit die maßgebliche Voraussetzung dafür, dass Menschen überhaupt am politischen Prozess partizipieren. Auch im Grundgesetz findet sich die Wertschätzung dieser Verbindung. Die Autonomie des Menschen wird darin >nicht nur aus Respekt vor seiner Individualität (geschützt), sondern auch als Voraussetzung eines demokratischen Gemeinwesens und als verfassungsrechtliches Legitimationssubjekt «.«33 Öffentlichkeit und Privatheit stehen demnach in dem Verhältnis einer inneren kritisch-produktiven Komplementarität zueinander.

Doch ist nicht mit dieser kritisch-produktiven Komplementarität bereits eine Unterscheidung verbunden, die ihrerseits höchst legitimationsbedürftig ist? Für das Verhältnis von Religion und Öffentlichkeit, wie es in der Öffentlichen Religionspolitik verhandelt wird, ist diese Differenzierung äußerst bedeutsam. Denn es macht einen erheblichen Unterschied, ob Religion einen Geltungsanspruch hat, der sich auf schlechthin alles bezieht, und damit der

30 | Reckwitz, Die Gesellschaft der Singularitäten 2017, 436.

31 | Vgl. Gerhardt, Öffentlichkeit 2012. Ferner Imhof, Die Krise der Öffentlichkeit 2011; Imhof, Theorie der Öffentlichkeit 2008; Negt, Kluge, Öffentlichkeit und Erfahrung 1977; Schiewe, Öffentlichkeit als Begriff 2004; Taylor, Modern Social Imaginaries 2004; McKee, The Public Sphere 2005.

32 | Riescher, Demokratische Freiheit 2010, 16. Vgl. hierzu Klöcker, Freiheit im Fadenkreuz 2017, 76-80.

33 | Klöcker, Freiheit im Fadenkreuz 2017, 80. 
Differenzierung von >öffentlich und >privat noch vorausliegt; ob sie sich auf einer intermediären Ebene zwischen staatlicher und privater Ebene ansiedelt; ob Religion staatlich situiert oder ob sie in die private Sphäre hineingedrängt wird. Das Ringen um gesellschaftliche Partizipation im Feminismus, dem es darauf ankommt, das Private bereits politisch werden zu lassen und so die Räume der Emanzipation zu öffnen, verweist doch zugleich auf die Brisanz wie die Begründungsnotwendigkeit dieser Differenzierung, die folglich ebenfalls für eine Öffentliche Religionspädagogik zu gelten hätte. Müssen nicht religionspädagogisch vor allem Medienöffentlichkeit, kirchliche Öffentlichkeit, politische Öffentlichkeit, zivilgesellschaftliche Öffentlichkeit analytisch wie hermeneutisch auseinandergehalten werden? Trägt dies nicht jeweils erheblich zum Geltungsanspruch und zur hermeneutischen wie pragmatischen Kraft der Religionspädagogik in ihrem jeweiligen Kontext bei? Ist >Öffentlichkeit< ein deskriptiver, ein empirischer, ein normativer Begriff? Was bedeutet es, wenn die bisherige Öffentliche Religionspädagogik den rationalen Diskurs als Ort des »Beweises ihres Geistes und ihrer Kraft« (Lessing) anvisiert, obschon doch damit rationale und vernunfttheoretische Unterstellungen verbunden werden, die gegenwärtig alles andere als selbstverständlich sind? Was aus der Tradition eines sozialphilosophischen Liberalismus und eines kommunikationstheoretischen Universalismus einleuchtet, braucht noch lange nicht poststrukturellen oder postmodernen Einsprüchen Stand zu halten. ${ }^{34}$ Erfährt nicht der Öffentlichkeitsbegriff durch die derzeitigen Auseinandersetzungen um eine pluralitätsfähige oder heterogenitätsfähige Religionspädagogik eine radikale Anfrage? Welcher Öffentlichkeitsbegriff könnte es einer Öffentlichen Religionspädagogik ermöglichen, in einem angemessenen Maße auf die eskalierenden Heterogenitätsanmutungen der Gegenwart zu reagieren, die wesentlich mit den gegenseitigen Zusammenhängen von Differenz und Gleichheit in dem umkämpften Rahmen von Normativität und Macht zu tun haben? ${ }^{35}$ Das Desiderat eines theoretisch geklärten Öffentlichkeitsbegriffs ist offenkundig.

\section{Markierungen}

Das Fehlen eines umfassend reflektierten und ausgewiesenen Begriffs der Öffentlichkeit im Diskurs Öffentlicher Religionspädagogik wurde verschiedentlich kritisiert. So hält Friedrich Schweitzer in Bezug auf die Arbeit des Verfassers dieses Buches fest:

34 | Vgl. Tracy, The Analogical Imagination 1981; Butler, Anmerkungen zu einer performativen Theorie der Versammlung 2016.

35 | Vgl. Grümme, Heterogenität 2017. 
"Wie der Vf. immer wieder betont, muss die Religionspädagogik sich auf die Diskussion um öffentliche Bildung beziehen. Das geschehe am erfolgreichsten dort, wo sich die Religionspädagogik , einschalten will in das öffentliche Ringen um das gemeinsame Richtige und Gute`, indem sie sich an den ’Prinzipien von Gleichheit, Freiheit, Rationalität, Universalitätı orientiert (S. 84). Die Religionspädagogik müsse versuchen, argumentativ zu überzeugen, anstatt sich auf wie auch immer vorausgesetzte Wahrheiten zu berufen. Das ist eine überzeugende Position. Es wäre allerdings interessant, sie nun noch genauer mit verschiedenen Theorien der Öffentlichkeit und deren Rezeption etwa in der Erziehungswissenschaft ins Gespräch zu bringen. “36

\section{Ähnlich argumentiert Ulrich Riegel. ${ }^{37}$}

Demnach liegt das Hauptproblem einer Öffentlichen Religionspädagogik nicht in deren Anlage, in deren Gestalt und Design. Religionspädagogik öffentlich werden zu lassen, ist mehr oder weniger unstrittig. Bei genauerer Analyse ist es nicht das Anliegen, Religiöse Bildung, religiöses Lernen, religiöse Erziehung und Katechese in die öffentlichen Diskurse um Bildung, um Erziehung, ja - um es emphatisch auszudrücken - in die Suche nach dem common good einzubringen, was angefragt wird. Religionspädagogik dementsprechend wissenschaftstheoretisch zu positionieren, sie von ihrem theologischen, pädagogischen, ethischen, anthropologischen, subjekttheoretischen wie psychologischen Profil her öffentlichkeitstheoretisch $\mathrm{zu}$ fokussieren, ${ }^{38}$ ist zumindest grundsätzlich nicht problematisch. Das alles entscheidende Defizit scheint vielmehr das Denken des Öffentlichkeitsbegriffs selber zu sein. Nicht eine Theorie der Öffentlichkeit fehlt. Vielmehr bleibt offensichtlich der Begriff der Öffentlichkeit in einem grundsätzlichen Sinne klärungsbedürftig, seine Konstruktion und innere Logik.

Ein solches Desiderat lässt sich, gewiss mit Abstufungen, ebenfalls an drei prominenten Anläufen zu einer Öffentlichen Religionspädagogik aufzeigen. Dabei lässt sich in deren Anordnung eine zunehmende Intensivierung der Begrifflichkeit und Systematik hin zu einer Öffentlichen Religionspädagogik erkennen. In kurzen Strichen soll dies dargelegt werden.

\subsection{Annäherungen aus dem politikwissenschaftlichen Diskurs heraus: Judith Könemann}

Ohne ein dezidiertes Interesse an einem systematischen Entwurf einer Öffentlichen Religionspädagogik arbeitet Judith Könemann fein ziselierte Unterscheidungen im Verständnis von >Öffentlichkeit< heraus. Ihr Schwerpunkt liegt bei

36 | Schweitzer, Rezension zu Bernhard Grümme 2016, 993-995.

37 | Vgl. Riegel, Rezension zu Bernhard Grümme 2016.

38 | Vgl. hierzu den Ansatz von Grümme, Öffentliche Religionspädagogik 2015. 
der Verortung von Kirche, Theologie und Religionspädagogik, um daraus den »Öffentlichkeitscharakter« von Religionspädagogik und religiöser Bildung zu profilieren. ${ }^{39}$ Ausgehend von der Präsenz von Religion, von Kirche und religiöser Bildung in verschiedenen Ebenen und Teilen der Öffentlichkeit, kann diese nur recht eingeordnet werden, wenn das Phänomen der Öffentlichkeit genauer gefasst und auch von dem hiermit verwandten, aber nicht identischen Begriff der Zivilgesellschaft abgegrenzt wird. Verwandt sind beide Begriffe, weil beide von ihrem semantischen Gehalt her auf die Transformationsprozesse einer modernen Gesellschaft rekurrieren, die mit einem veränderten Verständnis von Politik einhergehen. Zusammengefasst unter dem politikwissenschaftlichen Governance-Theorem,${ }^{40}$ hat der Referenzbereich dessen, was mit >Politik gemeint ist, sich von seiner Beschränkung auf die Ebene des Staates und seiner Institutionen verabschiedet.

Wenn zwar nicht alles Politik ist, so ist doch überall Politik enthalten, geht es dort doch um die Herbeiführung von für alle geltenden Entscheidungen im Kontext von Macht. Politik kann verstanden werden als »die Regelung der gemeinschaftlichen Angelegenheiten einer Gesellschaft «. ${ }^{41}$ Politik ist »eine Denk und Handlungsform «, ${ }^{42}$ in der das allgemeine Zusammenleben der Menschen und menschlichen Gruppen problematisch geworden ist, mit der Aufgabe der »Erzeugung der notwendigen verbindlichen Regelungen durch Diskussion und gemeinsame Entscheidung ${ }^{4} .{ }^{43} \mathrm{Im}$ Zuge der \#ntgrenzung von Politik« (Ulrich Beck) in den Modernisierungsprozessen wandelt sich der Staat vom »Handlungs- zum Verhandlungsstaat«, indem er sich zunehmend aus vielen Handlungsfeldern zurückzieht. ${ }^{44}$ Das Politische weitet sich aus dem politischen System in andere soziale Zusammenhänge aus, so dass sich eine intermediäre Sphäre zwischen Staat und Bürgerinnen und Bürger schiebt, in der soziale und kulturelle Handlungs- und Kommunikationsprozesse über das common good vollzogen werden. Die Politikwissenschaft wie die Sozialphilosophie nennen diese Sphäre die der >Zivilgesellschaft oder die der >Öffentlichkeit, wobei in der gegenwärtigen politikwissenschaftlichen Debatte deren Verhältnis nicht hinreichend geklärt ist. ${ }^{45}$ Als ein besonderes Handlungsfeld zwischen Staat und Bürgerinnen und Bürgern kann die Zivilgesellschaft bzw. die Öffentlichkeit als sozialer Regelungsmechanismus sozia-

39 | Könemann, Theologie, Kirche und Öffentlichkeit 2016, 129.

40 | Vgl. Meyer, Was ist Politik 2010, 139-169.

41 Sander, Politische Bildung in den Fächern der Schule 1985, 19.

42 | Böckenförde, Was heißt heute eigentlich 'politisch، 1995, 3.

43 | Meyer, Was ist Politik 2010, 235-294.

44 | Sander, Politischer Bildung 2005, 257.

45 | Vgl. Liedhegener, Religion in Zivilgesellschaft 2016, 105-107. 
le, politische, kulturelle oder ökologische Probleme durch freiwilliges solidarisches Handeln regeln. ${ }^{46}$

Ohne dies nun näher zu begründen, verbindet Könemann beide Termini im Begriff einer »zivilgesellschaftlichen Öffentlichkeit«, die sie von einer politischen Öffentlichkeit abhebt. ${ }^{47}$ Eingeordnet in die gegenwärtige Suche nach einer public theology und Könemanns Differenzierung zwischen strukturellen und aktuellen Diskursen, hauptsächlich aber begründet in der für sie maßgeblichen Unterscheidung zwischen einer »gesellschaftlichen « und »politischen « Öffentlichkeit, ${ }^{8}$ gewinnt Könemann damit eine Kategorie, die ihr Bedeutung, Funktion und Sinn von Kirche, religiöser Bildung und Religionspädagogik in der Öffentlichkeit in differenzierter wie pointierter Weise zu beschreiben und damit zudem den so lange vermissten politischen Charakter religiöser Bildung wiederzugewinnen hilft.

"Die Religionspädagogik trägt auf diese Weise über die von ihr konzeptionierten und begleiteten Bildungsprozesse nun nicht nur zu individuellen und gemeinschaftlichen Orientierungen in den unterschiedlichen Lebens- und Weltverhältnissen bei, sondern auch dazu, Wirklichkeit erschließende Differenz- und Deutungskompetenz als einem wesentlichen Moment religiöser Bildung zu vermitteln und so die Teilhabe und Gestaltung gegenwärtiger Welt und Gesellschaft zu ermöglichen. Dies geschieht dann, wenn sie auf die ihr inhärente politische Dimension rekurriert, die so auch jedweder Gestaltung religiöser Bildungsprozesse zugehörig ist. Öffentlich im Sinne einer (zivil-)gesellschaftlichen Öffentlichkeit ist Religionspädagogik also dann, wenn sie im Modus der Situations- und Traditionserschließung Bildungskompetenzen fördert, die zur Beteiligung am Gemeinwesen, eben an der Zivilgesellschaft, verstanden als den gesellschaftlichen Ort, an dem die alle angehenden Themen und Anliegen verhandelt werden, beiträgt, und darin einen Beitrag zur Demokratiefähigkeit und zur Bildung in der Demokratie leistet.. ${ }^{49}$

Dabei gelingen Könemann feinsinnige Differenzierungen, die für die Öffentliche Religionspädagogik erhellend sind. Der öffentliche, genauer: zivilgesellschaftliche Beitrag der Kirchen beispielsweise kann dadurch abgehoben werden von einem Religionsunterricht, der sowohl in der gesellschaftlichen wie in der politischen Öffentlichkeit verortet ist. Als res mixta ist er einerseits auf der Ebene der politischen Öffentlichkeit angesiedelt, unterliegt er doch klaren grundgesetzlichen Regelungen; andererseits wird er von den Kirchen als Körperschaften öffentlichen Rechts auch politisch verantwortet. Bezogen auf

46 | Vgl. Meyer, Was ist Politik 2010, 263-271; Habermas, Ach, Europa 2008, 165.

47 | Könemann, Theologie, Kirche und Öffentlichkeit 2016, 138.

48 | Vgl. Gerhardt, Öffentlichkeit 2012, 235-368.

49 | Könemann Theologie, Kirche und Öffentlichkeit 2016, 150; vgl. auch Könemann, Art.: Politische Religionspädagogik 2016. 
religiöse Sprachfähigkeit und Handlungsfähigkeit finden sich in ihm jedoch zugleich Praktiken, die für eine zivilgesellschaftliche Öffentlichkeit relevant sind und die etwa im außerunterrichtlichen Rahmen der Schulpastoral mit ihren Angeboten von für das Zusammenleben bedeutsamen Orientierungen und sinnstiftenden Erfahrungen noch intensiviert werden. ${ }^{50}$ Unter Hinweis auf die Unterscheidung David Tracys zwischen einer akademischen, kirchlichen und gesellschaftlichen Öffentlichkeit,$^{51}$ zeigt Könemann zugleich den jeweiligen Öffentlichkeitscharakter der Theologie und der Religionspädagogik auf, der in charakteristischer Weise durchaus kontextuell und zielbezogen changiert. Daraus resultiert schließlich eine induktiv gewonnene Matrix, die letztlich im Hintergrund ihrer Überlegungen steht. Diese Matrix beruht auf den sich gegenseitig durchdringenden vier Feldern des Gesellschaftlichen, des Politischen, des direkten Agierens sowie des indirekten Agierens. Diese Matrix soll es erlauben, sowohl die jeweiligen Öffentlichkeiten, deren Praktiken, Orte und deren Logik zu unterscheiden, auf die die Religionspädagogik als wissenschaftliche Reflexion religiöser Bildung und Erziehung reflektiert. ${ }^{52}$

Von einer solchen Matrix und solchen Unterscheidungen kann eine Öffentliche Religionspädagogik profitieren. Sie führen weiter, weil sie in präziser und differenzierter Weise den Öffentlichkeitscharakter religiöser Bildung und religiöser Erziehung markieren. So werden theologische und religionspädagogische Positionen eingebracht, wobei die Öffentliche Theologie und die Politische Theologie naturgemäß besonderes Gewicht erhalten. Der Akzent liegt allerdings auf einer soziologischen und politikwissenschaftlichen Außenperspektive, erkennbar darum bemüht, sachkundig die Anschlussfähigkeit entsprechender religionspädagogischer Überlegungen aufzuweisen. Aus ihr heraus wird nach den Momenten der diversen Öffentlichkeiten gesucht, an die religionspädagogische Konzeptualisierung, Didaktik und Methodik anzuschließen vermögen. Das alles ist sehr erhellend. Nur unterbleibt eine kritische Erörterung dessen, was Öffentlichkeit eigentlich ist, genauer: wie sie zu denken ist.

Wohl zeigt Könemann verschiedene Teilöffentlichkeiten auf, wie sie sich in den funktionalen Ausdifferenzierungsprozessen der Moderne herauskristallisiert haben. Sie präpariert Elemente der Öffentlichkeit heraus (Diskursivität; Niederschwelligkeit, Intermediarität zwischen Staat und Bürgern etc.), die offensichtlich auf einer vorrangig diskurstheoretischen Basis beruhen, was sie aber eben nicht explizit macht. Der Öffentlichkeitsbegriff selber, seine Implikationen, seine Voraussetzungen, seine Praktiken und Konsequenzen, aber

50 | Vgl. Könemann, Theologie, Kirche und Öffentlichkeit 2016, 146-149.

51 | Vgl. Tracy, The Analogical Imagination 1981, 5-100; dazu: Telser, Habermas und die Öffentliche Theologie 2017.

52 | Vgl. Könemann, Theologie, Kirche und Öffentlichkeit 2016, 152. 
auch seine stillschweigenden Exklusionen: sie werden nicht einer kritischen Reflexion unterzogen. Angesichts der Anfragen von poststrukturalistischer, sozialphilosophischer oder auch feministischer Seite an ein diskurstheoretisches Öffentlichkeitskonzept ist dies verwunderlich. Müsste die Religionspädagogik nicht deutlicher wissen, worauf sie sich einlässt, wenn sie sich als eine Öffentliche Religionspädagogik konturiert? Offensichtlich wird damit ein erheblicher wissenschaftstheoretischer Präzisierungsbedarf.

\subsection{Gesuchte Anschlussfähigkeit an sozialphilosophische Zugänge: Manfred Pirner}

Ist Judith Könemann bestrebt, aus dem politik- und sozialwissenschaftlichen Diskurs heraus einen Öffentlichkeitsbegriff zu erarbeiten, von dem aus die öffentlichkeitsrelevanten Aspekte der Religionspädagogik in der Ausdifferenzierung verschiedener Lernorte analysierbar und reflektierbar werden, so setzt Manfred Pirner den Akzent anders. Er argumentiert stärker aus religionspädagogischer Perspektive und versucht, die sozialphilosophischen Debatten über das Gemeinwohl und den möglichen Beitrag der Religionen mit den religionspädagogischen Diskursen einer öffentlichkeitsrelevanten Bildung und deren Bedeutung für eine Allgemeine Bildung zusammenzuführen. ${ }^{53}$ Sein Interesse liegt vornehmlich darin, die Diskussionen der Sozialphilosophie als Anschlussstelle für religionspädagogische Prozesse so zu rekonstruieren, dass diese in ihrem Öffentlichkeitscharakter fruchtbar werden und zugleich ihrerseits aus diesem Dialog Impulse erhalten können. Sozialphilosophie und Theologie will er dabei in ein komplementäres Verhältnis setzen, um aus dieser Komplementarität schließlich Leitlinien und Perspektiven für eine Öffentliche Religionspädagogik abzuleiten.

Von theologischer Seite aus gilt es für Pirner, das Profil der Öffentlichen Religionspädagogik zu zeichnen. Dazu stellt er sich dezidiert in den Kontext der public theology, die im Unterschied zur Politischen Theologie sich als Beitrag zum Gemeinwohl verstehe und diese theologischen Beiträge »nicht auf auf politische Diskussions- und Entscheidungsprozesse im engeren Sinn beschränken, sondern die gesellschaftliche Öffentlichkeit in ihrer gesamten Breite im Blick haben « will. ${ }^{54}$ Vor dieser Folie systematisiert Pirner, der inzwischen in verdienstvoller Weise auch eine Forschungsstelle zur Öffentlichen Religionspädagogik begründet hat, die bisherigen Forschungen zu einer Öffentlichen Religionspädagogik. In beeindruckender Akribie und detaillierter Kenntnis führt er die bisherigen Argumentationsstränge in ihrem gemeinsamen Anliegen wie in ihrem je spezifischen Zugriff zusammen, um in diesem

53 | Vgl. Pirner, Öffentliche Religionspädagogik 2015.

54 | Pirner, Öffentliche Religionspädagogik 2015, 63. 
Konzert diverser Positionen seine eigene Perspektive auf eine Öffentliche Religionspädagogik zu skizzieren. Ein Verdienst liegt sicher allein schon darin, dass deren tiefe Verwurzelung in zentralen Traditionen der Religionspädagogik und damit ein Indiz für deren Kraft und Orientierungsfähigkeit deutlich wird..$^{55}$

Von der sozialphilosophischen Seite aus nimmt er bewusst die Diskussionen zwischen dem liberalen Ansatz John Rawls und der deliberativen Theorie kommunikativer Vernunft von Jürgen Habermas als Referenzpunkt, ${ }^{56}$ weil diese die sozialphilosophische Debatte über das Gemeinwohl pluralistischer Gesellschaften dominiert hätten.

"Denn die sozialphilosophische Grundfrage, was eine freiheitlich-demokratische, pluralistische Gesellschaft trägt und zusammenhält, findet ihre bildungstheoretische Entsprechung in der Grundfrage, auf welche Bildungsziele für öffentliche Bildung sich eine solche Gesellschaft einigen kann. Und die bildungs- und schultheoretische Frage, was der Religionsunterricht zu gemeinsamen gesellschaftlichen Bildungszielen - also zur 'Allgemeinbildung، - beitragen kann, hängt eng zusammen mit der gesellschaftstheoretischen Frage, welche Beiträge die Religionen auf welche Weise zum 'Gemeinwohk leisten können. " ${ }^{57}$

Dieses Vorgehen ist bereits bemerkenswert. Allein die faktische Dominanz von Rawls und Habermas, nicht eine inhaltliche Diskussion alternativer und konträrer Modelle sozialphilosophischer Ansätze genügt Pirner demnach als Begründung. Die Frage danach, ob nicht vielleicht andere sozialphilosophische Konzepte einen plausibleren Referenzpunkt für die Religionspädagogik bilden könnten, stellt sich für Pirner offensichtlich nicht. Es ist ein rein positivistisches Argument, dass die Auswahl begründet.

Um aus dem Gegensatz von Rawls und Habermas religionspädagogischen Nutzen ziehen zu können, ${ }^{58}$ rekonstruiert Pirner minutiös die Konzeption liberaler Öffentlichkeit bei Rawls und deren Gesprächsfähigkeit mit den Religionen. Öffentliche Vernunft und der overlapping consensus fungieren als Zentralbegriffe. Eine pluralistische Gesellschaft kann sich im Unterschied zu weltanschaulich mehr oder weniger geschlossenen Gesellschaften nicht mehr auf eine für alle gültige Vision guten und gerechten Lebens einigen. Zusammenhalt einer Gesellschaft wird nur dann erzeugt, wenn im Forum univer-

55 | Vgl. Pirner, Öffentliche Religionspädagogik 2015, 62-68.

56 | Vgl. Pirner, Religion und öffentliche Vernunft 2015. Ferner neuerdings Pirner, Öffentliche Religionspädagogik im globalen Horizont 2018; Pirner, Die blinden Flecken interreligiöser Kompetenzbildung 2018.

57 | Vgl. Pirner, Öffentliche Religionspädagogik 2015, 68.

58 | Vgl. Pirner, Öffentliche Religionspädagogik 2015, 68-72. 
saler, für alle geltender Vernunft sich die partikularen comprehensive doctrines der verschiedenen religiösen und kulturellen Traditionen zum Wohle des Ganzen einbringen. Damit diese jedoch den zumeist religiös unmusikalischen Zeitgenossen etwas sagen können, bedürfen sie der Übersetzung. Daraus resultiert dann ein überlappender Konsens verschiedener Traditionen im Forum der öffentlichen Vernunft.

Pirners Argumentation fokussiert besonders auf diese Übersetzungsnotwendigkeit, fungiert diese doch als Ansatzpunkt seiner eigenen religionspädagogischen Perspektive. Hierfür greift er auf Habermas Gegenentwurf zurück. Dieser wendet ja bekanntlich gegenüber Rawls ein, dass gerade eine öffentliche Vernunft die Gewichte der Übersetzung nicht einseitig zu Lasten der Religionen verteilen darf. Eine solche Asymmetrie unterlaufe die für alle geltende Inklusion der Bürgergesellschaft. Säkulare wie religiöse Bürgerinnen und Bürger sind zur Übersetzung ihrer eigenen Traditionen im Sinne öffentlicher Verständigung verpflichtet. Beide müssten miteinander und voneinander lernbereit wie diskursfähig im Kontext öffentlicher Vernunft sein. Habermas Folgerung eines »komplementären« Lernprozesses gewinnt zentrale Relevanz,$^{59}$ denn dieser legt jeder und jedem, ob säkular, agnostisch, atheistisch oder eben religiös, die gleiche Übersetzungspflicht auf. Nicht nur würde damit die Gesellschaft von den religiösen Traditionen profitieren. Nicht minder erhielten die religiösen Traditionen durch die Kraft aufgeklärter Vernunft zivilisierende und orientierende Impulse. Diese Komplementarität des Lernens verlangt demnach ein »dialogisch-kooperatives Unternehmen« von religiösen und nicht-religiösen Bürgerinnen und Bürgern. ${ }^{60}$

Aus diesem Konnex von Komplementarität und Übersetzung erwachsen nun die entscheidenden Leitlinien für Pirners Ansatz Öffentlicher Religionspädagogik. Ein solches wechselseitig-komplementäres Lernen würde bereits verfehlt, würde die Religionspädagogik ihre Rolle etwa so verstehen, dass die gesellschaftlichen Defizite lediglich als Frageraum interpretiert würden, in den hinein die Religionspädagogik ihre Antworten geben könnte. Dies würde die Relevanz säkularer Vernunft und die Angewiesenheit religiöser Traditionen auf das Gespräch mit den Anderen zu gering achten. Ähnliches würde unter veränderten Vorzeichen ebenfalls für eine Zivilreligion gelten, die an der kulturellen wie weltanschaulichen Heterogenität moderner Gesellschaften vorbeisieht. Vielmehr stehen säkulare wie religiöse Traditionen im Dienst am Gemeinwohl, das gerade deren Spannung in einem dialogischen Lernprozess produktiv aufnimmt. »Öffentlich christlich-religiöse Bildung ist

59 | Habermas, Kritik der Vernunft 2009, 117; vgl. Pirner, Öffentliche Religionspädagogik 2015, 71.

60 | Pirner, Öffentliche Religionspädagogik 2015, 73; genauer: Pirner, Re-präsentation und Übersetzung 2015. 
dann begründungstheoretisch v.a. vom historisch gewachsenen Vertrauen und der aktuellen Evidenz getragen, dass das Christentum inhaltlich einen Sprach-, Wahrnehmungs- und Reflexionsgewinn und damit letztlich einen Lebensgewinn für Individuum und Gesellschaft erbringt und hat den Auftrag, dies allen Schülerinnen und Schülern (gerade auch den anders- und nicht religiösen) didaktisch zu erschließen. « $^{61} \mathrm{Zu}$ kritischer Selbstreflexion gegenüber der möglichen gesellschaftlichen Funktionalisierung religiöser Bildung verpflichtet, stellt sich diese mitten in die gesellschaftlichen Diskurse hinein und überwindet dabei die individualistische Drift mancher Religionspädagogiken. Öffentliche Religionspädagogik kann so schließlich den Blick über den Religionsunterricht hinaus auf das Feld allgemeiner schulischer und nichtschulischer Bildung öffnen und in den lern- und korrekturbereiten Dialog mit anderen Fächern der Fächergruppe (wie der Ethik oder dem Religionsunterricht anderer Religionen) sowie in den mit anderen Schulfächern treten. Auf diese Weise avanciert schließlich der Religionsunterricht der Öffentlichen Religionspädagogik selber zu einem Ort, an dem der weltanschaulich-religiöse Diskurs praktiziert und damit jene Sprach-, Kommunikations- und Reflexionsfähigkeiten und offene Lernbereitschaft performativ eingeübt werden, derer eine plurale Gesellschaft bedarf. ${ }^{62}$

Mit diesen Überlegungen liefert Pirner die Grundlage für eine Öffentliche Religionspädagogik, die - theologisch fundiert und philosophisch anschlussfähig - sich zugleich lernbereit und dialogfähig zeigt. Gewiss müssen diese Grundlinien grundlagentheoretisch fundiert, religionspädagogisch kontextualisiert und religionsdidaktisch weiter konkretisiert werden. Stärker als Judith Könemann gelingt es ihm jedoch, den genuin religionspädagogischen Zugriff auf eine Öffentliche Religionspädagogik zu markieren. Gleichwohl findet sich eine vergleichbare offene Flanke. Man mag bereits kritisch einwenden, ob nicht schon ein Missverständnis der Politischen Theologie vorliegt. Diese versteht sich doch ihrerseits dezidiert als Neuentwurf einer kontextuellen gesellschaftskritischen Theologie in »Geschichte und Gesellschaft«, die weniger als die public theology am Gemeinwohl und dem möglichen Beitrag religiöser Traditionen interessiert ist, sondern die weitaus stärker als die public theology den kritischprophetischen, bei Metz gar apokalyptisch angeschärften Stachel biblischen Erbes produktiv wie kritisch auch auf struktureller Ebene einbringen will. ${ }^{63}$ Möglicherweise aber ist dies schon ein Indiz für eine zentrale Schwierigkeit,

61 | Pirner, Öffentliche Religionspädagogik 2015, 75.

62 | Vgl. Pirner, Öffentliche Religionspädagogik 2015, 77.

63 | Vgl. Metz, Glaube in Geschichte und Gesellschaft 1984; Metz, Memoria passionis 2006; als kritische Weiterentwicklung von Metz, dem empirische Defizite vorgehalten werden, die durch Rückgang auf Bourdieu zu kompensieren seien: Kreutzer, Politische Theologie für heute 2017. 
die mit einer eigentümlichen Beschränkung einer kritisch-selbstreflexiven Vernunft und der darauf beruhenden Konzeption von Öffentlichkeit bei Pirner zusammenhängt. Er diskutiert den Öffentlichkeitsbegriff in seinen verschiedenen Dimensionen. Er geht sogar soweit, »die ideologiekritische Frage nach den Wirkungsmechanismen und impliziten Normen von Öffentlichkeiten« eine zentrale Bedeutung innerhalb der Öffentlichen Religionspädagogik selber beizumessen. ${ }^{64}$ Damit jedoch greift er indessen lediglich jene Züge einer notwendigen kritischen Selbstreflexivität öffentlicher Vernunft auf, die er selber als wesentliche Momente der Öffentlichen Vernunft bei Rawls und Habermas ausgemacht hat. ${ }^{65}$ Es kommt ihm nicht in den Sinn, diese Form der Öffentlichkeit in den Bahnen liberaler Vernunft selber kritisch zu reflektieren und die deliberative kommunikative Vernunft grundsätzlich zu problematisieren. Diese bleibt als Referenzrahmen nicht nur unangetastet, sondern - wie bemerkt - unausgewiesen. Die Kategorien der Öffentlichkeit werden nicht nochmals kritisch hinsichtlich ihrer reflexiven Verwendung bedacht. Vor diesem Hintergrund kann er sich der Implikationen seiner Öffentlichen Religionspädagogik nicht hinreichend Rechenschaft gegeben, die etwa in der Perspektive einer Diskursanalyse Foucaults mit seinen Äußerungen verbunden sind. Pirner wirbt für interreligiöse und interkonfessionelle Verständigung und zu einem aus dem Menschenrechtsdiskurs rezipierten Inklusionsgedanken, der insbesondere als Impuls zur Inklusion homosexueller Menschen wichtige Lernprozesse innerhalb der Religionen angestoßen habe ${ }^{66}$ Wie stark freilich eine solche Rede wiederum auf hegemonialen Konstruktionen beruht, inwieweit der Inklusionsgedanke seinerseits mit einer geheimen Dialektik von Inklusion und Exklusion operiert, kann mit diesem spezifischen Vernunftinstrumentarium allein nicht bearbeitet werden. ${ }^{67}$

Insgesamt profiliert Pirner damit einen Begriff der Öffentlichkeit als axiomatische Basis seiner Öffentlichen Religionspädagogik, dessen diskursive Mechanismen ebenso wenig hinreichend bedacht werden wie ihre wissenschaftstheoretische Gestalt. Die Kategorien der Öffentlichkeit werden nicht ausreichend reflektiert.

64 | Pirner, Öffentliche Religionspädagogik 2015, 77.

65 | Vgl. Pirner, Öffentliche Religionspädagogik 2015, 68-72.

66 | Vgl. Pirner, Öffentliche Religionspädagogik 2015, 77.

67 | Vgl. Grümme, Heterogenität 2017, 206-244. 


\subsection{Ein systematischer Entwurf öffentlicher Religionspädagogik: Bernd Schröder}

Beschränken sich Pirners bisherige Überlegungen zur Öffentlichen Religionspädagogik auf eine »Perspektive «, ${ }^{68}$ so ist es Bernd Schröder, der wohl als einziger unter den Vertretern der Öffentlichen Religionspädagogik bislang einen weitgehend elaborierten Entwurf hierzu vorgelegt hat. Ohne dass hieraus freilich bislang eine durchsystematisierte Monografie erwachsen wäre, legt er für diese ein breites und tragfähiges Fundament, das er auf theologische, religionspädagogische, kirchliche wie gesellschaftliche Bezüge gründet. Sein Entwurf bleibt überwiegend programmatisch.

Religionspädagogik ist darin Bestandteil der verschiedenen Öffentlichkeiten in Kirche, Gesellschaft, Theologie.

"Sie hat rezeptiv teil an den Entwicklungen einer 'bürgerlichen Öffentlichkeit، bzw. pluraler Öffentlichkeiten, sie hat konstruktiv teil am Öffentlichkeitsanspruch von Evangelium, Kirche und Theologie, sie hat auf Grund des ihr eigenen Gegenstandsfeldes, ihrer zentralen Denkfiguren und ihrer Zielsetzung konstitutiv teil am Aufbau von religiös aufgeklärter Öffentlichkeit - und eben diese Teilhabe ist ihr historisch schon in ihrer Gründerzeit zugewachsen und entsprechend wahrgenommen worden." ${ }^{69}$

Den hier mitschwingenden Begriff aufgeklärter Öffentlichkeit entnimmt Schröder den genetisch-systematischen Rekonstruktionen von Jürgen Habermas und dessen Beschreibung eines Strukturwandels bürgerlicher Öffentlichkeit, die auf der normativ gefassten Partizipation der Freien und Gleichen beruht. Er weitet ihn aber unter dem Eindruck der gegenwärtigen öffentlichkeitstheoretischen Debatten. In feinen Distinktionen erhebt Schröder verschiedene Merkmale eines normativ anspruchsvollen wie analytisch aussagekräftigen Öffentlichkeitsbegriffs. ${ }^{70}$ Diese Öffentlichkeit ist - erstens - nicht bereits vorhanden, ist nicht bereits vorauszusetzen. Sie ist stets in diskursiven Prozessen je neu auch gegen Widerstände und Deformierungen zu erringen und durch eine Befähigung zur Teilhabe aufzubauen. Offen - zweitens - für alle, weshalb sie eine Öffentlichkeit der Gleichen und Freien sein soll, ist sie - drittens - auf für das Gemeinwohl relevante Themen bezogen. Die die Öffentlichkeit strukturierende Kommunikation wird - viertens - nicht selbstreferentiell für sich selber geführt. Sie ist ausgerichtet an der wachsenden Mündigkeit und Aufgeklärtheit der Teilnehmenden, hat diese doch die »gewaltlose Ermittlung des zugleich Richtigen und Rechten« in all den über das Private hinausgehen-

68 | Pirner, Öffentliche Religionspädagogik 2015, 68.

69 | Schröder, Öffentliche Religionspädagogik 2013, 123-124.

70 | Vgl. Schröder, Theologische Bildung 2017, $155 f$. 
den Angelegenheiten zum Ziel. ${ }^{71}$ In ihrem tendenziell universalen Referenzbereich, in ihrer Geltung für alle, liegt - fünftens - ihre Medialität begründet. Sie überschreitet die intersubjektive face-to-face-Kommunikation und hat längst in der Ausweitung der bürgerlichen Salons hin zu einer medial vermittelten Kommunikation durch Presse, Funk und Fernsehen die virtuellen Räume des Internets als Öffentlichkeit konstituiert. Allerdings ist Öffentlichkeit in zweierlei Hinsicht - sechstens - plural strukturiert. Öffentlichkeit ist einmal in sich plural, weil nur so ein Diskurs zwischen Gleichen und Freien möglich ist. Zugleich aber ist Öffentlichkeit in der Unterscheidung von anderen Öffentlichkeiten plural verfasst. Sie können entstehen durch räumliche Bezugsgrößen, durch gesellschaftliche Stratifizierungen, durch Antagonismen zwischen verschiedenen Gruppen als Teilöffentlichkeiten oder auch durch unterschiedliche Rezeptionsmuster von Medien. Gleichzeitig jedoch birgt die Öffentlichkeit auch eine »Dialektik,$^{72}$ sie ist nicht je schon gut. Denn Öffentlichkeit kann neben einer Partizipationsmöglichkeit auch Ausgrenzungs-, Repressions- und Kontrollfunktionen bekommen.

Aus diesem komplexen Gefüge an Implikationen ergibt sich, dass eine Sache nicht per se von sich her öffentlich ist. Sie kann Öffentlichkeit beanspruchen, sie kann sich selber einen Öffentlichkeitsauftrag attestieren. Aber es ist nach Schröder die Öffentlichkeit selbst, die entscheidet, wie in ähnlicher Weise Konrad Liessmann formuliert: »Erst wenn etwas faktisch eine Öffentlichkeit erreicht und im öffentlichen Diskurs Klärung erfährt, ist es öffentlich.« ${ }^{73}$

Dieser Öffentlichkeitsbegriff lässt verstehen, warum Bildung, auch religiöse Bildung öffentlich relevant sein können. »Öffentlichkeit (als Prozess) meint nicht den Diskurs um des Diskurses willen, sondern den kritisch-konstruktiven Diskurs, der auf gesteigerte Mündigkeit der Einzelnen und Demokratisierung der Gesellschaft zielt, Öffentlichkeit (als Status einer Sache) ist nicht für alle möglichen Gegenstände in Anspruch zu nehmen, sondern nur für die nicht-privaten, alle angehenden Fragen des Gemeinwohls. « ${ }^{74}$ Hier kommt Pädagogik ins Spiel, attestiert Schröder doch mit Volker Gerhardt der Öffentlichkeit selber eine eminent pädagogische Leistung als der vermutlich wichtigsten »Instanz in der Selbsterziehung des Menschengeschlechts «. ${ }^{75}$ Deshalb hat sich die Religionspädagogik »seit jeher als öffentlich verstanden «. ${ }^{76}$ Folge-

71 | Habermas, Strukturwandel der Öffentlichkeit 1990, 152.

72 | Schröder, Theologische Bildung 2017, 156. Vgl. Liessmann, Bildung als Provokation 2017, 176-178.

73 | Liessmann, Bildung als Provokation 2017, 156.

74 | Schröder, Öffentliche Religionspädagogik 2013, 117.

75 | Gerhardt, Öffentlichkeit 2012, 512; vgl. Schröder, Theologische Bildung 2017, 155.

76 | Schröder, Öffentliche Religionspädagogik 2013, 124. 
richtig ist Bildung eine öffentliche, das Gemeinwohl betreffende Angelegenheit. Gleichzeitig aber lässt dieser Öffentlichkeitsbegriff verstehen, inwiefern das Evangelium, inwiefern Theologie und Religionspädagogik je schon einen Öffentlichkeitsanspruch und die Kirche im Rückgründung darauf einen Öffentlichkeitsauftrag haben, nicht aber je schon öffentlich sind. ${ }^{77}$ Daraus abgeleitet versteht Schröder die Religionspädagogik in diesem Sinne als öffentlich:

"Religionspädagogik ist konstitutiv auf Öffentlichkeit (als Adressat, Gegenstand und Ziel) bezogen. Sie ist (nicht nur) im Blick auf diese ihre Öffentlichkeit im Kanon der Disziplinen am engsten mit der ethischen Theologie verwandt. Wie jene ist sie [...] auf ihre Art , die der [...] Lebenswirklichkeit zugewandte Weise, die Grundfragen der Theologie selbständig [...] zu entfalten`, ich möchte ergänzen: sie als öffentliche Angelegenheit zu entfalten. ${ }^{78}$

Die Öffentlichkeit ihrerseits ist demnach an der Konstitution der Relevanz von Kirche, Theologie und Religionspädagogik maßgeblich beteiligt. Zwar kann man mit Schröder aufzuzeigen versuchen, warum religiöse Bildung für eine aufgeklärte Öffentlichkeit sinnvoll und bedeutsam sein müsste. In dieser geht es doch um die Anbahnung eines wert- und existenzbezogenen Selbstverstehens aller Bürgerinnen und Bürger, um die Erschießung von Sinnressourcen für die Gesellschaft, um die Grundlegung eines gesellschaftlichen, interkulturellen und interreligiösen Dialogs, um die kritische Aufklärung der eigenen Tradition und um eine kritische Selbstrelativierung gesellschaftlicher, politischer und ökonomischer Absolutheitsansprüche. ${ }^{79}$ Aber genau diese Konstellation, diese konstitutive Relevanz der Öffentlichkeit für die Zuschreibung des Öffentlichkeitscharakters einer Wirklichkeit, macht es unumgänglich, nach der Struktur und dem Rang von Religion in der Öffentlichkeit, nach Säkularisierung, Privatisierung und Pluralisierung zu fragen, daraufhin die Sinn- und Orientierungsleistung religionspädagogischer Prozesse und theologischer Bildung auszurichten und das eigene Selbstverständnis zwischen Identität und Verständigung, oder radikaler: zwischen den Extremen exklusivistischer Selbstverschränkung einerseits und kommunikativer Selbstsäkularisierung andererseits zu konturieren. ${ }^{80}$

Erhellend ist Schröders Ausdifferenzierung von drei bedeutsamen unterschiedlichen Modi der Öffentlichkeitswirksamkeit: der Selbstbeschränkung,

77 | Vgl. Schröder, Öffentliche Religionspädagogik 2013, 118-122; Schröder, Theologische Bildung 2017, 156.

78 | Schröder, Öffentliche Religionspädagogik 2013, 111.

79 | Vgl. Schröder, Theologische Bildung 2017, 157.

80 | Vgl. Schröder, Theologische Bildung 2017, 158-165. 
des positionell-pluralismusfähigen Dialogs, der Distinktion. ${ }^{81}$ Insofern Religionspädagogik und theologische Bildung in die Öffentlichkeit drängen, haben sie zu entscheiden, welchen Modus sie wählen, um ihrem Sinn und ihren Adressaten am besten gerecht zu werden. Schröder liefert mit diesem fein ziselierten, vielschichtigen und mehrdimensionalen Öffentlichkeitsbegriff eine beeindruckende Begründung einer Öffentlichen Religionspädagogik. Klar werden Öffentlichkeit und Religionspädagogik jeweils profiliert und in ihrer intrinsischen Wechselwirkung diskutiert. Ihm gelingt eine ausdifferenzierte Semantik des Öffentlichkeitsbegriffs, die dessen Strukturen herauspräpariert und das Verhältnis seiner Elemente bis in Einzelheiten hinein analytisch freilegt. Unterscheidungen wie Bezüge zwischen deskriptiver und normativer Ebene werden sichtbar und religionspädagogisch fruchtbar gemacht. Die normative Ausrichtung einer Öffentlichen Religionspädagogik hat sich demnach im Rahmen einer normativen Bestimmung der Öffentlichkeit wie in dem einer empirisch und hermeneutisch analysierten Öffentlichkeit zu artikulieren. Insbesondere die aus dem Öffentlichkeitsbegriff selber abgelesene pädagogische Dynamik lässt sich als Anschlussstelle wie als Orientierungslinie für eine Öffentliche Religionspädagogik begreifen. Öffentlichkeit impliziert gerade in ihrer Finalisierung auf Mündigkeit und Autonomie der Subjekte wesentlich eine pädagogische Dimension.

Einem solchen Öffentlichkeitsbegriff kann die Öffentliche Religionspädagogik damit wesentliche Kategorien ihrer Selbstkonzeptionierung entlehnen, nicht zuletzt auch deshalb, weil dieser überdies offen ist für kritische Reflexionen der Dialektik und Ideologisierbarkeit moderner Öffentlichkeit. In materialer Hinsicht ist das von Schröder erarbeitete semantische Potential religionspädagogisch wegweisend. Formal jedoch bleibt es defizitär. Denn obschon er in beeindruckender wie maßstabgebender Weise die Öffentlichkeit in ihren Implikationen, Strukturen und Momenten denken kann, thematisiert Schröder nicht das Denken der Öffentlichkeit selber. Er gibt sich zu wenig Rechenschaft hinsichtlich der Begriffe und der Vernunft, mit denen er Öffentlichkeit denkt.

An einem Beispiel lässt sich dieses Desiderat illustrieren. $\mathrm{Zu}$ den elementaren Merkmalen der Öffentlichkeit zählt Schröder die prinzipielle Offenheit für alle, die teilnehmen wollen und für »möglichst viele unter denen, die über bestimmte Voraussetzungen für Partizipation verfügen: Literalität, einschlägiges Diskursinteresse und kommunikative Umgangsformen«. Daraus folgt: »Diejenigen, die teilhaben, werden als gleich anerkannt.«82 Man kann diese Ausführungen sicherlich als Beleg für die erwähnte intrinsische pädagogische Dimension der Öffentlichkeit interpretieren. Um teilhabefähig zu sein, braucht es Prozeduren und Praktiken, in denen die hierfür notwendigen Fä-

81 | Vgl. Schröder, Theologische Bildung 2017, $163 f$.

82 | Schröder, Theologische Bildung 2017, 155. 
higkeiten, Motivationen und Kenntnisse angebahnt werden. Dies ist das institutionell verankerte traditionelle Geschäft der Pädagogik. Doch wer verbürgt, dass alle diese Fähigkeiten erlangen können? Werden die jeweilig individuellen wie zugleich strukturellen Voraussetzungen einer solchen Teilhabe auch nur annähernd reflektiert, wie dies im Kontext einer inklusiven oder auch einer heterogenitätsfähigen Religionspädagogik diskutiert wird? ${ }^{83}$ Ohne sich selber hinreichend über die Implikationen, über die Konsequenzen und hermeneutischen Operationen Rechenschaft zu geben, wird schlicht eine im Modus diskursiver kommunikativer Rationalität gedachte Vernunft vorausgesetzt. In deren Lichte, mit ihren Operationen wird dann, gewiss unter Aufnahme neuerer kritischer Fortschreibungen, ein materialer Öffentlichkeitsbegriff entfaltet, der im Wesentlichen auf Habermas Analytik des Öffentlichkeitsbegriffs beruht. Ob Schröder durch die Art, Öffentlichkeit zu denken, möglicherweise trotz gegenläufiger Intention zu Exklusionen, hegemonialen Strukturen und Missachtungen der Vielfalt heterogener Lebenswelten kommt, wird von ihm nicht selbstreflexiv bedacht. Ob es eventuell noch andere Modi, Öffentlichkeit zu denken, ob es nicht seiner Intention noch besser entsprechende und diese nicht konterkarierende Vernunftformen gibt, wird nicht erwogen. Dies aber unterläuft die eigene erklärte Zielsetzung, in diesem Öffentlichkeitsbegriff die innere Pluralität, die Heterogenität, ja den Antagonismus verschiedener, etwa marginalisierter und privilegierter Öffentlichkeiten abzubilden oder auch die mit der Öffentlichkeit verbundene dunkle Seite ihrer Ideologisierbarkeit zu reflektieren. ${ }^{84}$ Kurz: Schröder kann wohl die Ideologisierbarkeit von Öffentlichkeit denken, nicht aber hinreichend die Ideologisierbarkeit des Öffentlichkeitsbegriffs selber. Sein Öffentlichkeitsbegriff bleibt formal unterbestimmt und die Verbindung zwischen Form und Inhalt unklar.

\section{Auftrag zu einer Metatheorie Öffentlicher RELIGIONSPÄDAGOGIK}

So ist nun auch am elaboriertesten Öffentlichkeitsbegriff im Konzert der gegenwärtigen Öffentlichen Religionspädagogik die entscheidende Schwäche markiert. Weder Könemann, weder Pirner noch Schröder - und auch der Autor dieser Zeilen in seinem eigenem Entwurf Öffentlicher Religionspädagogik nicht - bedenken das Denken des Öffentlichkeitsbegriffs hinreichend. Weder eine selbstkritische Reflexion der eigenen Begriffsbildung, weder eine Diskussion der Konzeption der zugrunde gelegten Vernunft noch eine selbstreflexive Überprüfung der verwendeten Prozeduren, Operatoren und Praktiken

83 | Vgl. Grümme, Heterogenität 2017, 206-244; Schweiker, Prinzip Inklusion 2017.

84 | Vgl. Schröder, Theologische Bildung 2017, 156. 
lässt sich im gegenwärtigen Diskurs Öffentlicher Religionspädagogik in angemessener Qualität nachweisen. So eindrucksvoll der Öffentlichkeitsbegriff in materialer Hinsicht auch ist, wie sehr dieser jeweils in seiner systematischen Kraft und religionspädagogischen Potenz überzeugt, so schwach bleibt dessen metatheoretische Reflexion. Das Desiderat liegt somit auf epistemologischer Ebene und damit auf dem Feld der Wissenschaftstheorie. Insbesondere das Wie, weniger das Was des Öffentlichkeitsbegriffs gilt es zu bedenken. Wie muss Öffentlichkeit gedacht werden, damit sie inhaltlich angemessen gefüllt werden kann? Wer bestimmt, was angemessen ist? Im Fokus müssen darum die Form des Öffentlichkeitsbegriffs stehen, seine Begriffsbildung, weniger seine Inhalte. Nicht die Öffentlichkeit steht im Mittelpunkt, sondern die Weise, wie sie gedacht wird. Nicht die Frage der Religion in der Öffentlichkeit, nicht die Formen diverser Öffentlichkeiten und deren Verhältnis zueinander, nicht das Verhältnis von privat und öffentlich, all dies ist nicht fokussiert. Die folgenden Überlegungen kreisen allein um den Begriff der Öffentlichkeit - und dies in religionspädagogischem Interesse. Es geht um dessen rationale und pragmatische Konstruktion. Mit anderen Worten: wer hier eine ausgewiesene Konzeption von Öffentlichkeit erwartet, die in das Konzert anderer Theorien eingespielt werden soll, wird ebenso enttäuscht wie derjenige, der eine Systematik Öffentlicher Religionspädagogik erwartet. Es geht schlicht um die begriffliche Konstruktion des Öffentlichkeitsbegriffs.

Allerdings ist die Sache komplizierter. Die Frage nach dem Was lässt sich zwar offensichtlich nie ohne das Wie angemessen bearbeiten. Zugleich aber ist auch die Suche nach dem Wie auf das Was angewiesen. Die Form braucht ihrerseits den Inhalt. »Gedanken ohne Inhalt sind leer, Anschauungen ohne Begriffe sind blind. « $^{85}$ Die Art, Öffentlichkeit zu denken, muss intrinsisch korrelieren mit ihrem inhaltlich-strukturellen Profil. Zumindest kann deshalb die Suche nach einem angemessenen Begriff der Öffentlichkeit nicht gänzlich abstrahieren von ihren inhaltlichen Konturen.

Damit kristallisiert sich die Hauptaufgabe der folgenden Überlegungen heraus. Begriffsklärung scheint dringlich geboten. Keine weitere Theorie der Öffentlichkeit, keine detaillierte inhaltliche Analyse diverser Öffentlicher Religionspädagogiken ist beabsichtigt, schon gar kein eigener systematischer Entwurf. Diese bilden in erster Linie einen Entdeckungs- und Problematisierungszusammenhang für einen zu konturierenden Öffentlichkeitsbegriff der Öffentlichen Religionspädagogik. Primär geht es um die Profilierung des Öffentlichkeitsbegriffs auf grundlagentheoretischer Ebene. Wir bewegen uns also auf der Ebene der Denkform. Mit der >Denkform< ist eine Größe gemeint, die eine Theoriebildung, deren Kategorien und Form, strukturell prägt, ohne

85 | Kant, Kritik der reinen Vernunft 1990, B 75, A 48. 
unvermittelt und direkt in Erscheinung zu treten. ${ }^{86}$ Danach handelt es sich bei Denkformen

"niemals um leere, gegen jeden Inhalt noch gleichgültige Formen, sondern durchaus schon um Gefüge von Gehalten [...], die sich gegenseitig bestimmen. Denkformen sind bereits [...] bestimmte Auslegungen der Gesamtwirklichkeit, die dann als ,Vorverständnis ' bei allem weiteren Verstehen von Wirklichkeit fungieren. Und es ist eben die schon interne Bestimmtheit eines Denkens, durch die alle Inhalte, die es aufnimmt, ihrerseits bestimmt werden, so wie es umgekehrt selbst durch sie weiterbestimmt und möglicherweise auch zur Revision veranlaßt wird." 87

Den folgenden Überlegungen liegt demnach das präzise Bemühen um die Denkform des Öffentlichkeitsbegriffs zugrunde. Im Fokus stehen zwei Aspekte, die insofern auch den Gang der Untersuchung bestimmen: 1. einen analytisch-kritischen und 2. einen konstruktiven Teil.

Demnach geht es 1. um die interdisziplinäre Analyse diverser Reflexionen von >Öffentlichkeit< (Abschnitt C). Da es sich um wissenschaftstheoretische Grundlegungen des Öffentlichkeitsbegriffs handelt, werden deshalb entweder vor allem solche Ansätze ausgewählt, die auf grundlagentheoretischer Ebene im Hintergrund bereits vorhandener Konzepte Öffentlicher Religionspädagogik stehen. Dies gilt insbesondere für die Diskurstheorie Habermas. Oder es werden solche hinzugezogen, die sich an eben dieser abarbeiten, sich dagegen profilieren, von dorther Impulse beziehen oder sich radikal anders positionieren. Sie haben exemplarische Bedeutung für maßgebliche philosophische Denkrichtungen, die auch pädagogisch wie religionspädagogisch federführend sind. Es sind also empirische Gründe wie Gründe der Exemplarität. Die Wahl der Ebene der Denkform bringt es überdies mit sich, dass nicht primär substantielle Öffentlichkeitstheorien herangezogen werden. Im Zentrum stehen vielmehr philosophische Entwürfe, aus denen bestimmte Konturierungen der Öffentlichkeitsbegriffs erwachsen. Dass diese ihrerseits entweder von diesen Autorinnen und Autoren selber oder von Rezipientinnen und Rezipienten zu einem materialen Entwurf einer umfassenden Öffentlichkeitstheorie ausformuliert werden, ist wiederum nicht primärer Gegenstand der Untersuchung. Nicht die Binnenlogik der einzelnen Ansätze, nicht deren Autorinnen und Autoren stehen im Vordergrund. Es geht um eine Analytik und Systematik des jeweiligen Öffentlichkeitsbegriffs.

Aus der Diskussion der einzelnen Ansätze heraus obliegt schließlich dann dem 2. Teil die konstruktive Profilierung eines Begriffs von Öffentlichkeit, der

86 | Vgl. Grümme, Auf Sand gebaut 2004, 266-279.

87 | Pröpper, Evangelium und freie Vernunft 2001, 13. 
als Grundlage einer Öffentlichen Religionspädagogik fungieren könnte (Abschnitt D; E).

Insgesamt beabsichtigen diese Überlegungen damit eine kritisch-konstruktive Reflexion des Öffentlichkeitsbegriffs in religionspädagogischer Absicht, nicht mehr, aber auch nicht weniger. Ihr Akzent ist epistemologischer und damit wissenschaftstheoretischer Natur. Insofern sind diese Überlegungen Bestandteil einer noch zu schreibenden wissenschaftlichen Metatheorie Öffentlicher Religionspädagogik im Kontext von Heterogenität. 


\section{Konzepte der Öffentlichkeit}

Gewiss trägt jede Auswahl von Öffentlichkeitstheorien einen dezisionistischen Zug. Manche drängen sich religionspädagogisch förmlich auf. Manche sind wichtig, weil sie religionspädagogisch bereits in Anspruch genommen werden, davon einige bewusst und explizit, andere dagegen eher klandestin. Andere sind erst herbei zu zitieren, weil deren Potential bislang unausgeschöpft ist. Nicht alle Theorien der Öffentlichkeit können hier verhandelt werden. Es gilt, eine Auswahl zu treffen, diese zu begründen und zudem zu erläutern, warum die Besprechung dieser Öffentlichkeitstheorien in der gegebenen Reihenfolge erfolgt.

Auswahl und Anordnung gehen in dieser Untersuchung primär aus einem empirischen Argument hervor, orientieren sie sich doch - wie eben erwähnt - am Kriterium der faktischen Dominanz. Daher beginnt die Diskussion mit der Deliberativen Öffentlichkeitstheorie. Wohl kaum eine hat politisch, philosophisch, soziologisch wie auch religionspädagogisch ein solches Gewicht. Deren Diskussion arbeitet dann in ihr Frageüberhänge und Desiderate heraus, die andere Öffentlichkeitstheorien markieren und auf die diese selber produktiv-kritisch reagieren. Das aber bietet wiederum den Anschlusspunkt für eine an dieser Stelle ihrerseits aussagekräftige Öffentlichkeitstheorie. Dieses Vorgehen vernetzt die diversen Theorien miteinander, indem es ein Forum ihrer kritischen Auseinandersetzung in religionspädagogischer Absicht begründet.

\section{Deliberative Öffentlichkeit: Jürgen Habermas}

Die Feststellung ist sicher keine Übertreibung, dass kaum jemand den Begriff der Öffentlichkeit in der Moderne so scharf profiliert hat, wie Jürgen Habermas. Dieser ist vor allem auf die Öffentlichkeit der Bürger, der Citoyen, fokussiert. 


\subsection{Bürgerliche Öffentlichkeit}

Habermas ging es in seinem 1962 erschienenen Werk »Der Strukturwandel der Öffentlichkeit« darum, die bürgerliche Kommunikation in Salons, in gelehrten Gesellschaften, in Kaffeehäusern als das Forum politischer Vergesellschaftung, als Vollzug politischer Willensbildung und als Kommunikationsraum der prinzipiell Gleichen, Freien und Ebenbürtigen herauszuarbeiten.

Hier kommt es zu einer Trennung von Staat und Gesellschaft, von Öffentlichem und Privatem, hier formierte sich der Wille der liberal-aufgeklärten Bürger gegenüber einer Ständegesellschaft und absolutistischen Herrschaft. Nicht ein überkommener Status, nicht ein ererbtes oder zugestandenes Privileg, nein, die Deliberation der Freien und Gleichen ist der Grundzug dieser bürgerlichen Öffentlichkeit, in der die Privatleute zu öffentlichem Vernunftgebrauch zusammenkommen. Öffentlichkeit ist also nicht das, was Menschen in Talkshows, bei Twitter oder Facebook von sich preisgeben. Es ist keine Öffentlichkeit von Zuschauern und Zuhörern, die Privates und Öffentliches vermengen. Sie ist der Raum »für Sprecher und Adressaten, die einander Rede und Antwort stehen. Es geht um den Austausch von Gründen, nicht um die Bündelung von Blicken. Die Teilnehmer an Diskursen, die sich auf eine gemeinsame Sache konzentrieren, kehren ihrem privaten Leben gleichsam den Rücken. Sie brauchen nicht von sich selbst zu sprechen. Öffentlichkeit und Privatsphäre vermischen sich nicht, sondern treten in ein komplementäres Verhältnis. ${ }^{1}$

Öffentlichkeit hat folglich mit Vernunft zu tun und ist durch vor allem drei Merkmale geprägt:

1. der gleiche Zugang aller zu dieser Kommunikation, losgelöst von Rang und wirtschaftlichem Einfluss;

2. die Offenheit der Themenwahl, die durch den Willen der Teilnehmer selbst konstituiert wird, wodurch ein »Interpretationsmonopol« staatlicher oder kirchlicher Autoritäten zurückgedrängt wird; ${ }^{2}$

3. die gemeinsame, gewaltfreie, diskursive, also nur durch die Kraft des besseren Arguments geprägte Ermittlung des Richtigen und Rechten und die Ausdehnung dieses Diskurses in eine aufgeklärte, freie und selbstbestimmte Öffentlichkeit hinein. ${ }^{3}$

1 I Habermas, Zwischen Naturalismus und Religion 2005, 15.

2 | Habermas, Strukturwandel der Öffentlichkeit 1990, 97; vgl. Schröder, Öffentliche Religionspädagogik 2013, 109-132; Turner, Habermas' Öffentlichkeit 2009; Günther, Wingert, Die Öffentlichkeit der Vernunft und die Vernunft der Öffentlichkeit 2001.

3 | Vgl. Habermas, Strukturwandel der Öffentlichkeit 1990, 97ff.152ff. 
Für Pierre Bourdieu ist freilich das Ideal des souveränen Bürgers, der »informiert und engagiert politische Urteile zu fällen vermag«, eine »Ideologie«, insofern »Fähigkeit und Bereitschaft zu politischer Meinungsbildung klassenspezifisch verteilt ist «. ${ }^{4}$ Doch Habermas weiß selbst, dass er hiermit nur ein kontrafaktisches Idealbild herauspräpariert, die es als Realität so nie gegeben hat und auch nicht gibt. Aber sie ist immerhin »als objektiver Anspruch gesetzt «. ${ }^{5}$ Diese Idee bringt er mitten in der Adenauerzeit gegen den Zerfall bürgerlicher Öffentlichkeit in Stellung. Öffentlichkeit ist ein kritischer wie normativer Begriff gegen Prozesse von Ökonomisierung, gegen die Auflösung von Privatheit durch staatliche Macht, gegen die Privatisierung staatlicher Aufgaben oder den die Mündigkeit untergrabenden Einfluss der Kulturindustrie, die die Öffentlichkeit vom »kulturräsonierenden zum kulturkonsumierenden Publikum « degenerieren lässt. ${ }^{6}$ Nur als kritischen Begriff kann Habermas Öffentlichkeit »als Kampfplatz und Schlachtfeld« würdigen. ${ }^{7}$

\subsection{Deliberation und Kommunikative Vernunft}

Diese normative kultur- und gesellschaftskritische Theorie der Öffentlichkeit, die etwa auch Parallelen bei Richard Sennett findet, ${ }^{8}$ spitzt Habermas unter den veränderten erkenntnistheoretischen Rahmenbedingungen seiner Theorie des Kommunikativen Handelns noch weiter zu. Habermas rekurriert unter dem spannungsvollen Einfluss kantischer Transzendentalphilosophie, Kritischer Theorie, aber auch der Gesellschaftsanalyse Max Webers auf die Alltagssprache. Es geht ihm mit seinem Abschied von der klassischen Bewusstseinsphilosophie um den Aufweis einer im Medium intersubjektiven Sprachvollzugs hindurch tönenden kontrafaktischen Rationalität, die im Rückbezug auf die in der Kommunikation jeweils vorausgesetzten universalen Geltungsansprüche nachmetaphysisch erst allgemeine Normen und universalisierbare Wahrheitsansprüche zu denken erlaubt. Dabei bildet für ihn das verständigungsorientierte, reziprok dialogische, »auf Einverständnis zwischen den beteiligten Subjekten « ausgerichtete kommunikative Handeln die Basis menschlichen Denkens und Handelns. ${ }^{9}$ Er nennt seinen Ansatz >nachmetaphysisch<, weil dieser zwar Denken nicht verleugnet, aber in ihm eine bloß fragile, »transitorische Einheit der Vernunft« aufleuchtet, die nicht dem idealistischen

4 | Müller, Pierre Bourdieu 2014, 263.

5 | Habermas, Strukturwandel der Öffentlichkeit 1990, 97.

6 | Habermas, Strukturwandel der Öffentlichkeit 1990, 248; vgl. Nanz, Öffentlichkeit 2009, 358-360.

7 | Müller, Pierre Bourdieu 2014, 267.

8 | Vgl. Sennett, Der Verfall 1998.

9 | Arens, Religion als Kommunikation 2001, 148. 
Bann einer über Mannigfaltiges triumphierenden Allgemeinheit verfällt. ${ }^{10}$ Gegenüber dem postmodernen Pluralitätspathos und der systemtheoretischen Differenz plädiert er allerdings für die Aufrechterhaltung verallgemeinerbarer Wahrheitsansprüche. Wahrheit ist nicht mehr objektivistisch oder mentalistisch, sondern prozedural wie handlungstheoretisch zu denken. ${ }^{11}$ Ein solcher Wahrheitsbegriff als Hintergrund der deliberativen Öffentlichkeitstheorie ist universal und dabei zugleich integrativ und offen, rekurriert jenseits idealistischer Engführungen eines Letztbegründungskonzeptes auf die Begründungsfrage und erweist - wie wir noch sehen werden - seine hermeneutische Anschlussfähigkeit hinsichtlich der adäquaten Buchstabierbarkeit biblischer Traditionen oder auch eines angemessenen Begriffs verantwortlicher Subjektivität in interkommunikativen Handlungszusammenhängen. ${ }^{12}$

Habermas bindet damit die Generierung universaler Normen als Implikationen von Öffentlichkeit an den deliberativen Diskursprozess selber. Die von ihm vorgeschlagene, vom Symbolischen Interaktionismus G.H. Meads entlehnte Theorie einer idealen Rollenübernahme nimmt den kantianischen Universalisierungsansatz auf, konkretisiert ihn jedoch im intersubjektiv-pragmatischen Diskurs, der in seinem reflexiven Charakter einen umfassenderen Rationalitätsanspruch hat als ein bloßes Gespräch.

"Unter den Kommunikationsvoraussetzungen eines inklusiven und zwanglosen Diskurses unter freien und gleichen Teilnehmern ist jeder gehalten, sich in die Perspektive und damit in das Selbst- und Weltverständnis aller anderen zu versetzen; aus dieser Perspektivenverschränkung baut sich eine ideal erweiterte Wir-Perspektive auf, aus der alle gemeinsam prüfen können, ob sie eine strittige Norm zur Grundlage ihrer Praxis machen wollen; das soll eine gegenseitige Kritik an der Angemessenheit von Situationsdeutungen und Bedürfnisinterpretationen einschließen. Auf dem Wege sukzessiv vorgenommener Abstraktionen kann sich dann der Kern verallgemeinerungsfähiger Interessen herausschälen. ${ }^{13}$

Habermas' kommunikative Vernunft und die in ihr gründende Diskursethik beansprucht sowohl aus dem »normativen Gehalt der notwendigen pragmatischen Voraussetzungen von Argumentation« kontrafaktisch ein allgemeines Moralprinzip zu gewinnen als auch die »diskursive Einlösung von normativen Geltungsansprüchen« als die entscheidende Basis von Öffentlichkeit zu ge-

10 | Vgl. Habermas, Texte und Kontexte 1991, 35-155; Habermas, Theorie des kommunikativen Handelns 1981.

11 | Vgl. Habermas, Wahrheit und Rechtfertigung 1999.

12 | Arens, Fundamentale Theologie im Anspruch kommunikativer Rationalität 2002, 58.

13 | Habermas, Wahrheit und Rechtfertigung 1999, 76. 
nerieren. Sie bindet nämlich »die Gültigkeit von Normen an die Möglichkeit einer begründeten Zustimmung vonseiten aller möglicherweise Betroffenen, soweit diese die Rolle von Argumentationsteilnehmern übernehmen. Nach dieser Lesart ist die Klärung politischer Fragen, soweit es ihren moralischen Kern betrifft, auf die Einrichtung einer öffentlichen Argumentationspraxis angewiesen. ${ }^{14}$

Öffentlichkeitsrelevante Entscheidungen werden also in normativer Hinsicht prozedural im Rückgang auf die dem sprachlichen Diskurs innewohnenden Wahrheitsansprüche, nicht aber auf der Basis eines je schon bestimmten Urzustands oder eines je vorab bestimmten Guten gebildet. Die Diskursethik sieht gegenüber solchen Ansätzen »den moralischen Gesichtspunkt im Verfahren einer intersubjektiv durchgeführten Argumentation verkörpert, welches die Beteiligten zu einer idealisierten Entschränkung ihrer Deutungsperspektiven anhält« ${ }^{15}$ Dieser durch Interaktion gestiftete Raum der Öffentlichkeit ist universal, d.h. »für potentielle Gesprächspartner, die anwesend sind oder hinzutreten können, prinzipiell offen «. ${ }^{16}$ Öffentlichkeit steht also, ähnlich wie bei Durkheim und Dewey, unter den Voraussetzungen einer »gleichberechtigten Teilnahme, ausreichenden Informiertheit und größtmöglichen Freiheit aller «. ${ }^{17}$ Legitim sind in diesem Zusammenhang demnach solche Normen, die im Hinblick auf alle gerechtfertigt werden können, die als Gleiche und Freie in diesen Diskurs eintreten, in dem sie sich wechselseitig aufeinander beziehen. Allgemeinheit, Gleichheit und Reziprozität sind damit die Prinzipien dieser Öffentlichkeit. ${ }^{18}$

Freilich stellt Habermas diesem prozeduralen Zugriff auf Öffentlichkeit den Solidaritätsbegriff an die Seite. Dabei steht ein strikt intersubjektiver Subjektbegriff im Hintergrund. Nach Habermas »formen und erhalten sich die Identität des Einzelnen und die des Kollektivs « in kommunikativen Bildungsprozessen »gleichursprünglich $«{ }^{19}$ Insofern gewinnt eine einzelne Person ihre Identität inmitten des »lebensnotwendigen Geflechts reziproker Anerkennungsverhältnisse $\ll{ }^{20}$

Habermas früher Öffentlichkeitstheorie ist vorgeworfen worden, die Pluralität verschiedener Teilöffentlichkeiten zu unterschätzen und das Politische als Modell von Öffentlichkeit zu verabsolutieren. Damit würde eine Tendenz

14 | Habermas, Strukturwandel der Öffentlichkeit 1990, $39 f$.

15 | Habermas, Wahrheit und Rechtfertigung 1999, 76.

16 | Habermas, Faktizität und Geltung 1992, 437. Vgl. Calhoun, Habermas and the Public Sphere 1992; Kellner, Habermas, the Public Sphere, and Democracy 2000.

17 | Honneth, Das Recht der Freiheit 2011, 569.

18 | Vgl. Forst, Das Recht auf Rechtfertigung 2007, 127-187.

19 | Habermas, Erläuterungen zur Diskursethik 1991, 15.

20 | Habermas, Erläuterungen zur Diskursethik 1991, 16. 
zu einer Dominanz des Politisch-Staatlichen gegenüber der unübersehbaren, für eine vitale Demokratie freilich überlebensnotwendigen Vielfalt ganz unterschiedlicher Öffentlichkeiten erkennbar. Diese gehe mit einer Homogenisierung des Öffentlichkeitsbegriffs selber einher, die einzig dem Politischen entlehnt sei. ${ }^{21}$

Als Reaktion auf diesen Vorwurf konzipiert Habermas >Öffentlichkeit< in differenzierter Weise neu. In seinem zweiten Hauptwerk »Faktizität und Geltung « von 1992 ist Öffentlichkeit »am ehesten als Netzwerk für die Kommunikation von Inhalten und Stellungnahmen, also von Meinungen« zu beschreiben. ${ }^{22}$ Diese Öffentlichkeit ist ein durch die freie, gleichberechtigte Kommunikation aller potentiellen Teilnehmer konstituierter öffentlicher Raum zwischen politisch-staatlicher Ebene mit ihren Institutionen einerseits und dem lebensweltlichen Raum des Privaten andererseits. Hier werden politische Willensbildungsprozesse vorangetrieben, die dann auf der Ebene politischer Institutionen zu Entscheidungen ausformuliert werden. Eine solche Öffentlichkeit lässt sich der Zivilgesellschaft zuordnen. ${ }^{23}$ Sie bildet eine »intermediäre Struktur« zwischen dem politisch-institutionellen System, der privaten Lebenswelt und den funktional ausdifferenzierten Handlungssystemen. ${ }^{24}$

Dementsprechend unterscheidet Habermas zwischen verschiedenen Teilöffentlichkeiten, die sich inmitten der »vermachteten Öffentlichkeit« in ihrer unübersichtlichen Vielfalt herauskristallisiert haben. ${ }^{25}$ Diese stehen in einem Kommunikationszusammenhang, der sich räumlich in eine Pluralität internationaler, nationaler, regionaler, sachlich nach funktionalen Gesichtspunkten oder Themenschwerpunkten und auch nach Organisationsdichte, Kommunikationsforum und Reichweiten ausdifferenziert. Das Spektrum für solche wissenschaftlichen, literarischen, religiösen, kirchlichen, künstlerischen, feministischen, alternativen sozial-, gesundheits- und wissenschaftspolitischen »Öffentlichkeiten« reicht »von der episodischen Kneipen-, Kaffeehaus- oder Straßenöffentlichkeit über die veranstaltete Präsenzöffentlichkeit von Theateraufführungen, Elternabenden, Rockkonzerten, Parteiversammlungen oder Kirchentagen bis zu der abstrakten, über Massenmedien hergestellten Öffentlichkeit«. ${ }^{26}$ Diese Teilöffentlichkeiten stehen aber nicht schlicht wie in der Systemtheorie als Umwelten nebeneinander. Sie sind zueinander »porös «, ${ }^{27}$ weil

21 | Vgl. Dalferth, Öffentlichkeit, Universität und Theologie 2000, 48-55.

22 | Habermas, Faktizität und Geltung 1992, 436.

23 | Vgl. Habermas, Faktizität und Geltung 1992, $443 f$.

24 | Habermas, Faktizität und Geltung 1992, 451.

25 | Habermas, Strukturwandel der Öffentlichkeit 1990, 28.

26 | Habermas, Faktizität und Geltung 1992, 452.

27 | Habermas, Faktizität und Geltung 1992, 452. Zu digitalen Medienöffentlichkeiten vgl. Binder, Oelkers, Der neue Strukturwandel von Öffentlichkeit 2017. 
nur so soziale Bindungskräfte, lebensweltliche Verankerungen und Motivationen für gesellschaftliches Engagement entstehen können und sich zugleich jenes Forum bildet, in dem sich ein politisch relevanter Wille erst zu formen vermag. Deshalb sind sie auch auf die politische Öffentlichkeit hingeordnet, jener normativ gefüllten Idee des real versammelten Publikums der Citoyen, dem Habermas am ehesten die Bindungskraft und regulatorische wie legitimierende Potenz zutraut, derer eine so höchst heterogene Gesellschaft des 21. Jahrhunderts bedarf. ${ }^{28}$

Die Pointe der deliberativen Öffentlichkeitstheorie liegt darin, den intrinsischen Zusammenhang von Erkenntnisgewinn und Freiheitsgewinn freigelegt zu haben, jedenfalls wenn politisches Handeln vernunftorientiertes Handeln sein will. Insofern avanciert für Habermas die politische Öffentlichkeit als der »Inbegriff« derjenigen Kommunikationsbedingungen, unter denen diskursive, mit der Kraft des besseren Arguments rational vollzogene Meinungs- und Willensbildung von Staatsbürgern zustande kommen können, zum »Grundbegriff einer normativ angelegten Demokratietheorie ${ }^{29}{ }^{29}$ Von Anfang an, so der Versuch, im Rückgang auf die bürgerliche Öffentlichkeit die Fundamente und Basisannahmen eines demokratischen Öffentlichkeitsbegriffs freizulegen, sollte die innere Wechselwirkung einer Rationalisierung der Politik und der kommunikativen Freiheit herausgearbeitet werden. Denn die politischen Entscheidungen durften doch nur dann für sich reklamieren, vernünftig und richtig zu sein, »wenn alle Staatsbürgerinnen und Staatsbürger gleichberechtigt und zwanglos bei der Entscheidungsfindung hatten zusammenwirken können «. ${ }^{30}$ Wegen dieses Rechtfertigungszwangs der Politik vor dem Forum der Öffentlichkeit ist Öffentlichkeit der Prüfstein der Demokratie und das »Ende der Arkanpolitik«. ${ }^{31}$ Dies kehrt nun das überkommene vordemokratische Begründungs- und Abhängigkeitsverhältnis um: Die Öffentlichkeit begründet letztlich den Staat, nicht der Staat die Öffentlichkeit. ${ }^{32}$

Diese Zuordnung lässt nun aber zugleich Rückschlüsse zu auf die durch formale Verfahren vollzogene Integration der Gesellschaft.

"Unter Bedingungen moderner Gesellschaften gewinnt insbesondere die politische Öffentlichkeit des demokratischen Gemeinwesens eine symptomatische Bedeutung für die Integration der Gesellschaft. Komplexe Gesellschaften Iassen sich nämlich normativ nur noch über die abstrakte und rechtlich vermittelte Solidarität unter Staatsbürgern zusammenhalten. Zwischen Bürgern, die sich persönlich nicht mehr kennen, kann sich

28 | Vgl. Meyer-Wilmes, Ist Öffentlichkeit öffentlich 2000, 120-125.

29 | Habermas, Strukturwandel der Öffentlichkeit 1990, 38.

$30 \mid$ Honneth, Das Recht der Freiheit 2011, 528.

31 | Horster, Jürgen Habermas 2010, 16.

32 | Vgl. Honneth, Das Recht der Freiheit 2011, 569 
nur noch über den Prozess der öffentlichen Meinungs- und Willensbildung eine brüchige Gemeinsamkeit herstellen und reproduzieren."

Daher lässt sich der Zustand einer Demokratie »am Herzschlag ihrer politischen Öffentlichkeit abhorchen«. ${ }^{33}$

Doch wirkt die zivilgesellschaftliche Öffentlichkeit keineswegs ungebrochen in das politische System hinein. Dies würde gerade die Integrationsleistungen der Öffentlichkeit wieder schwächen, um die es doch Habermas zu tun ist. Deshalb differenziert Habermas zwischen Zentrum und Peripherie im politischen System. Er übernimmt dabei das Schleusenmodell seines Schülers Bernhard Peters, das auch - wie wir noch sehen werden - für den Ort der Religion in der Öffentlichkeit und die Pflicht zur Übersetzung religiöser Gehalte relevant sein wird. ${ }^{34}$ Institutionen wie Parlamente, Exekutive und Legislative sowie Verfahren bilden das Zentrum des politischen Systems, während die Peripherie durch die verschiedenen Teilöffentlichkeiten gebildet wird. Initiativen, die durch die Teilöffentlichkeiten eingebracht werden, müssen, um politisch wirksam werden, diese »Schleusen demokratischer und rechtsstaatlicher Verfahren am Eingang des parlamentarischen Komplexes passieren «. ${ }^{35}$ Dies kann Gefahren verhindern helfen, dass entweder die administrative Macht der Bürokratie ungeschützt die Gesellschaft ergreift und die Lebenswelten kolonisiert oder dass sich die soziale Macht bürgerlicher Selbstverständigungsprozesse und damit die immer partikular bleibenden Visionen guten Lebens, wie sie in Weltanschauungen und Religionen prominent zum Ausdruck kommen, politisch mit Allgemeinheitsanspruch durchsetzen wollen. Ungefiltert ist ein Austausch nicht möglich. Allein so ist die Integration einer heterogenen Gesellschaft, ohnehin stets prekär und fluide, überhaupt erreichbar.

Andererseits aber sind der Staat wie die politische Öffentlichkeit in ihren politisch relevanten Deliberationen auf die zivilgesellschaftlich kondensierten lebensweltlichen Ressourcen unbedingt angewiesen. »Gerade die deliberativ gefilterten politischen Kommunikationen sind auf Ressourcen der Lebenswelt - auf eine freiheitlich-politische Kultur und eine aufgeklärte politische Sozialisation, vor allem auf die Initiativen meinungsbildender Assoziationen - angewiesen, die sich weitgehend spontan bilden und regenerieren, jedenfalls direkten Zugriffen des politischen Apparats nur schwer zugänglich sind. ${ }^{36}$ Diese Zivilgesellschaft ist der Ort, wo sich die in den verschiedenen Vereinen,

33 | Habermas, Zwischen Naturalismus und Religion 2005, 25. Zu Habermas' Ausdifferenzierung verschiedener Öffentlichkeiten Renner, Postsäkulare Gesellschaft und Religion 2017, 90-102.

34 | Vgl. Peters, Der Sinn von Öffentlichkeit 2007, 44-50.

35 | Habermas, Faktizität und Geltung 1992, 432.

36 | Habermas, Faktizität und Geltung 1992, 366. 
in Parteien, in Bürgerinitiativen, in NGO's, aber auch in den Kirchen und Religionsgemeinschaften artikulierten Teilöffentlichkeiten aufeinander diskursiv beziehen. Zumindest in normativer Weise sollen alle nach den Prinzipien von Gleichheit, Freiheit, Rationalität und Universalität beteiligt werden. Es geht, wie Habermas sagt, um die »ebenso egalitäre wie universalistisch ausgerichtete, solidarische Einbeziehung aller, gerade auch der ausgegrenzten Anderen «.37 Damit wird aus der Perspektive des Öffentlichkeitsbegriffs die Auseinandersetzung mit Religion relevant.

\section{3 Öffentlichkeit und Religion. Ein Exemplum deliberativer Öffentlichkeitstheorie}

Es ist hier weder Anlass noch Möglichkeit, das überaus nuancenreiche Verhältnis zwischen Habermas und der Religion in seiner Gestalt und Genese zu diskutieren. ${ }^{38}$ Hier soll es verstanden werden als ein prominentes Beispiel für die komplexe Beziehung partikularer Traditionen zu Zivilgesellschaft und Politik. Religion ist für Habermas inzwischen schon lange nicht mehr ein überholtes, nur relativ zum progredierenden Säkularisierungsprozess als Kontingenzbewältigungspraxis (Hermann Lübbe) zu duldendes Traditionsgut, wie er es noch im Rückgriff auf Max Weber in seiner Theorie kommunikativen Handelns ausgefaltet hatte. ${ }^{39}$ Religion selber wird als Ressource für subjektive und gesellschaftliche Identitäts- und Sinnstiftungsprozesse in den unübersichtlichen Prozessen der Moderne als in sich selber relevant bewertet, eine Annahme, die ihn schließlich in nicht ganz unmissverständlicher Weise von einer »postsäkularen Gesellschaft « sprechen lässt. ${ }^{40}$ Es sind demnach subjekttheoretische, modernitätstheoretische wie gesellschaftlich-politische Aspekte, die in seiner philosophischen Haltung zur Religion ineinander spielen.

Religion ist für ihn zunächst und vor allem »ursprünglich >Weltbild< oder >comprehensive doctrine $<$ auch in dem Sinne, dass sie die Autorität beansprucht, eine Lebensform im Ganzen zu strukturieren «. ${ }^{41}$ Als solche birgt sie

37 | Arens, Kritisch, kirchlich, kommunikativ 2012, 435.

38 | Vgl. Viertbauer, Gruber, Habermas und die Religion 2017; Langthaler, Nagl-Docekal, Glauben und Wissen 2007.

39 | Vgl. zu einer Neuinterpretation der Säkularisierungstheorie aus der Perspektive Max Webers: Joas, Die Macht des Heiligen 2017.

40 | Beck, Der eigene Gott 2008, 70; vgl. 114-122; Manemann, Wacker, Politische Theologie - gegengelesen 2008; Joas, Braucht der Mensch Religion 2004, 124ff; Breul, Religion in der politischen Öffentlichkeit 2015, $114 \mathrm{ff}$.

41 | Habermas, Zwischen Naturalismus und Religion 2005, 117. 
»Sinn für das, was fehlt und sanders sein könnte « ${ }^{42}$ Genau darin spielt sie auf der Ebene der zivilgesellschaftlichen Öffentlichkeit eine wichtige Rolle. ${ }^{43}$

Eine solche Religion ist freilich keine Zivilreligion, keine Religion der Bürger. Bei diesem besonders in den USA und in Frankreich anzutreffenden Phänomen handelt es sich um eine Religion, die als gemeinsames Band aller fungiert, um gerade in pluralen Gesellschaften nach der Trennung von Kirche und Staat eine Art Zusammenhalt zwischen den Bürgern eines Staates herzustellen. ${ }^{44}$ Es liegt auf der Hand, dass nur eine Minimalreligion, die um ihre wesentlichen dogmatischen Inhalte beraubt ist, dazu taugt. Sie ist eine Religion jenseits der Kirchen und verfassten religiösen Gemeinschaften und hat große Nähe zu einer Kulturreligion. Sie ist weder Staatsreligion noch Privatreligion. Vielmehr zeichnet es »diese religiösen und theologischen Gehalte aus, dass sie auf einen möglichst weitgehenden Konsens unter den Staatsbürgern ausgelegt sind «, 45 die die Bürger unbeschadet der »Freiheit zur eigenen Konfession religiös an das Gemeinwesen binden «. ${ }^{6}$ Ein Gemeinwesen ist auf diese Unterstützung angewiesen. »Ohne die Vision von einer gerechten Gesellschaft ist es schwierig, die heranwachsende Generation vom Sinn einer Mitarbeit am gesellschaftlichen Ganzen zu überzeugen. Traditionen erhalten sich nicht von selbst. >Gewohnheiten des Herzens< entwickeln sich nur langsam. Mut zur Freiheit, Gerechtigkeitsliebe und Toleranz sind nicht selbstverständlich.« ${ }^{47}$ Nur zivilreligiös sei der Bedarf »nach religiös codiertem Systemvertrauen « zu befriedigen, ohne das eine funktional ausdifferenzierte Gesellschaft nicht zusammengehalten werden könne. ${ }^{48}$ Weltanschaulich neutral sei der Staat nur im Blick auf die konkurrierenden Konfessionen und Weltanschauungen. »Im Blick auf sich selbst kommt der Staat ohne eine religiös-weltanschauliche Selbstvergewisserung nicht aus. $\ll^{49}$ Eine solche Zivilreligion sei auch deshalb weiterführend, weil einerseits Religion zivilisiert, andererseits durch diesen Transzendenzbezug sowohl die Selbstverabsolutierung des Staates kritisch konterkariert als auch ein zu einer Weltanschauung verdichteter radikaler La-

42 | Habermas, Ach, Europa 2008, 84; vgl. Reder, Schmidt, Ein Bewusstsein von dem, was fehlt 2008.

43 | Vgl. Habermas, Glauben und Wissen 2001, 13.

44 | Vgl. Graf, Die Wiederkehr der Götter 2004, 70ff; Schieder, Wieviel Religion verträgt Deutschland 2001; Vögele, Zivilreligion 1994.

45 | Vögele, Zivilreligion in der Bundesrepublik Deutschland 1994, 18; vgl. Lübbe, Religion nach der Aufklärung 2004, 316; Schmidt, Pitschmann, Religion und Säkularisierung 2014.

46 | Lübbe, Religion nach der Aufklärung 2004, 321.

47 | Schieder, Wieviel Religion verträgt Deutschland 2001, $201 \mathrm{f}$.

48 | Schieder, Meyer-Magister, Neue Rollen der Religion 2013, 34.

49 | Schieder, Wieviel Religion verträgt Deutschland 2001, 202. 
izismus unterlaufen würde. ${ }^{50}$ Allerdings wären nun nicht mehr die institutionalisierten Religionen der Bezugspunkt, sondern der Grundkonsens einer verdünnten, entdogmatisierten Minimalreligion.

So mit Pluralität, Individualisierung und Säkularisierung umzugehen heißt jedoch, den Wahrheitsanspruch der biblischen Gotteshoffnung nicht mehr ins Gespräch mit der Zivilreligion einbringen zu können. Letztlich handelt es sich bei der Zivilreligion um nichts anderes als um eine "marktkonforme Kommodifizierung der Religion,$^{51}$ die die prophetischen Impulse, die Kritik am Bestehenden, die Visionen für eine Neue Welt aus der Hoffnung auf das Reich Gottes abblendet. Es ist schon signifikant, dass selbst der Agnostiker Habermas anmerkt, dass »keine noch so geschickt geschneiderte Zivilreligion « der allenthalben festzustellenden »Entropie des Sinns vorbeugen « könne. ${ }^{52}$ Habermas beansprucht dagegen die Religionen in ihren unverstellten Orientierungsleistungen und Wahrheitsansprüchen öffentlichkeitstheoretisch zu würdigen, auch für die heterogene Gesellschaft und das politische Zusammenleben.

Signifikant für seine Öffentlichkeitstheorie ist nun jedoch der Weg, wie er dies tut. In einer kritischen Reformulierung der berühmten These ErnstWolfgang Böckenfördes unterscheidet Habermas das liberale, das republikanische und das von ihm favorisierte deliberative Demokratiemodell und geht im Gefolge eines Kantischen Republikanismus davon aus, dass unter den unhintergehbaren Bedingungen des säkularen Staates keine Weltanschauung mehr normsetzend für alle wirksam sein kann. ${ }^{53}$ Der demokratische Staat vermag seine Legitimation allein losgelöst von religiösen und metaphysischen Überlieferungen im Rahmen der oben skizzierten kommunikativen Vernunft prozedural aus den vorausgesetzten unbedingten Geltungsansprüchen rationaler Argumentation zu erzeugen. Dieser kommt so zu einer »autonomen, ihrem Anspruch nach für alle Bürger rational akzeptablen Begründung der Verfassungsgrundsätze « ${ }^{54}$ Angesichts der funktionalen Ausdifferenzierung der Moderne und der Pluralisierungsprozesse muss der Verfassungsstaat weltanschaulich neutral handeln und darf insofern nur auf Grundlagen beruhen, die sich weltanschaulich neutral rechtfertigen lassen und von Gläubigen, Nichtgläubigen und Andersgläubigen akzeptiert werden können. Jedoch verweist in Habermas Augen die zunehmend »entgleisende Modernisierung«, die das demokratische Band »mürbe« und die Solidarität »auszehren« kann, ${ }^{55}$ auf

50 | Vgl. Schieder, Sind Religionen gefährlich? 2011, 302-307.

51 | Hochgeschwender, Amerikanische Religion 2007, 171.

52 | Habermas, Faktizität und Geltung 1992, 631.

53 | Vgl. Habermas, Ach, Europa, 2008, 138ff.

54 | Habermas, Zwischen Naturalismus und Religion 2005, 109; vgl. 116.

55 | Habermas, Zwischen Naturalismus und Religion 2005, 109.111. 
Traditionen außerhalb der prozeduralen Vernunft. Schon die praktische Vernunft verfehlt ihre »eigene Bestimmung, wenn sie nicht mehr die Kraft hat, in profanen Gemütern ein Bewusstsein für die weltweit verletzte Solidarität, ein Bewusstsein von dem, was fehlt, von dem, was zum Himmel schreit, zu wecken und wach zu halten «. ${ }^{56}$ Und gerade der demokratische Staat bedarf angesichts zunehmender Krisen einer innengeleiteten, überzeugungsbasierten Legitimation seiner Bürger, die über die einer bloß pragmatischen Akzeptanz hinausgeht. Solche Traditionen können jenes politische Engagement für das Gemeinwesen ermöglichen, das von Staatsbürgern »in der Rolle demokratischer Mitgesetzgeber « erwartet wird. ${ }^{57}$ Insofern beruht der Staat auf vorpolitischen Quellen, um sich nicht von »knapper werdenden Sinn-, Solidaritäts- und Gerechtigkeitsressourcen « abzuschneiden, die auch zu supererogatorischen Handlungen zu motivieren vermögen.$^{58}$ Bei allen Reserven bezüglich theologischer Aussagen, anerkennt Habermas in zunehmendem Maße damit die unverlierbare Würde religiöser Tradition. ${ }^{59}$ Deren semantischen Potentiale seien noch nicht ausgeschöpft. ${ }^{60}$

Für Habermas vollzieht sich eine »Säkularisierung, die nicht vernichtet«, allerdings im Modus der Übersetzung. ${ }^{61}$ Denn ohne Übersetzung sei die Religion in ihrer immer partikularen Bedeutung nicht für alle verständlich und deshalb eben nicht universalisierbar.

"Durch eine Verbindung von Deliberation und Inklusion können demokratische Verfahren Legitimität erzeugen, weil sie die Vermutung begründen, dass die Resultate im gleichmäßigen Interesse aller liegen und daher allgemein akzeptabel sind. Die Bedingung der Inklusion, also der angemessenen Beteiligung aller potentiell Betroffenen am Verfahren, würde aber verletzt, wenn die kollektiv verbindlichen Entschlüsse nicht in einer allgemein zugänglichen Sprache formuliert und gerechtfertigt würden. Insbesondere religiöse Sprachen würden diese Bedingung verletzen. « ${ }^{62}$

Für Habermas ist die Präsenz der Religion in der Öffentlichkeit gerade in ihrer Authentizität gesellschaftlich und politisch relevant. »Auch ich möchte den

56 | Habermas, Ein Bewusstsein von dem, was fehlt 2008, 30f. Der "gegenwärtigen Philosophie fehlen Benjaminsche Worte, die über bloße Kulturkritik hinausgehen «: Habermas, Eine Replik 2008, 95.

57 | Habermas, Zwischen Naturalismus und Religion 2005, 109.

58 | Habermas, Eine Replik 2008, 99.

59 | Vgl. Reder, Schmidt, Ein Bewusstsein von dem, was fehlt 2008; Habermas, Die Dialektik der Säkularisierung 2008, 33-46.

60 | Vgl. Habermas, Glauben und Wissen 2001, $24 f$.

61 Habermas, Glauben und Wissen 2001, 29.

62 | Habermas, Nachmetaphysisches Denken II 2012, 174. 
authentischen Charakter der religiösen Sprache in der Öffentlichkeit bewahren, weil ich davon überzeugt bin, dass es sehr wohl verschüttete moralische Intuitionen einer säkularen Öffentlichkeit geben könnte, die sich durch eine bewegende religiöse Rede freilegen ließen. Wenn man Martin Luther King Jr. zuhört, spielt es keine Rolle, ob man säkular ist oder nicht. Man versteht, was er meint. « ${ }^{63}$ Ein säkularer Staat wie eine heterogene Gesellschaft ist auf solche Quellen moralischer wie sinnstiftender Inspiration dringend angewiesen.

"Wenn die schrille Polyphonie aufrichtiger Meinungen nicht unterdrückt werden soll, dürfen die religiösen Beiträge zu moralisch komplexen Fragen wie Abtreibung, Sterbehilfe, vorgeburtliche Eingriffe in das Erbgut usw. nicht schon an der Wurzel der demokratischen Willensbildung abgeschnitten werden. Religiösen Bürgern und Religionsgemeinschaften muss es freistehen, sich auch in der Öffentlichkeit religiös darzustellen, sich in einer religiösen Sprache und entsprechender Argumente zu bedienen. In einem säkularen Staat müssen sie freilich auch akzeptieren, dass der politisch relevante Gehalt ihrer Beiträge in einen allgemein zugänglichen, von Glaubensautoritäten unabhängigen Diskurs übersetzt werden muss, bevor er in die Agenden staatlicher Entscheidungsorgane Eingang finden kann [...]. Denn staatlich sanktionierte Entscheidungen müssen in einer allen Bürgern gleichermaßen zugänglichen Sprache formuliert und gerechtfertigt werden können." ${ }^{64}$

Hier ist also jene von Bernhard Peters formulierte Schleusenfunktion zwischen Zentrum und Peripherie zu erkennen, von der bereits die Rede war. ${ }^{65}$ Diese Funktion wahrzunehmen, diese Funktion wird nun der Übersetzung zugeordnet. Habermas unterscheidet zwischen der Ebene des Staates, dem Zentrum, die weltanschaulich neutral bleiben müsse, und der politischen Öffentlichkeit selber, der Peripherie. Er spricht von »institutionellen Schwellen zwischen der >wilden $<$ politischen Öffentlichkeit« der Zivilgesellschaft und den »staatlichen Körperschaften« als einem »Filter«, um »aus dem Stimmengewirr der öffentlichen Kommunikationsabläufe nur die säkularen Beiträge« durchzulassen. Religiöse Stellungnahmen im Parlament können gestrichen werden. Deren Wahrheitsgehalte gehen aber nur dann nicht verloren, wenn die »fällige Übersetzung schon im vorparlamentarischen Raum selbst geleistet wird $\ll .{ }^{66}$

63 | Habermas, Taylor, Diskussion 2012, 95. Zu detaillierten Analysen und Hintergründen Renner, Postsäkulare Gesellschaft und Religion 2017, 103-215.

64 | Habermas, Wie viel Religion verträgt der liberale Staat? Über die schrille Polyfonie der Meinungen und ihre Filterung; in: NZZ, 04.08.2012, Nr. 179 (2012), S. 63; vgl. Breul, Religion in der politischen Öffentlichkeit 2015, 138.

65 | Vgl. Peters, Der Sinn von Öffentlichkeit 2007, 44-50.

66 | Habermas, Zwischen Naturalismus und Religion, Frankfurt 2005, 137. 
Gleichwohl ist es wiederum für Habermas' Öffentlichkeitstheorie in einem ganz entscheidenden Sinne bezeichnend, welches Design Habermas dieser Übersetzungspflicht gibt. Im Anschluss an die Gesellschaftstheorie John Rawls hält er die Neutralität des Staates für elementar. Nur so sind jene Legitimationen zu erzeugen, derer ein demokratisches Gemeinwesen bedarf und die erst gesellschaftlichen Zusammenhalt ermöglichen: die gleichmäßige und gleichberechtigte Beteiligung aller Bürgerinnen und Bürger, die sich zugleich als Autoren wie als Adressaten der Gesetze verstehen einerseits und die epistemische Voraussetzung einer rationalen, für alle prinzipiell nachvollziehbaren und verstehbaren diskursiven Auseinandersetzung andererseits. ${ }^{67}$ Für Rawls ist es in diesem Zusammenhang wichtig, dass alle Bürger ihre jeweiligen Weltanschauungen als comprehensive doctrines unverstellt einbringen können. Auf der Basis von Gründen sollen die Staatsbürger sich in diesen unterschiedlichen Weltanschauungen respektieren und so in strittigen Fragen einen overlapping consensus finden. ${ }^{68}$ Doch obschon - wie wir gesehen haben - dieser overlapping consensus für Manfred Pirner weder der kleinste gemeinsame Nenner zwischen verschiedenen Positionen noch eine Zivilregion ist, ${ }^{69}$ zeigt Rainer Forst genau dieses mit seinem negativ konnotierten Begriff »Schnittmengenkonsens« auf. Wer

"würde auf den Gedanken kommen, den Protestierenden auf dem Platz des Himmlischen Friedens oder denen, die in Nigeria die Hungerlöhne eines Ölmultis anklagen, oder den aufstehenden Mönchen in Burma sagen, sie mögen doch bedenken, dass ihre Gerechtigkeits- und Menschenrechtsforderungen über die minimale Schnittmenge eines interkulturellen overlapping consensus hinausgehen, der zwischen 'Repräsentanten aller Weltreligionen/-kulturen (und seien es nur 'staatliche`) geschlossen würde «? ${ }^{70}$

Offensichtlich fehlt Rawls hier der Horizont universalisierbarer Begründungen, der kriterielle Unterscheidungen erlaubt.

Gleichwohl erarbeitet auch Rawls eine Grundlage gesellschaftlichen Zusammenhalts. Es sind die säkularen Verfassungsgründe, die von allen Bürgern beherzigt werden müssen und die sie zu öffentlichem Vernunftgebrauch zwingen. »The ideal of citizenship imposes a moral, not a legal duty - the duty of civility - to be able to explain to one another on those fundamental questions how the principles and policies they advocate and vote for can be supported

67 | Vgl. Habermas, Zwischen Naturalismus und Religion 2005, 126.

68 | Vgl. Rawls, Political Liberalism 1993.

69 | Vgl. Pirner Öffentliche Religionspädagogik 2015, 68-70.

70 | Forst, Normativität und Macht 2015, 206. Vgl. zu theologischen Reformulierungen im Ausgang von der Kenosistheologie Kreutzer, Politische Theologie für heute 2017, 61-65. 
by the values of public reason. The duty also involves a willingness to listen to others and a fairmindedness in deciding when accomodations to their views should reasonably be made. « ${ }^{71}$ Traditionen sind nur insoweit auf der Ebene der Öffentlichkeit legitim, insoweit sie den »values of public reason« entsprechen, von denen alle annehmen, dass sie von jedermann, von den religiösen wie den nicht-religiösen Bürgerinnen und Bürgern gleichermaßen, akzeptiert werden können. ${ }^{72}$ Das aber begründet einen Vorbehalt, eine Bedingung, der die Übersetzung partikularer Traditionen in die allen zugängliche säkulare Vernunft verlangt. Während der öffentliche Gebrauch nicht-öffentlicher Gründe unter Übersetzungsvorbehalt stehe, gelte dies in gleiche Maße nicht für die säkulare Vernunft selber.

An dieser Stelle wendet jedoch Habermas kritisch ein, dass hier eine Asymmetrie vorliegt, die einseitig zu Lasten der religiösen Traditionen geht und damit auch die angezielte Integration der Bürgerinnen und Bürger in einer gleichberechtigten und gerechten Gesellschaft konterkariere. Zudem könnten ja auch die säkularen Bürger nicht wissen, ob sie sich nicht doch in der Marginalisierung religiösen Traditionen durch deren Privatisierung von Sinnressourcen und verschütteten Intuitionen abschneiden. Daher sei auch von Säkularen eine Übersetzung gefordert, die insofern zudem gesellschaftlich hoch bedeutsam sei, weil diese mit der kritischen Selbstreflexion der säkularen Vernunft und ihrer Dialektik einhergehe. Säkulare Vernunft sei eben nur im kritischen Rekurs anzueignen. ${ }^{73}$ Obschon Habermas wie Rawls an einer Neutralität des Staates festhält, verweigert er sich deren Verabsolutierung im Sinne einer laizistischen Weltanschauung und erlegt beiden, religiösen wie nicht-religiösen Zeitgenossen, eine Übersetzungspflicht auf. Damit sind beide, religiöse wie nicht-religiöse Staatsbürger, gleichermaßen als demokratische Staatsbürger in das lernbereite Verhältnis gesetzt, den anderen »auch aus kognitiven Gründen « in einem »komplementären Lernprozess « ernstzunehmen. ${ }^{74}$

Habermas deliberative Öffentlichkeitstheorie versucht damit durch die beiden Instrumente der Trennung von Zentrum und Peripherie und der allgemeinen Übersetzungspflicht von säkularen wie religiösen Traditionen jene Grundlagen einer heterogenen wie gerechten Gesellschaft inmitten der Transformationsprozesse der Moderne zu denken, die ihr Legitimation wie Innovationskraft verleihen. Dies jedoch ist nicht unumstritten.

71 | Rawls, Political Liberalism 1993, 217. Zu Rawls liberalem Prozeduralismus vgl. Dierksmeier, Qualitative Freiheit 2016, 232-265.

72 | Rawls, Political Liberalism 1993, 786.

73 | Vgl. Habermas, Zwischen Naturalismus und Religion 2005, 133-138.

74 | Habermas, Zwischen Naturalismus und Religion 2005, $116 \mathrm{f}$. 


\subsection{Debatten um den Öffentlichkeitsbegriff}

Habermas' Öffentlichkeitstheorie ist viel Kritik entgegengehalten worden. Sondiert man das Feld, wird man drei Ebenen unterscheiden können. Die erste Ebene ist die Kritik an der Öffentlichkeitstheorie, wie sie in Habermas Habilitationsschrift entfaltet worden ist. Als Reaktion darauf hat Habermas, wie bereits angedeutet, inzwischen seinen Öffentlichkeitsbegriff kritisch weiterentwickelt. Die Kritik daran bildet die zweite Ebene. Die fundamentalste Kritik siedelt sich auf der grundlagentheoretischen Ebene an. Auf dieser dritten Ebene geht es um die handlungstheoretische Begründung der Öffentlichkeit im Konzept der kommunikativen Vernunft. Für unser vorrangig grundlagentheoretisch situiertes Erkenntnisinteresse muss hier das Hauptaugenmerk liegen.

Insbesondere Habermas Habilitationsschrift ist heftigster Kritik unterzogen worden. Es sind vor allem Identitätsfragen, die zu vernachlässigen Habermas hauptsächlich aus feministischer Sicht vorgeworfen wird. Indem die Diskurstheorie letztlich einen idealisierten Bürgerlichkeitsbegriff voraussetze und »lediglich die männliche, eurozentrische Sicht von Öffentlichkeit artikuliere«, sehe sie letztlich am eigentlichen »Strukturwandel der Öffentlichkeit« vorbei, der die Demokratie zutiefst gefährde. ${ }^{75}$ Sie unterstelle unreflektiert und unausgewiesen einen am Diskurs und an Rationalität ausgerichteten, daran interessierten und vor allem zur Teilnahme daran je schon befähigten männlichen weißen Bürger. ${ }^{76}$ Eine solche Idealvorstellung räsonierender Öffentlichkeit lasse gleichwohl erahnen, dass »die Beziehung zwischen Öffentlichkeit und Status komplexer ist, als Habermas nahelegt. Die Tatsache allein, daß ein Forum der Beratung zu einem Raum erklärt wird, in dem Statusunterschiede ausgeklammert und ausgeglichen werden, macht ihn noch nicht dazu. $\ll^{77} \mathrm{Zu}$ dem schließe dies andere Öffentlichkeiten aus. Während dies bereits für die Salonkultur nicht statthaft gewesen sei, würde dies angesichts verschiedener Öffentlichkeiten und vor allem angesichts der durch marginalisierte Gruppen verkörperten subalternen »Gegenöffentlichkeiten « vollends illegitim. ${ }^{78}$ Habermas Verabsolutierung einer Öffentlichkeit beruhe auf der wertenden Annahme, dass »die institutionelle Beschränkung des öffentlichen Lebens auf eine

75 | Wilfred, Das Christentum und der globale demokratische Prozess 2007, 475.

76 | Vgl. Fraser, Öffentlichkeit neu denken 1996; Benhabib, Modelle des öffentlichen Raums 1995; Kojima, Die Öffentlichkeiten der Erziehung 2015, 60-70; Meyer-Wilmes, Ist Öffentlichkeit öffentlich 2000, 113-126.

77 | Fraser, Öffentlichkeit neu denken 1996, 157. Vgl. auch Fraser, Neue Überlegungen zur Öffentlichkeit 2001.

78 | Fraser, Öffentlichkeit neu denken 1996, 163; vgl. Asen, Seeking the Counter 2000; Bohmann, Expanding dialogue 2004; Fenton, Downey, Counter Public sphere 2003; Wimmer, (Gegen-)Öffentlichkeit 2007. 
einzige, alles umspannende Öffentlichkeit wünschenswert und positiv ist, wohingegen eine Vielzahl von Öffentlichkeiten eine Abkehr von der Demokratie und keine Annäherung daran darstellt«. ${ }^{79}$ Dies schließe jedoch nicht nur das Private in einen vorpolitischen Raum ein, sondern exkludiere verschiedene Bevölkerungsschichten.

Diese Schwäche in der Zuordnung von >öffentlich blendung von Identitätsfragen und der »Überstilisierung der bürgerlichen Öffentlichkeit« ist von Habermas später selbst eingeräumt worden. ${ }^{80}$ Wenn

"die moderne Öffentlichkeit verschiedene Arenen für einen über Druckerzeugnisse, also Bildung, Information und Unterhaltung vermittelten, mehr oder weniger diskursiv ausgetragenen Meinungsstreit umfasst, in denen nicht nur verschiedene Parteien von locker assoziierten Privatleuten miteinander konkurrieren, sondern von Anfang an ein dominierendes bürgerliches auf ein plebejisches Publikum trifft, und wenn man weiterhin die feministische Dynamik des ausgeschossenen Anderen im Ernst berücksichtigt, dann ist das [...] Modell der widerspruchsvollen Institutionalisierung der Öffentlichkeit im bürgerlichen Rechtsstaat zu starr angelegt. . ${ }^{81}$

Folgerichtig profiliert Habermas darum seine Öffentlichkeitstheorie diskurstheoretisch in »Faktizität und Geltung « in der bereits erläuterten Weise als Netzwerk verschiedener Öffentlichkeiten. ${ }^{82}$ Gewiss bleibt das Phänomen der Idealisierung einer an Aufklärung und Kritik ausgerichteten räsonierenden Öffentlichkeit teilnahmewilliger Zeitgenossen, das freilich weniger - wie noch zu zeigen sein wird - als Indikator eines Defizits als ein legitimer normativ-kritischer Maßstab interpretiert werden kann. ${ }^{83}$ Gewiss überwindet diese Öffentlichkeitstheorie nicht den Nationalstaat als ihren Referenzrahmen, obschon Habermas in seinem nicht nachlassenden Engagement für Europa in der postnationalen Konstellation zunehmend einer »Transnationalisierung der bestehenden nationalen Öffentlichkeiten« das Wort redet. ${ }^{84}$ Doch die entscheidende Frage ist, ob nicht gerade diese kommunikative Vernunft selber öffentlichkeitstheoretisch problematisch ist. Habermas würde damit wohl Symptome beseitigen, nicht aber die grundlegende Schwierigkeit bewältigen, Identitäten und Partikuläres nicht angemessen denken zu können.

79 | Fraser, Öffentlichkeit neu denken 1996, 162.

80 | Habermas, Der Strukturwandel der Öffentlichkeit 1990, 15.

81 | Habermas, Der Strukturwandel der Öffentlichkeit 1990, 21.

82 | Vgl. Habermas, Die Einbeziehung des Anderen 1996, $451 \mathrm{f}$.

83 | Gegen Schröder, Öffentliche Religionspädagogik 2013; Dalferth, Öffentlichkeit, Universität und Theologie 2000, 46-50.

84 | Habermas, Ach, Europa 2008, 191; vgl. Habermas, Die postnationale Konstellation 1998; Habermas, Zur Verfassung Europas 2011; Nanz, Öffentlichkeit 2009, 360. 


\subsection{Kritik}

Verschiedene Aspekte seiner Diskurstheorie sind darum kritisch zu diskutieren:

\subsubsection{Universalität - Partikularität}

Kaum einer hat Habermas derart scharf auf grundlagentheoretischer Ebene angegriffen wie Volker Gerhardt. Seinerseits verwurzelt in aristotelischen wie kantianischen Traditionen und rückbezogen auf den sehr breiten Öffentlichkeitsbegriff Hannah Arendts, wirft er Habermas eine prinzipielle Verengung von Öffentlichkeit vor. Bei Hannah Arendt ist Öffentlichkeit bereits im Selbstverhältnis des Individuums angelegt. Bezogen auf den antiken Polis-Gedanken ist der Mensch für sie ein öffentliches Wesen, hingeordnet auf den öffentlichen Raum, weshalb Öffentlichkeit zum Zentralbegriff des Politischen avanciert. ${ }^{85}$ Dies unterminiert nicht die für sie überdies wesentliche Unterscheidung von Öffentlichkeit und Privatheit, aber lässt sie doch den Menschen als homo publicus begreifen, für den Öffentlichkeit der Raum ist, »in dem sich die Einzigartigkeit des individuellen Daseins nicht nur zeigen, sondern auch bewähren kann «. ${ }^{86}$ Dort, wo Menschen handelnd, denkend, demonstrierend, feiernd zusammenkommen, dort entsteht und vollzieht sich Öffentlichkeit. Eine solche Öffentlichkeit bekommt teilweise spontanen, instantanen, dynamischen, in verkrusteten Systemen durchaus befreienden, mitunter revolutionären Charakter, in dem die Bevölkerung den öffentlichen Raum zu dominieren beginnt. Ein solches »Assoziationsmodell« der Öffentlichkeit unterscheidet sich grundsätzlich vom deliberativ-diskursiven Öffentlichkeitsmodell bei Habermas. ${ }^{87}$

Gerhardt wendet nun gegenüber Habermas ein, dass dieser ein solches breites Assoziationsmodell nicht erreiche und damit seinen eigenen Allgemeinheitsanspruch nicht einlöse. Öffentlichkeit als formales Verfahren kommunikativer Vernunft zu begreifen, das nur die Kraft universalisierbarer Argumente gelten lasse, binde die Teilnahme an der Öffentlichkeit an vorwegdefinierte Kriterien wie Rationalität und Teilnahmebereitschaft. Aber er unterbindet damit »den die Vernunft tragenden freien Austausch der Argumente«. Dies sei zwar dem gut gemeinten Wunsch entsprungen, »die Öffentlichkeit vor sich selbst zu schützen. Doch die in dieser Absicht in Vorschlag gebrachte

85 | Vgl. Arendt, Macht und Gewalt 1970; Arendt, Über die Revolution 1963.

86 | Gerhardt, Öffentlichkeit 2012, 216; vgl. Gerhards, Öffentlichkeit 1998; Liessmann, Bildung als Provokation 2017, 155-224. Ferner Salvatore, The Public Sphere 2007; Sennett, The Fall of Public Man 1977.

87 | Vgl. Seyla Benhabib, Modelle des öffentlichen Raums 1995, $101 \mathrm{ff}$. 
>deliberativeく Öffentlichkeit verkennt die Logik der Öffentlichkeit. Die kann sich am besten entfalten, wenn sie durch nichts behindert wird « ${ }^{88}$

Ohne einer detaillierten Auseinandersetzung mit Gerhardt vorzugreifen, ${ }^{89}$ muss doch darauf aufmerksam gemacht werden, dass auf normative Kriterien im Öffentlichkeitsbegriff nicht verzichtet werden darf. Nicht nur, dass daran der Zerfall von Öffentlichkeit in der Gegenwart gemessen werden kann..$^{90}$ Die Öffentlichkeit selber braucht solche normativen Kriterien, weil ohne sie jene institutionellen Strukturen, grundrechtlichen Verankerungen und zivilgesellschaftlichen Prozesse nicht die nötige Kraft erhalten, um insbesondere »die Macht der Medien zu brechen und die fortbestehenden Benachteiligungen zu bekämpfen «. ${ }^{91}$ Im Unterschied zu solchen weichen, weitgreifenden Konzepten in der Spur Arendts und Gerhardts liegt in einer solchen Fundierung in einem auf das Verfahren abhebenden, prozeduralen Begriff kommunikativer Vernunft eine der zentralen Stärken.

Durch ihren Universalitätsanspruch, nachmetaphysisch artikuliert, kann eine solche Öffentlichkeitstheorie begründen, warum Öffentlichkeit zumindest tendenziell alle umfasst. Öffentlichkeit und Autonomie der Subjekte werden im Gedanken handlungstheoretisch grundierter Intersubjektivität korreliert. Fundiert in der Diskustheorie werden Freiheit und Gleichheit intrinsisch aufeinander bezogen. Alle haben das Recht, sich am öffentlichen Diskurs zu beteiligen. Von dorther ist darum auch der kritische Maßstab zu gewinnen, dass alle in den Stand gesetzt werden müssen, dieses Recht wahrnehmen zu können. Andernfalls würde der eigene Universalisierungsanspruch unterhöhlt. Indem System und Lebenswelt kritisch aufeinander bezogen und kommunikative und instrumentelle Vernunft kritisch unterschieden werden, wird eine Widerstandsinstanz gegen jene destruktiven Kolonisierungstendenzen erst rational begründbar, die die Öffentlichkeit unterminieren. Weil Habermas wiederholt Wert darauf legt, dass normative und empirische Argumentation sich in seinem Öffentlichkeitsbegriff einander wechselseitig durchdringen, setzt er sich gewiss der nicht immer von ihm angemessen bewältigten Schwierigkeit aus, präzise zu unterscheiden, wo er Empirie oder wo er regulative Idee meint. Manche seiner empirischen Annahmen zum Strukturwandel der Öffentlichkeit sind als zeitbedingt von der historischen Forschung längst überholt worden. ${ }^{92}$ Zentral aber bleibt der Ertrag, dass seine Öffentlichkeitstheorie Unterscheidungskriterien im Streit um Öffentlichkeit erlaubt. Wo ein-

88 | Gerhardt, Öffentlichkeit 2012, 227.

89 | Vgl. C 2.

90 | Vgl. Honneth, Das Recht der Freiheit 2011, 547.

91 | Honneth, Das Recht der Freiheit 2011, 549.

92 | Vgl. Gerhards, Neidhardt, Strukturen und Funktionen 1990, 5-10; Gerhards, Politische Öffentlichkeit 1994; Neidhardt, Öffentlichkeit 1994. 
zig die Kraft des besseren Arguments gilt, wo der Diskurs verständigungsorientiert ist, wird Gewalt als Struktur von Öffentlichkeit ebenso illegitim wie die affektive Aufwallung ekstatischer Emotionalität. So bietet Habermas' Öffentlichkeitstheorie einen alle Visionen guten Lebens und alle partikularen Traditionen übergreifenden universalisierbaren Maßstab der Kritik. »Wer will die Kritikerin des indischen Kastenwesens, die dieses komplett zurückweist, darauf hinweisen, doch bitte simmanent< vorzugehen? Oder die Kritik des Patriarchats in einer Gesellschaft, in der dieses kaum je herausgefordert wurde, daran erinnern, keine >fremde Sprache< zu sprechen «? ${ }^{93}$

Gleichwohl erkauft dieser prozedurale Formalismus seine Kraft durch eine kategoriale Schwäche. Zwar stellt Habermas seinem prozeduralen Öffentlichkeitsbegriff den Solidaritätsbegriff und die Ausrichtung an konkreten Lebenswelten an die Seite, die in partikularen Traditionen verwurzelt sind. ${ }^{94}$ Habermas kann auf diese Weise die lebensweltlich verankerten Praxen mitsamt der darin insbesondere durch die kolonisierenden Übergriffe des Systems vorkommenden Verletzungen subjektiver Identitäten würdigen. Er will auf dem öffentlichkeitstheoretisch bedeutsamen Feld der Gerechtigkeitstheorie die Intuition von Mitleidsethiken und Fürsorgeethiken sowie Erfahrungen der Lebenswelten und die Visionen guten Lebens aus aristotelischen Traditionen über den Formalismus des transzendentalen Zugriffs Kants hinaus für den Öffentlichkeitsbegriff übernehmen. Allerdings verbleibt er dabei im übergeordneten, alles strukturierenden Rahmen seines formalen Prozeduralismus, der die entscheidenden Kriterien bestimmt. »Die Diskursethik erweitert gegenüber Kant den deontologischen Begriff der Gerechtigkeit um jene strukturellen Aspekte des guten Lebens, die sich unter allgemeinen Gesichtspunkten kommunikativer Vergesellschaftung überhaupt von der konkreten Totalität jeweils besonderer Lebensformen abheben lassen - ohne dabei in die metaphysischen Zwickmühlen des Neoaristotelismus zu geraten.« ${ }^{95}$ Die motivierende und identitätsverbürgende Kraft lebensweltlicher Einbindungen in Gemeinschaften werde durch diese Traditionen zwar gesichert. Problematisch aber sei der im Neoaristotelismus ausgedrückte Partikularismus, der umso verhängnisvoller wäre, je pluraler die jeweilige Gegenwart ausfalle. Demgegenüber sichere allein der Prozeduralismus einer lebensweltlich gebundenen diskursiven Vernunft die normative Kraft einer universalen Moral und damit einer nicht-partikularen Vorstellung von Gerechtigkeit für die Konzeption der Öffentlichkeit. Denn nur so, nur bei einer Abstraktion von bestimmten Inhalten des Gerechtigkeitsdenkens, könne ein übergreifender Maßstab von

93 | Forst, Normativität und Macht 2015, 15.

94 | Vgl. Habermas, Erläuterungen zur Diskursethik 1991, 16.

95 | Habermas, Erläuterungen zur Diskursethik 1991, 20. 
Gerechtigkeit und Moral zur Geltung gebracht werden. ${ }^{96}$ Nur so wären die diversen Teilöffentlichkeiten mit deren partikularen Traditionen angemessen öffentlichkeitstheoretisch zu denken.

Aber verliert nicht Habermas die berechtigten Intuitionen hinsichtlich der lebensweltlichen, gemeinschaftlichen Einbindung von Moral und Gerechtigkeit in seiner Diskursethik doch wieder aus dem Auge, in dem er die konkreten Zusammenhänge und Inhalte von Gerechtigkeit in seinem universalen, rein formalen Prozeduralismus letztlich überwölbt? Von G.H. Meads Kritik an Kant ist ja zu lernen, »dass der kategorische Imperativ als solcher nur dazu dienen könne, Handlungen einem Universalisierungstest zu unterwerfen, nicht aber, herauszufinden, welche Handlungen überhaupt adäquat seien «. 97 Hätten nicht die konkreten Ethiken guten Lebens wichtige Impulse für eine allgemeine Theorie der Öffentlichkeit zu bieten? Müssten nicht beide Argumentationslinien, formal-prozedurale und materiale, universalistische wie partikulare, aufeinander bezogen werden, wie dies Hans Joas vorschlägt? »Im Diskurs wird geprüft, wozu sich Personen evaluativ hingezogen fühlen; sie können sich ohne Wertbindung nicht zur Teilnahme am Diskurs und zur Einhaltung seiner Regeln motiviert fühlen; und sie fühlen sich nur dann an das Resultat des Diskurses gebunden, wenn dies aus ihrer Wertbindung folgt oder die Erfahrung der Teilnahme selbst Wertbindung entstehen lässt.« ${ }^{98}$ Joas identifiziert demgegenüber bei Habermas eine »tiefe Skepsis gegen jeden Beitrag konkreter Werttraditionen und partikulärer Bindungen zur sozialen Integration moderner Gesellschaften«, wofür letztlich ein »antitraditionalistischer

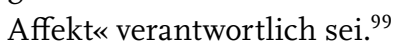

Nach unseren Ausführungen zum Beitrag der Religion zur Öffentlichkeit trifft dies zwar eher John Rawls als Habermas. Gleichwohl wird an der Religion auch bei Habermas ein Frageüberhang, ein Desiderat erkennbar. Es geht um den Rang von Identität, von Partikularität, von Differenz, kurz: um den Status, den Alterität in der kommunikativen Vernunft hat. Damit einher geht die Kritik an der Form dieser Rationalität selber, an der Art, wie sie ihre Begriffe konstruiert und wie sie dies nochmals selbstreflexiv kritisch bedenkt.

96 | Vgl. Habermas, Erläuterungen zur Diskursethik 1991, 9-48.

97 | Joas, Die Entstehung der Werte 1999, 266. Vgl. zu philosophischen Hintergründen Reder, Liberal, deliberativ oder dekonstruktivistisch 2017.

98 | Joas, Glaube als Option 2012, 142; vgl. Joas, Die Entstehung der Werte 1999, 285.

99 | Joas, Die Entstehung der Werte 1999, $290 f$. 


\subsubsection{Religion}

Dabei steht zunächst nicht primär die von Habermas Übersetzungspostulat aufgeworfene Problematik im Zentrum, ob sich religiöse Gehalte überhaupt angemessen übersetzen lassen..$^{100}$ In welch einer Vernunft, in welch einer Sprache, in welch einer Praxis lässt sich die Radikalität der Reich-Gottes-Botschaft übersetzen, ohne die semantischen Gehalte zu schwächen oder die Eigenlogik anderer Sprachen und Rationalitäten autoritär zu überformen? Lässt sich das Wesentliche der biblischen Hoffnung ohne Substanzverlust übersetzen? Belehrt durch den Postkolonialismus zeigt sich gegenwärtige Kulturwissenschaft sensibel für die machtförmigen Strukturen jeder Übersetzung: Übersetzen heißt doch immer auch Fremdes zu repräsentieren, für dieses zu sprechen. Sie kann eine Bereicherung, eine Erweiterung des Eigenen sein, kann zur Verständigung beitragen, kann aber auch Moment einer einseitigen Assimilation und von Macht werden. ${ }^{101}$ Der »social turn der translation studies « macht auf die kontextuelle Verortung von Übersetzung aufmerksam. ${ }^{102}$ Aber lässt sich die Bedeutung überhaupt allein in der sprachlich artikulierten Semantik erfassen oder bedarf es für die Übersetzung nicht einer teilnehmenden, erfahrungsgesättigten Beobachtung, weil Bedeutung stets in einer bestimmten kulturellen Praxis verwurzelt ist? In der gegenwärtigen Kulturtheorie wird dementsprechend Übersetzung in einen weiteren Rahmen gesetzt und als »Medium des Kulturverstehens « begriffen. ${ }^{103}$ Man müsse in eine andere Kultur eintauchen, müsse eine »dichte Beschreibung (Clifford Geertz) in einer erfahrungsbezogenen Innenperspektive erlangen.

Doch die weitaus radikalere Frage ist die nach einer angemessenen Deutung von Religion. Bei näherem Hinsehen wird dort allerdings eine begrenzte Hermeneutik erkennbar. Habermas Öffentlichkeitstheorie rekurriert einseitig auf einen funktionalen Religionsbegriff, von dem er überwiegend einen funktionalistischen Gebrauch macht. Der kritische Eigenwert religiöser Traditionen wird abgeblendet. Damit geht die beinahe diastatische Trennung von Glauben und Wissen einher. ${ }^{104}$ Trotz gegenteiliger Bekundungen bereits in seiner berühmten wie wirkungsvollen Rede zum Thema im Jahre 2001 bleibt für ihn Religion opak, kognitiv unzugänglich. Den »opaken Kern religiöser Erfah-

100 | Vgl. Reder, Religion in säkularer Gesellschaft 2013, 110-116; Renner, Postsäkulare Gesellschaft und Religion 2017, 120-130.

101 | Vgl. Renn u.a., Vorwort der Herausgeber 2002, 9; Pirner, Übersetzung 2012; John, Diskursethik und Leidenserfahrungen 2017, 169-172.

102 | Nassehi, Die letzte Stunde der Wahrheit 2017, 198.

103 | Vgl. Renn u.a., Übersetzung als Medium 2002.

104 | Vgl. Gerhardt, Glauben und Wissen 2016, 17-75. 
rung« als Basis von Religion kann Philosophie lediglich umkreisen. ${ }^{105}$ Dieser bleibt dem »diskursiven Denken so abgründig fremd« wie der undurchdringliche Kern ästhetischer Erfahrungen ${ }^{106}$ Hierin unterscheidet sich Religion von anderen ethischen Konzeptionen des Guten: »Religiös verwurzelte existentielle Überzeugungen entziehen sich durch ihren gegebenenfalls rational verteidigten Bezug auf die dogmatische Autorität eines unantastbaren Kerns von infalliblen Offenbarungswahrheiten der Art von vorbehaltloser diskursiver Erörterung, denen sich andere ethische Lebensorientierungen und Weltanschauungen, d.h. weltliche >Konzeptionen des Guten $<$ aussetzen. $\ll^{107}$ Eingebettet in rituelle und sakrale Praktiken, die ihrerseits in gesellschaftlichen Konstruktionsprozessen stehen, ${ }^{108}$ fundiert in nicht-falliblen Glaubensüberzeugungen, stehen diskursives Denken und religiöse Überzeugungen in einem Verhältnis der Asymmetrie. Religiöse Überzeugungen sind diskursiv exterritorial, sie bringen also ihre prinzipielle »Diskursunfähigkeit« ans Licht. ${ }^{109}$ Mit solchen Alternativen wird Habermas aber kaum dem Rationalitätsgehalt von Religion und Glaubens selber gerecht. Dieser ist wohl - wie wir noch sehen werden - eigens zu begründen, aber durchaus rational und diskursiv auszuweisen. ${ }^{10}$ Hingegen delegitimiert Habermas im Widerspruch zur eigenen Reklamation einer öffentlichen Bedeutung von Religion deren Rang für eine Öffentlichkeitstheorie durch deren diskurstheoretische Abwertung. Religion ist diskurstheoretisch nicht satisfaktionsfähig. Indem er die von außen für die Vernunft undurchdringbar gehaltene Religion aus den politischen Prozeduren prinzipiell ausschließt, relativiert er die überschießende Wucht religiöser Traditionen. ${ }^{111}$

105 | Habermas, Zwischen Naturalismus und Religion 2005, 150. Vgl. zu Hintergründen Renner, Postsäkulare Gesellschaft und Religion 2017, 224-229.

106 | Habermas, Zwischen Naturalismus und Religion 2005, 149.

107 | Habermas, Zwischen Naturalismus und Religion 2005, 202.

108 | "Ritualization is first and foremost a strategy for the construction of certain types of power relationships, effective within particular organizations": Bell, Ritual Theory, Ritual Practice 1992, 197; dazu: Uhl, Vom Ritual zur Sprache - Von der Sprache zum Ritual 2017.

109 | Breul, Religion in der politischen Öffentlichkeit 2015, 154.

110 | Vgl. Breul, Religion in der politischen Öffentlichkeit 2015, 216-246; Reder, Liberal, deliberativ oder dekonstruktivistisch 2017, 140-142.

111 | Vgl. Reder, Religion in säkularer Gesellschaft 2013, 100-126; Schmidt, Pitschmann, Religion und Säkularisierung 2014; Maeve Cooke zeigt im Rückgang auf Wittgenstein und Charles Taylor auf, dass auch nichtreligiöse Argumente und Begründungen auf lebensweltlichen, in Erfahrung begründeten Wahrnehmungsveränderungen beruhen können. Eine solche säkulare Hermeneutik der Offenbarung zeigt für sie, dass erstens die strikte Unterscheidung von ethischen Konzeptionen des Guten und von Religion so nicht zu halten ist und zweitens ein Rekurs auf Offenbarung per se daher nicht ein 
Dagegen könnte aus religiöser Sicht durchaus das kritisch-produktive Potential von Religion betont werden. Für Jon Sobrino hängen »Kritik an heutigen Demokratien und Wege zu ihrer Humanisierung von der biblischjesuanischen Tradition her« zusammen. ${ }^{112}$ Deshalb, so der politische Theologe Jürgen Manemann, ist im gegenwärtigen Zeitalter der Verfeindungen und der Dominanz des Allgemeinen über das Besondere die

"demokratische Gesellschaft gut beraten, auf das in den biblischen Traditionen enthaltene Veränderungspotential zu achten. Moralität entsteht nämlich nicht [...] in der Gleichheit, sondern dadurch, dass man den Armen, den Waisen und der Witwe dient. Zentral für die biblischen Traditionen ist der Imperativ der Anerkennung fremden Leids. Dadurch wird die Theorie und Praxis von der Gerechtigkeit bzw. Gleichheit in der liberalen Gesellschaft immer wieder neu im Blick auf die konkreten Menschen in ihrer unendlichen Würde befragt [...]. Die egalitäre Einstellung der Mitglieder demokratisch verfasster Gesellschaften wird durch dieses ,individuelle Gerechtwerden` vervollständigt. «113

Dieses »Leidensapriori« kann in kritischer Absetzung von einem rein formalen »Verständigungsapriori« den politischen Diskurs orientieren. ${ }^{114}$ Dies aber wirft erneut ein kritisches Licht auf die Kommunikative Vernunft selber.

\subsubsection{Diskurstheorie}

Wie Helmut Peukert in beeindruckenden Grenzreflexionen unter Bezug auf Walter Benjamin zeigen konnte, wird die kommunikative Rationalität angesichts des Leidens der Protagonisten geschichtlich verwirklichter Freiheit sowie der unschuldigen Opfer der Geschichte ihrem eigenen Universalismuspostulat nicht gerecht. Sie blendet letztlich die Abhängigkeit der Subjekte von allen anderen aus und übersieht das konkrete Schicksal der im Gang der Geschichte Exkludierten. Ohne diese sind aber eine ideale Kommunikationsgemeinschaft und damit ein universaler nachmetaphysisch geprägter Wahrheitsbegriff nicht denkbar. ${ }^{115}$ Daher ist eine solche Rationalität durch einen prinzipiellen Traditionsbezug zu erweitern, »indem sie anamnetisch und innovatorisch geöffnet

grundlegendes Hindernis für religiöse Traditionen in der Öffentlichkeit darstellen kann: Cooke, Nicht zugänglich 2017, 202-207. Andreas Telser verweist auf den kulturprotestantisches Sozialisationshintergrund von Habermas, der es inm verwehre, religiöse Erfahrungen über die religiösen Sprachspiele hinaus etwa seitens der Philosophie für zugänglich zu halten: Telser, Habermas und die Öffentliche Theologie 2017, 191.

112 | Vgl. Sobrino, Kritik an den heutigen Demokratien 2007.

113 | Manemann, Über Freunde und Feinde 2008, 86. Gegen eine liberale Privatisierungsstrategie vgl. Mette, Nicht gleichgültig bleiben 2017, 13-16.

114 | Metz, Monotheismus und Demokratie 1996, 46.

115 | Vgl. Peukert, Die Frage nach der Allgemeinbildung 1987, 300-318. 
und damit wirklich offen und universal « wird im Sinne universaler Gerechtigkeit, anamnetischer Solidarität und innovatorischer Kreativität. ${ }^{116}$ Die kommunikative Vernunft müsste daher aufgesprengt werden durch eine vorgängige Irritation: Sensibel geworden für das, was fehlt, ${ }^{117}$ hätte sie sich zu öffnen für die normativen und orientierenden Gehalte, die aus fremden Traditionen entgegenkommen, wie dies mit dem Alteritätsgedanken verbunden ist. ${ }^{118}$ Eine solche vom Anderen her eröffnete kommunikative Praxis, die auf ein intersubjektives, befreiendes, neue Perspektiven, ungeahnte Möglichkeiten realisierendes und dabei das Gegebene transformierendes und Systemimperative aufsprengendes Handeln rekurriert, ist verwurzelt in sprachlich verfassten Kommunikationsprozessen. Sprache und Freiheit, Sprache und Anerkennung, Sprache und Identitätsstiftung in gesellschaftlichen Kontexten hängen zusammen. Sprechen als eine wirklichkeitsstiftende wie wirklichkeitsverändernde Kraft bildet jenen Raum intersubjektiver Freiheit, in der Menschen ihre Identität erst gewinnen und zugleich gesellschaftliche Strukturen und Öffentlichkeiten verändert werden können. ${ }^{119}$

Doch wie ist dies zu denken? In der Tradition der Diskursanalyse Michel Foucaults ist die kommunikative diskursive Vernunft einer grundsätzlichen Kritik unterzogen worden, die gegenwärtig in postmodernen wie postkolonialen Strömungen Unterstützung findet. Jede Begriffsbildung, jeder Diskurs beruht demnach auf einer geheimen Dialektik von Inklusion und Exklusion. Begriffliche Rede von normativen Orientierungen nimmt performativ Exklusionen vor, indem sie bestimmte Identitäten schafft. Dissens wird durch die normative Ausrichtung an konsensualen Prozeduren delegitimiert oder wenigstens so stark geschwächt, dass dies die Kraft fremder, begrifflich uneinholbarer Traditionen in ihrer auch epistemischen und rationalen Würde marginalisiert. Indem Habermas Politik und Öffentlichkeit durch seine normative Theorie Grundlage, Ziel und Form geben will, indem er dadurch einschätzen helfen will, ob und wie gegebene Praktiken dazu beitragen können, wird Habermas in signifikanter, von uns später noch detaillierter zu erläuternden Weise unkritisch gegenüber dem von ihm selber entwickelten Sinn von Normativität. ${ }^{120}$ Für Judith Butler unterliegt demnach die kommunikative Vernunft einem Code der Macht und der Ausgrenzung von Alterität, freilich ohne dass

116 | Arens, Fundamentale Theologie im Anspruch kommunikativer Rationalität 2002, 66. Zu Fundierungen und Hintergründen John, Diskursethik und Leidenserfahrungen 2017.

117 | Vgl. Reder, Schmidt, Ein Bewusstsein von dem, was fehlt 2008.

118 | Vgl. Grümme, Vom Anderen eröffnete Erfahrungen 2007.

119 | Vgl. Peukert, Erziehungswissenschaft - Religionswissenschaft - Theologie - Religionspädagogik 2004, 69.

120 | Vgl. Butler, Was ist Kritik 2013, 224. Vgl. C 5. 
sie sich dessen eingedenk wäre. Man kann zwar zu Recht einwenden, dass die im Hintergrund stehende Diskursanalyse auf poststrukturalistischer Basis mit zu starken Verallgemeinerungen umfassender Wahrheitsregime und Konstellationen einer durch und durch von Macht durchwirkten Öffentlichkeit agiert, die mehr Homogenität versprechen als empirisch gegeben ist. ${ }^{121}$ Dies führt Habermas in seiner Replik zu der These, dass bei Foucault letztlich kein Bezug mehr zwischen Öffentlichkeit und den Anderen gegeben sei und deshalb wegen der diagnostizierten Verabsolutierung des Ausschlussmechanismus innerhalb der kommunikativen Vernunft (anders als im Rahmen der deliberativen Öffentlichkeit) ein »Potential der Selbsttransformation« durch Alterität nicht mehr gegeben ist. ${ }^{122}$

Doch unterschätzt Habermas nicht doch den Zusammenhang von »Normativität und Macht«? ?23 Wäre nicht von Judith Butler und Nancy Fraser her einzuwenden, dass er Macht- und Exklusionsfragen nicht als Gegenstand der Reflexion, wohl aber als Implikationen seiner eigenen Theoriebildung zu wenig berücksichtigt? Mit anderen Worten: Machtfragen werden von Habermas als Materialobjekte reflektiert, nicht aber als Formalobjekte. Immerhin zeigt doch die Diskursanalyse, dass »moderne Macht durch das Gewähren von Freiheit und nicht einfach durch Unterdrückung funktioniert « ${ }^{124}$ Systemstabilisierung läuft subtiler, die Macht der Diskurse untergründiger. Hier liegt der »prinzipielle Bruch « zwischen Foucault und Habermas. »Kommunikatives Handeln gelangt nicht auf die mikrophysikalische Ebene von Disziplinar-Strategien, die Menschen diskursiv ergreifen. Widerstand, so nicht regiert und diszipliniert zu werden, ist für Foucault möglich und nötig, aber eine herrschaftslose positive Gestaltung erstrebter Zustände ist nicht möglich und eine verfehlte Diskursivierung. $\ll^{125}$ Braucht es nicht einen schärferen Blick auf die Vernunft selber in Bezug auf die in ihr wirksamen Mechanismen von Hegemonie und »noumenaler Macht«, wie Rainer Forst mit Blick auf Foucault und Gramsci fragt? ${ }^{326}$ Wenn Macht vor allem diskursiver Natur ist und über Wahrheitsregime epistemisch, also im Raum des Kognitiven agiert, müsste sich doch eine deliberative Öffentlichkeitstheorie solchen Implikationen stärker Rechenschaft geben und eine diskursive Vernunft diskurstheoretisch-selbstreflexiv »verflüssigt< werden $\ll{ }^{127}$

121 | Vgl. Forst, Normativität und Macht 2015, 74.98f.

122 | Habermas, Strukturwandel der Öffentlichkeit 1990, 20.

123 | Forst, Normativität und Macht 2015, 3.

124 | Forst, Kritik der Rechtfertigungsverhältnisse 2011, 162.

125 | Sander, Macht 2017, 153.

126 | Forst, Normativität und Macht 2015, 74.

127 | Forst, Normativität und Macht 2015, 11. 
Daraus resultiert ein vernunftheoretischer Dreiklang unverzichtbarer Momente, die öffentlichkeitstheoretisch ineinandergreifen: Ein nachmetaphysischer Anspruch auf Allgemeinheit, die Anerkennung von Besonderheit und Alterität und zugleich eine selbstreflexiv-machtsensible Kritik müssten in dieser auf Emanzipation und Freiheit abhebenden Öffentlichkeitstheorie zusammengehen.

"Auch wenn freilich nicht verhindert werden kann, dass sich in den Diskursen unbemerkt Machtgefälle einschleifen, so ist deren Identifikation durch das Profil kommunikativer Rationalität als notwendige Bedingung des emanzipatorischen Erkenntnisinteresses ausgewiesen. Selbst Foucault hatte trotz seiner prominenten Kritik zu bedenken gegeben, dass Diskurse nicht ,ein für alle Mal der Macht unterworfen، sind, sondern ebenso zum ,Hindernis, Gegenlager, Widerstandspunkt und Ausgangspunkt für eine [...] entgegengesetzte Strategie werden können. Sie scheinen in ihrer Polyvalenz unter den Vorzeichen einer anhaltenden Spurensuche und im Erbe einer Hermeneutik des Verdachts für latente Machtmechanismen m.E. demnach ein aussichtsreicher Versuch zu sein, auch in hyperkomplexen Gesellschaften eine Orientierung zu geben, ohne dabei Heterogenität durch Homogenität ersetzen zu müssen. “128

Aus diesen drei Perspektiven der Kritik ergibt sich ein komplexes Resultat für den Begriff von Öffentlichkeit:

Zunächst sollte die Unverzichtbarkeit von Normativität für eine deliberative Öffentlichkeitstheorie deutlich geworden sein, liefert sie doch Kriterien für die Öffentlichkeit und ihren Diskurs. Öffentlichkeit ist auf die Maßstäbe von Universalität, von Gleichheit und wechselseitiger Rechtfertigung angewiesen. Denn diese markieren Raum wie Grenze von Geltung wie von Toleranz.

Doch genau darin wird zugleich ein dreifacher Frageüberhang deutlich:

1. Wie sind Universalität und Partikularität im Öffentlichkeitsbegriff angemessen ins Verhältnis zu setzen? 2. Wie sind Normativität und Differenz, Identität und Alterität zu denken? Und schließlich 3. Wie kann eine normativ bestimmte Öffentlichkeitstheorie so gefasst werden, dass sie ihre eigenen begrifflichen Performanzen und Konstruktionsmechanismen selbstreflexiv kritisch erfasst - im Dienste der Öffentlichkeit und der Subjekte selber?

Gesucht wird also eine Öffentlichkeitstheorie, die sich in der Dialektik von Normativität und Macht artikuliert. So kann sie dem Identitätsversprechen und der sinnstiftenden wie orientierenden Kraft auch und gerade der religiösen Traditionen entsprechen, die in ihrer bestimmten Positionalität Wahrheit beanspruchen und zugleich ihrerseits nicht unvernünftig sein wollen.

Doch war vielleicht die soeben geäußerte Insistenz auf Normativität ein wenig voreilig? Spricht nicht doch manches dafür, den Diskurs der Öffentlichkeit

128 | Weber, Zwischen Kampf um Anerkennung 2017, 117. 
nicht mit Schwellen von Rationalität, Informiertheit und Motivation zu versehen? Die gegenwärtigen Debatten um Elitendiskurse, mainstream-Medien oder fake-news gehen doch in eine solche Richtung. Müssten nicht alle gehört werden? Dies wäre doch auch religionspädagogisch relevant. Wenn Religionspädagogik aus ihrem theologischen wie pädagogischen Erbe heraus eine besondere Sensibilität für die Marginalisierten und Exkludierten haben sollte, wenn sie in Kinder- und Jugendtheologie auch auf unkonventionelle Weise den jeweiligen Subjekten theologisch wie religionspädagogisch Gehör verschaffen will, kann dies doch öffentlichkeitstheoretisch nicht folgenlos bleiben. Darum scheint es angeraten, die Theorie noch genauer zu untersuchen, die eine solche allgemeine Öffentlichkeit zu profilieren versucht.

\section{Liberale ÖffentlichKeit: Volker Gerhardt}

Man kann Volker Gerhardts fulminanten Entwurf einer Theorie der Öffentlichkeit als philosophisches Grundlagenwerk der politischen Philosophie im 21. Jahrhundert einordnen. Man kann es aber zugleich als radikalen Gegenentwurf zu der schlechthin dominanten Theorie der Öffentlichkeit und deren Strukturwandel in den Transformationsprozessen der Moderne lesen, wie sie Jürgen Habermas in seiner Habilitationsschrift von 1962 und in deren kritischer Fortschreibung zu einer deliberativen Theorie der Öffentlichkeit vorgelegt hat. Daraus gewinnt sie einen erheblichen Teil ihrer Dynamik, sowohl in ihrer positiven wie in ihrer kritischen Tendenz. Erste Konturen sollen gezeichnet werden, aus denen sich dann eine epistemologisch-wissenschaftstheoretische Systematik ergibt.

\subsection{Systematisch-genetische Annäherungen}

Gerhardt geht es - und hier liegt die positive Dynamik seiner Theorie - wesentlich um den kritisch gegenüber Habermas gerichteten Nachweis, dass es eine Öffentlichkeit nicht erst mit der Entwicklung einer bürgerlichen Öffentlichkeit in den Salons, den Medien und des verständigungsorientierten gemeinschaftlichen wie intersubjektiven Miteinanders ab dem 17. Jahrhundert gegeben hat. Ein unvoreingenommener Blick in die Geschichte zeige vielmehr, dass bereits in der Antike von einer Sphäre der Öffentlichkeit als gesellschaftlichem und politischem Forum der Sinnfindung, der Vergewisserung von Einheit, der Beratung und Entscheidung ausgegangen werden kann. Öffentlichkeit habe sich bereits im Alten Orient entwickelt, sei dann ein zentrales Element gesellschaftlicher und politischer Selbstverständigungsprozesse bei den Griechen und dann durch eine spezifische Transformation ins Rechtliche zu einem wesentlichen Ordnungselement der römischen Gesellschaft und des 
römischen Staates geworden. ${ }^{129}$ Obschon im Mittelalter nochmals intensiviert durch eine Verinnerlichung und transzendente Ausweitung vor dem Hintergrund des Gottesgedankens, weil das Handeln in der »Öffentlichkeit wie ein Auftritt vor dem Auge Gottes erscheint« und dadurch intrinsisch mit dem Postulat der Wahrhaftigkeit und Aufrichtigkeit verbunden wird, ${ }^{130}$ bleibt Öffentlichkeit ein durchgehender Zug vergemeinschafteten und politischen Lebens bis in die Moderne.

Grundlegend ist dabei die Unterscheidung von >publicus und >privatus<, von >öffentlich $<$ und >privat<: publicus ist das, was alle angeht, privatus das, was die Individuen betrifft. Entscheidend für Gerhardt ist freilich der Gebrauch, den er von dieser Unterscheidung macht. Beide Aspekte, Öffentlichkeit und Privatheit, hebt er nicht ineinander auf, etwa in dem Sinne, dass der Sinn des Privaten im Öffentlichen bestehe oder die Individuen sich erstmals in der Öffentlichkeit zusammentäten und diese durch diesen Zusammenschluss erst konstituierten. Vielmehr setzt er sich strikt von einem kontraktionalistischen, also vertragstheoretischen Zugang ab. Der politische Raum der Öffentlichkeit entsteht bei den Römern, so Gerhardt, der dies zu seiner eigenen Position machen wird, nicht durch einen Gründungsakt nach dem Muster moderner Vertragstheorien, in dem sich die Subjekte zusammentun, sich verabreden und einen Vertrag miteinander eingehen, um etwa den Raum zwischen ihren Gütern zum Gemeingut zu erklären. Alle leben bereits »immer schon« in Gemeinschaft und damit bereits in einer Öffentlichkeit, die Gerhardt als eine gesellschaftliche Öffentlichkeit qualifiziert. ${ }^{131}$ Unter explizitem Wunsch, diese Gemeinschaft zu zivilisieren, zu intensivieren, durch Arbeit, Technik und Kultur aufzubauen, auf Entscheidungen mit für alle geltenden Verbindlichkeitscharakter hinzuführen und mit rechtlichen Codierungen zu gestalten, zu ordnen und abzusichern, vollzieht sich dann das, was Gerhardt die »politische Öffentlichkeit« nennt. ${ }^{132}$

Auf diese Weise sind zwei Differenzierungen vorbereitet, die einen wesentlichen Argumentationsstrang seiner Theorie bilden: die Unterscheidung von Öffentlichkeit und Privatheit und die zwischen gesellschaftlicher und politischer Öffentlichkeit. Gerhardt ist klar, dass der Raum der Privatheit durch die Dominanz der Öffentlichkeit gefährdet ist, die ihr andererseits zweifellos gebührt. Weil eben das Interesse aller das Interesse eines jeden Einzelnen umfasst, besitzt die Öffentlichkeit Vorrang. Gleichwohl hängt jedoch das öffentliche Ganze davon ab, dass es jeder Einzelne prüft und es aus eigener

129 | Vgl. Gerhardt, Volker, Öffentlichkeit 2012, 48-136; Ferner Gerhardt, Die Öffentlichkeit Gottes 2016; kritisch dazu Zoll, Volker Gerhardts öffentliche Theologie 2016.

130 | Gerhardt, Öffentlichkeit 2012, 124.

131 | Gerhardt, Öffentlichkeit 2012, 50.

132 | Gerhardt, Öffentlichkeit 2012, 46. 
Freiheit heraus will. »Das öffentliche Ganze kann sich nur erhalten, wenn die Bürger mit eigenen Augen erkennen, was das Recht erfordert - kurz: wenn sie aus eigener Einsicht tun, was für alle das Beste ist.« ${ }^{133}$ Damit sind Öffentlichkeit und Privates aufeinander in kritischer Weise verwiesen. Öffentlichkeit braucht das Private als Korrektiv und als Bewahrheitungs- und Realisierungsinstanz, das Private ist auf Öffentlichkeit angewiesen, weil hier die kommunikativen Verständigungsprozesse stattfinden und die für alle verbindlichen Entscheidungen getroffen werden. Der Sinn der Öffentlichkeit besteht demnach darin, zusammen etwas zu tun, was im Interesse aller steht. Dafür aber muss das Öffentliche offensichtlich sein, darf nicht verborgen oder aufs Private allein beschränkt bleiben. Es muss prinzipiell von allen eingesehen und verstanden werden. Hierin besteht der prinzipiell liberale Grundzug dieser Öffentlichkeitstheorie. Liegt darin schon ein Vollzug von Aufklärung gewissermaßen avant la lettre, darf die Parallele von Öffentlichkeit und Aufklärung deshalb keineswegs auf die Neuzeit reduziert werden.

\subsection{Profil}

Damit kristallisieren sich aus Gerhardts Auseinandersetzung mit der griechischen polis-Konzeption wie mit der res publica-Theorie (unter besonderer Akzentuierung Ciceros) bereits die wesentlichen Elemente seines Öffentlichkeitbegriffs heraus: Öffentlichkeit basiert auf Anschauen und Erkennen, auf Erleben und Wissen, auf Entscheidung und der Kraft des rechtlich codierten »Bewusstseins von gemeinsamer Entscheidung «. ${ }^{134}$

Öffentlichkeit meint daher immer zwei Aspekte: 1. Das, was omnipräsent ist, was vor aller Augen steht, was alle einsehen können. Es ist das Gegenteil von Nicht-öffentlich, von opak, verborgen. Öffentlich ist das, was alle sich vergegenwärtigen können. 2. Öffentlichkeit meint ein Verfahren und damit korrespondierend einen Raum der Entscheidungen, des Verständigens, des Beratens, des Austragens von Konflikten und der rechtlichen Codierung getroffener Entscheidungen. ${ }^{135}$ Je öffentlicher ein solcher Prozess ist, je mehr Menschen daran teilnehmen, desto tragfähiger und desto sinnvoller die Entscheidungen.

Daraus resultiert ein dreifach gegliederter Öffentlichkeitsbegriff. Er umfasst - erstens - den rechtstattlich definierten Raum öffentlichen Handelns, zweitens - die Gesamtheit der Auffassungen und Meinungen der Bürgerinnen und Bürger eines Staates. Jeder soll Zugang zu Informationen und zugleich die Möglichkeit haben, sich selber einzubringen; und schließlich - drittens

133 | Gerhardt, Öffentlichkeit 2012, 53.

134 | Gerhardt, Öffentlichkeit 2012, 55.

135 | Vgl. Gehring, Lob der nicht privaten Vernunft 2013. 
- alle Menschen, mithin die Weltöffentlichkeit. »Sie ist die legitimierende Instanz des Menschenrechts, aber auch der denkbar größte Rahmen, in dem sich alles bewegt, was Menschen angeht. « $^{136}$ Damit ist der Begriff der Öffentlichkeit ins Universale geweitet. Gerade deshalb aber verlangt er eine Differenzierung, auf die wir später noch zurückkommen werden.

Zwar ist nach diesem weiten Verständnis alles Gemeinschaftsrelevante öffentlich. Aber nicht alles wird bereits zu politisch verbindlichen Entscheidungen verdichtet, durch Recht geordnet und codiert. Daher muss - wie bereits angedeutet - eine gesellschaftliche von einer politischen Öffentlichkeit unterschieden werden. ${ }^{137}$ In der gesellschaftlichen Öffentlichkeit bezieht sich ein »Selbst durch die Mitteilung eines Sachverhalts auf Andere seiner selbst, so dass jeder Andere darauf mit Bezug auf denselben Sachverhalt zustimmend, abweichend oder abwehrend reagieren kann ${ }^{138}$ Als elementare Bedingung einer solchen Öffentlichkeit kann die Beteiligung möglichst vieler und die Bezugnahme auf eine Vielfalt an Lebensfragen gelten. Aufgabe der gesellschaftlichen Öffentlichkeit ist es demnach, die freie und gleiche Anteilnahme aller $\mathrm{zu}$ organisieren und zu gewährleisten und damit in Bezug auf aktuelle Lebensfragen und andere relevante Sachverhalte Einvernehmen unter Wahrung der Anerkennung individueller Eigenständigkeit herzustellen. ${ }^{139}$ Diese gesellschaftliche Öffentlichkeit muss nicht eigens geschaffen werden. Sie bildet sich in dem Moment, sobald eine größere Zahl von Menschen voneinander wissen und aktiv ihre Lebensprobleme bearbeiten. Als solche stellt sie die Vorstufe der politischen Öffentlichkeit dar, ${ }^{140}$ in der diese gesellschaftliche Öffentlichkeit sich verdichtet und sich über die Prozesse der Partizipation, Repräsentation und rechtlichen Konstitution institutionell verankert. Schon das Interesse an einer solchen Institutionalisierung ist Teil der politischen Öffentlichkeit. ${ }^{111}$

Offensichtlich lässt sich demnach Öffentlichkeit in ihren Formen und Leistungen nicht auf den politischen Bereich beschränken. Politische Öffentlichkeit ist auf die gesellschaftliche Öffentlichkeit angewiesen. Diese ist deren unverzichtbare elementare Bedingung, ohne die politische Öffentlichkeit weder Grund noch Bewährungs- und Legitimationsraum sein könnte. Gleichwohl erfüllt sich der »Sinn der Öffentlichkeit« erst in einer politischen Organisation und damit in der politischen Öffentlichkeit.

136 | Gerhardt, Öffentlichkeit 2012, 37.

137 | Vgl. Gerhardt, Öffentlichkeit 2012, 25ff;

138 | Gerhardt, Öffentlichkeit 2012, 25.

139 | Vgl. Gerhardt, Öffentlichkeit 2012, 507.

140 | Vgl. Gerhardt, Öffentlichkeit 2012, 26.

141 | Vgl. Gerhardt, Öffentlichkeit 2012, 305ff. 
"In der Politik sind selbst jene, denen es um bloße Macht geht, genötigt, das gesellschaftliche Handeln nach dem Modell rechtsförmiger Institutionen zu denken. Sie müssen sich verständiger zeigen, als es innen nach ihrem Interessenstandpunkt naheliegt. Sie haben sich an einem Ganzen zu orientieren, das sie selbst relativiert. Die Beherrschten müssen zumindest glauben können, es gehe um Ziele, die dem Ganzen und damit dem Wohl Aller dienlich sind. Die dazu erforderliche Sphäre der Verständigung über das Alle betreffende Handeln ist die Öffentlichkeit. “" ${ }^{142}$

Angesichts einer solchen historisch-systematisierenden Rekonstruktion wird die Verve verständlich, mit der sich Gerhardt - und dies ist die erwähnte kritische Dynamik seiner Öffentlichkeitstheorie - von Konzeptionen distanziert, die den Öffentlichkeitsbegriff mit dem Modernebegriff kurzschließen. Ein unvoreingenommener Blick in die Geschichte zeige eben, dass bereits in der Antike von einer Sphäre der Öffentlichkeit als gesellschaftlichem und politischem Forum der Sinnfindung, der Vergewisserung von Einheit, der Beratung und Entscheidung ausgegangen werden muss. Dies zu bestreiten, wie dies Jürgen Habermas und Axel Honneth mit Blick auf den exkludierenden Charakter der Polis tun, die eben nicht alle, sondern nur einen bestimmten Teil der Gesellschaft zu Bürgern erklärt, würde bedeuten, mittelalterliche Straßen nicht Straßen nennen zu dürfen, weil sie nicht den modernen Verkehrswegen entsprechen, und den antiken Staat nicht Staat nennen zu dürfen, weil er nicht den Kriterien des Nationalstaats des 19. Jahrhunderts gerecht werde. ${ }^{143}$

Hauptverantwortlich dafür sei der verengte, ja restriktive Öffentlichkeitsbegriff der deliberativen Vernunft. Öffentlichkeit würde beschränkt und in ihrer »prinzipiell Offenheit schaffenden Funktion« verkannt, wenn man sie vorab an »noch so gut gemeinte Regeln bindet«. Eine solche Position »hegt ein Ressentiment gegen das freie Urteil der Andersdenkenden und reglementiert die Zukunft. Öffentlichkeit ermöglicht den Einspruch eines jeden und kann daher nicht vorgeben, was den Vorbehalt begründet und in welche Richtung sich der Meinungsaustausch entwickelt. Wer der Dynamik öffentlicher Prozesse mehr vorgeben will als die Freiheit der beteiligten Personen, schränkt bereits deren Freiheit ein. ${ }^{144}$ Daraus folgt eine Fundamentalkritik an der Kritischen Theorie als Hintergrundtheorie: »Die zukunftsoffene, damit freilich auch riskante Leistung der Öffentlichkeit wird auf die Dimension einer methodologischen Bevormundung zurechtgestutzt. Dass die Konzeption der deliberativen Öffentlichkeit weiterhin unter dem Titel einer >kritischen Theorieくverhandelt wird,

142 | Gerhardt, Öffentlichkeit 2012, 305.

143 | Vgl. Gerhardt, Öffentlichkeit 2012, 136.

144 | Gerhardt, Öffentlichkeit 2012, 506. 
ist Ausdruck einer autoritär halbierten Rationalität, die Kritik nur gelten lässt, solange man sie selber äußert. ${ }^{145}$

Eine solche Vehemenz verlangt nach Erklärung und Legitimation. Diese liegen in den epistemologischen Hintergrundannahmen von Gerhardts Öffentlichkeitsbegriffs.

\subsection{Soziomorphes Bewusstsein als Grund der Öffentlichkeit}

Provokanter für idealistische und subjektzentrierte Philosophie kann das Axiom kaum sein, auf das Gerhardt seine Öffentlichkeitstheorie gründet: er spricht von der »Soziomorphie « des Selbstbewusstseins, ${ }^{146}$ mit dem er die Perspektive radikal wendet. Nicht nimmt er seinen Ausgangspunkt beim Selbstbewusstsein des einzelnen Subjekts. Das Selbstbewusstsein als das scheinbar Privateste des Menschen sei vielmehr ein Spezialfall des Öffentlichen, in dem alle Menschen verbunden seien: dem Bewusstsein als die »ursprüngliche Weltoffenheit des Menschen «. ${ }^{147}$ Öffentlichkeit wird nicht erst konstituiert, wenn sich Einzelsubjekte zusammentun. Sie ist die jeder bewussten Praxis, jedem bewussten Denken vorauslaufende Bedingung der Möglichkeit. Öffentlichkeit sei so gesehen transzendental im menschlichen Bewusstsein verankert. Allein in der Öffnung des Bewusstseins auf alles und die Unterstellung einer allgemeinen Verständnisfähigkeit und einer gemeinsamen Welt lassen sich Bedeutungen konstruieren, lässt sich gemeinsames Verstehen ermöglichen und Erkenntnis vollziehen. Auch wenn die Menschen leibliche und biografische Differenzen haben, so haben sie doch gemeinsam, dass sie sich genauso wie alle anderen auf die gleichen Sachverhalte beziehen können. Bewusstsein, ist so »das Organ des Menschen, mit der sich die Welt so erschließen kann, dass er sie mit seinesgleichen teilen und als Raum für gemeinsames Handeln nutzen kann. Wenn überhaupt, dann ist das Bewusstsein das Organ für die Öffentlichkeit einer Welt, die allen, die darin etwas erkennen, zugänglich ist. « ${ }^{148}$ Jede auf sachliche Verständigung ausgelegte Praxis setzt die Partizipation des Bewusstseins am Allgemeinen voraus. Sie unterstellt bereits ein Bewusstsein, das auf eine gemeinsame Welt ausgerichtet ist. Nur so, nur indem so Bedeutungen konstituiert werden, sind Verständigungen möglich. »So bewegt sich der Mensch in der >Objektivität< einer Welt, an der er selbst beteiligt ist. Sein >Umfeld $<$ nimmt >Weltcharakter< an. >Weltcharakter bezeichnet die Einheit, die sich aus der prozeduralen Gemeinsamkeit der sich überlagernden Einzel-

145 | Gerhardt, Öffentlichkeit 2012, 506.

146 | Gerhardt, Öffentlichkeit 2012, 20.

147 | Gerhardt, Öffentlichkeit 2012, 14.

148 | Gerhardt, Öffentlichkeit 2012, 372. 
perspektiven ergibt und damit als ein öffentlich konstituierter Raum aus >Bedeutungen $<$ begriffen werden kann. $\ll^{149}$

Gerhardt bringt damit in charakteristischer Weise Kants Universalisierungsformel, die im Hintergrund des Kategorischen Imperativs steht, epistemologisch zur Geltung und konstelliert diese mit Aristoteles' Anthropologie des zoon politicon, Karl Poppers Begriff der Offenen Gesellschaft, Plessners Anthropologie der Exzentrizität menschlichen Bewusstseins sowie Hannah Arendts Öffentlichkeitsbegriff, wie sie ihn in Vita Activa gegen die Bestreitung des Begriffs bei Heidegger als bloßes Gerede des Man zur Geltung bringt. ${ }^{150}$ Öffentlichkeit ist der Raum, wo Privates und Öffentliches in ihrer Unterschiedlichkeit zusammenkommen. Öffentlichkeit muss als Raum begriffen werden, in dem sich die Einzigartigkeit individuellen Bewusstseins nicht nur zeigen, sondern geradezu »bewähren kann«. ${ }^{151}$

Das Selbstbewusstsein sei deshalb in sich bereits soziomorph, so Gerhardt, da es konstitutiv auf Öffentlichkeit angelegt sei. In ihm verbindet sich »ein Ich mit der Gemeinschaft von seinesgleichen«, indem es sich auf ein sachlich verselbstständigtes Moment der Welt bezieht. ${ }^{152}$ Darin liegt seine trianguläre Struktur des Dreiklangs von Ich-Welt-Wir, ${ }^{153}$ was es überdies Gerhardt erst ermöglicht, von der öffentlichen Form des Bewusstseins zu sprechen. Dieses »ist die erste und elementare Form der Öffentlichkeit. Es ist die hochkultivierte Form menschlicher Selbstorganisation, in der ein Individuum durch direkten Bezug auf einen Sachverhalt gleichermaßen bei sich selbst und bei allen Anderen ist, sofern sie sich über den gleichen Sachverhalt verständigen. « ${ }^{154}$ Diese soziomorphe Struktur des Selbstbewusstseins lässt Gerhardt gar eine Analogie zwischen der im Selbst angelegten kommunikativen Struktur und der Öffentlichkeit konstruieren. ${ }^{155}$ So will er sowohl subjekthafte Individualität und die intersubjektiven Konstitutionsbedingungen des Bewusstseins würdigen wie den öffentlichen Charakter, der es dem Bewusstsein erst ermöglicht, vom Standpunkt vieler anderer Perspektiven her zu denken und so gesellschaftlich wie politisch zu agieren. ${ }^{156}$

Gerhardt geht in der Betonung des Öffentlichkeitscharakters des Bewusstseins noch weiter. Im Begriff des >Geistes< fasst er jene Kondensate und Sedimente des Bewusstseins zusammen, die dem Selbstbewusstsein in Form

149 | Gerhardt, Öffentlichkeit 2012, 300; vgl. $14 f$.

150 | Vgl. Gerhardt, Öffentlichkeit 2012, 159-189. 213-220.298-300.

151 | Gerhardt, Öffentlichkeit 2012, 216.

152 | Gerhardt, Öffentlichkeit 2012, 20.

153 | Vgl. Gerhardt, Öffentlichkeit 2012, 20.

154 | Gerhardt, Öffentlichkeit 2012, 41.

155 | Vgl. Gerhardt, Öffentlichkeit 2012, $35 f$.

156 | Vgl. Gerhardt, Öffentlichkeit 2012, 368 
von Traditionen und Institutionen entgegenkommen. ${ }^{157}$ Auf diese Weise im Bewusstsein verankert, avanciert die Öffentlichkeit letztlich zu nichts Geringerem als zur »transzendentalen Formel« von Recht und Politik, ${ }^{158}$ wie Gerhardt mit Bezug auf Kants Ewigen Frieden formuliert. Politisches Handeln ist auf die Gesamtheit menschlichen Handelns bezogen, das genau hierfür Öffentlichkeit benötigt. Zugleich erfüllt sich deren Sinn in der Politik. Von daher wird die gegenseitige Verwiesenheit von Partizipation, Repräsentativität und rechtlicher Konstitution im Raum von gesellschaftlicher und vor allem von politischer Öffentlichkeit nachvollziehbar. Politik verlangt die freie und gleiche Teilhabe aller, die in Gesellschaften das Prinzip der Repräsentanz einfordert und sich in rechtsförmigen Regeln konstituiert. ${ }^{159}$

\subsection{Konsequenzen}

Diese Rekonstruktion der epistemologischen Grundlagen erlaubt nun ein besseres Verständnis von Gerhardts Kritik an Habermas und zugleich von Gerhardts Öffentlichkeitstheorie selber. Insofern das Bewusstsein konstitutiv auf Öffentlichkeit verwiesen, ja insofern es selber öffentlich ist und damit Öffentlichkeit und Bewusstsein elementar korrelieren, sind die gesellschaftliche wie die politische Öffentlichkeit auf jedes einzelne Bewusstsein angewiesen. Andererseits gewinnt sie ihrerseits durch diese Rückgründung in vernünftigem Bewusstsein Rationalität. Die einzige Voraussetzung sind Freiheit, Gleichheit und Zugänglichkeit. Insoweit »die Öffentlichkeit als eine ins gesellschaftliche Ganze ausgestülpte Vernunft begriffen werden« kann, strebt Vernunft nach dem Richtigen und nach kritischem Aufdecken von Fehlern durch öffentliche Prüfung. ${ }^{160}$ Gerhardt geht davon aus, dass die Aufnahme vieler Gesichtspunkte eine Überlegung umfänglich sichert und im Ergebnis besser begründen lässt. Je mehr Menschen in diesem Prozess beteiligt sind, desto tragfähiger das Ergebnis. Trotz der mitunter möglichen Erfahrung, dass Vernunftprozesse auch zerredet werden können, hält Gerhardt fest:

"Die Unterstellung, dass in der Beteiligung Vieler eine größere Chance auf bessere Einsicht liegt als im Räsonnement eines Einzelnen, bleibt dennoch in Kraft. Zwar ist durch nichts bewiesen, dass die Menge über mehr Vernunft verfügt als der Einzelne. Gleichwohl bietet die über die Öffentlichkeit ermöglichte Partizipation - eben durch die Beteiligung vieler Köpfe - eine statistisch steigende Chance für die Entdeckung von Fehlern

157 | Vgl. Gerhardt, Öffentlichkeit 2012, 445-448. 490ff.

158 | Gerhardt, Öffentlichkeit 2012, 159; ferner: Gerhardt, Immanuel Kants Entwurf 1995.

159 | Vgl. Gerhardt, Öffentlichkeit 2012, 308-368.

160 | Gerhardt, Öffentlichkeit 2012, 277. 
sowie für die Berücksichtigung einer größeren Zahl von Gesichtspunkten. So erscheint die Öffentlichkeit als eine Vernunft, an der durch die Beteiligung Vieler so gut wie Alle Anteil nehmen, auch wenn es de facto so sein sollte, dass nur ein kleiner Teil mitwirken kann. ${ }^{161}$

Allein die Existenz einer räsonierenden Öffentlichkeit selber, allein ihr Funktionieren, verbürgt »Reflexion und Progression « der Öffentlichkeit. ${ }^{162}$

Eine größere Hochschätzung der Öffentlichkeit ist kaum möglich, wenn sie in ihrer reflexiven Kraft gegründet wird auf den Prozess der Prüfung, auf den Prozess wechselseitiger argumentativer Klärung wie auf die durch argumentative Kommunikation und Beratung erst ermöglichte breite Zustimmung aller. Kriterien für Wahrheit, für Geltung und Legitimität, die nicht in diesem Prozess selber bereits impliziert sind, von außen applizierte Maßstäbe für Progression im Sinne von Emanzipation und Kritik würden diesen Prozess der Öffentlichkeit hingegen nur torpedieren.

"Nach allem, was wir über die Ausbreitung des Wissens bei vielen Menschen wissen, erfolgt die kritische Prüfung schon von selbst - insbesondere dann, wenn für Widerspruch gesorgt ist. Also genügt es, Zugänglichkeit und Offenheit herzustellen. Folglich reichen die Kriterien der Freiheit und der Gleichheit aus, die jedem Teilnehmer an öffentlichen Diskursen zuzugestehen sind. Wer mehr will, wird weniger erreichen. Eine vorab zur Bedingung erhobene Regel der ,Deliberation steht in Gefahr, das preiszugeben, was die Öffentlichkeit bereits von sich aus so wertvoll macht, nämlich das freie, ungebundene Nachdenken eines jeden, der sich in seinen Interessen angesprochen fühlt. " ${ }^{163}$

Je mehr Menschen aktiv teilhaben am Prozess öffentlicher Verständigung, je intensiver und tragfähiger, je zielführender und partizipativer das aus diesen Prozessen öffentlicher Verständigung, Beratung und Entscheidung resultierende gesellschaftliche und politische Zusammenleben. Ein solcher Öffentlichkeitsbegriff ist gespeist von einem ungebrochenen Zutrauen in menschliche Verständigungsbereitschaft und Verständigungsfähigkeit. Schon das allein erfordert eine kritische Auseinandersetzung, nicht zuletzt aus religionspädagogischer Perspektive.

161 | Gerhardt, Öffentlichkeit 2012, 277.

162 | Gerhardt, Öffentlichkeit 2012, 278.

163 | Gerhardt, Öffentlichkeit 2012, 281; vgl. 492. 


\subsection{Kritik}

Gerhardt entwickelt einen sehr weiten Öffentlichkeitsbegriff. Bewusstseinsmäßig begründet, ist jede bewusste Tat, jedes Denken und jede Praxis bereits öffentlich. Bewusstsein steht nicht allein in intersubjektiven Konstitutionsbedingungen. Es ist immer schon öffentlich. Je nach Grad expliziter, reflexiver und institutioneller Verdichtung, je nach Ebene, Gegenstand und Ziel unterscheiden sich dabei eine gesellschaftliche und politische Öffentlichkeit. Gerhardt gelingt damit ein Öffentlichkeitsbegriff, der für alle offen ist. Öffentlichkeit ist das Forum der Freien und Gleichen, in der diese sich über gemeinsame Angelegenheiten und das common good verständigen. Öffentlichkeit ist also auf alle ausgerichtet, auf Freiheit, Gleichheit und Allgemeinheit. Der »Sinn der Öffentlichkeit« liegt darin, ${ }^{164}$ dass sich in ihr die Menschen als Subjekte erfahren und betätigen und aus diesen öffentlichen Verständigungsprozessen gesellschaftlicher Öffentlichkeit einen politischen Willen konstituieren. Menschen brauchen Gemeinschaft und Öffentlichkeit, um sie selbst zu sein, wie umgekehrt sich die Öffentlichkeit aus diesen Ressourcen individuellen Bewusstseins dauernd speist. In diesem Sinne ist Öffentlichkeit ubiquitär.

\subsubsection{Kriterien}

Doch woher sollen Kriterien gelungener Öffentlichkeit kommen? Was sind Maßstäbe für Beiträge im öffentlichen Gespräch? Sind alle zugelassen, auch die, die die Öffentlichkeit untergraben, die das Verständigungspostulat, das Freiheits- und Gleichheitspostulat negieren? Wo zieht man die Grenze? Oder kristallisiert sich - wie bei Gerhardt - die Wahrheit gleichsam prozedural heraus, ohne dass es vorgängige Beurteilungs- und Geltungsansprüche gäbe? Gerhardts Auseinandersetzung mit Habermas beruht ja letztlich auf seiner Ablehnung einer Normierung der Öffentlichkeit durch eine Außeninstanz. So zeigt sich die wertfreie, in einem universalisierbaren Sinne normativitätsabstinente Qualität der Öffentlichkeit bei Gerhardt. Sie ist funktional ausgerichtet.

"Der Sinn der Öffentlichkeit soll somit in der Funktion liegen, die sie notwendig übernimmt, sobald sie in einer Menge von Menschen wirksam wird und mit der Erwartung verbunden ist, ein die Menge als Ganze betreffendes Verhalten begünstigen zu können. Dazu muss sie nicht remanzipatorisch،, also mit bestimmten Erwartungen einer Befreiung von bestimmten Einschränkungen verbunden sein. Sie braucht auch kein sie intern auf Verfahren verpflichtendes normierendes Reglement. Es genügt vielmehr, dass sie mit Zielen verbunden ist, die ein einheitliches Handeln Vieler ermöglichen. “165

164 | Vgl. Peters, Der Sinn von Öffentlichkeit 2007.

165 | Vgl. Gerhardt, Öffentlichkeit 2012, $286 f$. 
Gewiss braucht sie normative Verbindlichkeiten. Die Öffentlichkeit muss mehr sein als ein bloßer Austausch von Ansichten und Meinungen. Aber diese Normativität ist eine pragmatische Normativität im Dienste einer funktionierenden Öffentlichkeit. »Schon der Transfer von Meinung und Wissen ist an die Normen von Grammatik und Semantik gebunden. Die Pragmatik gibt Regeln des tätigen Lebens vor und schafft die Grundlage für eine gegenseitige Normierung äußeren Verhaltens. Es ist dieses Ineinander von Kenntnissen, Meinungen, Ansprüchen, Forderungen und Verbindlichkeiten, welches die Öffentlichkeit so unverzichtbar für die politische Organisation einer >Menge von Menschen< macht. «166

Obschon reduziert aufs Pragmatische, traut Gerhardt dieser funktionalen Öffentlichkeit zu, immanente Vorkehrungen gegen Machtmissbrauch zu generieren.

„Wenn keine Vorkehrungen gegen Meinungsmonopole getroffen werden, wenn Kritik untersagt, missachtet oder ausgeschaltet wird, wenn Minderheiten kein Gehör finden und es keine Förderung des freien Urteils einzelner gibt, dann führt eine machtbesetzte Öffentlichkeit zum Verlust der Vielfalt und zum Verfall individueller Wirksamkeit. Doch man darf die Manipulation der Öffentlichkeit nicht mit ihr selbst verwechseln. Dass man sie missbrauchen kann, bestätigt nur, wie realitätssüchtig sie ist. “167

Gerade dort, wo Missbrauch und Gewalt zu befürchten sind, gehört Öffentlichkeit darum zu den »ersten Bedingungen ihrer erfolgreichen Abwehr «. ${ }^{68}$ Die Öffentlichkeit konterkariert gerade aus ihrer eigenen Logik der gleichberechtigten und freien Teilnahme aller jeden Versuch einer Okkupation der Öffentlichkeit durch Macht und Hegemonie.

"Öffentlichkeit ist und bleibt das, was sich aus den Ansichten Einzelner zusammensetzt. Ihre Funktion erfüllt sie nur, wenn sie alle verfügbaren Quellen nutzt und die Vielfalt der Stimmen wiedergibt. Sie hat Gegensätze auszuhalten und im unwahrscheinlichen Fall von Einstimmigkeit nach Widerspruch zu suchen. In diesem von ihr selbst begünstigten Klima kontroverser Prüfung vergrößert sie die Chance der Individuen, ihre eigene Position zu finden. ${ }^{169}$

166 | Gerhardt, Öffentlichkeit 2012, 311.

167 | Gerhardt, Öffentlichkeit 2012, 537.

168 | Gerhardt, Öffentlichkeit 2012, 541.

169 | Gerhardt, Öffentlichkeit 2012, 538. 


\subsubsection{Normativitätsschwäche}

So sehr ein solches Zutrauen in die immanente funktionale Kraft der Öffentlichkeit beeindruckt, so sehr wirft dies Fragen auf. Reicht eine solche normativ enthaltsame Öffentlichkeitstheorie aus, genügend Kräfte zu binden, um den postulierten Sinn der Öffentlichkeit mit Leben zu erfüllen? Woher sollen Motivationen, Impulse und Dynamiken kommen, sich in dieser Öffentlichkeit zu engagieren? Muss sie nicht über eine rein pragmatische Funktionalität hinaus einen normativen Horizont haben, der bewegen, der motivieren, der Bindung und Engagement für das common good erzeugen kann? Dieser kann unter den heterogenen Bedingungen der Spätmoderne wiederum nicht im strengen Sinne inhaltlich substantiiert und konkretisiert sein, weil eben eine heterogene Öffentlichkeit nicht auf das Ideal einer partikularen Gruppe verpflichtet werden darf. Aber bereits im Ansatz solche normativen Horizonte wie Emanzipation und Autonomie auszuschalten, die durchaus unter Bedingungen von Heterogenität universalisierbar sind, ${ }^{170}$ bedeutet, auf die Potentiale eines solchen Dynamisierungs- und Orientierungsimpulses zu verzichten.

Damit wird jedoch zugleich die Möglichkeit einer kritischen Instanz von außen in Abrede gestellt. Wie lässt sich die Kraft zur Kritik, zur bestimmten Negation generieren? Öffentlichkeit ist auf die Maßstäbe von Gleichheit und Freiheit angewiesen, die für schlechthin alle gelten. Diese Maßstäbe müssen auf Universalität tendieren und sie müssen dabei auch ihre eigene Genese und ihre eigene Durchsetzung kritisch reflektieren. Dies kann der Öffentlichkeit allein nicht überlassen bleiben. Denn dann bleibt lediglich der Ausweg, manipulativer und hegemonialer Öffentlichkeit ihren Öffentlichkeitscharakter schlechthin zu bestreiten, was aber im Widerspruch steht zu der von Gerhardt ansonsten vertretenen Ubiquität von Öffentlichkeit.

Diese Aporie lässt sich anhand seines Umgangs mit der im und durch den Nationalsozialismus geschaffenen Öffentlichkeit studieren. Dieser sei, so Gerhardt, lediglich eine uneigentliche Öffentlichkeit, weil hier bloß ein theatralischer Auftritt von Lautsprechern des Führers zugelassen war. ${ }^{171}$ Erkennbar wird dieser von Gerhardt beschrittene Ausweg angesichts des von ihm sonst so vehement vertretenen weiten Öffentlichkeitsbegriffs selbstwidersprüchlich, wird hier doch über den Eigentlichkeitsbegriff eine Exklusion vorgenommen, die ihrerseits nicht begründet ausgewiesen wird. Zudem unterschätzt dies die performative und damit machtstabilisierende Kraft solcher öffentlicher Versammlungen. ${ }^{172}$

Es bleibt gewiss bislang eine offene Frage, wie diese Maßstäbe zu gewinnen sind. Die deliberative Öffentlichkeitstheorie Habermas hat ihrerseits offene

170 | Vgl. Grümme, Heterogenität 2017, 89-170.

171 | Vgl. Gerhardt, Öffentlichkeit 2012, 235.

172 | Vgl. Butler, Anmerkungen zu einer performativen Theorie der Versammlung 2016. 
Flanken, die einen ungebrochenen Rekurs darauf schwierig machen. Machtund Exklusionsfragen scheinen dort nicht angemessen traktiert. Doch werden durch die dort vollzogenen Horizonte von Universalität und Reziprozität Kriterien gesetzt, an denen sich jede Öffentlichkeitstheorie abarbeiten müsste - auch und gerade im Rahmen einer Öffentlichen Religionspädagogik. Denn Öffentliche Religionspädagogik rekurriert doch ihrerseits mit der biblischen Botschaft und deren für alle geltende Gerechtigkeits- und Erlösungsverheißung in integraler Wese auf eine Tradition mit Universalitätsanspruch. Damit ist zwar noch nichts darüber ausgesagt, wie dieser universale Geltungs- und Wahrheitsanspruch präzise zu konturieren ist, ein Unterfangen, dass unter den Bedingungen heterogener Gegenwart im höchsten Maße anspruchsvoll ist. Doch unter dem Niveau eines für alle geltenden Begriffs der Öffentlichkeit kann das Potential einer Theorie der Öffentlichkeit in deren kritischer wie in deren normativ-orientierender Perspektive nicht eingeholt werden.

\subsubsection{Religionspädagogische Perspektive}

So lässt sich religionspädagogisch festhalten: Gerhardts Theorie einer ubiquitären Öffentlichkeit bietet erhebliche fruchtbare Möglichkeiten, an die eine Öffentliche Religionspädagogik anknüpfen und die sie auf ihre Weise religionspädagogisch zur Geltung bringen kann. Einige seien genannt:

Der Bruch mit einem solipsistischen Individualismus, der von einem isolierten Subjekt ausgeht, wie er elementar mit diesem Konzept der Öffentlichkeit und der Soziomorphie individuellen Bewusstseins verbunden ist, kann bereits ein zentraler anthropologischer Ansatzpunkt sein. Die intersubjektiven Konstitutionsbedingungen verantwortlicher und freier Subjektivität sind unverlierbarer Geltungs- wie Bestimmungsgrund Öffentlicher Religionspädagogik. Das Postulat von Freiheit, Gleichheit und Allgemeinheit verweist die Religionspädagogik darauf, dass sie alles daran setzen muss, dies tatsächlich Realität werden zu lassen. Bemühungen um Bildungsgerechtigkeit und um ihre politische Dimension bekommen von dorther nochmals zusätzliche Kraft und Orientierung. ${ }^{173}$

Die intrinsische Relevanz des Pädagogischen setzt Maßstäbe und liefert eine systematische Begründungsleistung von pädagogischen Prozessen für die Realisierung von Öffentlichkeit. Wenn alle bereits zur Teilnahme an gesellschaftlicher Öffentlichkeit je schon berufen sind, müssen sie dazu befähigt und motiviert werden. Hierin liegt die eminent pädagogische Leistung der Öf-

173 | Vgl. Grümme, Bildungsgerechtigkeit 2014; Grümme, Religionsunterricht und Politik 2009. 
fentlichkeit als der vermutlich wichtigsten »Instanz in der Selbsterziehung des Menschengeschlechts «. ${ }^{174}$

Gerhardts Unterscheidung von gesellschaftlicher und politischer Öffentlichkeit hilft, den Raum zu bestimmen, in dem sich Öffentliche Religionspädagogik öffentlich einschalten kann. Auch wenn noch zu diskutieren ist, ob auch deren Beiträge auf eine politische Öffentlichkeit hindrängen und dort ihren letzten Sinn finden, so hilft diese Unterscheidung zur kritischen Selbstreflexion ihrer Ausrichtung und drängt gegebenenfalls zur Ausdifferenzierung ihrer Artikulationsforen. Dazu gehört auch die Dialektik von >öffentlich< und >privat<. Diese kann für eine Öffentliche Religionspädagogik instruktiv sein. Damit ist die Spannung zwischen Religion und Gesellschaft, Religion und Staat angespielt. Religionspädagogik rekurriert im Wesentlichen auf eine comprehensive doctrine, die das ganze Leben bestimmen will und hierfür Sinn- und Orientierungsleistungen wahrnimmt. Von dieser Dialektik wäre zu lernen, dass die biblische Botschaft nicht einfach ins Private abzudrängen ist, weil genau dadurch die Freiheit der Subjekte in ihrer gesellschaftskritischen und wirklichkeitsverändernden Kraft unterminiert würde. Zugleich aber wäre diese Freiheit wiederum dadurch gefährdet, würde die Öffentlichkeit sich totalisierend in jede Nische drängen und das Private aushöhlen. ${ }^{175}$

Der hier aufscheinende Klärungsbedarf zwingt die Öffentliche Religionspädagogik zur weiteren Reflexion dieser Spannung im Öffentlichkeitsbegriff. Er verweist zugleich auf Desiderate bei Gerhardt.

Das Problem der diagnostizierten Normativitätsschwäche liegt freilich nicht allein darin, dass dieser lediglich einen funktionalen Öffentlichkeitsbegriff begründet. Die Schwierigkeit besteht ganz wesentlich darin, dass die mit diesem Öffentlichkeitsbegriff verbundenen Erträge, wie sie soeben benannt wurden, wieder relativiert werden. Ein emphatisch auf Freiheit, Gleichheit und Allgemeinheit abhebender Begriff der Öffentlichkeit muss sich selber Begründungen, Geltungsansprüche und normative Horizonte geben, die diese einzulösen im Stande sind. Eine Öffentliche Religionspädagogik weiß darum, dass sie sich nicht ungebrochen als eine emanzipatorische Pädagogik verstehen darf, um die relative Autonomie des Pädagogischen nicht auszuhebeln. Emanzipation als Leitbegriff gesellschaftlicher Selbstverständigungsprozesse kann nur in religionspädagogischer Reformulierung adaptiert werden. Aber so verstanden, kann Emanzipation der Öffentlichen Religionspädagogik jene normative Ausrichtung liefern, derer sie in ihrer diakonischen Ausrichtung an der Autonomie und Subjektwerdung der Menschen bedarf. ${ }^{176}$ Das aber über-

174 | Gerhardt, Öffentlichkeit 2012, 512; vgl. Schröder, Theologische Bildung 2017, 155.

175 | Vgl. Klöcker, Freiheit im Fadenkreuz 2017, 76-80;

176 | Vgl. Grümme, Öffentliche Religionspädagogik 2015, 5-75. 
steigt den Referenz- wie Geltungsanspruch eines funktionalistischen Öffentlichkeitsbegriffs. Hier bleibt er defizitär.

Überdies fehlt eine selbstreflexive Komponente, die den Öffentlichkeitsbegriff über sich selber aufklärt. Weder wird seine Genese noch seine Struktur so reflektiert, dass seine Mechanismen, seine Operationen und Semantiken kritisch in Augenschein genommen werden. Der Diskurs der Öffentlichkeit selber muss kritisch reflektiert werden können. Kurz: es fehlt eine diskursanalytische Selbstreflexion dieses Öffentlichkeitsbegriffs. Dies aber ist erforderlich, um unausgewiesene Unterstellungen und methodische wie hermeneutische Präsuppositionen $\mathrm{zu}$ analysieren und Exklusionen oder hegemoniale Verzerrungen freizulegen.

Angesichts dessen bleibt lediglich eine begrenzte Anschlussfähigkeit von Gerhardts Öffentlichkeitsbegriff für die Öffentliche Religionspädagogik.

Dies liegt wohl auch darin begründet, dass systemisch-strukturelle Perspektiven stark zurückgefahren werden. Diese aber bieten durchaus weiterführende Möglichkeiten für die Öffentlichkeitstheorie. Das jedenfalls wäre der Impuls, der von der Systemtheorie her gesetzt wird. Doch führt er die Religionspädagogik wirklich weiter? Nirgendwo wird die Systemtheorie in einer derart starken Verdichtung artikuliert wie bei Niklas Luhmann. Darum gilt es, diese im öffentlichkeitstheoretischen Interesse näher zu betrachten.

\section{3. ÖFFEntLichKeIt ZWISChen System UNd UMWELt: NikLAS LUHMANN}

Die Systemtheorie Niklas Luhmanns ist neben der Theorie Kommunikativen Handelns wahrscheinlich die dominante soziologische Großtheorie des 20. Jahrhunderts. Als »Supertheorie [...] mit universalistischen (und das heißt auch: sich selbst und ihre Gegner einbeziehenden) Ansprüchen« beinhaltet sie eine Öffentlichkeitstheorie, ${ }^{177}$ die für die Öffentliche Religionspädagogik durchaus von Interesse ist. Denn seziermesserscharf kann sie verschiedene Teilöffentlichkeiten durch die Logik der Relation von System und Umwelt voneinander abheben. Sind nicht Religion und Bildung solche Teilöffentlichkeiten? Kann so nicht die Religionspädagogik besser verstehen, wie sie an welchen Orten agieren muss? Der bildungstheoretische Ertrag solcher systemtheoretischer Positionen in Pädagogik und Religionspädagogik liegt für manche vor allem darin, »eine interessante Erweiterung unseres Alltagsverständnisses der Wirkungsprozesse im Bildungssystem « zu erzielen, ${ }^{178}$ indem sie »das Handeln gegenüber Umwelten und die Eigenlogik von Subsystemen betonen sowie das

177 | Luhmann, Soziale Systeme 1984, 19.

178 | Fend, Neue Theorie der Schule 2008, 134. 
Wissen im System berücksichtigen «. ${ }^{179}$ Aber wird nicht durch die vollzogene Außenperspektive des reinen Beobachters die innere Logik religionspädagogischer Prozesse verfehlt, die eben auf Intentionen und Praktiken von Subjekten beruhen und deshalb eine handlungstheoretische Perspektive nicht außer Acht lassen dürfen? Um in dieser Spannung weiter zu sehen gilt es, zunächst in kurzen Strichen die Systemtheorie zu rekonstruieren, ${ }^{180}$ um dann den dort mitschwingenden Begriff der Öffentlichkeit zu profilieren. Dies ist dann mit religionspädagogischem Erkenntnisinteresse kritisch zu diskutieren.

\subsection{Systemlogik statt Subjekt. Von der Kultivierung der Beobachterperspektive}

Die Systemtheorie ist eine Supertheorie, die den Anspruch einer Universalperspektive stellt. Sie will die Eigenlogik der Subsysteme daraufhin befragen, wie sie zum Erhalt und zum Funktionieren des Gesamtsystems beitragen und beigetragen haben. Für Luhmann kommt »ein soziales System [...] zustande, wenn immer ein autopoietischer Kommunikationszusammenhang entsteht und sich durch Einschränkung der eigenen Kommunikation gegen eine Umwelt abgrenzt. Soziale Systeme bestehen demnach nicht aus Menschen, auch nicht aus Handlungen, sondern aus Kommunikationen«, die Sinn produzieren. ${ }^{181}$ Luhmann entwickelt eine Theorie funktionaler Differenzierung, die sich freilich durch deren entwicklungslogische, funktional-evolutive Prägung von der systemtheoretischen Gesellschaftstheorie Talcott Parsons unterscheidet. ${ }^{182}$ Die Aufgabe der Systeme besteht in der Reduktion von Komplexität durch eine bestimmte Kommunikation mithilfe jeweiliger Codes. Elementar hierfür ist die Trennung von System und Umwelt, also dem Bereich, der nicht durch das System erfasst ist. Teilsysteme sind demnach selbstreferentiell, autopoietisch und emergieren aus sich selbst. Systeme sind für einander Umwelt. Von außen sind Systeme nicht zu antizipieren, nicht direkt zu beeinflussen, sondern allenfalls indirekt zu irritieren. Systeme halten ihre eigene Logik und Identität aufrecht und grenzen sich zugleich von der Umwelt und anderen Systemen ab durch je bestimmte Kommunikationsmedien und je bestimmte binäre Codes. So vollzieht sich das Funktionssystem Politik im Medium Macht, das der Wirtschaft im Medium Geld, das der Wissenschaft im Medium Wahrheit und das der Religion im Medium Glaube. Wirtschaft konstituiert sich durch den binä-

179 | Domsgen, Systemische Perspektiven 2010, 11; vgl. Domsgen, Religionsunterricht vom lernenden Subjekt aus 2012.

180 | Im Folgenden greife ich in stark veränderter Form auf Überlegungen aus Grümme, Öffentliche Religionspädagogik 2015, 62-74 zurück.

181 | Luhmann, Ökologische Kommunikation 1986, 269.

182 | Vgl. Joas, Knöbl, Sozialtheorie 2011, 355ff. 
ren Code Zahlen - Nicht-zahlen, Politik durch Macht - Keine Macht, Religion durch Immanenz - Transzendenz. In diesem struktur-funktionalistischen Gefüge werden die Akteure nicht als Subjekte vorgestellt, sondern wesentlich als »hochkomplexe sinnbenutzende Systeme, die füreinander nicht durchsichtig und kalkulierbar sind«, als »selbstreferentiell geschlossene « Wirklichkeiten, die für einander black boxes bilden. ${ }^{183}$ Allenfalls kann die Logik anderer Systeme durch die immer begrenzte Übersetzung in die je eigene binäre Logik des Binnencodes überhaupt wahrgenommen und damit nur höchst bedingt beeinflusst werden.

Diese Teilsysteme sind nur zu beobachten und beobachten einander. Elementar ist Luhmanns Unterscheidung verschiedener Beobachtungsebenen, durch die die Teilsysteme sich selbst konstituieren und vollziehen. Eine Beobachtung erster Ordnung besteht darin, dass sie anderes oder sich selbst beobachtet, indem sie es unterscheidet und bezeichnet. Doch sie sieht selbst nicht, wie sie sieht. Das Teilsystem »Politik« z.B. sieht die Wirklichkeit politisch, blendet aber damit notwendig andere Perspektiven aus. Eine Beobachtung zweiter Ordnung beobachtet diese Beobachtung beim Beobachten. Dies ist die Ebene der Wissenschaften. ${ }^{184}$ Beobachtung wird reflexiv und kritisch. Doch beides Mal geht die Beobachtung mit einer Lücke, mit einem blinden Fleck einher. Denn die »Unbeobachtbarkeit der Beobachtung ist die Bedingung der Möglichkeit von Beobachtung, die Bedingung des möglichen $\mathrm{Zu}$ griffs auf Gegenstände «. ${ }^{185}$ In dieser Beobachtung zweiter Ordnung kann zwar dieser blinde Fleck beobachtet und kritisiert, aber nicht beseitigt werden. Dies gilt ebenfalls für die Beobachtung dritter Ordnung. Diese beobachtet die Beobachtung zweiter Ordnung. Sie ist als Beobachtung der Wissenschaft auf einer wissenschaftstheoretischen Ebene angesiedelt. ${ }^{186}$

Gleichwohl wäre trotz dieser an personale Vollzüge erinnernden Semantik Luhmann missverstanden, würde man hier personale Kategorien berücksichtigen. Im Gegenteil: »Wir haben den klassischen Begriff des Subjekts durch den Begriff des Beobachters ersetzt, um klarzustellen, daß die Operationen, die das Medium Sinn produzieren und reproduzieren, in der realen Welt ablaufen und nicht in einer transzendentalen Sphäre außerhalb der Realität. « ${ }^{187}$ Folgerichtig wird das Subjekt bei Luhmann im Sinne der alteuropäischen Tradition als Subjekt der Aufklärung und Mündigkeit, als Subjekt der Freiheit, der Erkenntnis und des Gefühls verabschiedet. Die Perspektive des engagier-

183 | Luhmann, Soziale Systeme 1984, 156; vgl. Füllsack, Die Habermas-LuhmannDebatte 2010, $168 f$.

184 | Vgl. Luhmann, Die Wissenschaft der Gesellschaft, 1990, 274.

185 | Luhmann, Die Religion der Gesellschaft 2002, 30.

186 | Vgl. Rothgangel, Religionspädagogik im Dialog I. 2014, $275 \mathrm{ff}$.

187 | Luhmann, Die Religion der Gesellschaft 2002, 28. 
ten Teilnehmers an gesellschaftlichen, politischen, kulturellen oder religiösen Prozessen wandelt sich in die des äußeren, distanzierten Beobachters. ${ }^{188}$

Dies wird im Begriff der Kommunikation deutlich. Sie ist nicht die Interaktion zwischen handelnden Subjekten. Es sind nicht Menschen, die miteinander kommunizieren. Die jeweiligen Teilsysteme werden nicht aus Menschen und deren Interaktionen konstituiert. »Alle Begriffe, mit denen Kommunikation beschrieben wird, müssen daher aus jeder psychischen Systemreferenz herausgelöst und lediglich auf den selbstreferentiellen Prozeß der Erzeugung von Kommunikation durch Kommunikation bezogen werden. ${ }^{189}$ Der Mensch »kann nicht kommunizieren; nur die Kommunikation kann kommunizieren $\ll .{ }^{190}$ Dies verändert das Kommunikationsverständnis radikal. Es geht nicht darum, die Intention eines Sprechers zu verstehen. »Vielmehr ist Kommunikation als ein auf drei Ebenen (Information, Mitteilung, Verstehen) ablaufender Prozess aufzufassen, der von den Intentionen der Kommunikationsteilnehmer unabhängig ist, der auf Anschlussfähigkeit, auf das Weiterlaufen der am Prozess beteiligten sozialen Systeme abzielt. Insofern ist nicht Verständigung das Ziel, sondern Verstehen, d.h. eine Fortsetzung kommunikativer Prozesse unter Berücksichtigung geltender Regeln und Erwartungsstrukturen. «191

\subsection{Implikationen}

Mit dieser systemkonstituierenden Bedeutung des distanzierenden Beobachtens wird neben dem Subjektbegriff der des Handelns radikal verändert. Wie der Subjektbegriff ist auch der Handlungsbegriff nur einer des Zuschreibens, nicht der autonom geleiteten Verantwortung: »Handlungen werden durch Zurechnungsprozesse konstituiert «. ${ }^{192}$ Nicht Handlungen, sondern strukturelle Systemkommunikationen handeln. Aber dies kann eben nicht die innere Logik des Teilsystems überschreiten. Wenn sich die Teilsysteme lediglich wechselseitig beobachten und höchstens vermittelt durch Übersetzungen in die eigene Kommunikation und Codierung einander irritieren können, dann geht ein übergreifender Einfluss auf andere Teilsysteme verloren. Beispielsweise werden so gesellschaftstheoretische Begründungen einer politischen Reglementierung von Wirtschaftsprozessen undenkbar. Überhaupt nur einen gesamtgesellschaftlichen Willen anzustreben, Wirtschaft politisch zu steuern

188 | Vgl. Ladwig, Moderne politische Theorie 2013, 217.

189 | Luhmann, Die Wissenschaft der Gesellschaft 1990, 24.

190 | Luhmann, Die Wissenschaft der Gesellschaft 1990, 31.

191 | Müller-Doohm, Jürgen Habermas 2014, 680.

192 | Luhmann, Soziale Systeme 1984, 228; vgl. Joas, Knöbl, Sozialtheorie 2011, 386. 
oder Umweltprobleme zu regulieren, wird damit als »schlicht lächerlich und zum Scheitern verurteilt« angesehen. ${ }^{193}$

Armin Nassehi, ein Schüler Luhmanns, bringt diese Abhängigkeit wie Selbstständigkeit gesellschaftlicher Teilsysteme gesellschaftstheoretisch präzise auf den Punkt und sei deshalb ausführlich zitiert:

"In diesem Sinne ist der gesellschaftliche Modernisierungsprozess als interner Emanzipationsprozess zu verstehen, in dem die funktionalen Logiken auf der einen Seite unabhängig voneinander werden, aber gerade darin auf der anderen Seite hochgradig voneinander abhängig werden. Wie sollte die Wirtschaft ohne rechtliche Vertragssicherheit und die kollektive Bindungswirkung politischer Entscheidungen auskommen, die Politik ohne eine funktionierende Geldwirtschaft und ein sanktionsbewehrtes Rechtssystem, wie Wissenschaft oder Kunst ohne ein funktionierendes Bildungssystem usw.? Was das Stück Gesellschaft bisweilen zu einem Drama macht, ist freilich die Tatsache, dass diese unterschiedlichen , Rollen ' weder von einem zentralen Regisseur aufeinander abgestimmt werden noch ein Skript haben, an dem sie sich abarbeiten können. Wenn man dieses Bild weiter bemühen will, spielt auf der Bühne Gesellschaft eher eine Laienspielschar, die, zur Echtzeit gezwungen, weder Probe- noch Korrekturmöglichkeiten hat, sondern ihre Struktur gewissermaßen improvisieren muss und dennoch zu Selbststabilisierungen auch im Hinblick auf die Wechselseitigkeit der operativ voneinander unabhängigen Funktionssysteme kommt. Es ist fundamental eine Gesellschaft der Gegenwarten." ${ }^{194}$

Es gibt wegen dieser funktionalen Differenzierung und der evolutiven, höchst kontingenten Wandelbarkeit der Teilsysteme keine integrierende Perspektive, keine Steuerungsmöglichkeit, keinen gesamtgesellschaftlichen Blick mehr. Mehr noch: Luhmann plädiert dafür, ebenso wie das alteuropäische Erbe der Anthropologie die Idee der Vernunft in der Tradition der Aufklärung »ins Museum für soziologische Altertumskunde abzustellen «. ${ }^{195}$ Ein moralischer Anspruch etwa, der für Politik gelten würde, wäre nur im Code der Politik, eine religiöse Wahrheit, die für Wirtschaft Relevanz hätte, lediglich im Code der Wirtschaft artikulierbar.

Mit dieser Zurückweisung von systemübergreifenden Ansprüchen, von Werten wie Gerechtigkeit und einer übergreifenden Wahrheitsperspektive artikuliert sich Luhmanns Systemtheorie »dezidiert nicht-normativ, ja geradezu antinormativ «. ${ }^{196}$ Luhmann hält folgerichtig eine Verständigungsrationalität für unbegründet. In kritischer Absetzung zu Habermas handlungstheoreti-

193 | Joas, Knöbl, Sozialtheorie 2011, 388.

194 | Nassehi, Gesellschaft der Gegenwarten 2011, 65.

195 | Luhmann, Die Wissenschaft der Gesellschaft 1990, 282.

196 | Joas, Knöbl, Sozialtheorie 2011, 366. 
schem Konzept kommunikativer Vernunft könne man nicht »aus der Sprache selbst eine Idealnorm des Bemühens um Verständigung « ableiten. ${ }^{197}$ Es war allerdings seinerseits Jürgen Habermas der hierin neben einem zweckrationalen, technokratischen Reduktionismus zugleich einen Ausfall gesellschaftskritischer Momente festgestellt hat. Luhmanns Systemtheorie hat eine Tendenz zur Affirmation des Bestehenden. ${ }^{198}$ Jenseits einer ironisierenden Distanz über gesellschaftliche Alternativen, über moralische, politische und rechtliche Steuerungsmechanismen des Ganzen überhaupt nur nachzudenken, diese Möglichkeit wird bereits auf theoretischer Ebene bestritten. ${ }^{199}$

\subsection{Systemtheoretische Öffentlichkeit}

Will man Luhmanns Begriff der Öffentlichkeit angemessen verstehen, muss man ihn eintragen in das Gesamtgefüge seiner Systemtheorie und der dort im Lichte der Modernisierungsprozesse stattfindenden funktionalen Ausdifferenzierungen verschiedener Teilsysteme. Allerdings räumt Luhmann dem Öffentlichkeitsbegriff keine dominante Rolle ein. Als Konzept hat er nie einen festen Ort in seinem Begriffsarsenal gefunden. Seine expliziten systematisierenden Ausführungen bleiben eher selten und tauchen vor allem im Kontext der Kommunikation durch neue Medien als einem neuen Teilsystem ab Mitte der 1970er Jahre auf. ${ }^{200}$ Manche meinen gar, der Öffentlichkeitsbegriff würde Luhmann nie ins systemtheoretische Konzept passen. ${ }^{201}$ Zwar hält er an manchen Stellen die Öffentlichkeit für den eigentlichen Souverän, ${ }^{202}$ doch trivialisiert er diese an anderen Stellen auf zufällige Begegnungen als »Kommunikation au trottoir « ${ }^{203}$ Diesen Begegnungscharakter von Öffentlichkeit nehmen Gerhards und Neidhardt zum Anlass, daraus bei ihm das Modell einer »Episodenöffentlichkeit« abzuleiten. ${ }^{204}$

Die Tatsache einer nur geringen systematisierten Ausarbeitung freilich hat wohl vor allem damit zu tun, dass Luhmann in dieser Form der Öffentlichkeit

197 | Luhmann, Die Gesellschaft der Gesellschaft 1998, 201.

198 | Vgl. Füllsack, Die Habermas-Luhmann-Debatte 2010, 154-181.

199 | Vgl. Joas, Knöbl, Sozialtheorie, 2011, 390.

200 | Vgl. Marcinkowski, Politische Öffentlichkeit 2002, 97; Kojima, Die Öffentlichkeiten der Erziehung 2015, 76,.

201 | Vgl. Gerhards, Neidhardt, Strukturen und Funktionen moderner Öffentlichkeit 1990, 5.

202 | Vgl. Luhmann, Ökologische Kommunikation 1986, 175.

203 | Luhmann, Ökologische Kommunikation 1986, 75; ähnlich 225; Vgl. Gerhards, Neidhardt, Strukturen und Funktionen moderner Öffentlichkeit 1990, 5ff.

204 | Gerhards, Neidhardt, Strukturen und Funktionen moderner Öffentlichkeit 1990, 23. 
noch jenes alteuropäische Subjekt und dessen Räsonieren in bürgerlichen Zirkeln und Salons wiedererkannte, dem er aber in den Prozessen der Moderne längst den Abschied gegeben hat. Es erinnert ihn an »humane Vorstellungen der Aufklärungszeit«, doch in hoch ausdifferenzierten Gesellschaften könnten sich Menschen nicht mehr »als Menschen begegnen und annehmen «. ${ }^{205}$ Wenn also von Öffentlichkeit in impliziter wie in expliziter Form die Rede ist, dann allenfalls in der systemtheoretischen Logik verschiedene Teilsysteme. Öffentlichkeit wird hier rein funktional analysiert hinsichtlich ihrer Relevanz für die Integration jeweils der einzelnen Teilsysteme sowie für deren Zusammenhalt und Abgrenzung voneinander. Darum kann Öffentlichkeit nur verstanden werden in der bereits erläuterten Logik von System und Umwelt. Bereits durch diese Verortung ist der jeder Normativität entledigte, streng funktionalistische Charakter von Luhmanns Öffentlichkeitsbegriff evident. Größer könnte die Differenz zur Theorie deliberativer Öffentlichkeit kaum sein.

Öffentlichkeit dient demnach der Kommunikation der verschiedenen Teilsysteme miteinander. Sie ist kein eigenes Teilsystem. Sie ist selber gerade nicht thematisch gebunden. Vielmehr hilft sie, dass die anderen Teilsysteme einander nach der Logik der verschiedenen Ebenen der Beobachtung beobachten können. In medialer Vermittlung beobachten sie sich im Forum der Öffentlichkeit selbst und zugleich die anderen Teilsysteme, wie diese sich beobachten, ohne die Intentionen, Absichten und Gründe der Beobachter ergründen zu können. So werden durch diese Fremd- und Selbstbeobachtung Grenzen gezogen und zugleich die Möglichkeit von Kommunikation gebahnt. Öffentlichkeit situiert sich zwischen den Teilsystemen, die einander Umwelten sind, auf den Ebenen der Beobachtung erster und zweiter Ordnung. Deshalb kann dieses Öffentlichkeitskonzept als »Spiegelmodell« bezeichnet werden. ${ }^{206}$

mErst im Umgang mit dieser Selbsterfahrung im Spiegel der Öffentlichkeit gewinnt ein soziales System die interne Fähigkeit zur Variation und Selektion, zur differentiellen Reproduktion, die sie in einer alle Außenseiten laufend verändernden Gesellschaft braucht - und die die Gesellschaft braucht, um sich als Differenzierungsprinzip sozialer Systemen zu erhalten, die ebenso indifferent wie sensitiv auf das reagieren, was sich in ihrer Öffentlichkeit abspieltı. Durch Beobachtung zweiter Ordnung wird den jeweiligen Systemen ermöglicht, Selbst- und Fremdreferenz zu unterscheiden und sich damit ein semantisches Einheitsbild von den Grenzen der eigenen Handlungsmöglichkeiten zu machen. "207

205 | Gerhardt, Öffentlichkeit 2012, 241.

206 | Kojima, Die Öffentlichkeiten der Erziehung 2015, 85; vgl. Luhmann, Die Wissenschaft der Gesellschaft, 1990, 181.

207 | Kojima, Die Öffentlichkeiten der Erziehung 2015, $78 f$. 
Zwei Beispiele seien zur Verdeutlichung genannt:

Vom Teilsystem >Politik aus gedacht, ist Öffentlichkeit eine intermediäre Größe, die zwischen den Ansprüchen des Teilsystems Politik, den Bürgern und den Ansprüchen anderer Teilsysteme vermitteln soll: »Politik kann über Öffentlichkeit die Themen und Meinungen der Gesellschaft beobachten und muß darauf reagieren. Die Gesellschaft kann umgekehrt über Öffentlichkeit die Politik beobachten und kontrollieren, ob deren Output mit ihren Interessen übereinstimmt. ${ }^{208}$

Im Kontext der Massenmedien zeigt Öffentlichkeit ihre funktionale Relevanz als »ein allgemeines gesellschaftliches Reflexionsmedium, das die Unüberschreitbarkeit von Grenzen und, dadurch inspiriert, das Beobachten von Beobachtungen registriert «. ${ }^{209}$ Ihre Aufgabe ist es folglich, Kommunikation an je neuen, durch die Massenmedien vermittelten Themen zu organisieren und so eine gesellschaftliche Kommunikation zu ermöglichen. ${ }^{210}$

Themen sind für Luhmanns Öffentlichkeitsbegriff nicht im Rahmen der Kategorien >wahr< oder >falsch< relevant. Sie sind Vehikel, die »ein gemeinsames Sichbeziehen auf identischen Sinn ermöglichen. [...] Die Funktion besteht nicht in der Richtigkeit der Meinungen, sondern in der Unsicherheit absorbierenden, Struktur gebenden Leistung von Themen «. ${ }^{211}$ Öffentlichkeit ordnet Themen, bringt neue ein, streicht welche und schafft auf diese Weise in der Unübersichtlichkeit eine gewisse Kohärenz im gesellschaftlichen Ganzen.

Somit wird deutlich, dass Öffentlichkeit bei Luhmann auf verschiedenen Ebenen situiert wird. Einerseits gehört es zur Logik der einzelnen Teilsysteme, dass diese in der Absetzung von anderen Teilsystemen und der im Zuge eigenen Selbstreferenz eigene Teilöffentlichkeiten bilden.

"Öffentlichkeit kann einerseits jeder Umwelt (Subsystem) angehören, ssei es ein Unternehmen oder eine Universität, sei es ein Altersheim oder ein Kindergarten, sei es eine politische Partei, eine Sekte oder ein Fußballverein`. Andererseits lässt sich Öffentlichkeit innerhalb (oder am Rand) jedes funktionalen Teilsystems wie Rechts-, Wirtschafts-, Religions-, Wissenschafts- oder Erziehungssystem einordnen, wie sich am Beispiel des politischen Systems zeigen lässt. Aus dieser Perspektive ergibt sich eine Vielzahl von Öffentlichkeiten in der Gesellschaft. “212

208 | Gerhards, Neidhardt, Strukturen und Funktionen moderner Öffentlichkeit 1990, 12.

209 | Luhmann, Die Realität der Massenmedien 1996, 184.

210 | Vgl. Kojima, Die Öffentlichkeiten der Erziehung 2015, 223-228.

211 | Luhmann, Politische Planung 1971, 13.15.

212 | Kojima, Die Öffentlichkeiten der Erziehung 2015, 80. 
Auf der anderen, die Teilsysteme übergreifenden Ebene, auf der die Teilsysteme sich in Selbstreferenz und Fremdreferenz voneinander abgrenzen, gewinnt der Öffentlichkeitsbegriff eine andere Funktion. Hier liegt sie »in der Integration und der Neutralisierung von aus engeren Teilsystemen der Gesellschaft stammenden Rollenanforderungen ${ }^{213}$ Es ist vor allem die Ebene der Zivilgesellschaft, in der die Grenzen zwischen Staat, Öffentlichkeit und Privatheit und damit das Verhältnis der diversen Teilöffentlichkeiten vollzogen werden.

Öffentlichkeit kann damit als eine Konkretisierung der Systemtheorie in Bezug auf deren kommunikationstheoretisches Muster gesehen werden. Die zentrale systemtheoretische Funktion der Öffentlichkeit nach Luhmann besteht in der Ermöglichung der Selbstbeobachtung einer Gesellschaft und damit der Sicherung ihres, in einem hoch fluiden Prozess je neu zu erringenden Zusammenhalts. ${ }^{214}$ Es ist ein streng normativ abstinentes Konzept, rein deskriptiv angelegt, funktional ausgerichtet. ${ }^{215}$ Intentionen von Subjekten werden in ihrer Relevanz negiert.

Damit aber werfen sich gerade aus der Sicht der Öffentlichen Religionspädagogik Fragen auf, die an die Wurzel der Systemtheorie gehen.

\subsection{Kritik}

Es ist hier nicht der Anspruch, die Systemtheorie Luhmann in ihrer außerordentlichen, in gewisser Weise selbst autopoietischen, selbstreferentiellen und von außen undurchdringlichen wie unübersehbaren Komplexität auch nur in ihren Grundzügen rekonstruiert zu haben. Deshalb ist deren umfassende Kritik hier nicht möglich, wohl aber eine kritische Auseinandersetzung.

Eine Würdigung müsste sicher hervorheben, dass Luhmann auf mehrere wichtige Faktoren aufmerksam macht: die Eigenlogik der funktional ausdifferenzierten Teilsysteme als Moment der Moderne; die Resistenz dieser Teilsysteme gegenüber überspannten Steuerungsprozessen; die strukturell-systemischen Begründungen und Bedingungen menschlicher Praxis. Menschliche Praxis kann nicht allein aus der Perspektive subjektiver, handlungsleitender Intentionen gedacht werden. Sie steht in kontextuellen Gefügen und unter Einfluss menschlicher Handlungen, die sich zu Strukturen des Handelns verdichtet haben. Gerade die Einsicht in solche makrosoziologische Steuerungsmechanismen und Organisationsbedingungen menschlicher Existenz führte (entgegen allerdings der Intention Luhmanns) auch zur Integration systemtheoretischer Elemente in die Handlungstheorie. ${ }^{216}$

213 | Kojima, Die Öffentlichkeiten der Erziehung 2015, 242.

214 | Vgl. Marcinkowski, Politische Öffentlichkeit 2002, $113 \mathrm{ff.}$

215 | Vgl. Kojima, Die Öffentlichkeiten der Erziehung 2015, 85ff.

216 | Vgl. Fresacher, Kommunikation 2006, 251-303. 
Gleichwohl kristallisieren sich vielfältige Probleme heraus, die hier nicht im Einzelnen erläutert werden können. Aus religionspädagogischer Sicht erscheinen Einwände nachvollziehbar, die Hauke Brunkhorst gerade aus dem Bemühen heraus vorbringt, die Relevanz der Systemtheorie für die Erziehungswissenschaft auszuloten.

\subsubsection{Subjekt}

Das eine Problem könnte man das Subjektproblem nennen. Luhmanns Versuch, nicht Personen, Subjekte und deren Interaktionen, sondern Systemkommunikationen als Referenzpunkte zu nehmen, verabschiedet den Menschen als verantwortliches freies Subjekt. Zwar verwendet Luhmann alltagssprachliche Begriffe wie Handlung, Subjekt, Reflexion, Zweck, Sinn. Auch hat er sich seit spätestens der 1980er Jahre um eine stärkere Würdigung des Subjektbegriffs bemüht. Doch, so Brunkhorst mit Rekurs auf Charles Taylor, diese Begriffe ohne Rekurs auf den in der Alltagssprache »sedimentierten, unausrottbar anthropozentrischen Sinn dieser Begriffe $«$ zu verwenden, entkleidet diese Begriffe »jedes verständlichen Sinnes. Da aber auch ein Systemtheoretiker keine sinnlose Sprache wollen kann, liegt die Annahme nahe, daß die Rede von Systemen, die Strategien verfolgen, die Zwecke haben, die sich selbst reflektierend zum Thema machen, die etwas Sinnvolles tun wie Komplexität reduzieren, ein heimliches Subjekt hat; und wenn es nicht das alteuropäische menschliche ist, dann muß es ein allgegenwärtiger Geist, ein >Gespenst im System sein. ${ }^{217}$ Liest man Systemtheoretiker der Gegenwart, so hat man den Eindruck, eher stehe die Logik und Semantik von Computertechnik und Kybernetik Pate als die der Handlungstheorie. ${ }^{218}$ In ähnlicher Weise hat Hans Joas diesen Subjektverlust kritisiert. ${ }^{219}$

\subsubsection{Differenz}

Das zweite Problem könnte man das Differenzproblem nennen. Wenn eine Systemtheorie sich in dem Maße radikalisiert, dass sie die Komplexität und Autonomie der jeweiligen Teilsysteme erhöht, dabei aber die lebensweltlichen Ressourcen der Subjekte unterspült, dann gefährdet sie die Gesellschaft insgesamt. Denn eine Systemautonomie ist nicht dasselbe wie eine Subjektautonomie, die nur durch lebensweltliche Einbindung zu haben ist. Erziehungswissenschaftlich ist dies destruktiv. Reflexive Autonomie als Ziel von Erziehung würde durch eine »nur mehr funktionalistisch reflektierte Erziehungswirk-

217 | Brunkhorst, Systemtheorie 2007, 1504; vgl. Oelkers, Tenorth, Pädagogik, Erziehungswissenschaft und Systemtheorie, 1987; Lenzen, Irritationen des Erziehungssystems 2004.

218 | Vgl. Nassehi, Die letzte Stunde der Wahrheit 2017, 66-80.

219 | Vgl. Joas, Knöbl, Sozialtheorie 2011, 375-390. 
lichkeit [...] verfehlt. Nur wenn sie dieses Ziel in ihren (Selbst-)Thematisierungen festhält, kann in ihr zwischen System- und Subjekt-Autonomie unterschieden werden. «220

Damit aber geht ein ungeschichtlicher Zug einher. In dem Begriffsgefüge Luhmanns ist nicht hinreichend ausweisbar, inwieweit die Ausdifferenzierungsprozesse selbst geschichtlicher Natur und damit das Resultat politischer wie gesellschaftlicher Prozesse sind. Einmal ausdifferenziert, ist es systemtheoretisch nur schwer vorstellbar, dass die autonomen, für einander Umwelten darstellenden Teilsysteme wieder ihre Codes und Programme und damit ihre Teilautonomie verlieren könnten. Pierre Bourdieu hält deshalb die Rede von sozialen Systemen für »zu objektivistisch«. Sie blendet die »Rolle von Macht, Herrschaft und Ungleichheit aus « und unterschätzt »folglich systematisch Spannungen und Konflikte im Alltag «. ${ }^{221}$ Das soziale und politische Feld als Kampf um Ressourcen und Positionen kann damit ebenso nicht hinreichend gewürdigt werden wie der Kolonisierungsdruck bestimmter Teilsysteme auf andere systematisch unterschätzt wird. »Eine einmal eingerichtete autonome Kunst erhält schon aufgrund ihrer autopoietischen Logik und Dynamik ihre Eigenständigkeit.« Für Bourdieu hingegen kann externer Druck auf das Kunstfeld und interne Anstöße im Feld etwa durch Ökonomisierung oder Politisierung die errungene Autonomie auch wieder »unterhöhlen«. ${ }^{222}$

\subsubsection{Wahrheit}

Dies führt drittens zum Normativitäts- und Wahrheitsproblem. Für Herbert Schnädelbach liegt es nahe, Luhmanns »subjektloses Verständnis von >Rationalität< als Ergebnis eines metaphorischen Fehlschlusses anzusehen, der auch vorliegt, wenn vom Denken von Computern oder vom Handeln von Automaten die Rede ist«. Deshalb scheidet Luhmanns Konzept der Systemrationalität »aus der Erbengemeinschaft der klassischen Philosophie der Vernunft aus«.223 Für diese These spricht, dass sich Luhmanns Systemtheorie aus der Logik ihrer Begründungen heraus eines Wahrheitsanspruches enthält, der über die innere Binnenlogik eines Teilsystems hinausgeht. Jenseits der Irritationen zwischen den für einander Umwelten bildenden sinnkonstruierenden Binnenkommunikationen, jenseits der vielschichtigen Beobachtungsebenen und deren Selbstbezugs (»re-entry«) sind universale normative Orientierungen unmöglich. Statt um universale Wahrheit geht es um »Schnittstellenmanagement« zwischen den einzelnen Teilsystemen, ${ }^{224}$ das im wesentlichen auf der Bearbeitung

220 | Brunkhorst, Systemtheorie 2007, 1505.

221 | Müller, Pierre Bourdieu 2014, 75.

222 | Müller, Pierre Bourdieu 2014, $223 f$.

223 | Schnädelbach, Vernunft 2007, $138 f$.

224 | Nassehi, Die letzte Stunde der Wahrheit 2017, 67 
von Übersetzungskonflikten beruht. Dieser Übersetzungskonflikt ist freilich »nicht prinzipiell lösbar, weil es zwischen den unterschiedlichen Logiken so etwas wie eine letztgültige Übertragung nicht geben kann«. Statt eine letzte Wahrheit zu imaginieren müssen die Akteure »aktiv mit der Perspektivendifferenz der Gesellschaft umgehen lernen «. ${ }^{225}$

Ein universaler Wahrheitsanspruch ist nicht nur nicht denkbar. Im Lichte der zentralen Rolle des Kontingenzbegriffs in der Systemtheorie Luhmanns löst dieser sich auf in die Volatilität begründungsentlasteter und normativitätsresistenter Viabilität. Damit aber bekommt die Systemtheorie eine affirmative Tendenz. Die Unterstellung, dass eine reine Beschreibung der Praxis möglich sei ohne Beteiligung an ihr, ist selbst bereits eine Praxis und damit gerade angesichts des Eindrucks zunehmender Entpolitisierung und des geringer werdenden Vertrauens in die Veränderbarkeit gesellschaftlicher und politischer Prozesse legitimationsbedürftig. »Den rein deskriptiv-beobachtenden Blick auf Gesellschaft gibt es nicht, so wie es auch nicht ausreicht, nur von Systemen zu sprechen. ${ }^{226}$

\subsubsection{Luhmann und die Öffentliche Religionspädagogik}

Diese Defizite machen es einer Öffentlichen Religionspädagogik nicht leicht, auf den systemtheoretischen Öffentlichkeitsbegriff zurückzugreifen. Einerseits kann er die Binnenlogik verschiedener Systeme würdigen und durch die Dialektik verschiedener Beobachtungsebenen präzise analysieren. Dies wäre insbesondere für die Vernetzung und Differenzierung verschiedener Lernorte des Glaubens und seiner Öffentlichkeit relevant. Auch würde dies die Eigenlogik etwa religiöser Bildung in der Familie im Unterschied zum Setting des RU in einem bestimmten Kontext (wie nicht zuletzt in dem weitgehend säkularisierten Kontext Ostdeutschlands im Unterschied zu dem in Westdeutschland) erst angemessen formulieren helfen. Ein solcher Öffentlichkeitsbegriff, artikuliert im Teilsystem Erziehung und Bildung, erlaubt es zudem, die spezifische Logik des Systems »Religionsunterricht« im Unterschied insbesondere zur »Umwelt« anderer Fächer, in der Binnenstruktur seiner Teilsysteme wie »Schüler« und »Lehrer«, in der Logik des Systems »Schule« oder auch dem der »Gesellschaft« präzise wie auch deren Vernetzung zu analysieren. ${ }^{227} \mathrm{Zu}$ dem kann ein Vorteil die in der Dialektik von System-Umwelt begründete Widerlegung einer »kausalen Durchgriffserwartung « sein. ${ }^{228}$ Dies verhindert

225 | Nassehi, Die letzte Stunde der Wahrheit 2017, $199 \mathrm{f}$.

226 | Striet, Sich selbst als geworden beschreiben wollen 2014, 17.

227 | Vgl. Domsgen, Grundlagen und Ziele einer systemischen Religionspädagogik. 2009, 18; Domsgen, Chancen und Grenzen 2009, 142.

228 | Scheunpflug, Mette, Anregungen aus Sicht einer systemtheoretischen Erziehungswissenschaft 2007, 41. 
aus der inneren Struktur der Systemtheorie heraus die überhitzte Semantik von Reform und Veränderbarkeit und hilft unterhalb der Ebene des Systems »Schule« hinaus bei der reflexiven Bearbeitung des Technologiedefizits im Religionsunterricht. ${ }^{229}$ Auf der wissenschaftstheoretischen Ebene bringt ein solcher Öffentlichkeitsbegriff für manche erstmals die tragfähige Basis, die diversen Teilöffentlichkeiten der verschiedenen Wissenschaften, mit denen die Religionspädagogik als Verbundwissenschaft notwendig zusammenarbeiten muss, in ein Verhältnis der angemessenen Kooperation zu bringen. Dieses muss normativ enthaltsam bleiben, um einen Dialog der Wissenschaften und der mit ihnen unauflöslich verbundenen Weltzugänge und Weltbilder erst möglich zu machen, und zugleich Eigenstand und Kommunikabilität der verschiedenen Wissenschaften zu begründen. ${ }^{230}$ Doch genau hier werden die Vorbehalte virulent.

Eine Öffentliche Religionspädagogik kann nicht über die Subjektschwäche hinwegsehen - und dies nicht allein aus pädagogischen und religionspädagogischen Gründen. Auch wenn in Luhmanns Systemtheorie die Logik der verschiedenen Beobachtungsebenen vom Wechsel der Teilnehmer- und Beobachterperspektive lebt, könnte man doch fragen, ob nicht begriffslogisch die Beobachterperspektive ein so großes Gewicht erhält, dass die erfahrungsbezogenen, personalen, hermeneutischen und damit zumindest normativitäts- und wertbezogenen Aspekte zurückgedrängt werden. Diese sind wesentlich mit einer Teilnehmerperspektive verbunden, die indessen angesichts der Subjektschwäche und des handlungstheoretischen Defizits nicht mehr angemessen denkbar sind. Für den überkommenen Religionsunterricht konfessioneller wie konfessionell-kooperativer Prägung haben diese freilich elementare Relevanz.

Aber mehr noch: Nicht zuletzt um eines angemessenen Öffentlichkeitsbegriffs willen muss die Öffentliche Religionspädagogik tiefe Vorbehalte anmelden. Die Verharmlosung der Rolle der »Handlungssubjekte im Interaktionsprozess und ihre Bedeutung im Entstehungsprozess sozialer Systeme« unterläuft die Qualität der Öffentlichkeit selber. ${ }^{231}$ Luhmann sieht durchaus, dass der Einzelne seine Individualität als Mensch ja erst in der politischen Öffentlichkeit artikuliert. Nur sei eben dieses subjektzentrierte Menschenbild der Aufklärung in der Moderne obsolet geworden - und damit ein solcher subjektbezogener, auf die Interaktionen der Subjekte abhebender Öffentlichkeitsbegriff. Insofern aber, so das Fazit Volker Gerhardts, verfehlt Luhmanns Systemtheorie »in ihrer wohltuend abkühlenden Sicht auf gesellschaftliche

229 | Vgl. Scheunpflug, Mette, Anregungen aus Sicht einer systemtheoretischen Erziehungswissenschaft 2007, 46-50; Büttner, Scheunpflug, Eine Einleitung in das Buch 2007, 11.

230 | Vgl. Rothgangel, Religionspädagogik im Dialog I. 2014, 16-19.268-275.

231 | Fend, Neue Theorie der Schule 2008, 135. 
Prozesse die Pointe der Öffentlichkeit«. ${ }^{232}$ Da sie darauf besteht, »in der Person des Einzelnen eine Umweltbedingung sozialer Systeme zu sehen, und nicht bereit ist, die in jeder Person immer auch gegebene gesellschaftliche Größe anzuerkennen, fehlt der Systemtheorie der Begriff für das Ineinander von Individualität und Sozialität«. ${ }^{233}$

Mehr noch: Über diese Subjektschwäche hinaus fallen die normative Enthaltsamkeit und die damit verbundene Absage an wahrheitstheoretische Relevanzen besonders ins Gewicht, obschon eben ein solches Defizit seinerseits im Öffentlichkeitsbegriff Gerhardts freigelegt worden ist. ${ }^{234}$ Mit dem auf funktional-pragmatische Viabilität zurückgefahrenen, ${ }^{235}$ normativ abstinenten Wahrheitsbegriff der Systemtheorie scheint Religionspädagogik im Diskurs der heterogenen Öffentlichkeiten nicht mehr begründungsfähig, nicht mehr diskursfähig, nicht mehr wahrheitsfähig. Diese Wahrheitsschwäche zeigt sich besonders stark in der »Aus- oder Abblendung von Gesichtspunkten, die über die Systemrationalität hinausreichen «. ${ }^{236}$ In der Logik der Systemtheorie lässt sich ein übergreifender, ein gar universaler Wahrheitsanspruch im Rahmen der Öffentlichkeit nicht mehr denken. Wie lässt sich jedoch dann verhindern, dass die Dialektik der verschiedenen Beobachtungsebenen in einem infiniten Regress endet? Wie lässt sich der Wahrheitsanspruch des christlichen Glaubens in seiner befreienden und die Menschen beanspruchenden Wucht überhaupt über das religionsinterne Sprachspiel hinaus denken? Denn dass die »Aktivitäten eines bestimmte Bereichs ihre eigene innere Rationalität kennen und die ältere Form der religiös fundierten Normsetzung nicht mehr zulassen, bedeutet keineswegs, daß solche Tätigkeiten nicht nach wie vor stark durch den Glauben geprägt werden können«. ${ }^{237}$ Wie lässt sich vom Menschen in biblischer Tradition jenseits personaler Kategorien reflektieren, wie lässt sich religiöse Bildung in ihrer Bezogenheit auf Autonomie und Mündigkeit überhaupt ansatzweise artikulieren? Verliert nicht die Religionspädagogik mit dieser Wahrheitsabstinenz ihre Mitte? Was unterscheidet dann eine solche Religionspädagogik noch von einem rein pragmatischen Dezisionismus? Eine solche Religionspädagogik würde wohl Differenzen wahren, wäre aber über diese Differenzen hinaus und deren Verhältnis betreffend nicht mehr in einem die Systeme übergreifenden Sinne reflexions- und auskunftsfähig. Wie aber wäre eine solche Religionspädagogik auf der Ebene der Bildungstheorie,

232 | Gerhardt, Öffentlichkeit 2012, 243

233 | Gerhardt, Öffentlichkeit 2012, 244.

234 | Vgl. C 2.

235 | Vgl. Domsgen, Grundlagen und Ziele einer systemischen Religionspädagogik 2009, 12-22; Schweitzer, Das lernende Subjekt 2009, 93-112.

236 | Schweitzer, Das lernende Subjekt 2009, 109.

237 | Taylor, Ein säkulares Zeitalter 2009, 707. 
in der Teilöffentlichkeit der schulischen Fächer wie über die Teilöffentlichkeit der Kirchen hinaus unter diesen Bedingungen noch ausweisbar oder gar legitimierbar? Sie könnte Rang, Status und Ansatz religiöser Bildung im Konzert anderer Bildungszugänge und anderer Weltmodellierungen nicht hinlänglich ins Spiel bringen. Auch ein moral point of view wäre nicht mehr formulierbar.

Damit rückt erneut ein starker normativer Akzent in den Fokus. Offensichtlich geht daran kaum ein Weg vorbei. Dies sollte in der bisherigen Diskussion von deliberativer Öffentlichkeitstheorie, liberaler und systemtheoretischer Öffentlichkeit herausgearbeitet werden. Allerdings arbeitet die Deliberative Öffentlichkeitstheorie im Wesentlichen mit dem Schleusenmodell. Religion hat wohl ihren Platz auf der zivilgesellschaftlichen Ebene. Wegen ihrer spezifischen Form ihrer Vernunft jedoch, die nicht die Universalisierungsfähigkeit säkularer Vernunft erreicht, bleibt Religion jedoch defizitär und ist auf der politischen Ebene und insbesondere auf der Ebene staatlicher Institutionen nicht ebenbürtig. Wird aber damit nicht eine Deklassierung vorgenommen, eine Diskriminierung der Religion? Unterschätzt dies nicht den rationalen Gehalt der Religion selber? Wir hatten ja ein solches Argument bereits gegen die Deliberative Öffentlichkeitstheorie ins Feld geführt. ${ }^{238}$ Diese Annahme jedenfalls bildet den Ausgangspunkt einer Öffentlichkeitstheorie, die maßgebliche Impulse aus dem pragmatisch gewendeten Kommunitarismus bezieht. Darum muss die Suche nach einem religionspädagogischen Öffentlichkeitsbegriff darauf Bezug nehmen.

\section{Pragmatische Öffentlichkeitstheorie: Charles Taylor}

Wie wir in der Auseinandersetzung mit der deliberativen Öffentlichkeitstheorie erarbeitet haben, will diese sehr wohl einer erfahrungsgesättigten religiösen Rede in der Öffentlichkeit Bedeutung zuschreiben. Auch diese könne, so Habermas, mit ihrer Authentizität sehr wohl Verständlichkeit, Wahrheits- und Orientierungsfähigkeit für die säkulare Vernunft beanspruchen, um vergessene Ressourcen freizulegen. Doch obschon jeder, der Martin Luther King Jr. zuhöre, verstehe, was er meine, bleibe religiöse Rede allerdings auf den vorinstitutionellen Raum der Politik beschränkt. ${ }^{239}$ Der Grund: Sie sei im letzten radikal verschieden von säkularer Rede. Auf der Ebene der Kognition gebe es zwar nur ein und dieselbe Vernunft. Deshalb könne man auch nicht von vornherein sagen, religiöse Gründe seien von vornherein irrational. »Der menschliche Geist ist in religiösen Traditionen genauso am Werk wie auf jedem

238 | Vgl. C 1.

239 | Vgl. Habermas, Taylor, Diskussion 2012, 95. 
kulturellen Gebiet, einschließlich der Wissenschaft.« ${ }^{240}$ Doch gebe es einen Unterschied zwischen Kategorien von Gründen. Während säkulare Vernunft sich allein auf das Argument stütze, auf für jeden zugängliche Gründe, ohne auf religiösen Erfahrungen und der Teilhabe an religiösen und kultische Praktiken zu basieren, ist religiöse Rede hingegen intrinsisch mit einem bestimmten Heilsweg verknüpft. »Somit hängen die Beweise für religiöse Gründe nicht nur von kognitiven Überzeugungen und ihrer semantischen Verkettung mit anderen Überzeugungen ab, sondern von existentiellen Überzeugungen, die in der sozialen Dimension der Zugehörigkeit, der Sozialisation und in vorgegebenen Praktiken wurzeln. $\ll^{241}$ Religiöse Rede sei deshalb im letzten opak, nur für Eingeweihte zu vollziehen und deshalb nicht zu verallgemeinern. Dagegen sei säkulare Rede von jedem verstehbar und mit von allen teilbaren Argumenten auch kritisierbar. Deshalb sei sie universalisierbar und das Forum, in dem sich im Modus der Übersetzung der jeweiligen partikularen Positionen religiöse wie nicht-religiöse Bürger versammeln können.

Die hier entscheidende Voraussetzung ist die kategoriale Differenz zwischen religiösen und nicht-religiösen Gründen. Doch ist diese triftig? An genau dieser Stelle widerspricht Charles Taylor. Sein Votum geht dahin, dass jede begründete Rede, sei sie religiös oder nicht-religiös, in bestimmten vorauslaufenden Wertbindungen bestehe.

"Der Unterschied ist, daß ich sage, man kann diese Art von Bezugnahmen nicht übersetzen, weil es sich um Bezugnahmen handelt, die das spirituelle Leben bestimmter Menschen wirklich berühren, das anderer hingegen nicht. Dasselbe gilt aber für den Verweis auf Marx und den auf Kant. Also versuchen wir uns anzuschauen, nicht warum wir diese Bezugnahmen aus Gründen der Fairness und Allgemeingültigkeit ausschließen müssen, sondern warum wir sie besonders behandeln müssen - und ich verstehe das mit der Sonderbehandlung immer noch nicht -, weil sie zu einer Art anderem Bereich gehören." ${ }^{242}$

Für Taylor ist demnach eine kategoriale Unterscheidung zwischen verschiedenen religiösen und nicht-religiösen Arten von Begründungen wegen der jeweils gleichermaßen vorauslaufenden tiefreichenden Fundierungen nicht möglich. Religion ist so gesehen kein Sonderfall. Sie hat einen zumindest analogen epistemologischen Status wie säkulare Philosophien. Damit aber ist bereits eine spezifische Öffentlichkeitstheorie angespielt, die nicht zuletzt deshalb interessant ist, weil sie offenkundig unmittelbare Konsequenzen für das Profil religionspädagogischer Selbstverständigungsprozesse birgt.

240 | Habermas, Taylor, Diskussion 2012, 90.

241 | Habermas, Taylor, Diskussion 2012, 92.

242 | Habermas, Taylor, Diskussion 2012, $94 \mathrm{f}$. 


\subsection{Anthropologie in modernekritischer Absicht}

Taylor wäre missverstanden, wollte man ihn als konservativen Denker einstufen, der hinter die Moderne zurückfallen wollte. Er ist kein Reaktionär. Ihm geht es vielmehr darum, in der kritischen Freilegung ihrer Aporien sein »Unbehagen an der Moderne« auszudrücken, um deren befreiende Impulse zu retten und deren selbstzerstörerischen Tendenzen entgegenzuwirken. ${ }^{243}$ Dafür konzentriert er sich auf das, was er für den Kristallisationspunkt der Moderne und ihrer Pathologien hält: den Menschen. Insofern läuft sein Werk insgesamt auf eine Philosophische Anthropologie mit der Absicht einer »therapeutischen Zeitdiagnose « hinaus, ${ }^{244}$ in der es ohne Romantisierungen und Verklärungen der Vormoderne um die Wiederherstellung einer verlorengegangenen Orientierung des Menschen und damit um das prekäre Gefüge zwischen Identität und Moral geht. »Wissen, wer man ist, heißt, daß man sich im moralischen Raum auskennt, in einem Raum, in dem sich Fragen stellen mit Bezug auf das, was gut oder schlecht ist, was sich zu tun lohnt und was nicht, was für den Betreffenden Sinn und Wichtigkeit hat und was ihm trivial und nebensächlich vorkommt. ${ }^{245}$ Dabei charakterisiert es seine Methodik, dass Taylor in Phänomenen, die nach allgemeinem Verständnis das Emanzipatorische und Befreiende der Neuzeit und der Moderne ausmachen, zugleich durch »anamnetische Selbstvergewisserungen « die dunkle Kehrseite freilegt und durch Blick in die kontingenten Begründungszusammenhänge Möglichkeiten für Unterbrechungen, Irritationen und Neuperspektivierungen anbahnt. ${ }^{246}$

\subsection{Pathologien der Moderne}

Im Lichte einer solchen Hermeneutik sind es vor allem drei Phänomene, an denen die Pathologien der Moderne besonders greifbar werden:

\subsubsection{Atomismus}

Erstens ist es für Taylor ein Individualismus, der in seiner Verabsolutierung des Einzelnen die eigenen Impulse konterkariert. Ein wesentliches Moment neuzeitlicher Aufbrüche ist die Freisetzung der Menschen aus unausgewiesenen Ordnungen, sei es gesellschaftlicher, staatlicher, privater oder auch religiös-kirchlicher Bindungen. Sie selber setzen sich ihre eigenen Zwecke, sie selber konstruieren jene Orientierungen und Weltanschauungen, aus denen

243 | Vgl. Taylor, Das Unbehagen an der Moderne 1995.

244 | Honneth, Die zerrissene Welt des Sozialen 2013, 228.

245 | Taylor, Quellen des Selbst 1996, 56.

246 | Goldstein, Perspektiven des politischen Denkens 2012, 177. Vgl. Taylor, Quellen des Selbst 1996, 27. 
heraus sie sinnvoll leben wollen. Jenseits der Konzentration auf den Bereich der Religion, wie dies Max Weber in seiner Rationalisierungsthese vorgenommen hatte, charakterisiert Taylor diesen Prozess der Diskreditierung überkommener Ordnungen, Sinngefüge und Hierarchien als »Entzauberung«. ${ }^{247}$ Damit wird bereits die angedeutete Ambivalenz dieses Vorgangs markiert. Einerseits bedingt diese Entzauberung die Möglichkeit, nun losgelöst von heteronomen Zwängen dem eigenen Gewissen zu folgen und sich selbst expressiv zu verwirklichen. Jedem Menschen ist diese Möglichkeit zur je eigenen unverwechselbaren Authentizität, so Taylor im Rückgang auf die Romantik, mitgegeben. Dieses »Ideal der Authentizität« verweigert sich einer Fremdbestimmung von außen. ${ }^{248}$ Moral kann so gesehen, im Unterschied zur Pflichtenethik Kants wie zur formalen Gerechtigkeitstheorie bei Habermas, nur in einer Korrespondenz liegen zwischen äußeren Quellen der Moral, die »im Inneren des Subjekts Resonanz finden «. ${ }^{249}$ Andererseits hat mit der Delegitimierung vorgegebener Traditionen, Bindungen und Ordnungen zugleich die Welt »manches von ihrer Zauberkraft eingebüß « ${ }^{250}$ Der Sinn für übergeordnete Zwecke, transsubjektive Horizonte, moralische Wertungen und gesellschaftliches wie gemeinschaftliches Zusammenleben geht verloren. »Die dunkle Seite des Individualismus ist eine Konzentration auf das Selbst, die zu einer Verflachung und Verengung des Lebens führt, das dadurch bedeutungsärmer wird und das Interesse am Ergehen anderer oder der Gesellschaft vermindert.« ${ }^{251}$ Das Subjekt wird aus allen Bindungen gelöst, wird vereinzelt, isoliert, wird aus werthaltigen Bezügen und vorauslaufenden, in der Sprache auch vorreflexiv mitgegebenen Bindungen isoliert und damit zu dem, was Taylor das »punktförmige< Selbst« nennt. ${ }^{252}$ Es ist die Beschreibung einer Haltung durchgängiger Selbstobjektivierung.

"Diese Haltung einzunehmen heißt: sich mit dem Vermögen der Objektivierung und Umgestaltung zu identifizieren und dadurch von allen Einzelmerkmalen abzurücken, die Gegenstände möglicher Veränderung sind. Was wir wesentlich sind, ist nicht von dieser letzteren Art, sondern wesentlich sind wir das, was sich imstande sieht, diese Merkmale festzusetzen und zu bearbeiten. Dies ist es, was durch das Bild des,Punkts im geometrischen Sinne des Ausdrucks angedeutet werden soll: Das eigentliche Selbst

247 | Taylor, Das Unbehagen an der Moderne 1995, 9.

248 | Taylor, Das Unbehagen an der Moderne, 38. Vgl. Knapp, Vernunft, Freiheit, Religion 2010.

249 | Taylor, Quellen des Selbst 1996, 880.

250 | Taylor, Das Unbehagen an der Moderne 1995, 9.

251 | Taylor, Das Unbehagen an der Moderne 1995, 10.

252 | Taylor, Quellen des Selbst 1996, 309 
ist rausdehnungslos', es ist nirgends außer in diesem Vermögen, Dinge als Objekte zu fixieren. « ${ }^{253}$

Erkennbar fokussieren diese subjekttheoretischen Analysen den Rationalismus Descartes als den entscheidenden Wendepunkt neuzeitlicher Denkgeschichte. Durch diese Wende entsteht eine radikale neue Ortsbestimmung des Ich, ja entsteht eigentlich erst das Subjekt im modernen Sinne. Denn im Unterschied zur klassischen metaphysischen Ontologie wird in das Subjekt verlagert, »was nach der früheren Anschauung gleichsam zwischen dem Erkennenden/Handelnden und der Welt bestand, sie miteinander verband und untrennbar werden ließ«. ${ }^{254}$ Nun ist der menschliche Geist allein der »ausschließliche Ort solcher Realitäten «. ${ }^{255}$ Subjekt und Objekt treten auseinander, das Ich verliert seine Einbindung in die sprachlich konstituierten Bindungen von Welt und Gemeinschaft. Es wird zu einer ungebundenen, haltlosen Entität, eben zu einem atomistischen Ich, das seine Identität gerade durch Herauslösung und »Desengagement« aus Traditionen, Strukturen und Gemeinschaften gewinnt. ${ }^{256}$ Daraus resultiert der Spitzensatz von Taylors anthropologisch motivierter Diagnose der Pathologien der Moderne: Diese kultiviere die

"Idealvorstellung von einem menschlichen Akteur, der sich selbst durch methodisches und diszipliniertes Handeln neu zu schaffen vermag. Erforderlich ist dazu die Fähigkeit, eine instrumentelle Haltung zu den eigenen gegebenen Eigenschaften, Begierden, Neigungen, Tendenzen und Gewohnheiten des Denkens wie des Fühlens einzunehmen, so daß diese bearbeitet werden können, wobei einige abgeschafft und andere verstärkt werden, bis man den gewünschten Vorgaben gerecht wird. «257

Es ist demnach vor allem der Cartesianismus, der wesentlich für die Neukonzeptionierung menschlichen Selbstverständnisses verantwortlich ist und damit zugleich für die Umgestaltung der menschlichen Vernunft. Hier, so reformuliert Taylor Wittgensteins berühmte Sentenz, liegt jenes Bild, das uns »gefangen« hält, weil es als »weitgehend unreflektiert bleibendes Hintergrundverständnis« den Horizont unserer Wirklichkeitsdeutungen und Selbstinterpretationen abgibt. ${ }^{258}$

253 | Taylor, Quellen des Selbst 1996, 309.

254 | Taylor, Quellen des Selbst 1996, 336.

255 | Taylor, Quellen des Selbst 1996, 335.

256 | Taylor, Quellen des Selbst 1996, 289.

257 | Taylor, Quellen des Selbst 1996, 289.

258 | Dreyfus, Taylor, Die Wiedergewinnung des Realismus 2016, 11. 


\subsubsection{Instrumentelle Vernunft}

Hierin wird bereits die zweite Pathologie der Moderne erkennbar: die Priorisierung der instrumentellen Vernunft. Sie verobjektiviert alles und trägt es ein in den Verfügungsraum dieser nun technisch geprägten Rationalität. Was vorher dem Verfügungsrahmen der Subjekte entzogen war durch deren Gründung im Schöpfungswillen Gottes oder einer unantastbaren Natur, wird nun durch die Entzauberung der Welt menschlichem Zugriff überantwortet. Verlieren die Geschöpfe ihren von Gott her oder von der Natur her verbürgten Wert, können sie zum Zweck des eigenen Glücks umgestaltet werden. Der einzige »Maßstab, der von nun an gilt, ist der der instrumentellen Vernunft«. ${ }^{259}$ Die Wirklichkeit wird in die Kategorien von Kosten-Nutzen-Analysen eingetragen und in diesem Muster bearbeitet. Sind gegenwärtige Verdinglichungstheorien stärker von Marx' Fetischismustheorem inspiriert, ${ }^{260}$ kommt Taylor zu einer Kritik der Verdinglichung, die phänomenologisch-kulturwissenschaftliche, vernunftanalytische und gesellschaftskritische Momente konstelliert und damit neuere Ansätze der Kritischen Theorie vorwegnimmt. ${ }^{261}$

Dennoch geht er weiter. Indem er die subjekttheoretischen Implikationen der Moderne und ihren drohenden »Sinnverlust« zusammenführt mit dem durch Instrumentelle Vernunft vollzogenen »Verblassen des moralischen Horizonts « kann er erst die Implikationen der im Prozess der Moderne wirksamen Entzauberung verstehen. ${ }^{262}$ Es ist ein $»$ Verlust an Resonanz, Tiefe oder Fülle eingetreten ${ }^{26}{ }^{63}$ die das autonome Subjekt aus sich selber nicht kompensieren kann. Sind auch gegenwärtige Reaktualisierungen des Resonanzbegriffs darum bemüht, sich in der Tradition der Kritischen Theorie zu verorten und eine Neubestimmung der Weltbeziehung vorzunehmen, ${ }^{264}$ mag daraus auch eine vieldimensionale Theorie der Resonanzen als Gegenentwurf zu den Entfremdungserfahrungen der Moderne entwickelt werden, ${ }^{265}$ so unterscheidet sich Taylors Ansatz davon dadurch, dass er diese Linien bis in eine weitausholende Säkularisierungstheorie ausfaltet. ${ }^{266}$ Man kann werkgenetisch sagen, dass sich in ihr seine subjekttheoretischen und modernekritischen Arbeiten verdichten. ${ }^{267}$ Zeigt Taylor in seinen denkhistorischen Analysen den Gang

259 | Taylor, Das Unbehagen an der Moderne 1995, 11.

260 | Vgl. Honneth, Verdinglichung 2015.

261 | Vgl. Jaeggi, Entfremdung 2016.

262 | Taylor, Das Unbehagen an der Moderne 1995, 17.

263 | Taylor, Das Unbehagen an der Moderne 1995, 13.

264 | Vgl. Rosa, Weltbeziehungen 2012.

265 | Vgl. Rosa, Resonanz 2016; Rosa, Gelingendes Leben 2017.

266 | Vgl. Taylor, Ein Säkulares Zeitalter 2009.

267 | Vgl. Kühnlein, Immanente Ausdeutung 2014; Goldstein, Säkularisierung der Vorsehung 2011; Knapp, Gott in säkularisierter Gesellschaft 2011. 
der Moderne als Gang großer »Subtraktionsgeschichten«, in der im Prozess der Entzauberung sukzessiv alle Mythen, alle metaphysischen und religiösen Weltanschauungen dahinschwanden, so dass »endlich Platz geschaffen wurde für die bereits existierende, ausschließlich auf den Menschen bezogene moralische Motivation «, ${ }^{268}$ so wäre der Prozess der Säkularisierung doch missverstanden, würde er nach dem überkommenen Muster einer von Max Weber her inspirierten klassischen Säkularisierungstheorie als ein mit der Moderne intrinsisch verbundener Glaubens- und Religionsverlust qualifiziert. ${ }^{269}$

Vielmehr unterscheidet er verschiedene Formen der Säkularisierung: eine Säkularisierung I, die den Glauben unter Bezug auf »das Öffentliche« definiert und ihn einordnet in eine Funktionale Differenzierung, die jeden Wirklichkeitsbereich nach jeweils eigener Logik verfasst sieht; ${ }^{270}$ eine Säkularisierung II, in der Glaube und Religion schlicht verschwinden, und eine Säkularisierung III, die die Bedingungen des Glaubens und der Religion in modernen Gesellschaften untersucht. ${ }^{271}$ Diese bei Taylor im Fokus stehende Ebene begreift Religion und Glaube nun nicht als eine verschwindende Größe. Religion und Glaube werden vielmehr transformiert und dadurch zugleich zu einer Option. ${ }^{272}$ Er rekonstruiert den Wandel von einer Gesellschaft, in der Glaube unhinterfragt und unangefochten war hin zu einer Gesellschaft, »in der dieser Glaube auch für besonders religiöse Menschen nur eine menschliche Möglichkeit neben anderen ist «. ${ }^{273}$

Im Hintergrund solcher Analysen, deren Potential für gegenwärtige Debatten um Pluralisierung und Individualisierung von Religion noch lange nicht eingeholt ist, ${ }^{274}$ steht hermeneutisch eine Ausweitung der epistemologischen Grundlagen. Spätestens in seiner Säkularisierungstheorie hat Taylor die Konzentration auf kognitive Momente des Modernisierungsprozesses geweitet auf affektive, leibliche, praktische und volitive Aspekte. Im Wesentlichen geht es ihm darum, den simmanent frame<, den Rahmen der Immanenz, aufzusprengen auf Größeres hin und das »abgepufferte Selbst« auf Anderes hin durchlässig und zu einem »porösen Selbst« werden zu lassen. ${ }^{275}$ Seine Anthropologie

268 | Taylor, Ein säkulares Zeitalter 2009, 420.

269 | Vgl. Pollack, Art. Säkularisierung 2016; Taylor, Ein säkulares Zeitalter 2009, 877; Joas, Die Macht des Heiligen 2017.

270 | Taylor, Ein säkulares Zeitalter 2009, 13.

271 | Vgl. Taylor, Ein säkulares Zeitalter 2009, 14f. Ähnlich Casanova, Public Religions 1994.

272 | Vgl. Joas, Glaube als Option 2012.

273 | Taylor, Ein säkulares Zeitalter 2009, 15.

274 | Vgl. Smith, How (not) to be secular 2014; Kühnlein, Immanente Ausdeutung 2014; Joas, Die Macht des Heiligen 2017.

275 | Taylor, Ein säkulares Zeitalter 2009, 899. 
zielt darauf ab, das Subjekt offen zu halten für Größeres, für Transzendenz, so dass für ihn in einer für manche verstörenden Prägnanz »kein Weg an der religiösen Dimension vorbeiführt«, nur die Wahl zwischen einer guten und einer schlechten Religion. ${ }^{276}$ Insofern wird erkennbar, wie sehr es Taylor um die genetische Analyse des In-die-Weltgestellt-seins geht und er hierbei auch expressive, ästhetische, performativ-praktische Aspekte bemüht. ${ }^{277}$ Das romantische Authentizitätsideal expressiver Subjektivität wird zum Ankerpunkt ganz unterschiedlicher »Formen des Religiösen in der Gegenwart«, wie Taylor im Rückgriff auf William James formuliert. ${ }^{278}$ Die in individuellen wie kommunikativen Prozessen performativ-zeichenhaft vollzogene Suche nach Ganzheitlichkeit, nach Sinnsuche ist der Ort des Religiösen, was aber noch nicht der Ort der Suche nach schlechthinniger Unbedingtheit im Sinne Paul Tillichs sein muss.

Charles Taylor hat diese Immanenzreligion am Beispiel der Kunst philosophisch rekonstruiert, diese eingeordnet in das in der Moderne aufkommende Phänomen expressiver Authentizität des Subjekts und deren Relevanz im Sinne einer Kontingenzbewältigungspraxis (Hermann Lübbe) aufgezeigt. ${ }^{279}$ Zugleich aber demonstriert er deren Begrenzungen, indem er sie unter Bezug auf Mikhail Epsteins Analysen im postkommunistischen Russland als »Minimalreligion« kennzeichnet oder - stärker auf die westliche Hemisphäre bezogen - als »Spiritualität ohne Religion «. ${ }^{280}$ Mit beiden ist eine subjektbezogene, innengeleitete Reaktion auf die Erfahrung von Sinnleere gemeint, die aber charakteristischerweise sich in einem wesentlichen Moment von dem unterscheidet, was Religion ausmache: dem Moment von Selbstenteignung, von Sichentzogensein hinsichtlich der Gewährung der eigenen Identität, des eigenen Gedeihens. Taylor entwickelt einen allgemeinen, weiten Begriff von Religion, der sich seiner Verwurzelung in der westlichen Welt der Moderne durchaus bewusst ist, und die er wegen seiner Innengeleitetheit »religiösen Glauben« nennt. Dieser sei definiert durch ein »Doppelkriterium: zum einen durch den Glauben an eine transzendente Realität, zum anderen durch das damit zusammenhängende Streben nach einer Transformation, die über das menschliche Gedeihen hinausgeht $\ll .{ }^{281}$ Doch so sehr es diese Suche nach Spiritualität, nach Religion oder vielleicht nach Glauben gibt: zum Kennzeichen des Säkularen Zeitalters gehört es, dass Religion und Glaube vor dem Hin-

276 | Taylor, Ein säkulares Zeitalter 2009, 1175. Kritisch Goldstein, Säkularisierung als Vorsehung 2011, 638ff.

277 | Vgl. Rosa, Is There Anybody Out There 2011.

278 | Vgl. Taylor, Die Formen des Religiösen 2002, 5-100.

279 | Vgl. Taylor, Ein säkulares Zeitalter 2009, 602ff.845ff.

280 | Taylor, Ein säkulares Zeitalter 2009, 893, 895.

281 | Taylor, Ein säkulares Zeitalter 2009, 851. 
tergrund des gewandelten Subjektverständnisses und einer veränderten Vernunftkonzeption ihre Selbstverständlichkeit verloren haben.

\subsubsection{Entpolitisierung}

Damit wird bereits die dritte Pathologie der Moderne berührt, die für Taylor unmittelbar aus der individualistisch-atomistischen Anthropologie und der Tendenz zur instrumentellen Rationalität folge: die »Entfremdung von der öffentlichen Sphäre, aus der sich dann der entsprechende Verlust der politischen Kontrolle ergibt ${ }^{282}$ Eine solche These basiert auf einer anthropologischen Freiheitsanalyse, die Taylor von seinem Lehrer in Oxford Isaiah Berlin übernimmt. Das moderne Freiheitsverständnis beruht im Kern auf der skizzierten Subjektzentrierung. Nicht mehr wird der Fixpunkt der Subjektkonstitution außerhalb des Subjekts gesucht, nicht mehr ist der Mensch Bestandteil einer sinnvollen Ordnung. »Seine pragmatischen Zwecke sind in seinem Inneren zu entdecken. Er ist sich selbst überlassen. Was für die umfassende Kosmische Ordnung gilt, wird schließlich auch auf die politische Gesellschaft übertragen. Daraus ergibt sich ein Bild des souveränen Individuums, das >von Natur aus < keiner Autorität verpflichtet ist. Der Zustand der Unterwerfung unter eine Autorität ist etwas, was erst geschaffen werden muß. « ${ }^{283}$ Entscheidend kommt es dementsprechend für das moderne Subjekt darauf an, alle Bindungen, alle Verpflichtungen und Verwurzelungen als heteronom abzustreifen. Insofern gehört es zur Verheißungen der Moderne, eine unbeschränkte und freie Wahl zu haben. Das wäre die höchste Freiheit, die Taylor als >Negative Freiheit< bezeichnet. Sie ist in dem Sinne ein »Möglichkeitskonzept«, deren hinreichende Bedingung eben die Abwesenheit von äußeren Hindernissen ist. ${ }^{284}$

Für Taylor ist diese an Hobbes und Bentham orientierte Sicht trotz aller Verheißungen eindimensional. Zum einen verabsolutiert sie die Möglichkeiten des Subjekts, zum anderen unterschätzt sie die vielfältigen Dimensionen von Freiheit. »Das Subjekt radikaler Wahl ist eine weitere Manifestation jener immer wiederkehrenden Figur, die unsere Kultur zu realisieren trachtet - das entkörperlichte Ego, das Subjekt, das alles Sein objektivieren kann, einschließlich seines eigenen Seins, und das in radikaler Freiheit wählen kann. Aber dieses Versprechen des totalen Selbstbesitzes bedeutet in Wahrheit den totalen Selbstverlust. « ${ }^{285}$ Diese etwas überraschende Bewertung einer im gegenwärtigen Freiheitsdiskurs durchaus wirkmächtigen Freiheitstheorie rührt von

282 | Taylor, Das Unbehagen an der Moderne 1995, 17.

283 | Taylor, Quellen des Selbst 1996, 344f.

284 | Taylor, Negative Freiheit 1992, 121.

285 | Taylor, Negative Freiheit 1992, 187; vgl. Goldstein, Perspektiven des politischen Denkens 2012, 186ff; Dierksmeier, Qualitative Freiheit 2016, 31-62; Schink, Freiheit 2017. 
Taylors Sensibilität für die Komplexität von Freiheit, die wesentlich mit der Gründung in der sich selbst verstehenden, sprachlich vermittelten Interaktion mit anderen Menschen zu tun hat. Freiheit ist nicht schon durch Abwesenheit äußeren Zwangs gegeben. Dazu gehört auch, dass man frei sein will, dass man das Bewusstsein seiner eigenen Freiheit hat und sich selber Ziele setzen kann. Die dem Negativkonzept entgegengesetzte »Positive Freiheit« meint demnach eine Freiheit, »die ganz besonders die Ausübung von Kontrolle über das eigene Leben betrifft. Dieser Auffassung zufolge sind wir nur in dem Maße frei, in dem wir tatsächlich über uns selbst und die Form unseres Lebens bestimmen. Der Freiheitsbegriff ist hier ein Verwirklichungsbegriff.« ${ }^{286}$ Freiheit wird umso größer, »je bedeutsamer die Ziele sind «. ${ }^{287}$

Das Entscheidende für Taylor ist freilich aus Sicht einer an Öffentlichkeit interessierten Perspektive, dass er trotz ihrer Trennung beide Freiheitskonzeptionen - wenn auch mit deutlicher Hierarchisierung - aufeinander bezieht.

"Freiheit schließt nun ein, daß ich zum einen imstande bin, meine wichtigen Ziele adäquat zu erkennen und die motivationalen Fesseln zu überwinden oder zumindest zu neutralisieren, und zum anderen, daß ich frei bin von äußeren Hindernissen. Die erste Bedingung (und auch die zweite, wie ich behaupten möchte) erfordert jedoch offensichtlich, daß ich zu etwas geworden bin, daß ich eine gewisse Voraussetzung von Selbsterkenntnis und Selbstverständnis erreicht habe. Ich muß dieses Selbstverständnis wirklich ausbilden, um wahrhaft und im vollen Sinne frei zu sein. ${ }^{288}$

Diese Konstellation ermöglicht es Taylor nun, die gesellschaftlich-politischen Dimensionen der Freiheit zu gewinnen, um darüber dann mit der angespielten Entfremdung von der politischen Sphäre eine wesentliche Pathologie der Moderne zu analysieren. Es ist demnach nicht allein die Frage, welche Gesellschaftsform dieser positiven Freiheit angemessen entspricht. Es geht zugleich auch darum, kritisch zu diagnostizieren, wo freiheitsmindernde, freiheitsvereitelnde oder gar freiheitsnegierende Momente gegenwärtig in der Moderne greifbar werden. Taylor spricht von Freiheitsverlust durch Entpolitisierung, spricht von einer spezifisch modernen Form des Despotismus, der zwar nicht diktatorisch unterdrückt, dem sich das Subjekt aber selbst in demokratischen Systemen durch sanfte paternalistische Entmündigung »ohnmächtig« gegenüber gestellt sieht. ${ }^{289}$

286 | Taylor, Negative Freiheit 1992, 121.

287 | Taylor, Negative Freiheit 1992, 144.

288 | Taylor, Negative Freiheit 1992, 144; aus sozial-konstruktivistischer Sicht vergleichbar Forst, Politische Freiheit 2017, 400-403.

289 | Taylor, Das Unbehagen an der Moderne 1995, 17. 
Wir werden noch sehen, wie dies öffentlichkeitstheoretisch durchschlägt. Entscheidende Voraussetzung allerdings für eine weiterführende Perspektive ist freilich jene bereits angedeutete Haltung Taylors zur Moderne. Im Unterschied zu Alasdair MacIntyre oder in bestimmter Weise auch bei Michel Foucault geht es ihm gerade nicht um deren »Preisgabe«. Stattdessen fordert er das kritisch-analytische Aushalten und produktiv-kritische Bearbeiten ihrer Konflikte und Aporien. ${ }^{290}$ Damit wendet er sich auch gegen eine bis in die Strukturen hineinreichende Totalisierung der Kritik, die für ihn als Theorien des

"schicksalhaften Verlaufs der Dinge abstrakt und verfehlt sind. Die uns zu Gebote stehenden Freiheitsgrade sind nicht gleich Null. Es hat durchaus Sinn, über die Frage zu beraten, welche Zwecke wir uns setzen sollten und ob die instrumentelle Vernunft in unserem Leben eine geringere Rolle spielen sollte als jetzt. Das Wahre an jenen Analysen ist allerdings, daß es nicht nur darauf ankommt, die Einstellung der einzelnen zu ändern. Der Kampf betrifft nicht nur 'Herz und Gemüt, so wichtig diese Auseinandersetzung auch sein mag. Der Wandel wird in diesem Bereich auch die Institutionen tangieren müssen, obwohl er nicht so radikal und so umfassend sein kann, wie es die großen Revolutionstheoretiker vorgeschlagen haben. “291

Taylors Verweigerung einer Totalkritik der Moderne kann zurückgreifen auf Ressourcen, die er im sich selbst interpretierenden Subjekt und dessen sprachlicher Einbindung sieht. ${ }^{292}$ Das wesentliche Merkmal der Menschen besteht im Unterschied zu naturalistischen, behavioristischen und utilitaristischen Anthropologien darin, »Welterschließer zu sein, und daß diese wesentliche Seinsweise es uns ermöglicht, die Rolle der Sprache ebenso zu verstehen wie die Tatsache, daß jede Kultur eine Auffassung des Sinns des menschlichen Lebens in sich birgt«. ${ }^{293}$ Aus seiner Vertrautheit mit Wittgensteins Sprachspieltheorie, mit der Phänomenologie Merleau-Pontys, der Existenzialanalyse Heideggers und der Sprachphilosophie bringt er im Rückgriff auf das Erbe der Romantik und dessen Selbstverwirklichungsideal, auf Kants Freiheitsdenken und Hegels Geschichtsphilosophie die subjektkonstituierende Bedeutung der Sprache ins Spiel. ${ }^{294}$ Sprache ist mehr als bloßes Mittel der Bezeichnung, wie er in Absetzung von der - dem erkenntnistheoretischen Paradigma der Moderne zuge-

290 | Rosa, Identität und kulturelle Praxis 1998, 380; zu Maclntyre Kühnlein, LutzBachmann, Vermisste Tugend 2015.

291 | Taylor, Das Unbehagen an der Moderne 1995, 73.

292 | Vgl. Joas, Die Entstehung der Werte 1999, 195-227; Joas, Die Macht des Heiligen 2017.

293 | Dreyfus, Taylor, Die Wiedergewinnung des Realismus 2016, 299.

294 | Vgl. Rosa, Identität und kulturelle Praxis 1998, 15-57; Honneth, Die zerrissene Welt des Sozialen 2013, 227-247. 
rechneten - Sprachphilosophie von Hobbes, Lockes, Condillac verdeutlicht, die er im Kürzel »HLC « ironisiert. »Words are given meaning by being attached to the things represented via the >ideas $<$ which represent them. ${ }^{295}$ Doch übersieht diese funktionale, lediglich weltabbildende Funktion der Sprache die weltkonstitutive Bedeutung der Sprache für die Subjekte. Diese finden sich in ihrem Leben je schon in sprachlich vollzogenen Sprachnetzen und Interpretationszusammenhängen vor, drücken sich existentiell je schon in sprachlichen Kontexten und unter grammatikalisch gegeben Voraussetzungen aus und gewinnen so in diesen sprachlich vollzogen Prozessen Sinn, intersubjektive Vernetzung und Identität. Welterschließung und Weltabbildung gehen insofern Hand in Hand, als das Subjekt in einem bezeichneten Sachverhalt sich selber sieht und interpretiert. »In der Sprache bringt der Mensch daher immer auch zum Ausdruck, welche Sicht er von der Welt besitzt. $\ll^{296}$

Der designativen Bedeutung von Sprache setzt Taylor unter Bezugnahme auf Hamann, Herder und Humboldt $(\mathrm{HHH})$ deren konstitutive Bedeutung entgegen. ${ }^{297}$ Es ist die »creative or constitutive power of language«, durch die die Tiefe und Kreativität des als »Language Animal« begriffenen Menschen artikuliert werden können. ${ }^{298}$ Offensichtlich findet Taylor in der Sprache als universales Gewebe zwischen den Menschen jenen Grund, der den modernen Atomismus überwindet, Gemeinschaft stiftet und zugleich Vollzugsraum guten Lebens ist. Mit dieser sprachlichen Verortung von Moralität und Ethik wird zugleich ein spezifischer Gerechtigkeitsbegriff erkennbar. Dies freilich sind Elemente, die öffentlichkeitstheoretische Brisanz haben und deshalb einer knappen Thematisierung bedürfen.

\subsection{Der Vorrang des Guten vor dem Gerechten}

Charles Taylor ist es darum zu tun, Gerechtigkeitsprinzipien in den konkreten Kontexten guten Lebens zu verwurzeln, diese aber zugleich dadurch über die partikulären Kontexte hinaus zu öffnen, dass sie auf »starken Wertungen « (Taylor) beruhen. Darunter fasst Taylor jene Wertungen zweiter Ordnung, die Unterscheidungen beinhalten »zwischen Richtig und Falsch, Besser und Schlechter, Höher und Niedriger, deren Gültigkeit nicht durch unsere eigenen Wünsche, Neigungen oder Entscheidungen bestätigt wird«. Sie sind vielmehr »von diesen unabhängig und bieten selbst Maßstäbe, nach denen diese be-

295 | Taylor, The Language Animal 2016, 4.

296 | Honneth, Die zerrissene Welt des Sozialen 2013, 239.

297 | Vgl. Taylor, The Language Animal 2016, 3-51.

298 | Taylor, The Language Animal 2016, 291. 
urteilt werden können « ${ }^{299}$ Indem sie durch ihre sprachliche Struktur moralische Landkaten begründen, erreichen solche starken Wertungen für Taylor damit einen transsubjektiven Verpflichtungsgrad und Maßstab, »der von meinen eigenen Vorlieben und Wünschen unabhängig ist und den ich anerkennen sollte ${ }^{300}$

Genau diesen Vorrang des Guten vor dem Rechten als Quelle und normative Kraft der Gerechtigkeit, gelebt in einer konkreten partikularen Gemeinschaft, proklamiert nun jene Strömung, die unter dem allgemeinen Label des Kommunitarismus sehr unterschiedliche Denker vereinigt. Diesem ist es darum zu tun, »Gemeinschaft und Gerechtigkeit« nicht additiv, sondern konstituierend zu denken. ${ }^{301}$ Indem das Gute den eigentlichen Sinn der Regeln von Gerechtigkeit dominiert, »wird das Rechte bestimmt «.302 Problematisch am Vorrang des Rechten vor dem Guten, wie dies danach bei Kant, bei Rawls und - wie wir gesehen haben - bei Habermas zu finden ist, ist danach vor allem die nur noch formale Bestimmung von Prinzipien der Gerechtigkeit und das damit einhergehende Subjektverständnis. Es ist ein isoliertes Selbst, das hier nach Taylor impliziert wird, losgelöst von allen vorgängigen Traditionen, Werten, Zielen, getrennt von allen sozialen Einbindungen, ohne moralische Tiefe, bestimmt durch eine rein negative Freiheit. ${ }^{303}$

Eine solche Vorstellung ist nicht nur eine leere, wirklichkeitsfremde Abstraktion von lebensweltlichen Erfahrungen der Menschen. Sie ist für den Gerechtigkeitsdiskurs selber in dreifacher Hinsicht problematisch. Kann man erstens - ernsthaft annehmen, dass sich Menschen, die sich zu bestimmten Werten hingezogen fühlen, von den eigenen Überzeugungen distanzieren, um in den Diskurs über Gerechtigkeit einzutreten, in dem dann möglicherweise genau diese eigenen Werte ganz in Frage gestellt werden? Warum sollen Menschen sich - zweitens - in diesen Diskurs überhaupt begeben, woher die Motivation nehmen? Warum sollen sie - drittens - sich an die aufgestellten Maximen halten ${ }^{304}$ Weil liberale und prozedurale Gerechtigkeitstheorien den grundlegenden und inneren Zusammenhang zwischen Identität und Moral,

299 | Taylor, Quellen des Selbst 1996, 17; vgl. auch Rosa, Identität und kulturelle Praxis $1998,108 \mathrm{ff}$.

300 | Taylor, Quellen des Selbst 1996, 17; vgl. Taylor, Negative Freiheit 1992, 9-51; Maclure, Taylor, Laizität und Gewissensfreiheit 2011, 49-55.

301 | Vgl. Brumlik, Brunkhorst, Gemeinschaft und Gerechtigkeit 1993; Arens, Manemann, Wie sollen wir zusammenleben 1996.

302 | Taylor, Quellen des Selbst 1996, 172.

303 | Vgl. Taylor, Negative Freiheit 1992, 118-145.

304 | Vgl. Joas, Knöbl, Sozialtheorie 2011, 672-677. 
zwischen dem Richtigen und dem Guten »nicht anerkennen, erklärt sich nun auch ihre realpolitische Wirkungslosigkeit «. ${ }^{305}$

Michael Sandel, der Kommunitarist und Schüler Taylors, setzt dagegen die Behauptung, dass Menschen in Gemeinschaften leben, eingebunden in bestimmte Institutionen wie Familie und Gemeinde, in gesellschaftliche Netzwerke, Lebensformen und Strukturen, aus denen sie ihre eigenen Werte, Orientierungen und Ziele bestimmen. Aus dieser orientierenden wie motivierenden Beheimatung heraus entstehen erst jene Prinzipien von Gerechtigkeit, die wegen ihrer Bindung an gemeinschaftliche Lebensformen Tragfähigkeit und dynamisierende Kraft erhalten. Mehr noch: Hierdurch lässt sich auch jene tiefgreifende Gesellschaftskrise überwinden, in die der Liberalismus mit seinem ungebundenen Selbst geführt hat. ${ }^{306}$

Insgesamt zeigt sich Taylor damit als Neo-Aristoteliker. Es ist diese sprachlich begründete, religiös sensible und gesellschaftspolitisch ambitionierte Philosophie, die den Pathologien der Moderne Widerstand entgegensetzen will. In ihr kommt dem Konzept der Öffentlichkeit eine zwar nicht dominante, aber doch nicht unwesentliche Rolle zu.

\section{4 Öffentlichkeit als Resultat moderner Transformationsprozesse}

Es zeigt bereits die kommunitaristische Verwurzelung seiner Öffentlichkeitstheorie, dass diese nicht schlicht im Zuge theoretischer Bemühungen der Politischen Philosophie, der Sozialethik, der Sprachphilosophie oder der Religionstheorie situiert ist. Sie hat vielmehr ihren konkreten Ort in den kulturpolitischen Debatten um Anerkennung und um Gleichberechtigung unterschiedlicher frankophoner und anglophoner Teile der kanadischen Gesellschaft. Die dort hochbrisante und bis in die Gegenwart nicht ausgestandene Debatte um Multikulturalismus, um Fremdheit, Differenz und Gleichheit, in die Taylor auch politisch und gutachterlich involviert war, wird gegenwärtig bis in die Frage nach dem Verhältnis von Kultur, Religion und Gewissensfreiheit hinein ausgezogen, die dabei insbesondere die Bedeutung von Laizität in den unterschiedlichen Kontexten Frankreichs und Nordamerikas problematisiert. ${ }^{307}$ Insofern löst Taylor in gewisser Weise performativ das ein, was ihm wissenschaftstheoretisch mit seinem Votum für eine wertbezogene, sprachlich-hermeneutisch vollzogene, kontextuelle Vernunft am Herzen liegt.

Taylors Öffentlichkeitsbegriff gewinnt Profil durch seine Gegenüberstellung zu anderen Formen der Vergesellschaftung, wobei der griechischen Polis

305 | Rosa, Weltbeziehungen 2012, 80.

306 | Vgl. Sandel, Liberalism 1982, 179-184.

307 | Vgl. Taylor, Multikulturalismus 2009; Maclure, Taylor, Laizität und Gewissensfreiheit 2011. 
nicht nur in einem exemplarischen Sinne eine dominante Funktion zukommt. Insofern können Genese und Gestalt moderner Öffentlichkeit nur im Rahmen der Transformationsprozesse der Moderne überhaupt verstanden werden, die freilich für Taylor insgesamt in der oben bereits angedeuteten Vieldimensionalität als Säkularisierungsprozesse gedeutet werden. ${ }^{308}$ Die dort beschriebenen Veränderungen dessen, was er in wegweisenden früheren Arbeiten als radikale Umgestaltung der »Social imaginaries« als den vor allem unreflex wirksamen Hintergrundannahmen kultureller, religiöser und gesellschaftlich-politischer Selbstverständigungsprozesse herausgearbeitet hatte, ${ }^{309}$ trägt er als Abbreviatur für die Moderne ein in seine monumentalen Reflexionen zum säkularen Zeitalter. Daher verwundert es nicht, dass Taylor die Form und Begründung der modernen Öffentlichkeit in der Ausdifferenzierung unterschiedlicher Wirklichkeitsbereiche von Religion, Kultur, Politik, Ökonomie lokalisiert. Er konfiguriert sie als eine Zwischenebene zwischen Politik und Gesellschaft. Das bestimmende Element ist dabei der Meinungsaustausch freier und gleichberechtigter Teilnehmer, wie er im Rückgriff auf Habermas frühe Öffentlichkeitstheorie formuliert: »Die Öffentlichkeit möchte ich als einen gemeinsamen Raum kennzeichnen, in dem die Angehörigen der Gesellschaft durch eine Reihe von Medien - durch Gedrucktes, auf elektronischem Weg und auch durch persönliche Begegnung - zusammenkommen, um Angelegenheiten von gemeinschaftlichem Interesse zu besprechen und so die Möglichkeit zur Bildung einer gemeinsamen Meinung über diese Angelegenheiten zu erhalten.« $\aleph^{310}$

Öffentlichkeit wird durch Interkommunikation konstruiert, die durch Medien wie Zeitungen, Flugblätter oder gegenwärtig Fernsehen, Radio und Internet vermittelt wird und damit synchroner wie diachroner Natur ist. Eine solche Öffentlichkeit ist mit einem derart vitalen normativen Impetus zum zentralen Merkmal moderner Gesellschaften avanciert, dass selbst autoritäre Systeme sich den Anschein von öffentlicher Unterstützung verschaffen. Sie existiert nicht an sich. Sie ist nicht bereits je schon da, so dass sich die Subjekte dort nur einfügen müssten und dort bereits einen Raum der Artikulation, der Willensbildung und Entscheidungsfindung vorfänden. Sie ist kein gemeinsamer Raum, der an nur einem Ort entsteht. Im Unterschied zu einem solchen »topisch gemeinsamen Raum« meint Öffentlichkeit vielmehr eine Vielzahl solcher Räume und zugleich das Überschreiten von konkreten Begegnungsräumen durch mediale Vermittlung. Moderne Öffentlichkeit ist demnach we-

308 | Vgl. Goldstein, Säkularisierung als Vorsehung 2011, 635-649.

309 | Vgl. Taylor, Modern Social Imaginaries 2004.

310 | Taylor, Ein säkulares Zeitalter 2009, 320. 
sentlich ein »metatopisch gemeinsamer Raum«, der die einzelnen Gemeinschaften, Gesellschaften und Staaten überschreiten kann. ${ }^{311}$

Eine solche Öffentlichkeit wird performativ durch Praxis gestiftet, in dem sich die Subjekte auf einen bestimmten Gegenstand fokussieren und sie dabei die Möglichkeit »zum wechselseitigen Gedankenaustausch haben, so daß sie zu einem bestimmten gemeinsamen Resultat gelangen können «.312 Entscheidend für die Konstituierung der Öffentlichkeit ist weniger das gemeinsame Ziel als der gemeinsame Akt. Konsensorientierung, nicht dauernde Bearbeitung von Dissens, erweist sich demnach als ein Kennzeichen dieser Öffentlichkeitstheorie. Dies geschieht in einem bestimmten kulturellen Horizont, in dem erst die gemeinsame Einigung erzielt werden kann. Dieser Horizont ist im Kern verbunden mit der »Mutation des sozialen Vorstellungsschemas « in der Moderne, das sich gegenüber vormodernen Orientierungen grundlegend verändert hat. ${ }^{313}$ Diese Aspekte konvergieren schließlich im Begriff der Öffentlichkeit als ein »außerpolitischer, säkularer, metatopischer Raum«.314

Doch was bedeutet diese konzise Definition genauer? Um Taylor präzise zu verstehen, gilt es, die einzelnen Elemente genauer anzusehen.

Die moderne Öffentlichkeit, wie sie sich im 18. Jahrhundert herausgebildet hat, ist außerhalb des politischen Raums situiert. Ohne Rücksicht auf politische Schranken verbindet sie alle aufgeklärten Teilnehmer gleichberechtigt miteinander. Sie steht nicht in einem bereits durch Gesetz gestifteten Rahmen gesellschaftlicher Identität. Das ist neu gegenüber vormodernen Vergesellschaftungsformen wie der griechischen-antiken Polis. Während die Polis keine Differenz zwischen politischer Entscheidungsfindung und Beratung und insofern keinen vorpolitischen Raum kannte, kennzeichnet es gerade die Moderne, dass zwischen politischer Entscheidungsfindung und gesellschaftlicher Beratung getrennt wird. »Gerade weil die öffentliche Meinung keine Macht ausübt, kann sie im Idealfall vom Parteigeist losgelöst und zugleich rational sein. « $^{315}$ Dies aber lässt in der Konsequenz die politische Macht legitimierungs- und überprüfungsbedürftig erscheinen, die eben nicht auf Gott, nicht auf den Kosmos oder die Natur zurückgeführt werden kann. Neu ist also die Öffentlichkeit als eine »eine Art von Diskurs, der aus der Vernunft hervorgeht und nicht aus der Macht oder der traditionellen Autoritä««..16 Dieser ist nicht von der Macht konstituiert. Er wird über sie geführt und ist kritisch an sie adressiert. Als solcher übersteigt dieser Diskurs die gegebenen sozialen

311 | Taylor, Ein säkulares Zeitalter 2009, 323-324.

312 | Taylor, Ein säkulares Zeitalter 2009, 321.

313 | Taylor, Ein säkulares Zeitalter 2009, 322.

314 | Taylor, Ein säkulares Zeitalter 2009, 339.

315 | Taylor, Ein säkulares Zeitalter 2009, 328.

316 | Taylor, Ein säkulares Zeitalter 2009, 328. 
Gebilde. »Dieser außerpolitische Status ist ein Aspekt des Neuen, demzufolge alle (oder zumindest alle fähigen und >aufgeklärten $\triangleleft$ ) Angehörigen einer politischen Gesellschaft als Personen aufgefasst werden sollten, die außerdem eine außerstaatliche Gemeinschaft bildeten. « ${ }^{317}$

Freilich ist diese Metatopik nicht das entscheidend Neue. Taylor zeigt am Beispiel der Kirche und der Kosmopolis, dass es metatopische Größen bereits in der Vormoderne gegeben hat. Es muss ein weiteres wesentliches Moment hinzukommen. Erst dieses konstituiert eine moderne Öffentlichkeit. Dieses ist das Moment der Säkularität. Dabei muss man sich den genannten vieldimensionalen Säkularisierungsbegriff Taylors vor Augen führen. Erst dies lässt verstehen, warum diese Öffentlichkeit von einer extremen Säkularität geprägt ist, radikal neu und beispiellos.

Vormodern war jede Gesellschaft und damit auch Öffentlichkeit eingeordnet in einem übergreifenden metaphysischen Rahmen, sei er gestiftet von Gott, von einer übernatürlichen Ordnung, einem seit unvordenklichen Zeiten geltenden Gesetz oder einem kosmisch-metaphysischen Zusammenhang. Öffentlichkeit wird damit in einem Horizont verortet, der alle verbindet, der alle zu einer Gesellschaft zusammenführt und zugleich unser gemeinsames Handeln übersteigt. In der Moderne

"dagegen ist die Öffentlichkeit eine Vorstellung, die durch nichts konstituiert ist, was über das in ihrem Rahmen vollzogene gemeinsame Handeln hinausginge, also über die Bildung einer gemeinsamen Meinung, zu der man nach Möglichkeit durch Gedankenaustausch gelangt. Sie existiert ausschließlich dadurch, daß wir in dieser Weise zusammen handeln. Dieses gemeinsame Handeln wird nicht durch einen Rahmen ermöglicht, der in einer handlungstranszendenten Dimension gestiftet werden muß - sei es durch einen Akt Gottes, eine große Kette der Wesen oder ein Gesetz aus unvordenklicher Zeit. Daher kommt es, daß die Öffentlichkeit etwas durch und durch Säkulares ist. " ${ }^{318}$

Im Unterschied zu traditionsbasierten Gesellschaften entsteht die moderne Öffentlichkeit durch gemeinsames Handeln. Dieses ist das öffentlichkeitskonstituierende Moment, nicht Tradition, nicht ein transzendierender Rahmen von Gott, Kosmos, Natur, nicht ein gemeinsames Ziel. Die Öffentlichkeit der Moderne »repräsentiert daher eine ganz neuartige Instanz: einen metatopischen gemeinsamen Raum und eine gemeinsame Handlungsinstanz ohne handlungstranszendente Fundierung - eine ausschließlich in den eigenen gemeinsamen Handlungen gründende Handlungsinstanz«.319 Diese Säkularität gründet Öffentlichkeit allein auf eine rein weltlich bestimmte Zeitvorstellung.

317 | Taylor, Ein säkulares Zeitalter 2009, 331.

318 | Taylor, Ein säkulares Zeitalter 2009, 333.

319 | Taylor, Ein säkulares Zeitalter 2009, 336. 
Sie fundiert sich weder in einer Ewigkeit noch in einer mythischen Ursprungszeit, die in Riten heilsstiftend in der Gegenwart aktualisiert werden kann. ${ }^{320}$

Daraus resultiert schließlich Taylors Definition der Öffentlichkeit: »Sie ist ein seinerzeit neuer, metatopischer Raum, in dem die Angehörigen der Gesellschaft Gedanken austauschen und zu einer gemeinsamen Meinung gelangen können. Als solche ist sie konstitutiv für eine metatopische Handlungsinstanz, von der jedoch angenommen wird, sie existiere unabhängig von der politischen Konstitution der Gesellschaft und ausschließlich in der weltlichen Zeit.« ${ }^{321}$ Dies lässt die Leistungsfähigkeit in einer modernen Gesellschaft verstehen. Ihr kommt eine zentrale Rechtfertigungsfunktion der Meinungs- und Willensbildung der Bürger zu. Nicht zu Unrecht steht sie im Hintergrund moderner Vertragstheorien. Hierher bekommen Politik und Staat ihre fortwährende Legitimation, weil doch in dieser öffentlichen Sphäre die Bürger als Adressaten des Rechts zugleich auch dessen Urheber sind. Hier konstituiert sich jene Volkssouveränität, an die die Regierung gebunden ist und die zugleich die Legislative unter Druck setzt. Eine solche Öffentliche Meinung »ist eine reflektierte Ansicht, die nicht nur die zufällig in der Bevölkerung vertretenen Anschauungen resümiert, sondern aus einer kritischen Debatte hervorgeht« - ohne Vermittlung durch die politischen Institutionen. ${ }^{322}$ Da sie deshalb die Möglichkeit hat, »ein Maximum an Rationalität zu erreichen«, besitzt sie nach Taylor »normativen Rang «. ${ }^{323}$

Allerdings ist diese Form von Normativität durchaus $\mathrm{zu}$ unterscheiden von der Normativität, wie sie Habermas in seiner Diskurstheorie entwickelt. Diese Differenz verdankt sich epistemologisch dem Gegensatz zwischen einer nachmetaphysisch-prozeduralen Normativität mit Universalitätsanspruch und einer hermeneutisch-pragmatischen Vernunft, die es im Verfahren des practical reasoning um vernunftgeleitetes Schließen geht. ${ }^{324}$ Wissenschaftstheoretisch markiert dies den Unterschied zwischen einem diskurstheoretischen Gerechtigkeitsdenken und einer auf das partikulare Gute ausgerichteten Philosophie, die mal bei der Gesellschaft, mal beim Subjekt Maß nimmt.

"Habermas hat bei der Konzipierung der Diskursethik die Öffentlichkeit moderner, weltanschaulich pluraler Gesellschaften im Blick; es geht um eine für prinzipiell alle akzeptable, normativ verbindliche Regelung von Handlungskonflikten, um auf diese Weise Gerechtigkeit unter freien und gleichen Bürgern zu schaffen. Taylor hingegen rückt die

320 | Vgl. Taylor, Ein säkulares Zeitalter 2009, 336ff.

321 | Taylor, Ein säkulares Zeitalter 2009, 339.

322 | Taylor, Ein säkulares Zeitalter 2009, 325.

323 | Taylor, Ein säkulares Zeitalter 2009, 327.326.

324 | Vgl. Taylor, Quellen des Selbst 1996 140f; Joas, Die Entstehung der Werte 1999, 214-217; Knapp, Vernunft, Freiheit, Religion 2010, 299. 
menschliche Selbstfindung und -verwirklichung unter neuzeitlichen Prämissen in den Fokus. Von daher steht nicht so sehr die gesellschaftliche Öffentlichkeit als vielmehr das Individuum im Vordergrund; die Herstellung von Gerechtigkeit wird in Abhängigkeit gesehen von dem, was für den Menschen gut ist, was inm die Findung seines wahren Selbst ermöglicht. “325

Gewiss, wie wir gesehen haben spricht auch Taylor von >Diskurs $<$. Auch bei ihm ist von Einheit die Rede, die gerade durch mediale Vermittlung metatopisch hergestellt wird. Habermas gewinnt allerdings die Normativität aus den formalen Prozeduren diskursiver Deliberation. Dadurch wird eine politische Öffentlichkeit hergestellt. Demgegenüber braucht nach Taylor diese Öffentlichkeit keinen Filter der rationalen-formalen Deliberation, da sie sich in ihrer Einheit »durch die Auswahl aus dem unüberblickbaren Feld des >free-floating von Meinungen, von mediatisierten Informations- und Diskursmaterialien< selbst generiert«.326

Angesichts der Verortung in den Zusammenhängen von Anerkennung und Pluralität ist allerdings bei Taylor das Desiderat einer grundlegenden Beachtung jener Differenz- und Heterogenitätsdiskurse geradezu auffällig, die seinerseits den späten Habermas immerhin zur Ausweitung seines Öffentlichkeitstheorems motiviert haben. ${ }^{327}$ Diese finden sich bei Taylor nicht.

So zeigt sich insgesamt: Entscheidend für das Profil von Taylors Öffentlichkeitsbegriff ist vor allem das Verhältnis von Partikularität und Allgemeinheit, von Visionen des guten Lebens und des Universalismus. Hier ist nicht der Ort, der hier zu verhandelnden Spannung zwischen Liberalismus, Republikanismus und Kommunitarismus demokratietheoretisch, politikphilosophisch oder religionstheoretisch detailliert nachzuspüren. Die Literaturlage ist kaum übersehbar. ${ }^{328}$ Unser religionspädagogischer Fokus lässt vielmehr den Ort der Religion in der public sphere zum zentralen Kristallisationspunkt der Debatte werden. Hier wird exemplarisch markiert, was Taylor mit Öffentlichkeit meint. Und hier wird dann auch die religionspädagogische Brisanz vollends markiert.

325 | Knapp, Vernunft, Freiheit, Religion 2010, $297 \mathrm{f}$.

326 | Klingen, Gefährdete Öffentlichkeit 2008, 112.

327 | Vgl. C 1.

328 | Vgl. Kühnlein, Lutz-Bachmann, Unerfüllte Moderne 2011; Brunkhorst u.a., Habermas Handbuch 2009; Brumlik, Brunkhorst, Gemeinschaft und Gerechtigkeit 1993; Fraser, Honneth, Umverteilung oder Anerkennung 2003. 


\subsection{Vernunftfähige Religion}

Taylors Zugang zur Religion in der Öffentlichkeit beruht auf der Verfugung von zwei Perspektiven, die nur analytisch zu trennen sind: einmal ist es sein bereits erläuterter Vernunftbegriff, dann ist es sein Verständnis von Säkularität. ${ }^{329}$ Beides führt ihn zu seinem Konzept der Religion in der Öffentlichkeit, das sich signifikant von Konzepten wie dem von Rawls oder dem von Habermas abhebt. Diese gelten (trotz der anderslautenden Selbstbezeichnung als deliberativer Ansatz bei Habermas) wegen der strikten Trennung von Religion und Staat und des universalistisch-normativen Ansatzes als liberal, während Taylor auf die Seite jener kommunitaristischer Ansätze gezogen wird, die sich neo-aristotelisch an Visionen des guten Lebens ausrichten. ${ }^{330}$

Dabei spielt die Neubestimmung des Laizismusbegriffs eine wesentliche Rolle, dessen Konturen Taylor in einer kritischen Relecture gewinnt. Gespeist aus seinen Erfahrungen aus Quebec, sensibilisiert aus den Diskussionen um Religion in der Öffentlichkeit in den USA und in Frankreich, greift er auf die ursprüngliche Intention des Laizismusbegriffs zurück, wie er in der Französischen Revolution entwickelt wurde. Diesem ging es im Kern um die Sicherung von Freiheit, Gleichheit, Brüderlichkeit in Sachen Religion. Alle sollen unbehindert, frei, gleichberechtigt und im brüderlich-solidarischen Blick auf die Anderen ihre Religion oder Weltanschauung leben können, und genau dadurch dann das Gemeinwohl und die Gesellschaft insgesamt stärken. ${ }^{331}$ Laizismus wäre dann die richtige Antwort des demokratischen Staats auf die Vielfalt und Pluralität verschiedener Religionen und Weltanschauungen.

Taylor kann nicht verstanden werden, wenn nicht die bereits erläuterte Ausweitung des Säkularisierungsbegriffs im Sinne einer rein immanenten Begründung kultureller, gesellschaftlicher und staatlicher Ordnung gesehen wird. Vor diesem Hintergrund gibt es »keinen Grund, der Religion eine von nichtreligiösen, >säkularen (in einem anderen gebräuchlichen Sinn des Worts) oder atheistischen Standpunkten abgehobene Sonderstellung zuzuweisen «.332 Während es in Frankreich zentral um die Privatisierung von Religion gehe, liege jedoch der Sinn der staatlichen Neutralität darin, »jegliche Bevorzugung oder Benachteiligung nicht nur religiöser Bekenntnisse, sondern überhaupt jeder Weltanschauung, sei sie religiöser oder nichtreligiöser Natur, zu vermeiden«.333 Andererseits sind für republikanisch-humanistische Traditionen

329 | Vgl. Taylor, Dilemmas and Connections 2011, 167-325.

330 | Vgl. Knapp, Vernunft, Freiheit, Religion 2010, 287; Rudolph, Rousseau absconditus 2011, 107-116.

331 | Vgl. Taylor, Neubestimmung des Säkularismus 2012, 55.

332 | Taylor, Neubestimmung des Säkularismus 2012, 57.

333 | Taylor, Neubestimmung des Säkularismus 2012, 58. 
demokratische Systeme auf eine vorlaufende Bejahung und Identifizierung angewiesen. Da freilich unter den Bedingungen weltanschaulicher Pluralität selbst eine Zivilreligion solches zu leisten nicht mehr im Stande sei, sind wir, so Taylor in überraschender Klarheit, geradezu zu einem »übergreifenden Konsens verurteilt«.334 Man ginge allerdings fehl in der Annahme, dass diese terminologische Reminiszenz an den Liberalismus John Rawls nun auch Taylor in eine ähnliche Richtung drängen würde, die säkulare Vernunft als das alles einigende und Verstehen ermöglichende Band zu sehen. Im Gegenteil. Vielmehr kommt hier Taylors erkenntnistheoretisches Argument zum Zuge, das den fundamentalen Unterschied in scharfen Worten markiert. Auch wenn er konzediert, dass der späte Rawls inzwischen die starke Asymmetrie zwischen säkularen und religiösen Bürgern beseitigt habe, auch wenn dieser derweil die Forderung relativiert habe, »daß man in einer durch religiöse und weltanschauliche Vielfalt geprägten Demokratie von allen Bürgern aus guten Gründen verlangen könne, sich ausschließlich in Vernunftbegriffen zu beraten und religiöse Überzeugungen an der Garderobe der öffentlichen Sphäre abzugeben «, 335 so bleibe bei Rawls die klare Favorisierung der säkularen Sprache und der säkularen Vernunft. Taylor spricht hier gar in Bezug auf den frühen Rawls vom »tyrannical character«, dem »despotischen Charakter« einer solchen liberalen Vernunft. ${ }^{336}$

Sei es bei Habermas, sei es bei Rawls: das Argument ist bei allen liberalen Zuordnungen von Religion in der Öffentlichkeit ähnlich. Säkulare Vernunft bietet »eine Sprache an, die jeder spricht und in der sich jeder verständlich machen bzw. überzeugen lassen kann. Religiöse Sprachen bewegen sich hingegen außerhalb dieses Diskurses, weil sie heteronome Voraussetzungen ins Spiel bringen, zu denen sich nur Gläubige bekennen können. Also sollten wir uns auf eine Sprache einigen, die alle teilen. « ${ }^{337}$ Stets wird unterstellt, dass Religion weniger rational als säkulare Vernunft und deswegen heteronom sei. Dies aber sei aus zwei Gründen problematisch. Erstens sei das Argument widersprüchlich, beruhe es doch auf einer petitio principii. Es setze voraus, was ausgesagt werden soll. So kann es nur die überzeugen, die es bereits teilen. Entweder kommt die religiöse Vernunft zu ähnlichen Einsichten wie die säkulare, dann aber ist sie überflüssig. Oder sie sei gefährlich, so dass sie erst recht abzulehnen ist. ${ }^{338}$ Zum anderen aber beruht das Argument auf einem verengten, eindimensionalen Vernunftverständnis. Im Hintergrund stehe ge-

334 | Taylor, Neubestimmung des Säkularismus 2012, 73.

335 | Taylor, Neubestimmung des Säkularismus 2012, 75.

336 | Taylor, Dilemmas and Connections 2011, 320; vgl. Taylor, Neubestimmung des Säkularismus 2012, 75.

337 | Taylor, Neubestimmung des Säkularismus 2012, 75.

338 | Vgl. Taylor, Neubestimmung des Säkularismus 2012, 76. 
nau jener »Mythos der Aufklärung«,339 jener Descartesianismus, dessen Problematik wir bereits in seinen ganzen Facetten herausgearbeitet haben. Dass Religion nicht gleichberechtigt neben säkularer Vernunft teil haben kann an der Grundlage gesellschaftlicher Verständigung, dass man ihr - im Gegensatz zur säkularen Vernunft - a priori mit Verdacht begegnet, dass man sie aussondert aus den anderen Versionen guten Lebens, all dies hält Taylor für unbegründet. Die Orientierungs- und Begründungsleistungen säkularer Moralkonzepte wie der des Kantianismus, Utilitarismus, des Hegelianismus oder der Diskursethik hätten bislang nicht mehr Plausibilität und Kraft bewiesen als ein schöpfungstheologisches Argument. Hätten die Menschen Martin L. King »besser verstanden, wenn er Kant zitiert hätte «, fragt er? ${ }^{340}$ Trotz der Fortschritte bei Rawls und insbesondere bei Habermas, was die Würdigung von Religion in der Öffentlichkeit angehe, geht Habermas »stets von einem erkenntnistheoretischen Bruch« zwischen säkularer Vernunft und religiösem Denken aus, weshalb er ersterer den Vorzug gebe. ${ }^{341}$

In der Tat: Oben haben wir bereits auf die kategoriale Differenz von Glauben und Wissen bei Habermas hingewiesen. Er verortet zwar beide in der Geschichte des Geistes, da beide im Zuge der Weltbildrevolution der Achsenzeit um Transzendenz bemüht seien, wodurch erst ein Bewusstsein von Kontingenz und subjektiver Verantwortung entstanden sei. Dies verlangt nicht zuletzt der säkularen Vernunft eine lernbereite Haltung gegenüber religiöser Vernunft ab, nicht zuletzt um der Tendenz zur Degenerierung zu einer instrumentellen Vernunft zu wehren. Diese wird sich »selbst nur verstehen lernen, wenn sie ihre Stellung zum zeitgenössischen, reflex gewordenen Bewusstsein klärt, indem sie den gemeinsamen Ursprung der beiden komplementären Gestalten des Geistes aus dem Schub der Achsenzeit begreift «.342 Gleichwohl bleiben religiöse und säkulare Vernunft um ihrer selbst willen getrennt: religiöse Vernunft basiert letztlich in Offenbarungserfahrungen und kultisch-rituellen Praktiken, die für säkulare Vernunft nicht erreichbar sind und opak bleiben; philosophische Vernunft würde sich von der »Strenge diskursiven Denkens dispensieren«, würde ins Schwärmen geraten und damit ihre genuine Orientierungsleistung verlieren, würde sie sich religiöse Gehalte ungebrochen zu Eigen machen. ${ }^{343}$ Doch trotz dieser Komplementarität priorisiert Habermas die säkulare Vernunft, bildet sie doch »in weltanschaulich

339 | Taylor, Neubestimmung des Säkularismus 2012, 79.

340 | Taylor, Neubestimmung des Säkularismus 2012, 87.

341 | Taylor, Neubestimmung des Säkularismus 2012, 76.

342 | Habermas, Ein Bewußtsein von dem, was fehlt 2008, 29; vgl. Knapp, Vernunft, Freiheit, Religion 2010, $296 f$.

343 | Habermas, Zwischen Naturalismus und Religion 2005, 257. 
pluralistischen Gesellschaften die einzige rational akzeptable Grundlage für eine normative Regelung von Handlungskonflikten«.344

Man kann nun nicht sagen, dass Taylor »unbedingt religiöser als Rawls, Habermas oder Rorty« ist, so die provozierende und sicher nicht von allen geteilte Einschätzung des Luzerner Philosophen Enno Rudolph. Aber Taylor »sieht im Anspruch der religiösen Sprachen ein Menschenrecht gegen den Exklusivismus der säkularisierten Uniformität«.345 Philosophisch dient ihm seine Sprach- und Vernunftkonzeption als Ansatzpunkt hierfür. Die in Lebensvollzüge und sprachliche Vernetzungen eingebettete Vernunft kann die Vernunfthaltigkeit der Religion und zugleich die Offenheit der säkularen Vernunft für Kreativität, Transzendenz und Glaube begründen. Dieses »umfassende Vernunftverständnis« kann zeigen: Die Vernunft besitzt »eine schöpferische Komponente; sie kann neue Weisen der Erfassung der Wirklichkeit, die sie zu verstehen sucht, erzeugen und muss dies auch tun [...] Man könnte dieses Phänomen auch als eine Art Glaube (faith) bezeichnen«.346 Religiöse Vernunft ist damit diskursfähig, ist auf der Ebene rationaler Debatten aussagekräftig und durchaus auch in einem normativen Sinne gehaltvoll, sinnstiftend wie orientierungsstark.

Damit hat Taylor die epistemologische und vernunfttheoretische Basis für die Legitimität der Religion in der Öffentlichkeit bereitet. Nur wie konturiert er diese angesichts der durchaus legitimen Argumente, die er selber für die staatliche Neutralität ins Feld geführt hat? Es muss in einem säkularen Staat Bereiche geben, in der die Sprache neutral bleibt. Dazu zählt er jedoch nicht schon den Bereich der öffentlichen Beratung (wie Rawls) und ebenfalls nicht die parlamentarischen Debatten (wie Habermas). Erst die »amtliche Sprache des Staates« lässt sich als jener neutrale Bereich bestimmen, weil sich nicht einsehen lasse, inwiefern Gesetze im Namen Buddhas, Kants, Jesu oder Karl Marx' unter Pluralitätsbedingungen Plausibilität beanspruchen könnten. ${ }^{347}$ Voraussetzung hierfür sei jedoch die Weiterentwicklung des traditionellen Laizitätskonzepts im Sinne einer »pluralistischen Laizität.« ${ }^{348}$ Dazu gehöre die Entwicklung einer »Ethik des Dialogs« als »politische Minimalmoral« bzw. eines »übergreifenden Konsenses«, den die Bürger lernen müssten.

"Diese müssen die Autorität der geteilten Prinzipien akzeptieren, die ihren politischen Institutionen zugrunde liegen, obwohl sie unterschiedlichen Auffassungen des Guten verpflichtet sind. Dabei handelt es sich in gewisser Weise um eine Vertiefung des Ideals

344 | Habermas, Die Zukunft der menschlichen Natur 2005, 151.

345 | Rudolph, Rousseau absconditus 2011, 115.

346 | Taylor, Replik 2011, $856 f$.

347 | Taylor, Neubestimmung des Säkularismus 2012, 77.

348 | Maclure, Taylor, Laizität und Gewissensfreiheit 2011, 146. 
der Toleranz, das die Beendigung religiöser Konflikte ermöglicht hat. Diese Art von Gesellschaft verlangt von ihren Bürgern, daß diese von ihren zum Teil recht tief reichenden moralischen und philosophischen Meinungsverschiedenheiten im Namen ihres grundlegenderen Interesses an einem Zusammenleben in einer ausreichend stabilen und harmonischen Gesellschaft abstrahieren“

und eine offene Diskussion über die Grundlagen und die Ausrichtung ihrer politischen Gemeinschaft führen. ${ }^{349}$ Jenseits der Marginalisierungen der Religion gegenüber der säkularen Vernunft in der Öffentlichkeit sowie im Gegensatz zu einem kognitiv-reduktionistischen Vernunftverständnis ist erst eine solche lernbereite Dialogizität in der Lage, Gleichheit, Freiheit und Brüderlichkeit zu realisieren. Dies freilich setzt den Bruch mit überkommenen Denkmustern voraus. »Eine Ordnung, die sich in der heutigen Demokratie aus gutem Grund als säkularistische bezeichnet, darf sich nicht primär als Bollwerk gegen die Religion verstehen, sondern als wohlmeinender Versuch, die drei [...] grundlegenden Ziele zu verwirklichen [...]. Sie muss versuchen, ihre institutionellen Arrangements so zu gestalten, daß sie zwischen den verschiedenen Weltanschauungen ein Höchstmaß an Freiheit und Gleichheit garantieren, statt geheiligten Traditionen treu zu bleiben. ${ }^{350}$

\subsection{Hanan Alexanders Pädagogik als Konkretisierung}

Aus religionspädagogischer Perspektive sind diese Debatten zwischen Liberalismus und Kommunitarismus kein beiläufiges Spiel. Sie sind schon deshalb relevant, weil sich in letzter Zeit Positionen häufen, die die öffentliche Bedeutung religiöser Bildung und Erziehung reklamieren und sich dabei explizit auf Taylor oder andere Vertreter des Kommunitarismus berufen. Exemplarisch soll die kurze Erörterung eines solchen Ansatzes zeigen, inwieweit sich eine Öffentliche Religionspädagogik mit solchen Positionen auseinandersetzen muss.

Ein besonders prominentes Beispiel hierfür ist der Versuch des jüdischen Erziehungsphilosophen Hanan Alexander, Erziehung in einer pluralen demokratischen Gesellschaft zu konturieren. Beheimatet in den USA und Professor für Philosophie der Erziehung in Haifa, basiert er seine Überlegungen auf Erfahrungen in beiden Kontexten. ${ }^{351}$ Der zentrale Fokus seiner Theorie liegt darin, Erziehung als einen integralen Weg für ein gelingendes Gemeinwesen wie für das gute Leben der Individuen aufzuweisen. Als solche zielt sie im Wesent-

349 | Maclure, Taylor, Laizität und Gewissensfreiheit 2011, $141 f$.

350 | Taylor, Neubestimmung des Säkularismus 2012, 85.

351 | Vgl. Alexander, Reimagining Liberal Education 2015, 2-15. 
lichen auf eine »pedagogy of difference «,352 die ihre Maximen aus zwei Quellen bezieht: der Hebräischen Bibel wie der säkularen Vernunft. Wichtige Impulse kommen aus dem Neo-Aristotelismus, der Dialogik Martin Bubers, dem Pragmatismus von William James und John Deweys und der Philosophie Isaiah Berlins. Erziehung muss für Alexander mit einem solchen, höchst elaborierten Konzept aufwarten, um der Übermacht technokratischer Pädagogik mit deren vornehmlich quantifizierender Methodik überhaupt mit Plausibilität und Kohärenz entgegentreten zu können. Letztlich ist dort nämlich nichts weniger berührt als die nachgerade klassische Spannung zwischen Liberalismus und Republikanismus, zwischen liberalen kantianischen und hegelianisch inspirierten kommunitaristischen Traditionen, ja zwischen Glaube und Vernunft.

In dem Maße, in dem Alexander dabei den Primat liberaler Vernunft attackiert und diese in ihrem normativen Universalismus als Grundlage für eine an Differenz und Demokratie ausgerichtete Gesellschaft prinzipiell in Zweifel zieht, in dem Maße konturiert er demgegenüber seine Differenzpädagogik, die auf der »cultivation of transcendental concepts of the good « beruht. ${ }^{353}$ Diese will gerade nicht a-liberal sein. Vielmehr will sie liberale Traditionen durch deren Konfrontation mit neoaristotelischen und pragmatischen Positionen weiterentwickeln. Er will auf den Feldern der Pädagogik und Erziehung einen kritisch fortgeschriebenen Liberalismus, »that celebrates particularity and distinctiveness in ways that recognize the rights of both majority and minority cultures while enhancing the individual capacity for intelligent choice, personal freedom, and respect for difference required in democratic regimes «.354

Sein Programm eines »Reimagining liberal education« fußt damit philosophisch auf einem »liberal communitarianism « und erkenntnistheoretisch auf einem »transcendental pragmatism «. ${ }^{355}$ Dementsprechend zielt Alexander gerade auf eine Pädagogik, die die »chimera of neutrality« überwindet und in kritischer pragmatischer Fortschreibung des Liberalismus Traditionen von Moral, Ethik, Spiritualität und Religion einbringt. ${ }^{356}$ »Liberal education under these conditions entails initiation into a transcendental vision of the good embodied in a dynamic heritage that is willing to engage rival accounts of the truth and different visions of how best to live, not exposure to weak personalized cultures or indoctrination into dogmatic traditions closed to alternatives. $\ll^{357}$

352 | Alexander, Reimagining Liberal Education 2015, 90; als Referenzpunkt: Dewey, Die Öffentlichkeit 1996.

353 | Alexander, Reimagining Liberal Education 2015, 1.

354 | Alexander, Reimagining Liberal Education 2015, 3.

355 | Alexander, Reimagining Liberal Education 2015, 4.

356 | Alexander, Reimagining Liberal Education 2015, 9; vgl. 150-200.

357 | Alexander, Reimagining Liberal Education 2015, 9. 
Methodisch gehören zu diesem Programm mindestens zwei Schritte: erstens eine kritisch-dekonstruktive Analytik des Liberalismusbegriffs und zweitens die Konstruktion einer positiven Alternative. Nach all dem, was wir bereits angedeutet haben, verwundert es kaum, dass bei beiden Aufgaben Charles Taylor stets eine wichtige Referenzgröße darstellt. Dies wird bereits deutlich bei Alexanders Liberalismuskritik. Es ist nicht nur die »tendency towards homogeneity«, die liberale Demokratien prägt, die »appear to be more accepting of nonaligned secularism than of abiding commitment to ancestral tradition «. 358 Es ist die damit vollzogene Priorisierung säkularer Vernunft wegen der mit ihr verbundenen »idea of rationality as rigorously neutral«.359

Diese Priorität wird, wie gesagt, liberaler Vernunft wegen ihrer Leistungsfähigkeit eingeräumt, in einer pluralen Gesellschaft den einzig möglichen Verständigungs-, Orientierungs- und Sinnstiftungsrahmen zwischen den partikularen und teilweise konfligierenden Überzeugungen und Weltbildern abzugeben. Die schwierigsten und am stärksten bedrängenden Dilemmata einer pluralistischen und offenen Demokratie könnten durch sie gelöst werden: Wie kann der zentrale liberale Wert wechselseitigen Respekts und friedvoller Koexistenz mit den ernsthaften Überzeugungen aus Glauben, Kultur und nationalen Traditionen vermittelt werden? Wie kann in und über nationale(n) Trennungen hinaus das Verhältnis zwischen öffentlichen und privaten, zwischen allgemeinen und partikularen Feldern angemessen gestaltet werden? Die Antwort: Nur durch Neutralität sei die Einheit in Vielfalt und die Vielfalt in Einheit überhaupt denkbar. Diese Vorstellung sei als unhinterfragte Hintergrundannahme neben den gegenwärtigen gesellschaftlichen und kulturellen Debatten auch in Schule und wissenschaftlicher Pädagogik dominant. Sie wirke in den Zielbestimmungen dessen, was Schüler und Studenten lernen, wie Schule und Universität organisiert, welche Inhalte traktiert und wie sie vermittelt werden. Curricula in Schule und Universität, die Debatten um die Alimentierung und Existenz öffentlicher und privater Schulen, die Frage nach dem Stellenwert religiöser Bildung in öffentlichen Schulen, die je neu auszulotende Frage nach dem Profil einer demokratischen citizenship und deren pädagogische Voraussetzungen: all dies wird in der Sicht Hanan Alexanders durch diese Neutralitätsdominanz geprägt. ${ }^{360}$

Doch ist diese Neutralitätsforderung liberaler Vernunft in mehrfacher Hinsicht problematisch. Einmal verwickelt sich diese Neutralitätszuschreibung in Selbstwidersprüche, ein Argument, was auch Taylor gegenüber liberaler Vernunft vorgebracht hat. Von einen neutralen »view from nowhere« auszugehen, kann nicht bewiesen werden, ohne bereits zu unterstellen, was erst

358 | Alexander, Reimagining Liberal Education 2015, 2.

359 | Alexander, Reimagining Liberal Education 2015, 5.

360 | Vgl. Alexander, Reimagining Liberal Education 2015, 135-150. 
noch demonstriert werden soll. ${ }^{361}$ Entscheidender freilich als dieses logische Problem sind vor allem zwei grundlegende Schwierigkeiten, die letztlich den Öffentlichkeitscharakter partikularer Traditionen betreffen: 1. unterstellt es $\mathrm{zu}$ oft ein »distorted, even intolerant, picture of faith and other traditions as necessarily cracy, dogmatic, or divisive, a representation that limits our ability to identify those seeking to live in peace with others who are different « ${ }^{362}$ 2. transportiert eine solche Neutralitätsforderung liberaler Vernunft ein Ideal persönlicher Autonomie, das vor allem selbstzentriert ist. Denn anstatt den Menschen je schon in das Gewebe von Traditionen und weltbildhaften Narrationen verwickelt zu denken, anstatt ihn ausgesetzt und konfrontiert mit den Nöten der Anderen zu sehen, würde hier die vom Subjekt her gedachte Vernunft dominieren. Am Ende drohe dies gar dazu zu führen, »that one loses the ability to commit to anything at all ${ }^{363}$

Spätestens hier wird der aporetische Zug der liberalen Neutralitätsforderung offenkundig. Sie konterkariert genau das, wessen eine offene plurale Demokratie bedarf, nicht zuletzt auf dem Feld politischer und gesellschaftlicher Lernprozesse für das common good. Denn dies unterminiert die identitäts- wie gesellschaftskonstituierenden Lernprozesse im Kern. »Identity is constructed out of the contingent historical traditions by means of which humans engage the world. Learning to make intelligent choices concerning how to define oneself within the context of such traditions is what education is all about. The systematic study of how this is accomplished should lead us toward, not away from, substantive engagement with the values of those traditions. $\aleph^{364}$ Plurale Demokratien brauchen Lernprozesse in Schule und Universität, in denen die Bürger ihr gesellschaftliches Engagement gründen in bestimmten ethischen, kulturellen oder religiösen Traditionen, während sie zugleich zu akzeptieren lernen, dass die anderen dies aus deren jeweiligen Traditionen und Lebenswegen tun, die durchaus verschieden von den eigenen sind. Um aber den anderen zu akzeptieren, »one must know oneself, but to know oneself one must also accept the other«.365 Diese Fähigkeit zur interkulturellen und interreligiösen Verständigung, zum politischen Engagement und zur persönlichen Identität wird in ebensolchen Begegnungen zwischen den differenten Traditionen aus einer jeweiligen erfahrungsgesättigten Binnenperspektive heraus gelernt. Lernen erfolgt durch Wechsel der jeweiligen Teilnehmerperspektive und dessen kritischer Reflexion. »One can acquire the capacity to make independent choices given that we can never stand outside of the lives we lead by learning

361 | Vgl. Alexander, Reimagining Liberal Education 2015, 4-6.90.

362 | Alexander, Reimagining Liberal Education 2015, 6.

363 | Alexander, Reimagining Liberal Education 2015, 6.

364 | Alexander, Reimagining Liberal Education 2015, 13.

365 | Alexander, Reimagining Liberal Education 2015, 16. 
to be different and to respect the difference of others. This requires an understanding of the traditions to which one is heir or with which one chooses to affiliate that is open to exposure and critique according to traditions other than one's own. ${ }^{366}$ Religion und ein sehr weit gefasster Begriff von Spiritualität sind dabei von eminenter Wichtigkeit, weshalb auch spirituelle und religiöse Erziehung in die öffentliche Schule gehören. ${ }^{367}$

Im Hintergrund dieser Pädagogik, die sich dezidiert in den normativen Rahmen einer pluralen Demokratie einordnet, steht nun genau jene Hermeneutik sprachlich vermittelter Interaktionen und starker Wertungen, wie sie Taylor und auf seine Weise auch der Kommunitarist Michael Walzer vornehmen. Demnach lassen sich weder philosophische Vernunft noch pädagogische Praxis außerhalb der konkreten Bindungen an lebensweltliche Praxen, Narrationen und geschichtliche Überlieferungen artikulieren. Während Walzer mit seiner gerechtigkeitstheoretischen Differenzierung zwischen solchen »thick moral traditions « und den in formal-abstrakten Universalismen gegründeten »thin moral traditions « für Alexander moraltheoretisch wichtig wird, ${ }^{368}$ leitet Alexander von Taylor die Orientierung an einem expressionistischen Selbst ab, das in interkommunikativen, sprachlich-narrativen Traditionszusammenhängen lebt. Aber ebenfalls auf grundlagentheoretischer Ebene wird Taylor maßgeblich. Denn von ihm her gewinnt er schließlich jene Kriterien, die erst Orientierung in der Pluralität distinkter Werte und Traditionen liefern.

Damit aber berühren wir den Kern von Alexanders Position, wo auch virulent wird, ob diese tatsächlich die eigenen Ansprüche einlösen kann, die Orientierungs- und Begründungsleistungen der säkularen Vernunft in der liberalen Tradition eines Rawls oder Habermas kritisch fortzuschreiben. Es liegt in der Logik von Alexanders Ansatz, dass »faith and rational traditions - those that call for affiliation and those that insist upon the rigors of critical inquiry belong on a more equal footing than has heretofore been allowed by most philosophical accounts of the relation between them «. ${ }^{609}$ Doch wie soll, wo Religion und säkulare Vernunft auf einer Ebene angesiedelt sind, Vermittlung, wie soll kriterielle Unterscheidung zwischen guter und schlechter Tradition möglich sein? Alexander ist ein solches Erfordernis durchaus bewusst, braucht es doch auch für ihn »a robust form of pluralism that presupposes, at least as a regulative principle, a higher good beyond the boundaries of our various perspectives, the possibility and substance of which can only be perceived from within the

366 | Alexander, Reimagining Liberal Education 2015, 9; vgl. 11.

367 | Vgl. Alexander, Reimagining Liberal Education 2015, 4.215-222.

368 | Vgl. Alexander, Reimagining Liberal Education 2015, 158.223. Vgl. neuerdings zur Relevanz Walzers für die Politische Theologie Kühnlein, Exodus, Exilpolitik und Revolution 2017.

369 | Alexander, Reimagining Liberal Education 2015, 11. 
confines of those very boundaries « ${ }^{370}$ Allerdings tendiert die säkulare neutrale Vernunft durch ihre homogenisierende Wirkung zur Abblendung von Differenzen. Ein formaler Prozeduralismus oder ein universaler Liberalismus sind $»$ too universal «. ${ }^{371}$ Daher ist es das Konzept jener starken Wertungen, jene »strong evaluation, based on norms that emanate from beyond the self «, 372 denen Alexander im Rückgang auf Taylor diese Leistungen zutraut.

Doch reicht tatsächlich diese in den lebensweltbezogenen Wertungen situierte Normativität aus, um jene Kraft zu generieren, die Alexanders Ansatz braucht, um seine eigenen Ziele einzulösen? Oder ist jene Figur der starken Wertungen zu schwach? Gewiss, Hanan Alexander verschafft Traditionen und Visionen des guten Lebens im Feld säkularer Pädagogik durch pädagogische, religiöse wie philosophische Argumente auf ganz beeindruckende Weise Gewicht. Aber bleibt sein hermeneutischer Rahmen gerade in heterogenen Kontexten nicht doch zu leichtgewichtig, in denen doch Kriterien und Kategorien zur Urteilsbildung in pädagogischen Zusammenhängen unerlässlich sind? In besonderer Radikalität gilt dies doch für das Feld der Religionen mit deren immanenten absoluten Wahrheitsansprüchen.

Mit dieser Problematisierung des von Alexander verwendeten hermeneutischen Instrumentariums kommt daher wiederum sein Gewährsmann Taylor ins Spiel. Fraglich ist, ob Alexanders Überhangprobleme auch die von Taylor sind. Dem soll eine kritische Diskussion nachspüren.

\subsection{Kritik}

Partikulare Traditionen in der säkularen Moderne zur Geltung zu bringen, um im Dienste des Ganzen und zur individuellen Identitätsstiftung Kraft, Orientierung, Motivation und Sinnstiftung zu generieren, darin liegt sicherlich ein zentraler Verdienst von Taylors Öffentlichkeitstheorie. Die fruchtbare Wirksamkeit auf dem Feld der Pädagogik machen die Arbeiten Alexanders eindrucksvoll deutlich. Die Voraussetzung hierfür ist sicherlich der spezifische epistemologische Status, den Taylor partikularen Visionen des guten Lebens in der Öffentlichkeit einräumt. Für Taylor werden partikulare Traditionen nicht ins Private abgedrängt wie in laizistischen Versionen säkularer Vernunft. Obschon Habermas Religionen in die Geschichte der einen Vernunft einordnet, bleiben diese letztlich für die säkulare Vernunft opak. Hier setzt Taylor diametral andere Akzente, will er doch den besonderen epistemologischen Status solcher Traditionen gegenüber der Vernunft dekonstruieren. Damit aber dekonstruiert er auch die Asymmetrie zwischen säkularer Vernunft und Vi-

370 | Alexander, Reimagining Liberal Education 2015, 10.

371 | Alexander, Reimagining Liberal Education 2015, 14.

372 | Alexander, Reimagining Liberal Education 2015, 122; vgl. $136 \mathrm{ff}$. 
sionen des guten Lebens, die selbst Habermas zumindest in bestimmten Bereichen öffentlicher Selbstverständigungsprozesse nicht überwinden will. Für Taylor sind alle Traditionen zunächst einmal diskursfähig im dialogischen Ringen um das gemeinsame Gut, eine Überlegung, aus der Alexander ja faszinierendes pädagogisches Kapital schlagen kann. Gerade in dem Ringen postsäkularer Gesellschaften um die Gegenwart von Religion in der schulischen Öffentlichkeit sind dies nicht zuletzt für die Religionspädagogik enorm triftige Gedanken. Denn sie können argumentativ legitimieren, und nicht nur durch rechtliche oder konventionelle Rahmenbedingungen abgesichert erscheinen lassen, warum Religion und Ethik in die Schule gehören. Es sind pädagogische, religiöse wie gesellschaftliche Gründe, die für deren schulische Präsenz sprechen.

Mit der gleichberechtigten Teilhabe aller Traditionen neben der säkularen Vernunft wird freilich das Problem der Verhältnisbestimmung von Universalität und Partikularität brisant. Aus religionspädagogischem Interesse an einem grundlagentheoretischen Design des Öffentlichkeitsbegriffs liegt hier der sensible Punkt. Schafft es Taylor mit seiner Vernunft jene Unterscheidungskriterien zu generieren, die doch in religiös aufgeladenen heterogenen Lebenswelten um der Wahrheitsfähigkeit und Diskursivität der jeweiligen Traditionen in der Öffentlichkeit erforderlich sind? Woran kann, um die Sache auf den Punkt zu bringen, die Differenz zwischen Religion und Astrologie festgemacht und begründet für Außenstehende ausgewiesen werden? Wo liegt die Differenz zwischen Esoterik und Glauben? Mag Habermas trotz seinem Bemühen um eine lebensweltliche Grundierung der diskursiven Vernunft die konkreten Kontexte zu stark abgeblendet haben, ergibt sich doch bei Taylor die umgekehrte Problematik. Für Taylors Konzept »starker Wertungen« mag gelten, dass eine Öffentlichkeitstheorie, die konkrete, »nur in beschränkten Kontexten gültige Kriterien heranzuziehen imstande ist, in mancher Hinsicht für die jeweilige Lebenswirklichkeit weit folgenreicher« ist, als eine, »die auf abstrakt-universalistische Maßstäbe und Prinzipien angewiesen bleibt, welche notwendigerweise mit einer Vielzahl von Gesellschaftsformen vereinbar sein müssen «.373 Aber im selben Maße wird doch deutlich, dass diese partikularen Visionen des Guten eines übergreifenden Rahmens bedürfen, der diese »zugleich übergreift und eine differenzierte Praxis der Kritik innerhalb und über sie hinaus « ermöglichen kann. ${ }^{374}$ In heterogenen Demokratien läuft das Ansinnen, bestimmte Konzepte guten Lebens für alle verbindlich zu machen, auf einen Regress hinter die Ausdifferenzierungsprozesse der Moderne hinaus. Werte und Normen müssen in ihrer Gültigkeit für alle legitimiert werden. Sie benötigen daher ebenso eine universale Perspektive wie das Feld des öffentli-

373 | Rosa, Art.: Kommunitarismus 2011, 223.

374 | Forst, Kritik der Rechtfertigungsverhältnisse 2011, 18. 
chen Diskurses zwischen den Traditionen. Auf dem Feld der Ethik hält Rainer Forst aus dem Erbe Kritischer Theorie daran fest, dass in pluralen Kontexten, »in denen keine geteilten ethischen Überzeugungen überzeugende Antworten liefern«, es Normen erfordert, »die auf andere, (ebenfalls) intersubjektive Weise gerechtfertigt werden können. Dort erst beginnt die Frage der Gerechtigkeit«.375 Diesen Status normativer Unterscheidungsfähigkeit lässt jedoch Taylors Öffentlichkeitskonzept vermissen. Er blendet damit aus, dass selbst bei philosophischer Adaption partikulare Traditionen wie »auch theologische Aussagen begründungspflichtig bleiben «. ${ }^{376}$

Für eine öffentliche Religionspädagogik resultiert daraus ein Frageüberhang von solch starkem Gewicht, der ihr zu denken geben müsste: Wie lassen sich partikulare Traditionen und Öffentlichkeit in ihrem Verhältnis so bestimmen, dass damit die Ressourcen, die eine plurale Demokratie benötigt, generiert werden können? Wie lassen sich Universalität und Partikularität, Normativität und Lebenswelten, wie lassen sich das Gute und das Gerechte angemessen in Beziehung setzen? Welchen Rang hat dabei die religiöse Tradition? Wie wirkt sich dies auf der Ebene der schulischen Öffentlichkeit aus, in der wie in einem Mikrokosmus des makrosoziologischen Gefüges in Gestalt diverser Schulfächer distinkte Weltorientierungen und Weltbildkonstruktionen mit distinkten evaluativen, ja normativen Aufladungen so zusammenkommen, dass sie alle gemeinsam und jeweils als diese selbst ihren Beitrag zur Bildung der Heranwachsenden leisten?

Und, noch fundamentaler: teilt nicht auch dieser Zugang zur Öffentlichkeit mit anderen bislang erörterten Zugängen eine gemeinsame Verengung aufs Diskursive und Kognitive? Hat sich nicht in den Straßen und Plätzen der Metropolen längst eine neue Form der Konstitution von Öffentlichkeit etabliert, deren Herausforderungen für den Öffentlichkeitsbegriff in der Philosophie, in der Politischen Theorie oder gar in der Religionspädagogik größtenteils nicht einmal im Ansatz wahrgenommen werden? Es gibt neue Theorien einer solchen Öffentlichkeit, die deshalb ins Gespräch zu bringen sind. Aber nicht nur deshalb: Sie bringen überdies einen weiteren Aspekt ein, der bisher wohl mehrfach angespielt, aber nicht ausgefaltet wurde.

375 | Forst, Kontexte 1994, 349.

376 | Markus Knapp, Gott in säkularer Gesellschaft 2011, 678; vgl. Goldstein, Säkularisierung als Vorsehung 2011. 


\section{Poststrukturalismus und Performative ÖFFENTLICHKEIT: JUDITH BUTLER}

Bislang stellte sich als eines der zentralen Probleme des Öffentlichkeitsbegriffs das Verhältnis zwischen Partikularität und einer normativ bestimmten Universalität heraus. Ob bei Habermas, Gerhardt, Luhmann oder Taylor: Stets ging es um das prekäre Ringen darum, wie bestimmte Lebenswelten, Traditionen oder auch Visionen guten Lebens so miteinander vermittelt werden können, dass das Ganze befördert und zum Wohle aller ausgestaltet werden kann. Eklatant wird dies auf dem Felde der Religion und der bedrängenden Frage nach ihrem Platz in der Öffentlichkeit. Was aber in diesem Streit bislang nur angedeutet wurde, waren die Mechanismen der Öffentlichkeitstheorie selber, die wiederum auf das Profil der Öffentlichkeit massiven Einfluss haben. In unserer Auseinandersetzung mit der Deliberativen Öffentlichkeit wurde zumindest als Frageüberhang markiert, dass die in der Konturierung des Öffentlichkeitsbegriffs performativ vollzogenen Mechanismen nicht frei von Macht und Exklusion sind. ${ }^{377}$ Wenn dies ein grundsätzliches Phänomen jeder Öffentlichkeitstheorie wäre, müsste dies öffentlichkeitstheoretisch reflektiert werden, um die damit gegebene Ideologieanfälligkeit selbstkritisch zu untersuchen.

Eine der maßgeblichen Theorien der Öffentlichkeit, die auf diese performativen Mechanismen von Macht und Exklusion in besonderer Intensität und Schärfe reagiert hat und zudem den Referenzbereich von Öffentlichkeit über die rational-begrifflichen Vollzüge auf performative Praktiken der Leiblichkeit und der Versammlung ausweiten möchte, legt Judith Butler vor. Sie entwickelt ihr eigenes Konzept in der Auseinandersetzung mit der demokratietheoretisch wirkmächtigen und gegenwärtig wieder hoch brisanten Öffentlichkeitstheorie Hannah Arendts und greift zurück auf den Poststrukturalismus Michel Foucaults, der wie kaum ein zweiter die Prägung des Denkens und Handelns durch unreflektiert wirksame, strukturell verdichtete Machtmechanismen freigelegt hat.

Ohne die einzelnen Phasen des heterogenen Werks Foucaults oder Butlers hier rekonstruieren zu können, ${ }^{378}$ muss religionspädagogische Öffentlichkeitstheorie auf beide, auf Foucault wie Butler, rekurrieren, um nicht möglicherweise in Fallen zu tappen, die ihrer eigenen Intention konterkarierend entgegenstünden.

377 | Vgl. C 1.

378 | Vgl. Honneth, Saar, Geschichte der Gegenwart 2013. 


\subsection{Poststrukturalistische Anbahnungen bei Foucault}

Im Poststrukturalismus Michel Foucaults werden Theorien und Begriffe in den Kontext von Praxis und sozialer Distinktionen gesetzt. Feste Bedeutungen, ontologische Zuschreibungen, ungeschichtliche, quasi als Natur festgeschriebene Essentialisierungen, Wesensbeschreibungen werden aufgelöst und der bedeutungsbestimmenden Macht der Diskurse zugeschrieben. ${ }^{379}$ Jedes Sprechen, jedes Handeln, jedes Denken gewinnt seine Bedeutung in konkreten hermeneutischen Auseinandersetzungen, die von dem dynamischen und höchst komplexen Gefüge von Erkenntnis und Interesse im Zeichen von gesellschaftlicher und kultureller Hegemonie und politischer Macht geprägt werden. Der »mikrophysische Typus« der Macht bei Foucault setzt voraus, ${ }^{380}$ dass in »jeder Gesellschaft die Produktion des Diskurses zugleich kontrolliert, selektiert, organisiert und kanalisiert wird - und zwar durch gewisse Prozeduren, deren Aufgabe es ist, die Kräfte und die Gefahren des Diskurses zu bändigen, sein unberechenbar Ereignishaftes zu bannen, seine schwere und bedrohliche Materialität zu umgehen «. ${ }^{31}$ Insofern ist Sprechen »als anrufendes, machtproduktives Sprechen zu verstehen ${ }^{382}$ Diese Mechanismen aufzudecken, zu entlarven und ideologiekritisch zu konterkarieren ist das Ziel dessen, was Foucault >Diskursanalyse $<$ nennt.

Zwei Felder sollen diese Logik illustrieren, die religionspädagogisch hochrelevant sind.

In Bezug auf Bildung stellt sich Foucault die Frage, warum trotz der emphatischen Versprechungen von Autonomie, Subjektivierung und Mündigkeit durch Bildung gerade diese nicht eingelöst werden. Diskurstheoretisch wirft er einen entlarvenden Bick auf die Erziehungs- und Bildungssysteme:

"Die Erziehung mag de jure ein Instrument sein, das in einer Gesellschaft wie der unsrigen jedem Individuum den Zugang zu jeder Art von Diskurs ermöglicht - man weiß jedoch, daß sie in ihrer Verteilung, in dem, was sie erlaubt, und in dem, was sie verhindert, den Linien folgt, die von den gesellschaftlichen Unterschieden, Gegensätzen und Kämpfen gezogen sind. Jedes Erziehungssystem ist eine politische Methode, die

379 | Vgl. Emmerich, Hormel, Heterogenität - Diversity - Intersektionalität 2013, 107.9-15. Detailliert Budde, Die Rede von der Heterogenität 2012; zu Hintergründen Knauth, Jochimsen, Einschließungen und Ausgrenzungen 2017; Meyer, Theorien der Intersektionalität zur Einführung 2017.

380 | Konersmann, Die Unruhe der Welt 2015, 236.

381 | Foucault, Die Ordnung des Diskurses 1991, $10 \mathrm{f}$.

382 | Rose, "Alle unterschiedlich!" 2014, 143. 
Aneignung der Diskurse mitsamt ihrem Wissen und ihrer Macht aufrechtzuerhalten oder zu verändern." 383

Diskurstheoretisch besteht demnach ein intrinsischer Zusammenhang von Macht und Erziehung der Subjekte, handelt es sich doch dabei »um die großen Prozeduren der Unterwerfung des Diskurses«. Was für das Gerichtssystem, das Justizsystem, die Psychiatrie, ja selbst für den schriftstellerischen Akt des Schreibens gilt, den man gemeinhin für frei und kreativ hält, gilt nicht zuletzt für Schule und Universität: »Was ist denn eigentlich ein Unterrichtssystem wenn nicht eine Ritualisierung des Wortes, eine Qualifizierung und Fixierung der Rollen für die sprechenden Subjekte, die Bildung einer zumindest diffusen doktrinären Gruppe, eine Verteilung und Aneignung des Diskurses mit seiner Macht und seinem Wissen.« ${ }^{384}$

Im Bezug auf die sprachanalytischen Reflexionen von Beichtgesprächen will Foucault Bildungsprozesse als subtile Ausübungen von Macht entlarven. Deren subtile Machtmechanismen bestehen darin, dass machtförmige Strukturen der Gesellschaft sich gerade so durchsetzen, dass die Subjekte frei zu sein glauben. Eine solche Führung beruht »nicht auf Zwang, sondern auf der Bereitschaft, sich führen zu lassen«. Sie beruht auf der Einübung in das, was aus Sicht liberaler Selbstbestimmung paradox erscheinen muss: »freiwillige Knechtschaft als höchste Form individueller Freiheit«. ${ }^{385}$ In der Suche der Subjekte nach Autonomie reproduziere sich eine Asymmetrie, die Foucault »Pastoralmacht « nennt. ${ }^{386} \mathrm{Wie}$ der Beichtvater gemeinsam mit dem Büßenden, wie der >Hirte $<$ gemeinsam mit dem >Schaf< die Ordnung des Beichtens und der spirituellen Führung bejaht, so setzt sich darin die Macht des Diskurses durch. Demgemäß kann »Bildung selbst als eine gesellschaftliche Transformation durch individuelle Formation und so als spezifische Form der >Führung der Führungen (Foucault) gelesen werden «.387 Der innere Zusammenhang von Macht und Bildung besteht darin, dass Bildung letztlich Selbst-Kontrolle kultiviert und damit in Machtzusammenhänge einweist, die sich darin hinter dem Rücken der Subjekte reproduzieren. Bildung und Macht müssen also kritisch zusammen gedacht werden, um diese Diskursmacht dekonstruieren zu können. »Damit kann nicht nur die moderne Pädagogik überhaupt, sondern ins-

383 | Foucault, Die Ordnung des Diskurses 1991, $29 f$.

384 | Foucault, Die Ordnung des Diskurses 1991, 30; vgl. Ulrich Bröckling Gute Hirten führen sanft 2017, 15-73.

385 | Bröckling, Gute Hirten führen sanft 2017, 22.

386 | Vgl. Foucault, Das Subjekt und die Macht 1987; Steinkamp, Lange Schatten der Pastoralmacht 2015.

387 | Ricken, Die Ordnung der Bildung 2006, 25; vgl. Schweitzer, Bildung 2014, 120-126. 
besondere die Figur der >Bildung als zentrales Moment einer säkularisierten Pastoralmacht verstanden werden, deren Fruchtbarkeit und Effektivität gerade darin liegt, im Abweis von Fremdbestimmung und Repression den eigenen formierenden Zugriff auf die Lebensführung der Menschen selbst unkenntlich zu machen und als >stellvertretende Sorge auszugeben. « $^{388}$

Eine solche Macht der Diskurse prägt aber ebenfalls unser Verständnis dessen, was wir mit Körperlichkeit und Leiblichkeit meinen. Im Lichte der Diskursanalyse gibt es eine »Disziplinierungsgeschichte des Körpers«. ${ }^{389} \mathrm{Mi}$ chel Foucault hat die disziplinierende und machtförmige Seite im Blick auf Institutionen zugespitzt. Der Körper wird zum Objekt der Beherrschung, der Kontrolle, der immer feineren Inspektion und Unterordnung. Alles wird einer totalen Sichtbarmachung unterzogen. Andererseits bringt dies die Individuen auch hervor, nun aber in einer noch diffizileren Form der Entsubjektivierung des Körpers. Die Körper stellen sich aus, inszenieren und präsentieren sich nach einem internalisierten Vollkommenheitsideal, das die Natur des Körpers sukzessive zu überformen droht. ${ }^{390}$ Der Körper ist »somit Prinzip, Material und Produkt von Machtverhältnissen «, aber zugleich auch der Vollzug, in dem die Subjekte »ihr spezifisches >Körpersubjekt< selbst hervorbringen«. ${ }^{391}$

Dies ist bis in den gegenwärtigen Gender-Diskurs brisant, wonach geschlechtliche Identitäten neben einem naturhaften Moment wesentlich identitätslogisch und sozial und damit unter dem Einfluss performativ wirkender Machtmechanismen konstruiert sind. »Sex< wird also nicht einfach in >gender aufgelöst, sondern geht diesem etwa im Sinne des Begehrensvermögens voraus, realisiert sich jedoch quasi als >gender < und damit auch unter den Bedingungen diskursiver Praxen und deren normierender Macht.« ${ }^{392}$ Jede Äußerung über Fragen des Geschlechts ist demnach »immer ein Verhandeln mit der Macht«. ${ }^{393}$

Die Pointe der Diskursanalyse liegt demnach in einer Diskursivierung der Begriffe. In dieser machtkritischen Diskursanalyse wird danach gefragt, wie Begriffe geprägt, welche Bedeutungen in sie eingeschrieben, welche Mecha-

388 | Ricken, Die Ordnung der Bildung 2006, 212; vgl. auch Ricken, Balzer, Judith Butler 2012.

389 | Zirfas, Pädagogik und Anthropologie 2004, 88.

390 | Vgl. Foucault, Die Ordnung der Dinge 1990; Foucault, Die Heterotopien 2005; Schmidinger, Zichy, Tod des Subjekts 2005.

391 | Zirfas, Pädagogik und Anthropologie 2004, 89.

392 | Wendel, Gendersensible Theologie 2015, 86; vgl. Grümme, Menschen bilden 2012, 158-192; Wendel, 'Als Mann und Frau schuf er sie، 2009, 160-164; Wendel, Sexualethik und Genderperspektive 2011, 48-56; Pinker, Das Geschlechterparadox 2009; Laubach u.a., Gender 2017.

393 | Butler, Anmerkungen zu einer performativen Theorie der Versammlung 2016, 47. 
nismen von Exklusion, Inklusion und Hierarchisierung im Diskurs vollzogen werden. Dabei kann folgende Annahme als axiomatische Basis gelten: Es gibt keine an sich geltende Wahrheit, es gibt nichts Feststehendes. Wahrheit wird diskursiv produziert, wobei hier Machtkonstellationen den Diskurs präformieren.

Dies hat neben wahrheitstheoretischen Konsequenzen ebenfalls massive subjekttheoretische Implikationen. Die Subjekte werden in dieser stets prekären Auseinandersetzung von normierender Macht, Identitätssuche und diskursiver Auseinandersetzung gedacht. ${ }^{394}$ Das Selbst- und Weltverhältnis der Subjekte bleibt in die ausdifferenzierten performativen Praktiken seines Vollzugs konstitutiv verwickelt. ${ }^{395}$ Dies prägt performativ die intersubjektiven Prozesse der Subjekt- und Identitätskonstitutionen. »Dass die Macht Bestand hat, dass man sie annimmt, wird ganz einfach dadurch bewirkt, dass sie nicht bloß wie eine Macht lastet, die nein sagt, sondern dass sie in Wirklichkeit die Dinge durchläuft und hervorbringt, Lust verursacht, Wissen formt und einen Diskurs produziert. $\ll^{396}$ Macht ist demnach nicht einfach etwas heteronom Verhängtes. Macht kann »nur über >freie Subjekte< ausgeübt werden, insofern sie >frei< sind « 397 Sie wirkt, indem sie innerlich bejaht wird - und formt damit die Subjekte. »Diese Form der Macht gilt dem unmittelbaren Alltagsleben; sie teilt die Individuen in Kategorien ein, weist ihnen ihre Individualität zu, bindet sie an ihre Identität und erlegt ihnen das Gesetz einer Wahrheit auf, die sie in sich selbst und die anderen in ihnen anzuerkennen haben. Diese Machtform verwandelt die Individuen in Subjekte. ${ }^{398}$ Demnach wird das Subjekt in den machtgeleiteten Prozessen gesellschaftlicher Diskurse und performativen Praktiken der »Subjektivation « je neu konstituiert. ${ }^{399}$

Man kann Foucault durchaus vorwerfen, die Mechanismen der Macht so $\mathrm{zu}$ verallgemeinern und zu einem »Kryptonormativismus « zu übersteigern, ${ }^{400}$ dass die Spielräume der Subjekte marginalisiert werden. Dennoch gibt es exterritoriale Gebiete, gibt es Horizonte, die von der alles in sich bergenden Macht der Diskurse nicht erfasst werden. Bei ihm, so etwa Rainer Forst, sei eher eine neo- als poststrukturalistische Tendenz festzustellen,

394 | Vgl. Foucault, Die Ordnung des Diskurses 1991; dazu Fassin, Das Leben 2017, 83-88.

395 | Vgl. Jergus u.a., Heterogenität 2014, 154-164; Schmidinger, Zichy, Tod des Subjekts 2005.

396 | Foucault, Schriften III 2003, 197.

397 | Foucault, Schriften IV 2005, 287; vgl. Forst, Normativität und Macht 2015, 74-76

398 | Foucault, Schriften IV 2005, 275.

399 | Budde, Einleitung 2013, 13.

400 | Fassin, Das Leben 2017, 85. 
"von allumfassenden Wahrheitsregimen ('Episteme`) oder Machtkonstellationen ('Dispositive`) auszugehen, die wesentlich homogener erscheinen, als sie eigentlich sind. In einer bestimmten historischen Epoche überlagern sich verschiedene religiöse, wissenschaftliche und institutionelle Praktiken, denen bestimmte Formen der subjektivierung، entsprechen; doch diese Formen erscheinen in mehreren Versionen und werden auf vielfältige Weise reproduziert, die Raum für Differenz und Kritik lassen“,

ja auch Möglichkeiten für die Konstituierung einer Gegen-Macht und für Kritik an den diskursiven Praktiken selber. ${ }^{401}$ Michael Walzer wirft Foucault im Blick auf diese Universalisierung der Macht gar eine Entpolitisierung vor, weil sie die Möglichkeiten Prozeduren realer Veränderungen negiert, ${ }^{402}$ stattdessen aber sich in einem »bequemen Nihilismus « zurückzieht. ${ }^{403}$

Diese Tendenz zur Totalisierung des Diskurses hängt vor allem mit Foucaults Subjektschwäche zusammen. Auch wenn er insbesondere in seinen späten Arbeiten zur Sexualität eine Akzentverschiebung vorgenommen hat, auch wenn sich hier gar Spielräume für ein Subjekt denken lassen, »sich selbst heute anders $\mathrm{zu}$ verstehen und sich anders zu sich zu verhalten « im Gefüge der diskursiven Sexualnormen, ${ }^{404}$ so kann er das theoretische Dilemma nicht überwinden, in das ihn seine Dekonstruktion des Subjekts und die Entlarvung subjektiver Identität als eine »gewaltsam produzierte Fiktion « bringt: »Obwohl alles an seiner Kritik der Moderne auf das Leiden des menschlichen Leibes unter den disziplinierenden Akten der modernen Machtapparate konzentriert scheint, findet sich in seiner Theorie nichts, was dieses Leiden als Leiden artikulieren könnte. ${ }^{405}$ Wo die »Pastoralmacht« (Foucault), wo die Macht der Diskurse wie etwa in der Bildung universal wird, wo es kein Außerhalb mehr gibt, dann kann dies zwar die Kritik bis an die Wurzel führen, weil sie gerade in Bildungsprozessen für die subtilen unbewussten Formen der Machtausübung und der Machtstrukturen sensibilisiert. Sie kann jedoch ebenso zu einem Zynismus angesichts der Unausweichlichkeit von Macht werden. »Zynisch wird eine solche Sicht spätestens dann, wenn dazu keinerlei Alternativen mehr aufgezeigt werden können. « ${ }^{406}$

Dennoch: Von Foucault kann zumindest die Sensibilität für die dunkle Seite der Vernunft gelernt werden, für die Exklusionen und die Mechanismen von Hegemonie und Macht, die noch im Willen zur Würdigung der jeweiligen Identitäten im Spiel sein können. Die Ordnungsformen des Vernunftdiskurses

401 | Forst, Normativität und Macht 2015, $74 f$.

402 | Vgl. Walzer, The Politics of Michel Foucault 1986.

403 | Schieder, Vom erwählten Volk zum Volk, was wählt 2017, 128.

404 | Honneth, Saar, Geschichte der Gegenwart 2013, 1675.

405 | Honneth, Die zerrissene Welt des Sozialen 2013, 91-92.

406 | Schweitzer, Bildung 2014, 124. 
»arbeiten mit Exklusionen und Inklusionen, sie definieren Teilnahmemöglichkeiten. Diese sind wiederum an die Qualifikation dessen gekoppelt, was als vernünftig klassifiziert und zugelassen wird. $\aleph^{407}$

Eine solche Schlussfolgerung hat nicht nur subjekttheoretische Implikationen, wie sie in besonderer Radikalität derzeit von Judith Butler aufgenommen werden. Sie stellt vieles infrage, was auch religionspädagogisch über Identitätskonstitutionen und Subjekt gedacht wird. ${ }^{408}$ Vor allem jedoch hat dies erhebliche Folgen für jede Öffentlichkeitstheorie. Was wir bereits als offene Flanke der Deliberativen Öffentlichkeitstheorie markiert haben, kann damit nun auf ein breiteres und besser begründetes Fundament gestellt werden. Die Diskursanalyse fragt jede Öffentlichkeitstheorie auf ihre performativ vollzogenen Mechanismen von Macht und Exklusion an. Darum lohnt es sich, dies am Beispiel der Öffentlichkeitstheorie Judith Butlers weiter zu verfolgen, die freilich zunächst in ihren subjekttheoretischen Grundierungen aufgesucht werden muss. ${ }^{409}$

\subsection{Subjektivierung und Identitätsbildung}

Judith Butler verortet die Subjekte in den unabgeschlossenen Prozessen von Sozialität, die nicht begrifflich vorwegzunehmen, sondern nur narrativ zu rekonstruieren sind. Allerdings sind diese Narrationen wegen ihrer Eingewobenheit in diese sozialen Prozesse nie vollständig möglich. »Diese Rechenschaft, von mir selbst, die ich im Diskurs gebe, drückt also das lebendige Selbst nie vollständig aus, enthält es nie vollständig: noch während ich Antwort gebe, sind mir meine Worte genommen; ins Wort fällt mit die Zeit eines Diskurses, die nicht dieselbe ist wie die Zeit meines Lebens. $\aleph^{410}$ Damit wird bereits erkennbar, wie stark Butler die Ausgesetztheit des Subjekts denkt. Es ist nicht so, dass es eine geschichts- und sozialitätsabgewandte Innenseite und eine den Anderen zugewandte Außenseite gäbe. Sozialität und ihre Normen sind der Ort, wo die Macht der Diskurse subjekttheoretisch wirksam wird und wo die Subjekte erst konstituiert werden. »Das Ich, das handelt, tut dies in einem Schmelztiegel unterschiedlicher wiederholbarer Beziehungen, von denen manche nicht zu rekonstruieren sind. $\aleph^{411} \mathrm{Zu}$ einem Subjekt werde ich, wenn ich eine »narrative Darstellung meiner selbst versuche, nachdem ich von jemandem angespro-

407 | Hoff, Die Vernunft der Ordnungen 2017, 85.

408 | Vgl. Platzbecker, Religiöse Bildung 2013; aber auch Pirker, fluide und fragil 2013.

409 | Vgl. zum folgenden in starker Überarbeitung Grümme, Heterogenität 2017, 111-115.

410 | Butler, Kritik der ethischen Gewalt 2007, 51.

411 | Butler, Kritik der ethischen Gewalt 2007, 176; vgl. auch Werner, »Ins Wort fällt mir die Zeit» 2015, 41-73. 
chen und aufgefordert wurde, mich an den zu wenden, der sich an mich wendet ${ }^{4}{ }^{42}$ Diesen Prozess, der zugleich aus dem Moment des Unterworfenwerdens durch Macht und dem der Subjektwerdung besteht, nennt Butler - ganz ähnlich wie Foucault - »Subjektivation« oder »Subjektivierung«.413

In paradoxaler Weise versucht Butler hier unter Aufnahme der Machttheorien Foucaults und Louis Althussers einerseits und der Psychoanalyse andererseits die höchst komplexen Zusammenhänge der Subjektkonstitution zu denken. Sowohl die einseitigen Fixierungen auf Machtstrukturen, die in einer Totalisierung von Macht deterministisch an menschlicher Freiheit vorbeizulaufen drohen, als auch die struktur- und systemvergessenen Implikationen bestimmter Traditionen der Psychoanalyse überwinden wollend, bringt Butler beide Stränge kritisch wie produktiv zusammen.

"Nach dem Doppelsinn von 'Subjektivation ، als Unterordnung und Werden des Subjekts besteht die Macht als Unterordnung in einer Reihe von Bedingungen, die dem Subjekt vorhergehen und es von außen bewirken und unterordnen. Diese Formulierung gerät jedoch ins Schwanken, sobald wir daran denken, daß es vor dieser Wirkung gar kein Subjekt gibt. Die Macht wirkt nicht nur auf ein Subjekt ein, sondern bewirkt im transitiven Sinn auch die Entstehung des Subjekts. Als Bedingung geht die Macht dem Subjekt vorher. Wird die Macht jedoch vom Subjekt ausgeübt, verliert sie den Anschein ihrer Ursprünglichkeit; in dieser Situation eröffnet sich die umgekehrte Perspektive, daß Macht die Wirkung des Subjekts ist und daß Macht das ist, was Subjekte bewirken [...]. Weil Macht vor dem Subjekt gar nicht intakt ist, verschwindet der Anschein ihrer Vorgängigkeit, wenn sie auf das Subjekt einwirkt, und das Subjekt entsteht (und leitet sich her) aus dieser zeitlichen Umkehrung im Horizont der Macht. Als Handlungsfähigkeit des Subjekts nimmt die Macht ihre gegenwärtige zeitliche Dimension ein. " ${ }^{414}$

Macht wird also nicht von einem Machtzentrum intentional ausgeübt. Sie artikuliert sich vorreflex im Diskurs, in dem sie und durch den sie zugleich reproduziert wird, wie Butler in ihrer kritischen Reformulierung von Foucaults »Biopolitik« ausführt. ${ }^{415}$

Das Subjekt ist demnach grundlegend verwickelt in eine diskursiv-machtvoll strukturierte Sozialität und darin sich selbst entzogen. Es ist auf eine radikale Alterität hin offen, von der es Anerkennung erhofft, weshalb es sich selbst auf Normen einlässt, die erst festlegen, was als anerkennungsfähig zu gelten

412 | Butler, Kritik der ethischen Gewalt 2007, 24.

413 | Butler, Psyche der Macht 2002, 8; Butler, Die Macht der Geschlechternormen 2009, 72 .

414 | Butler, Psyche der Macht 2002, 18.

415 | Butler, Anmerkungen zu einer performativen Theorie der Versammlung 2016, 252. 
hat. Auf Anerkennung angewiesen und dabei von Anfang an gesellschaftlichen Bedingungen unterworfen zu sein, die nie ganz die eigenen sind, eine solche Ausgesetztheit kennzeichnet letztlich die »melancholische Struktur der Subjektivität« ${ }^{416}$ Es gibt so etwas wie eine »verkennende Anerkennung «, ${ }_{47}^{47}$ die durch Anerkennung performativ das unterläuft, was eigentlich in der Anerkennung gesucht wird. Anerkennung steht demnach entgegen des ihr oft entgegengebrachten Enthusiasmus in einer Dialektik von Inklusion und Exklusion.

Butler reklamiert die Anerkennungsbedürftigkeit eines jeden Menschen aus intersubjektiver Kommunikation. Andererseits wird aber damit bereits ein bestimmtes Kategorienschema und Bewertungsmuster mitgeliefert, wonach der Andere auch anerkennbar und damit nach diesem Muster anerkennungswürdig ist.

"Bezeichnet 'Anerkennung، einen Akt oder eine Praxis oder gar ein Aufeinandertreffen von Subjekten, so steht der Begriff der 'Anerkennbarkeit، für die allgemeineren Bedingungen, die ein Subjekt auf die Anerkennung vorbereiten oder ihm die dazu nötige Form vermitteln. [...]. Diese Kategorien, Konventionen und Normen, die ein Subjekt zum möglichen Subjekt der Anerkennung machen und überhaupt erst Anerkennungsfähigkeit herstellen, liegen dem Akt der Anerkennung selbst voraus und ermöglichen inn zuallererst. In diesem Sinne geht die Anerkennbarkeit der Anerkennung vorher.." ${ }^{418}$

Damit wirken sozialen Normen in die subjektkonstitutiven Prozesse der Anerkennung hinein, wirken damit aber zugleich integrativ wie exkludierend. »Selbst wenn man eine Form der Anerkennung auf alle Menschen ausdehnt, bleibt die Prämisse bestehen, dass weite Teile dennoch nichtanerkennbar bleiben, und dieses Machtgefälle wird mit jeder Erweiterung jener Form der Anerkennung reproduziert.«419 Mit dieser Ratifizierung und Reproduktion der Anerkennungsnormen in jedem Selbstvollzug des Subjekts wird das Feld des Anerkennbaren erheblich eingeschränkt. ${ }^{420}$

Aber gerade weil das Subjekt in diesen Anerkennungsprozessen nie mit sich identisch ist, sondern sich inmitten der geschichtlichen Zusammenhänge findet, die mit Gewalt und Freiheit zu tun haben, liegt hierin andererseits auch der Ansatz von Ethik. Indem wir auf die »Befriedigung« begrifflichen Erkennens und darin auf das Verstehen des Anderen verzichten, »lassen wir den An-

416 | Koller, Bildung anders denken 2012, 65.

417 | Bedorf, Verkennende Anerkennung 2010.

418 | Butler, Raster des Krieges 2010, 13.

419 | Butler, Anmerkungen zu einer performativen Theorie der Versammlung 2016, $12 f$.

420 | Vgl. Butler, Anmerkungen zu einer performativen Theorie der Versammlung 2016, 52-53. 
deren leben [...]. Wenn den Anderen leben zu lassen Teil einer jeden Definition der Anerkennung sein müsste, dann würde eine solche Anerkennung weniger auf dem Wissen gründen als vielmehr auf der Einsicht in dessen Grenzen«, wie Butler mit Blick auf Foucaults Ethik sagt. ${ }^{421}$

Die Frage der Ethik erscheint an den Grenzen »unserer Systeme der Verständlichkeit [...], dort wo wir uns fragen, was es heißen könnte, einen Dialog fortzuführen, für den wir keine gemeinsame Grundlage annehmen können, und wo wir uns gleichsam an den Grenzen unseres Wissens befinden und dennoch Anerkennung zu geben und zu empfangen haben: weil da jemand ist, der anzureden und dessen Anrede zu empfangen ist «. ${ }^{422}$ Ethik beruht folglich auf einer radikalen Asymmetrie, die nicht nochmals begrifflich zu fassen ist. Sie ist absolut heteronom, weil sie vom Anspruch des Anderen an das Subjekt erfolgt, das hiermit erst konstituiert wird. Der Mensch steht in einer Passivität, die jeder Unterscheidung von Aktiv-Passiv noch voraus liegt. Dieser »vor-ontologische Zustand« einer tiefen Verletzbarkeit, einer Vulnerabilität, wie Butler in ihrer poststrukturalistischen Begründung von subjekthafter Verantwortung betont, ist eine

„Passivität, die nicht in ihr Gegenteil verkehrt werden kann. Um dies nachzuvollziehen, müssen wir uns eine Empfänglichkeit für andere vorstellen, die nicht gewollt und nicht gewählt ist und zugleich die Bedingung unserer Ansprechbarkeit durch andere, ja sogar eine Bedingung unserer Verantwortung für sie ist. Das heißt unter anderem, dass Empfänglichkeit eine Nichtfreiheit am Ursprung unserer selbst bezeichnet und dass wir paradoxerweise auf der Grundlage dieser Empfänglichkeit, bei der wir keine Wahl haben, für andere verantwortlich werden. ${ }^{423}$

Formuliert in der Logik der Anerkennung: man muss sich verwunden lassen, muss seine Souveränität aufs Spiel setzen, seine Verletzlichkeit anerkennen. »Anerkennung zu fordern oder zu geben heißt gerade nicht, Anerkennung dafür zu verlangen, wer man bereits ist. Es bedeutet, ein Werden für sich zu erfragen, eine Verwandlung einzuleiten, die Zukunft stets im Verhältnis zum Anderen zu erbitten. $\ll^{424}$

Ein solches narratives, von Andersheit her gebrochenes und entfremdetes, zugleich aber zu sich eröffnetes Subjektdenken ermöglicht in seinem Widerspruch gegen identitätslogische Fixierungen und Naturalisierungen eine Dy-

421 | Butler, Kritik der ethischen Gewalt 2007, 60.

422 | Butler, Kritik der ethischen Gewalt 2007, 33.

423 | Butler, Kritik der ethischen Gewalt 2007, 119.

424 | Butler, Gefährdetes Leben 2005, 62; vgl. zu einer theologischen Interpretation dieses Zusammenhangs von Vulnerabilität und Anerkennung Kohl, Die Anerkennung des Verletzbaren 2017. 
namik, die in der konstruktivistisch und poststrukturalistisch befeuerten Gender- und Queerthematik zum Austrag kommt. Dies macht auf die diskursiven Verwurzelungen von Vernunft in Praktiken von Macht und gesellschaftlichen Konstruktionen aufmerksam, eine Überlegung, die jede Theorie kritisch mit sich selbst konfrontiert. Folgerichtig verlangt Butler von jeder Vernunft kritische Selbstreflexivität. »Hier ist ein kritisches Denken gefragt, das den Rahmen des Kampfes um Identität nicht einfach hinnimmt, einen Rahmen, der immer schon existierende Subjekte voraussetzt, die einen ganz bestimmten öffentlichen Raum besetzen und deren Differenzen grundsätzlich beigelegt werden können, wenn wir nur die rechten Mittel finden, um sie zusammenzubringen. $\aleph^{425}$

\subsection{Entnormierte Vernunft?}

Freilich erfordert dies eine bestimmte Vernunft, die sich insbesondere von einem rationalen Universalismus diametral unterscheidet. Dies wird exemplarisch deutlich an Butlers Kritik am normativen Universalismus von Habermas, mit der sie sich zugleich affirmativ auf Foucault bezieht. Habermas wendet sich gegen die frühe Phase der Kritischen Theorie bei Theodor W. Adorno und deren Kritikverständnis. Zwar kann aus seiner Sicht eine rein negativistische Kritik Grundlagen dekonstruieren, kann soziale und politische Hierarchien in Frage stellen. Sie vermag sehr wohl weiterführende Perspektiven einführen, um eine selbstverständlich und unhinterfragte Wirklichkeit auf neue Möglichkeiten und Alternativen hin aufzusprengen. »Aber keine dieser Handlungen kann uns zeigen, in welche Richtung wir zu gehen haben, noch können sie uns verdeutlichen, ob diese unsere Handlungen gewisse Arten normativ gerechtfertigter Ziele verwirklichen. ${ }^{426}$ Jede Kritik benötige dafür ein starkes normatives Fundament, die starke normative Urteile ermöglicht. Nur so kann der Politik eine Grundlage mit klaren Zielen und normativen Horizonten vermittelt werden und nur so werden wir befähigt, die gegebenen Praxen daraufhin zu überprüfen, inwieweit sie diese Ziele realisieren helfen. Seine Diskurstheorie kommunikativen Handelns soll diese universalisierbare Grundlage der Normativität schaffen.

In den Augen Butlers bleibt jedoch bei Habermas insofern eine Leerstelle, als er die geforderte Selbstreflexivität der Vernunft nicht auf seine Diskurstheorie selber anwendet.

"In dieser Art von Kritik der Kritik wird Habermas merkwürdig unkritisch gegenüber dem Sinn von Normativität, den er selbst entwickelte. Denn die Frage, was wir zu tun haben,

425 | Butler, Raster des Krieges 2010, 151.

426 | Butler, Was ist Kritik 2013, 223. 
setzt voraus, dass das 'Wir geformt wurde, und sie setzt weiter voraus, dass feststeht, dass die Handlung dieses ,Wir möglich ist und dass das Feld, in dem das ,Wir zu handeln vermag, eingegrenzt ist. Sollten alle diese Formationen und Abgrenzungen normative Konsequenzen haben, muss nach den Werten gefragt werden, die die Handlung vorbereiten, und das wird eine wichtige Dimension für eine jede kritische Untersuchung normativer Fragen sein. ${ }^{427}$

Zudem wirft Butler der Diskursethik vor, gerade die performativen Sprechakte, die dem Konsens widersprechen, zu delegitimieren. Mehr noch: es sei kein Sprechakt zulässig, »der dem anderen performativ die Möglichkeit nimmt, einen Konsens durch Sprache herzustellen $\ll .{ }^{428}$ Eine angemessene Form der Rationalität, so Butler in ihrer Anlehnung an Foucault, »muss auch die Arten von Subjekten erklären können, die durch diese Rationalität ermöglicht und hervorgebracht werden ${ }^{429}$

Darum setzt sie einem solchen, für abstrakt gehaltenen Universalismus ein Normativitätsdenken entgegen, das sich seiner Ambivalenz und Dialektik bewusst ist. Normen sind erforderlich, um ethische und politische Ziele $\mathrm{zu}$ formulieren, eine Welt, wie sie sein sollte, $\mathrm{zu}$ imaginieren, eine Praxis $\mathrm{zu}$ orientieren. Indem sie die Normalität unterbricht, müsste sie auch die Welt, wie sie sein sollte, und »Brüche mit der Normalität schützen und denen, die solche Brüche wagen, Unterstützung und Bestätigung schenken «. ${ }^{40}$ Indessen ist mit einer solchen Normativität unausweichlich die Kehrseite verbunden, Normalisierungsstandards zu setzen, die ihrerseits als implizite Normierungen soziales Leben kanalisieren und zu Exklusionen und Stigmatisierungen führen. Sie vereinen Menschen hinsichtlich geteilter Zielhorizonte gesellschaftlicher Veränderungen, zugleich verkörpern sie Manifestationen sozialkultureller Macht. »Einerseits verweist sie auf die Ziele und Bestrebungen, die uns leiten, die Prinzipien, nach denen wir gezwungen sind, $\mathrm{zu}$ handeln oder miteinander zu sprechen, die gemeinsam geteilten Vorannahmen, von denen wir Orientierung erhalten und die unseren Handlungen die Richtung weisen. Andererseits verweist Normativität auf den Prozess der Normalisierung, die Art, wie bestimmte Normen, Ideen und Ideale unser verkörpertes Leben im Griff haben.« ${ }^{431}$ In solchen Normalitätsvorstellungen wird definiert, wer und unter welchen Bedingungen anerkennbar ist. Butler verweigert sich darum

427 | Butler, Was ist Kritik 2013, 224; vgl. Ludwig, Kritische Theorie und Kapitalismus 2013, 75-82.

428 | Butler, Haß spricht 2006, 139.

429 | Butler, Kritik der ethischen Gewalt 2007, 158.

430 | Butler, Anmerkungen zu einer performativen Theorie der Versammlung 2016, 48.

431 | Butler, Die Macht der Geschlechternormen 2009, 327. 
einem normativ ausgerichteten Letztbegründungskonzept, wie es bei Habermas oder auch bei Honneths Anerkennungstheorie vorliegt. ${ }^{432}$

Mit diesen Überlegungen haben wir aus drei Perspektiven heraus den Horizont auf Butlers Öffentlichkeitstheorie eröffnet: vernunfttheoretisch, weil die Fragen nach Normativität und Kritik, nach Universalität und Partikularität, nach Macht, Exklusion und Identität bereits intrinsisch die Sphäre der Öffentlichkeit affizieren; anerkennungstheoretisch, weil die Dialektik der Anerkennung auf die soziale Konstituiertheit der Subjekte verweist, die die Spannung zwischen Subjektsein und Verletzlichkeit erst vollends zum Austrag bringt; und schließlich subjekttheoretisch, insofern in der sozialen Konfiguration der Subjekte die unlösbare Verwobenheit der Körper in Geschichte und Gesellschaft markiert wird. »Als in der öffentlichen Sphäre geschaffenes soziales Phänomen gehört mein Körper mir und doch nicht mir. Als Körper, der von Anfang an der Welt der anderen anvertraut ist, trägt er ihren Abdruck, wird im Schmelztiegel des sozialen Lebens geformt. Erst später und mit einiger Unsicherheit erhebe ich Anspruch auf meinen Körper als den, der mir gehört, wenn ich das überhaupt jemals tue. ${ }^{433}$ Das den anderen überantwortete Sein des Menschen ist damit den Evaluationen und damit den Privilegierungen wie Stigmatisierungen der Gesellschaft ausgesetzt. »Es ist immer schon auf Normen und soziale und politische Organisationen verwiesen, die sich ihrerseits geschichtlich entwickelt haben, um die Gefährdung der einen zu maximieren und die der anderen zu minimieren. «434 Diese innere Verwobenheit von Innen und Außen des Körpers, der

"paradoxerweise sowohl randeren ausgeliefert als auch emphatisch gesprochen ,der eigener ist, ist die strukturelle Bedingung nicht nur der elementaren sozialen Situierung des Selbst und der daraus resultierenden Verwundbarkeit, sondern auch Grund der , primären Prägbarkeit durch andere, die sich dann im Anerkennungs- und Adressierungsgeschehen als Epigenesis des Selbst vom Anderen her realisiert, so dass sich das Eigene und das Fremde nicht grundsätzlich, sondern allenfalls aspekthaft voneinander unterschieden werden können «. ${ }^{435}$

Diese Formung durch kulturell-soziale Normen und Bedingungsgefüge lässt Butler deshalb in ihrer »Ontologie des Körpers« gar von der politischen Verfasstheit des Körpers in dessen Ausgeliefertsein und Verletztlichkeit sprechen. ${ }^{436} »$ Das bedeutet, dass jede (jeder) einzelne von uns zum Teil aufgrund

432 | Vgl. Rösner, Auf's Spiel gesetzte Anerkennung 2012.

433 | Butler, Gefährdetes Leben 2005, 43.

434 | Butler, Raster des Krieges 2010, $10 f$.

435 | Ricken, Bildsamkeit und Sozialität 2012, 346.

436 | Butler, Raster des Krieges 2010, 10. 
der sozialen Verwundbarkeit unserer Körper politisch verfasst ist - als ein Ort des Begehrens und der physischen Verwundbarkeit, als Ort einer öffentlichen Aufmerksamkeit, der durch Selbstbehauptung und Ungeschütztheit zugleich charakterisiert ist.«437

Die in der Geschichte politischer Theoriebildung vertretene Trennung von >öffentlich und >privat< muss angesichts solcher subjekttheoretischer Verfugungen als blasse Abstraktion erscheinen. Wo diese wie - in der Sicht Butlers etwa - bei Hannah Arendt unirritiert fortgeschrieben würde, ${ }^{438}$ wäre sie mit dem Ideologieverdacht zu konfrontieren.

Doch wie sieht Butler nun die Öffentlichkeit? Es ist nicht zu viel gesagt, dass ihre Überlegungen zu einer performativen Öffentlichkeit als Verdichtung ihrer Theoriebildung verstanden werden können. ${ }^{439}$

\subsection{Sprache, Performativität, Widerstand}

Die Überlegungen Butlers zur Öffentlichkeit bekommen ihre inhaltliche Mitte und ihre formale Dynamik durch die Konstellation, in die verschiedene Elemente ihrer Philosophie gesetzt sind. Kurz gesagt: Ihre Ontologie des Körpers, ihr Subjektdenken, ihr Begriff der Vulnerabilität werden zusammengebracht mit ihrer Theorie performativer Sprachhandlungen, die Butler in ihrer sprachphilosophischen Basis ausweitet auf non-verbale, körperliche Handlungen der Inszenierung. Durch sie gelangt sie schließlich zu einer »performativen Theorie der Versammlung «, mit der sie die politische Pointe der Öffentlichkeit in der aktuellen Situation demokratischer Aufbrüche und Befreiungsbewegungen freigelegt zu haben glaubt. ${ }^{440}$

Im Hintergrund ihrer Sprachphilosophie steht die Sprechakttheorie J.L. Austins, die sie freilich in der Auseinandersetzung mit Derrida, Foucault, Althusser und Bourdieu in einem ganz erheblichen Maße umgruppiert. Von Derrida her gewinnt sie die Sensibilität für Differenzen und die Kraft der Iteration, gegenüber Bourdieu und den von ihm vorrangig gesetzten sozialstrukturell-systemischen Akzenten macht sie auf die subjektiv-performativen Akte aufmerksam.

Bekanntlich unterscheidet Austin zwischen lokutionären, illokutionären und perlokutionären Akten. Erstere meinen das Sagen selbst, die zweiten die

437 | Butler, Gefährdetes Leben 2005, 37.

438 | Vgl. Butler, Anmerkungen zu einer performativen Theorie der Versammlung 2016, 64-68.

439 | Obschon Butler von sich selber sagt, keine Expertin auf dem Gebiet der Öffentlichkeit zu sein: vgl. Butler, Ist das Judentum zionistisch 2012, 102.

440 | Vgl. Butler, Anmerkungen zu einer performativen Theorie der Versammlung 2016, 10-30. 
Wirklichkeit und das Handeln, das mit dem Sagen selbst gestiftet wird, und schließlich die dritten die Wirklichkeit, die in der Konsequenz aus dem Gesagten folgt. Dies alles schießt zusammen im Phänomen der Performativität, verstanden als der Möglichkeit, mit Worten zu handeln und Realitäten wirklich werden zu lassen..$^{41}$ Im Moment sprachlicher Äußerungen wird eine Wirklichkeit gesetzt, vollzogen oder ins Leben gerufen. Der Urteilsspruch des Richters, der Taufspruch des Priesters, das Eheversprechen der Eheleute sind Beispiele für solche Handlungen. Sprache besitzt demnach größere Möglichkeiten, als Wirklichkeit nur zu bezeichnen, abzubilden oder instrumentell verfügbar zu machen. Sie hat die Kraft, soziale Wirklichkeiten und persönliche Identitäten zu erzeugen. Indem etwas gesprochen wird, wird es zur sozialen Tatsache.

Seine besondere Tiefenschärfe freilich erhält Butlers Performativitätsansatz vor dem Hintergrund ihrer Subjektivierungs- und Diskurstheorie. Durch diese diskursiv-performative Konturierung gibt es keine absoluten Referenzen. Alles ist im Fluss, nichts ist vollends sprachlich fixierbar, muss es doch je neu vollzogen werden. Wenn jede Rede ihrerseits Teil des machtgeleiteten Diskurses ist, wenn also jede Rede ihrerseits den Diskurs ratifiziert und damit fortschreibt, dann muss dies auch performativitätstheoretisch seinen Niederschlag finden. Die Souveränität, mit der Austins Theorie der Performativität das Subjekt bedenkt, muss deshalb aus Butlers Sicht dekonstruiert werden vor dem Hintergrund diskursiver Machtprozesse. Aus der Logik Austins gilt: "Jemand der performative Äußerungen wirkungsvoll einsetzt, spricht mit unbestrittener Macht. $\aleph^{442}$ Performativ sprechen heißt machtvoll sprechen. In berühmten Passagen zur Genealogie der Geschlechter arbeitet Butler dagegen heraus, dass solche performative Äußerungen nicht nur im Ausspruch des Arztes: »Dies ist ein Mädchen« das Geschlecht festlegen. Sie gewinnen ihre Kraft und Bestimmtheit dadurch, dass sich in ihnen über Konventionen, rituelle Wiederholungen, Zitierungen, narrative Konstruktionen und geschichtliche Zusammenhänge die Konstituierung des Subjekts durch Sprache artikuliert. Eine Sprachhandlung gelingt nicht primär, weil sie durch eine subjektive Absicht gesetzt und erfolgreich kontrolliert wird. Sie gelingt

"nur deswegen, weil in ihr frühere Sprachhandlungen nachhallen und sie sich mit autoritativer Kraft anreichert, indem sie vorgängige autoritative Praktiken wiederholt bzw. zitiert. Der Sprechakt ist nicht einfach nur in eine Praktik eingebettet, sondern er ist selbst eine ritualisierte Praktik. Das heißt, daß eine performative Äußerung nur soweit funktioniert, wie sie aus ermöglichenden Konventionen, durch die sie mobilisiert wird, schöpft und diese zugleich verdeckt. In diesem Sinne kann ein Begriff oder eine Äuße-

441 | Vgl. Austin, Zur Theorie der Sprechakte 1972.

442 | Butler, Haß spricht 2016, 80. 
rung nicht performativ funktionieren, wenn ihre Kraft nicht geschichtlich aufgebaut und zugleich verborgen ist. " ${ }^{443}$

Subjekttheoretisch höchst folgenreich, aber nur konsequent vor dem Hintergrund ihrer Subjektivierungstheorie, wird das Subjekt für Butler erst in diesen diskursiven, machtgeleiteten Akten der Performativität konstituiert. So kann sie festhalten: »Die Macht wirkt auf mindestens zweierlei Weise auf das Subjekt ein: erstens als das, was das Subjekt ermöglicht, als Bedingung seiner Möglichkeit und Gelegenheit seiner Formung, und zweitens als das, was vom Subjekt aufgenommen und im >eigenen< Handeln des Subjekts wiederholt wird.« ${ }^{444}$

Wir kommen damit an den sprachtheoretischen Kern der Subjektivierungstheorie. Bezogen auf die rechtlichen, politischen und moralischen Aspekte von hate speech, die Butler in berühmten Analysen freigelegt hat, aber gültig weit darüber hinaus, wird das Subjekt

"erst von der langen Kette verletzender Äußerungen mobilisiert: Es erlangt einen vorläufigen Status, in dem es die Äußerung zitiert und sich damit selbst als Ursprung der Äußerung schafft. Dieser Subjekt-Effekt ist aber nur eine Folge des Zitierens, ein abgeleiteter Effekt einer nachträglichen Metalepse, die das aufgerufene geschichtliche Vermächtnis von Anrufungen im Subjekt als ,Ursprung، der Äußerung verbirgt. “ ${ }^{445}$

Ein autonomes Subjekt, das nach idealistischer Logik vor dem Diskurs situiert wäre, ist damit zum Verschwinden gebracht. Das Subjekt ist nicht allein autoritativer Urheber der Sprache, ihm eignet keine ungebrochene Handlungsmacht, weil jede Rede bereits durch die stets zuvorkommende Anrede durch den Anderen bedingt ist und damit im Raum der Vulnerabilität steht. Das Subjekt wird diskursiv begründet, im sprachlich strukturierten Raum von Macht. Performative Handlungsmacht fällt deshalb nicht mit Beherrschung, sondern mit Verletzlichkeit zusammen. ${ }^{446}$

Es ist nun interessant zu sehen, dass Butler die Performativität der Sprache nicht allein zum Ort des Diskurses erklärt. Sprache hat ambivalenten Charakter. Diese bietet nämlich zugleich die Ressource, aus der sich Widerstandsmöglichkeiten gegen die Macht des Diskurses und die hegemonialen Praktiken in Gesellschaft und Politik speisen können. Damit bricht Butler mit der (ihrerseits jeweils verschieden gelagerten) negativen Totalisierung der Macht bei Foucault wie bei Adorno. Auch wenn die Subjekte je bereits in Zwängen

443 | Butler, Haß spricht 2016, 84.

444 | Butler, Psyche der Macht 2002, 18.

445 | Butler, Haß spricht 2016, 81.

446 | Vgl. Butler, Haß spricht 2016, $47 f$. 
leben, die sich performativ in deren Inanspruchnahme ihrer Freiheit realisieren, haben sie dennoch Möglichkeit und Recht zu einer kritischen Unterbrechung. Es sind performative Akte der Selbstinszenierung, die nicht »völlig außerhalb von Kultur, Macht und Diskurs« existieren, die aber aus »unvorhersehbaren Abweichungen« heraus entstehen. Sie reißen einen »Spalt in der Erscheinungssphäre« auf, einen Riss, einen Hoffnungsschimmer, der erst jene »kulturelle Möglichkeiten eröffnet, um die hoheitlichen Ziele all jener institutionellen Regime und Erziehungsstrukturen zu vereiteln«, die die Subjekte im Voraus zu erkennen und zu normalisieren trachten. ${ }^{447}$

Doch woher soll die Kraft zum Widerstand kommen? Butler rekurriert auf Derridas Begriff der $>$ Wiedereinschreibung . Durch ihn werden auch solche Begriffe wie >Subjekt< reformulierbar, die eigentlich post-strukturalistisch hoch problematisch geworden sind. In ihm lassen sich Spuren einer möglichen Kraft kritisch-produktiver Veränderung freilegen. Durch sie wird es möglich, aus Unterdrückung und Demütigungszusammenhängen auszubrechen. Butler will zeigen, dass »gerade in der Fähigkeit dieser Begriffe, eine nicht-gewöhnliche Bedeutung anzunehmen, ihr beständiges politisches Versprechen liegt. Ich würde sogar sagen, daß das Widerstandspotential solchen Aufrufens genau in dem Bruch besteht, den es zwischen einer gewöhnlichen und einer nicht-gewöhnlichen Bedeutung hervorruft. « $^{448}$ Die Kraft liegt nun darin, dass die Sprache gerade nicht ausschließlich - anders als Bourdieu meint - durch gesellschaftlich soziale Mechanismen determiniert ist. Indem sie mit den Kontexten bricht, denen sie dennoch verhaftet bleibt, sprengt sie den Bereich des Privaten und weitet sie die Kontexte des Sozialen ins Politische hinein. »Eine Äußerung kann ihre Kraft gerade aus dem Bruch mit dem Kontext gewinnen, den sie ausführt. Solche Brüche mit früheren Kontexten oder mit gewöhnlichen Anwendungen sind tatsächlich entscheidend für den politischen Vorgang der performativen Äußerung. Sprache nimmt genau dazu eine nicht-gewöhnliche Bedeutung an, um sich gegen das zu stellen, was sich im [sic!!] und als das Gewöhnliche sedimentiert hat.« ${ }^{449}$ Durch solche performativen Akte wird Widerstand möglich und damit auch ein gutes Leben im Falschen, wie Butler in ihrer berühmten Rede zur Verleihung des Theodor W. Adorno-Preises gegen Adorno betont. »Die Politik der Performativität ist auch eine Möglichkeit, inmitten des biopolitischen Systems«, dass Menschen ausschließt, ent-

447 | Butler, Anmerkungen zu einer performativen Theorie der Versammlung 2016, 47, 70. Analoge, und doch anders gelagerte Strategien zur Unterbrechung der Totalität der Macht finden sich bei Michel Certeau: vgl. Füssel, Zur Aktualität von Michel Certeau 2018, 100-150.

448 | Butler, Haß spricht 2016, $226 f$.

449 | Butler, Haß spricht 2016, 227. 
wertet, marginalisiert, »Werte zu äußern und darzustellen.« ${ }^{450}$ Wie sehr sich damit das Subjekt selber mit dem Handlungsdruck konfrontiert sieht, sich diesen Möglichkeiten inmitten des Verunmöglichenden zu stellen, wird durch Formulierungen Butlers noch betont, die beinahe an den philosophischen Existentialismus erinnern. Das Subjekt erfährt sich durch Werte in Anspruch genommen, die ihrerseits in Machtformen gründen, deren Autorität wiederum zu bezweifeln sind. Es befindet sich so gar in einer »Zwickmühle«: Will es sich in den Bedingungen lediglich einrichten, die das Leben wertvoll machen, oder will es Kritik an der herrschenden Weltordnung üben ${ }^{3451}$

\subsection{Performative Öffentlichkeit}

Über die systemisch-strukturelle Färbung hinaus markiert dies freilich die politische Dimension der Sprache. Das Feld der Politik wird auf diese Weise sprachtheoretisch wie subjekttheoretisch fundiert. Damit aber kommt nun der Begriff der Öffentlichkeit ins Spiel.

\subsection{1 Öffentlichkeit und Privatheit}

Vor dem Hintergrund diskursiver Konstitutionsprozesse subjektiver Identitäten, verschärft noch durch Butlers Ontologie des Körpers, wird nämlich vollends deutlich, dass mit einer solchen performativ-diskursiven Sprachtheorie die Grenzen zwischen Subjekt und Gesellschaft und damit die zwischen >öffentlich und >privat< porös werden. Überschreitet die Ontologie des Körpers bereits die Grenzen des Privaten, ${ }^{452}$ so zeigt sich darin die durchgängige Sozialität des Menschen. Mein Leben, so Butler, ist auch immer das Leben der anderen, das Leben der anderen ist auch immer unser Leben. Immer schon, von Anfang an, sind wir voneinander abhängig und werden wir von einer »sozialen Wert konstituiert ${ }^{453}$ Die Ordnung des Sozialen ist eine unabgeschlossene hegemoniale Ordnung im Raum der Diskurse, die sich in dauernden Konfigurationen und überraschenden Verbindungen je neu reproduziert. Jedes private Ordnungssystem in Familie und Gemeinschaft verweist je schon auf die umgreifenden sozialen, kulturellen, ökonomischen und politischen Bedingungsgefüge. ${ }^{454}$

450 | Butler, Anmerkungen zu einer performativen Theorie der Versammlung 2016, 267.

451 | Butler, Ist das Judentum zionistisch 2012, 106.

452 | Vgl. Geuss, Privatheit 2002.

453 | Butler, Anmerkungen zu einer performativen Theorie der Versammlung 2016, 144.

454 | Vgl. Jergus u.a., Autorität und Autorisierung 2012. 
Eine solche Anbindung von Öffentlichkeit an Sozialität ist keine Trivialität. Wir haben es hier vielmehr mit deren Grundierung in performativ vollzogenen Diskursen zu tun, die ihre Brisanz erst durch ihre vergleichende Konfrontation mit konkurrierenden Entwürfen der Öffentlichkeit gewinnt. Im Hintergrund unserer Überlegungen spielte unausgesprochen stets die radikale Differenz zur Diskurstheorie von Habermas oder zur liberal-universalistischen Theorie von Rawls hinein. Die Unterschiede zur Systemtheorie Luhmanns fallen gerade wegen des sprachtheoretisch-subjekttheoretischen Desiderats bei Luhmann ins Gewicht. Was aber Butlers Öffentlichkeitstheorie im besonderen Maße kennzeichnet, ist ihr Vergleich mit der Öffentlichkeitstheorie Hannah Arendts, die für die politische Theorie traditionsbildend und maßstabsetzend geworden ist und gegenwärtig wieder neu entdeckt wird. ${ }^{455}$

Gerade in ihrem Buch zur Performativität der Versammlung gewinnt Butler in einer ganz eindrücklichen Intensität ihren eigenen Öffentlichkeitsbegriff durch die kritisch-konstruktive Absetzung von Arendt, auch wenn man durchaus fragen kann, ob Butlers Interpretation Arendt vollends gerecht wird. So sehr sie mit Arendt das soziale Leben für hoch öffentlichkeitsrelevant hält, insofern der politische Raum performativ im Zusammenkommen der Menschen im Rahmen einer politischen Aktion entsteht, ${ }^{456}$ so sehr sie an sprachlich konstituierten Handlungsräumen als Orten gesellschaftlicher Selbstverständigungsprozesse festhält, so sehr ihr Arendts Rede von einem universalen Recht, Rechte zu haben, gerade in den gegenwärtigen Zeiten globaler Flüchtlingsströme und der Ausgrenzung von Migranten imponiert, ${ }^{457}$ so überwindet Butler doch Arendts strenge Trennung von Öffentlichkeit und Privatheit. Ohne einer totalen Politisierung der Wirklichkeit das Wort zu reden, stellt sie den Unterschied zwischen >öffentlich $<$ und >privat< »in Frage «.458

Verantwortlich für eine solche starke Trennung sei bei Arendt die neo-aristotelische Verwurzelung der Öffentlichkeitstheorie in dem kategorialen Gefüge der antiken polis. Durch diese hermeneutischen Anleihen, so ergiebig dies für einen demokratischen Republikanismus auch sein mag, übernimmt jedoch Arendts Interpretation in den Augen Butlers auch das hierarchische Gefälle zwischen Öffentlichkeit und Privatheit. Nicht dass dies an sich bereits problematisch wäre; die öffentlichen Angelegenheit werden und können nur in der Öffentlichkeit beraten und entschieden werden. Aporetisch für eine Öffentlichkeitstheorie wird diese Hierarchie aber spätestens dann, wenn sie -

455 | Vgl. Heuer u.a., Arendt Handbuch 2011, 11-58.

456 | Vgl. Butler, Anmerkungen zu einer performativen Theorie der Versammlung 2016, 168.

457 | Vgl. Butler, Anmerkungen zu einer performativen Theorie der Versammlung 2016, 68.

458 | Butler, Anmerkungen zu einer performativen Theorie der Versammlung 2016, 98. 
erstens - auf einer starken Unterscheidung von >öffentlich $<$ und >privat< beruht und - zweitens - wenn diese mit der anthropologischen Differenz zwischen Körper und Geist begründet wird. Diese Differenz geht bei Arendt einher mit der Unterscheidung von Notwendigkeit und Freiheit. ${ }^{459}$

Das Private ist demnach der vorpolitische Bereich. Hier werden Ressourcen wie Nahrung, Sexualität, Sterben, Tod, Obdach, Lebensunterhalt organisiert, eben der notwendige Hintergrund für das politisch Entscheidende, das sich in der Öffentlichkeit abspielt. Das Private ist der Bereich des Körpers, der als »Stütze« des Öffentlichen und damit des Politischen fungiert. ${ }^{460}$ Andererseits bedeutet diese Privatisierung des Notwendigen, dass die materiellen Probleme ihrerseits privatisiert sind. Sie sind nicht primär Gegenstand öffentlicher Beratungen. Das Öffentliche hingegen ist der Bereich der Politik. Hier herrscht die Freiheit des Kreativen, des Kulturschaffenden, nicht die Reproduktion des Notwendigen. Freiheit dominiert über Notwendigkeit, Geist über Körper, auch wenn für Butler Arendt keinem cartesianischen oder platonischen Dualismus unterliegt. ${ }^{461}$ Braucht das Öffentliche das Private, so ist doch der politische Bereich der alleinige Bereich, in dem Revolutionen geschehen und wo auch allein die Motivationen für gesellschaftliche Veränderungen reifen. Der politische Bereich ist der einzige, so Arendt, »in dem Menschen wirklich frei sein können ${ }^{4}{ }^{62}$ Arendts Öffentlichkeitstheorie, wie sie besonders in deren Grundlagenwerk Vita Activa ihren Niederschlag gefunden hat, lässt sich nach Butler folgendermaßen bündeln:

"Die Öffentlichkeit, in der sich der Sprechakt als paradigmatische Handlung erweist, ist in ihren Augen eine, die schon von der Privatsphäre getrennt ist, dem Bereich von Frauen, Sklaven, Kindern und Menschen, die zu alt oder zu schwach zum Arbeiten sind. Alle diese Gruppen werden in gewissem Sinne mit der körperlichen Daseinsform assoziiert, die sich durch die ,Vergänglichkeit، ihrer Arbeit auszeichnet, und echten Taten gegenübergestellt, zu denen die Herstellung kultureller Werke und die gesprochene Tat gehören. “463

459 | Dass Arendt damit die klassische Unterscheidung von Marx zwischen dem Reich der Freiheit und dem Reich der Notwendigkeit kritisch reformuliert, wäre abzuleiten aus Kern, "Es rettet uns kein höh'res Wesen“ 2017, 113-118.

460 | Butler, Anmerkungen zu einer performativen Theorie der Versammlung 2016, 264; vgl. 261-267.

461 | Vgl. Butler, Anmerkungen zu einer performativen Theorie der Versammlung 2016, 263.

462 | Arendt, Über die Revolution 1963, 145.

463 | Butler, Anmerkungen zu einer performativen Theorie der Versammlung 2016, 64. Vgl. Arendt, Vita activa 1981. 
Öffentlichkeitstheoretisch sind damit erhebliche Implikationen verbunden: 1. der Ausschluss der Frauen von der Öffentlichkeit, werden diese doch primär dem Privaten assoziiert; 2. die öffentliche Dominanz der Männer und schließlich nicht zuletzt 3. die Abwertung der Kämpfe um Emanzipation und Befreiung gegenüber der schon vorhandenen Freiheit.

„Für Arendt scheint, wer aus Notwendigkeit handelt, vom Körper her zu handeln, aber Notwendigkeit kann nie eine Form der Freiheit sein (sie ist ihr Gegenteil) und Freiheit kann nur von demjenigen erreicht werden, die, nun ja, keinen Hunger haben. [...]. Wenn der Körper auf der Stufe der Notwendigkeit bleibt, dann kann offenbar keine politische Erklärung der Freiheit eine verkörperte sein." ${ }^{464}$

Im Lichte der Theorie des Diskurses betrachtet, verbietet sich eine solche Entkörperlichung der Sprechakte genauso wie die Privatisierung des Materiellen. Was ist, so fragt Butler plakativ, mit der Möglichkeit, dass man wütend, hungrig, frei und vernünftig ist? »Wenn wir über Vergänglichkeit und Sterblichkeit nachdenken, befinden wir uns [...] schon mitten im Politischen.«465 Was angesichts empirischer Einsichten zur höheren Sterblichkeit und schlechteren Lebenschancen von Armen selbst in den spätindustriellen Staaten des Westens unmittelbar einleuchtet, wird von Butler politisch generalisiert. Eine politische Erklärung von Freiheit muss sich zurückbeziehen auch auf das Notwendige. Die Trennung des Vorpolitischen und Politischen wird damit obsolet. Der Kampf um Anerkennung ist zugleich ein Kampf um Gleichheit der materiellen Ressourcen, die Sorge um Identitäten ist von der Auseinandersetzung um Gerechtigkeit unablösbar. Materielle Bedingungen sind schlicht untrennbar von der politischen Versammlung. Es gilt genau das Umgekehrte: Die Versammlung ist selber der Ort, wo materielle Grundlagen verändert werden, ja wo die »Infrastruktur zum Teil der neuen Aktion« und ihrerseits zu einem »Gemeinschaftsakteur « wird. ${ }^{466}$ Wenn demnach Politik auf die Schaffung von lebbaren Räumen und die Bewahrung lebbarer Bedingungen ausgerichtet ist, dann lässt sich der Erscheinungsraum der Freiheit nie ganz von Fragen nach der Infrastruktur und nach dem Notwendigen trennen. Diese bedingen nicht nur politische Aktion, sondern sie sind ihrerseits wesentlich »auch an der Schaffung des politischen Raums beteiligt $\ll .{ }^{467}$ Erst wenn das Private ins Politi-

464 | Butler Anmerkungen zu einer performativen Theorie der Versammlung 2016, $65 f$.

465 | Butler, Anmerkungen zu einer performativen Theorie der Versammlung 2016, 67.

466 | Butler, Anmerkungen zu einer performativen Theorie der Versammlung 2016, 168.

467 | Butler, Anmerkungen zu einer performativen Theorie der Versammlung 2016, $168 f$. 
sche geweitet und damit öffentlich wird, kann es gesellschaftliche Veränderungen geben, wie Butler an den Demonstrationen auf dem Tahirplatz aufzeigt. ${ }^{468}$

\subsection{2 Öffentlichkeitstheoretische Ausweitung des Performativitätsbegriffs}

Gegen Arendt bringt Butler nun im Begriff des >Prekariats< und in dem normativ aufgeladenen Begriff des >lebbaren Lebens< diese Gleichberechtigung des Kampfes um Gerechtigkeit und Gleichheit öffentlichkeitstheoretisch zur Geltung und verbindet dies mit einem Sprach- und Handlungsbegriff, der von »der Verkörpertheit sozialer Handlungs- und Ausdrucksformen« und damit von »verkörperter und pluraler Performativität« ausgeht. ${ }^{469}$ Hatte Butler - um es mit den Titeln zweier ihrer hier besonders einschlägigen Arbeiten zu sagen - noch in der diskurstheoretischen Reformulierung der Sprechakttheorie sich um die sprachbezogene »Politik des Performativen« bemüht, so arbeitet sie dies nun vor dem Hintergrund der Körperdiskurse zu einer »performativen Theorie der Versammlung « aus. ${ }^{470}$ Hierdurch gewinnt sie die Basis, die Sprechakte über kognitiv-diskursive Prozesse hinaus auf die Sphäre der Körper auszuweiten. Sie öffnet die Sprechakttheorie ins Vorkognitiv-Performative. Insofern Performativität Handlungsfähigkeit impliziert, muss ein veränderter Performativitätsbegriff auch die Bedingungen des Handelns untrennbar mit einbeziehen. Das, was bei Arendt das Vorpolitische war, wird jetzt zum Gegenstand politischen Handelns und unter Handlungsgesichtspunkten im Begriff des >Prekariats< verdichtet. Dem Prekariat, dem es an Infrastruktur mangelt, an Anerkennung und Inklusion, wird Teil einer sich konstituierenden Öffentlichkeit. Im Gegensatz zur Verleugnung der politischen Relevanz des Materiellen bei Arendt analysiert Butler bereits die Mechanismen dieser Verleugnung selber und wendet dies kritisch-konstruktiv: »Tatsächlich bildet die Kritik jener nicht beachteten Abhängigkeit den Ausgangspunkt für eine neue Körperpolitik, die mit der Einsicht in die menschliche und zwischenmenschliche Abhängigkeit beginnt, oder anders gesagt: eine Politik, die der Beziehung zwischen Prekariat und Performativität Rechnung trägt.« ${ }^{471}$ In dem die prekär lebenden Menschen sich versammeln, bekommt das Materielle, bekommt der Kampf um Gleichheit und Freiheit eine Verkörperung. Körperliche Inszenierung, ob sprachlich expliziert oder nicht, ist demnach bereits performatives Handeln -

468 | Vgl. Butler, Anmerkungen zu einer performativen Theorie der Versammlung 2016, $130 \mathrm{ff}$.

469 | Butler, Anmerkungen zu einer performativen Theorie der Versammlung 2016, 34. 470 | Vgl. Butler, Haß spricht 2016; Butler, Anmerkungen zu einer performativen Theorie der Versammlung 2016.

471 | Butler, Anmerkungen zu einer performativen Theorie der Versammlung 2016, 265. 
und damit politisch. Menschliches Versammeln, ob technisch, virtuell vermittelt oder nicht, ist damit ein Akt der Herstellung von Öffentlichkeit und damit bereits ein politischer Akt.

"Jeder Protest, egal wogegen er sich richtet, ist implizit immer auch eine Forderung, zusammenzukommen und sich versammeln zu können und zwar aus freien Stücken, ohne Angst vor Polizeigewalt oder politischer Zensur. Es geht also nicht nur um den Körper in seinem Kampf mit der Prekarität und seinem Ringen um Persistenz, der im Zentrum so vieler Demonstrationen steht, sondern auch um den bei diesen selbst anwesenden Körper, der seinen Wert und seine Freiheit aufs Spiel setzt und zur Schau stellt und durch die verkörperte Form der Versammlung eine politische Forderung aufstellt. « ${ }^{472}$

Hier konstituiert sich Öffentlichkeit, hier artikuliert sich in einem expressiven Ausdruckshandeln des Versammelns, des Gestikulierens, des Demonstrierens, des Stillstehens die Volkssouveränität als Basis demokratischer Institutionen und Prozeduren. Wo sich eine Gruppe von Menschen zusammenfindet, konstituiert sich das >Volk< im öffentlichen Raum, wobei Butler stets auf der fluiden wie pluralen Gestalt des Volkes insistiert. Es gibt keine totale Repräsentation.

Hierfür allerdings müssen keine verbalen expliziten Forderungen erhoben werden. Allein das Zusammenkommen und die damit vollzogene Willensbekundung, das Volk zu bilden als demokratische Instanz, vollziehen bereits einen performativen Akt politischer Öffentlichkeit und politischer Willensbekundungen. ${ }^{473}$ Schon das Zusammenkommen der Körper in öffentlichen und virtuellen Räumen machen ein »plurales und performatives Recht zu erscheinen geltend«, eines, das den »Körper in die Mitte des politischen Feldes rückt und das in seiner expressiven und bezeichnenden Funktion eine leibliche Forderung nach lebenswerten wirtschaftlichen, gesellschaftlichen und politischen Bedingungen darstellt, die nicht mehr durch von außen auferlegte Formen der Prekarität erschwert werden«. ${ }^{474}$ Auf diese Weise avanciert der Körper bei Butler zur politischen Protestform und wird so politiktheoretisch etabliert.

Ein solches Zusammenkommen ist gespeist aus der sozialen Interdependenz der Menschen, aus der Abhängigkeit voneinander, aus den Erfahrungen der konstitutiven Verletzlichkeit und Gefährdetheit. Öffentlichkeit ist damit ein Ort, wo die Menschen sich einander aussetzen, wo sie sich verletzen las-

472 | Butler, Anmerkungen zu einer performativen Theorie der Versammlung 2016, 28.

473 | Vgl. Butler, Anmerkungen zu einer performativen Theorie der Versammlung 2016, 67-70.202-210. Zu begrifflichen Klärungen des Volksbegriffs Wildt, Volk, Volksgemeinschaft, AfD 2017, 15-50.

474 | Butler, Anmerkungen zu einer performativen Theorie der Versammlung 2016, 19; vgl. $79 \mathrm{ff}$. 
sen, wo sie selber verletzen, aber wo sie zugleich Verantwortung übernehmen. Vulnerabilität und Verkörperung korrelieren. ${ }^{475}$

Freilich entgeht auch diese Formierung politischer Willensbildung als >Volk nicht jener Dialektik von Inklusion und Exklusion, die Butler anerkennungstheoretisch bereits durchdekliniert hat, und die sie nun anhand solcher prominenter Beispiele wie des amerikanischen Axioms »We the people«, der Demonstrationen der Occupy-Wall-Street-Bewegung, des Arabischen Frühlings, aber auch in ihren sensiblen Wahrnehmungen zu Pegida-Demonstrationen freilegt. Niemals kann das Handeln des Volkes und die damit performativ vollzogene Konstituierung als Volk dieses als Ganzes umfassen. Indem es benennt, indem es Identitäten anvisiert und konstituiert, schafft es Ausgrenzungen. Eine solche performative Inszenierung des »Wir« bleibt der Logik des Diskurses verhaftet - und ist doch zugleich das Forum, »inmitten des biopolitischen Systems « kritische Impulse einzubringen. ${ }^{476}$

Will man die politische Kraft und das politische Potential von Versammlungen, will man die öffentlichkeitskonstituierende Dynamik von Zusammenschlüssen öffentlichkeitstheoretisch wie politisch würdigen, so lässt dies fragen, ob die überkommene Hermeneutik des Sprechakts diesem Prozess einer verkörperten Performativität noch entspricht. Eine solche Ausweitung des Performativitätsbegriffs verlangt deshalb die Erweiterung seiner epistemologischen und praxeologischen Grundlagen. Auf politiktheoretischer Ebene wie auf der sprachphilosophischen Ebene der Sprechakttheorie problematisiert Butler die Verengung auf Verbalisierung. Muss nicht der Begriff politischen expressiven Handelns von der Dominanz der Verbalisierung befreit und auf das Handeln der Körper geweitet werden? »Tatsächlich müssen wir neu über den Sprechakt nachdenken, um zu begreifen, was bestimmte Arten körperlicher Inszenierungen tun und schaffen: Die versammelten Körper >sagen<, dass sie nicht frei verfügbar sind, auch wenn sie nur still dastehen. Diese Ausdrucksmöglichkeit ist Bestandteil der pluralen und verkörperten Performativität. « ${ }^{477}$ Die Versammlung von Körpern, das Handeln von Körpern äußern etwas auf ihre Weise, die »genau genommen weder diskursiv noch vordiskursiv ist. Mit anderen Worten, Versammlungen haben schon vor und unabhängig von den spezifischen Forderungen, die sie stellen, eine Bedeutung.« ${ }^{478}$

Aussagekräftig ist die Verhältnisbestimmung. Nicht nur, dass verkörperte Performativität eine Bedeutung haben kann, die verbalisierte Berichte schrift-

475 | Vgl. Butler, Anmerkungen zu einer performativen Theorie der Versammlung 2016, 195.

476 | Butler, Anmerkungen zu einer performativen Theorie der Versammlung 2016, 267; vgl. 201-241.

477 | Butler, Anmerkungen zu einer performativen Theorie der Versammlung 2016, 29.

478 | Butler, Anmerkungen zu einer performativen Theorie der Versammlung 2016, 15. 
licher oder mündlicher Art übersteigt. Sprechakte sind erst der zweite Akt, artikulieren sie doch etwas, was bereits auf der Ebene der Körper stattfindet. Es wird bereits ein politischer Wille formiert, »bevor irgendjemand etwas sagt oder in der Gebärdensprache ausdrückt « ${ }^{479}$ Die Inszenierung politischer Selbstbestimmung ist daher »notwendigerweise eine Kreuzung aus Sprachlichem und Leiblichem ${ }^{4}{ }^{480}$

\subsubsection{Religion als Index für Alterität}

Könnte man bisher den Eindruck haben, Butler würde eine Homogenisierung von Öffentlichkeit vorschweben, so wäre dies ein Missverständnis. Öffentlichkeit ist nicht konsensual zu denken. Ihre Zurückweisung der diskurstheoretischen Konsensorientierung bei Habermas reformuliert Butler auch öffentlichkeitstheoretisch. Es ist für die gegenwärtigen Auseinandersetzungen um den Säkularisierungsbegriff instruktiv, wenn sie dies über die Rolle der Religionen in der Öffentlichkeit angeht. Ihr Fokus ist dabei weniger die Auseinandersetzung mit der Säkularisierungstheorie. Ihr Fokus ist die Problematisierung der Unterscheidung von >öffentlich und >privat<, die nicht nur im Kampf um Gleichheit und Freiheit, sondern ebenfalls religionspolitisch belangreich ist. Sie kritisiert die »protestantische« Form der Öffentlichkeit und deren Privatisierung von Religion, so als ob Religion einer säkularen Öffentlichkeit gegenüberstünde und das entscheidende Problem gesellschaftlicher Verständigungsprozesse darin liegen würde, wie diese und ob diese öffentlichkeitswirksam zu sein hätte. Es sei vielmehr eine Frage der jeweiligen Religion, wie diese sich zum öffentlichen Leben verhalte.

„Wenn wir die Unterscheidung zwischen dem Öffentlichen und dem Privaten ohne den protestantischen Imperativ, die Religion zu privatisieren, nicht vornehmen könnten, dann zeichnet die Religion - bzw. eine tonangebende religiöse Tradition - unmittelbar für den begrifflichen Rahmen verantwortlich, in dem wir uns bewegen. Dies ergäbe in der Tat einen ganz anderen Ausgangspunkt für eine kritische Untersuchung der Rolle der Religion im öffentlichen Leben, da das Öffentliche und das Private in einem sich wechselseitig ausschließenden Verhältnis zueinander stünden, das in wichtiger Hinsicht von vornherein ,inı der Religion angesiedelt wäre.« ${ }^{481}$

Damit ergibt sich ein dynamisches, spannungsvolles Verhältnis zwischen den Religionen und der Öffentlichkeit, das ihr jeweiliges Profil von der jeweiligen Religion erhält. Anhand der anhaltenden Debatten um Zionismus, Antisemi-

479 | Butler, Anmerkungen zu einer performativen Theorie der Versammlung 2016, 227.

480 | Butler, Anmerkungen zu einer performativen Theorie der Versammlung 2016, 221.

481 | Butler, Ist das Judentum zionistisch 2012, 104. 
tismus und die Rolle Israels zeigt sich für Butler das Spezifische des Judentums: Es gehört in die Öffentlichkeit, und hält doch kritische Distanz zum politischen Leben. Es ist selber ein »antiidentitäres Projekt«. ${ }^{82}$ Ausgesetzt der Alterität des leidenden Anderen aus seiner ethischen Grundhaltung heraus, ergibt sich aus solchen »jüdischen Bezugspunkten« die für Butler »zwingende Forderung«, staatliche Gewalt offen und öffentlich anzuprangern. ${ }^{483}$ Uns soll hier nicht die Angemessenheit ihrer Israelkritik beschäftigen, die kräftigen Widerspruch erfahren hat. Öffentlichkeitstheoretisch relevant jedoch ist daran, dass sie den spezifischen Beitrag der jüdischen Religion darin sieht, mitten in die Öffentlichkeit hineinzugehören, selber eine jeweilige Zuordnung von Öffentlichkeit und Privatheit zu realisieren, und dabei die öffentlichkeitstheoretische Perspektive zu verändern. Nicht mehr steht eine angezielte Übereinkunft im Horizont der Öffentlichkeit. Jüdische Religion verkörpert als fortwährende lebendige Erinnerung »die Grenzen des Hörbaren und sinnlich Wahrnehmbaren, die die Öffentlichkeit ausmachen «.484 Der religiöse Beitrag zur Öffentlichkeit beruht demnach gerade auf der Abwesenheit von Übereinstimmung, ${ }^{485}$ auf den Stachel im Fleisch, wie man im Rekurs auf das prophetische Erbe sagen könnte. Mit anderen Worten: Religion ist die kritische Instanz, die die Öffentlichkeit vor ihrer Totalisierung und ihrer völligen Systematisierung im Begriff bewahrt. Sie ist jener kritische Impuls, jene Transzendenz, die alle immanenten Universalismen dekonstruiert und die Öffentlichkeit auf Anderes konstitutiv offenhält. Das deutet bereits auf den Ertrag dieser Performativen Öffentlichkeitstheorie.

\subsection{Kritik}

Butler liefert gewiss nicht eine ausgefeilte systematisch konturierte Öffentlichkeitstheorie. Entwickeln Habermas, Taylor, Gerhardt und auf seine Weise auch Luhmann breit angelegte genealogische Sozialtheorien der Öffentlichkeit, so bietet Butler vor allem »eine Syntax des Öffentlichen« ${ }^{486}$ Sie akzentuiert die praktischen und hermeneutischen Konstitutionsbedingungen der Öffentlichkeit in performativen Prozessen körperlicher und sprachlicher Selbstinszenierungen. In Zeiten zunehmender Virtualisierung auf die politische Potenz von Körpern und des Embodiment aufmerksam gemacht zu haben, ist demokratietheoretisch hoch verdienstvoll. Indem sie diese diskurstheoretisch interpretiert, wird eine machtsensible Perspektive eingenommen, die zugleich die mit

482 | Butler, Ist das Judentum zionistisch 2012, 107.

483 | Butler, Ist das Judentum zionistisch 2012, 106.

484 | Butler, Ist das Judentum zionistisch 2012, 131.

485 | Vgl. Calhoun, Nachwort 2012, 190.

486 | Mendieta, VanAntwerpen, Einleitung 2012, 18. 
der Konstitution der Öffentlichkeit vollzogenen Inklusionen und Exklusionen analysieren hilft - eine Perspektive, die auch soziologisch hoch bedeutsam ist bei der Analytik von Benachteiligungsstrukturen und deren politischer Sprengkraft. ${ }^{487}$ Verbunden mit einer Radikalkritik an Essentialismus und einer ungeschichtlichen Metaphysik, kritisiert Butler damit jene holistischen Entwürfe, die im Zugriff auf Öffentlichkeit die Individuen in ihrer Alterität, Freiheit und Widerständigkeit relativieren. Religion wird als Teil wie als kritisches Moment der Öffentlichkeit gegenüber voreiligen Säkularisierungen rehabilitiert und zugleich für eine Ethik relevant, die ihr Profil von einer im Anruf des Anderen gestifteten Verantwortung gewinnt. Ethik und Macht werden zusammengedacht und - besonders brisant in gegenwärtigen Zeiten einer Fixierung auf reine Identitätspolitik - das Ringen um Gleichheit und Identität, um Freiheit und Gerechtigkeit intrinsisch aufeinander bezogen. ${ }^{488}$ Statt aus »jedem Diskurs mit dem Fremden und dem Nicht-Identischen einen liberalen Einsegnungsgottesdienst $\mathrm{zu}$ machen ${ }^{4}{ }^{89} 9$ sind die Selbstachtungsperspektiven verschiedener Identitäten und das universalisierbare Gleichheitspostulat streng aufeinander verwiesen.

Dies ist - um hier zunächst nur besonders signifikante Momente hervorzuheben - religionspädagogisch ebenso relevant wie die Ausweitung der Sprechakttheorie zu einer Theorie körperlicher Performanz. Einer inzwischen weitgehend etablierten performativen Religionspädagogik würde eine solche ideologiekritische und machtsensible Hermeneutik gut tun, um sich selber vor leichtfertigen Affirmationen oder gar Instrumentalisierungen zu schützen. Überdies kann durch ihre Theorie performativ konstituierter Räume politischen und öffentlichen Handelns eine religionspädagogische Öffentlichkeitstheorie sich Impulse für ihre Positionierung im spatial turn geben lassen. ${ }^{490}$ Das bedrängende Problem, wo Religion gelernt werden kann und von welchen Orten sich Religionspädagogik zu denken geben lassen müsste, könnte hierdurch neben der überdies zu bedenkenden Rolle von Körperlichkeit weiterführende Perspektiven erfahren.

Allerdings sieht sich insbesondere Butlers Subjektverständnis (und damit zugleich der Subjektivierungsgedanke Foucaults) zu Recht einer erheblichen Kritik ausgesetzt. Ist nicht ein solcher Subjektbegriff zu schwach, um gesellschaftlichen, ökonomischen und diskursiven Hegemonien Widerstand

487 | Vgl. Eribon, Rückkehr nach Reims 2017, $198 f$.

488 | Vgl. als Exemplum einer angeheizten Debatte Lilla, The once and future Liberal 2017, 19-96; aus kultursoziologischer Sicht Reckwitz, Die Gesellschaft der Singularitäten 2017, 27-110.

489 | Kühnlein, Politische Theologie 2017, 196.

490 | Vgl. Kaupp, Raumkonzepte in der Theologie 2016; Sander, Einführung in die Gotteslehre 2016, 17-39. 
entgegensetzen zu können? Zwar versuchen gewichtige Stimmen, aus der Konstellation von Subjekt, Anerkennung, Performativität und Macht im Subjektivationsbegriff selber dem Subjekt Kraft und Motivation zum Widerstand zuzuerkennen. Man kann durchaus auf Butler selber verweisen, die festhält: »Als gewollte Wirkung des Subjekts ist die Subjektivation eine Unterordnung, die das Subjekt über sich selbst verhängt. Wenn jedoch die Subjektivation ein Subjekt hervorbringt und ein Subjekt Vorbedingung der Handlungsfähigkeit ist, dann ist die Subjektivation die Begründung dafür, dass das Subjekt Garant seines Widerstandes und seiner Opposition wird. ${ }^{491}$ Gleichwohl bleibt die »Grundlage für ethisches Handeln, die Butler nennt, [...] lediglich eine schwache«, weil sie eben der Differenz zwischen dem Diskurs und dem eigenen Wollen zu wenig entgegenstellen kann, »da das eigene Wollen ja auch wieder im Diskurs entsteht «.492 Zur Beseitigung dieses Defizits bringt deshalb etwa Gunda Werner aus ihrer tiefen Kenntnis des Butlerschen Werkes ein transzendentalphilosophisches Freiheitsdenken als tragfähige Basis ein. ${ }^{493}$

Doch spielt die Pluralisierung und Hybridisierung von Identitäten bei Butler ihren Kritikern nicht ohnehin unfreiwillig und kontraintentional in die Hände?

"Wie dem Paradox einer Anrufung entgehen, die vereinheitlicht, indem sie Unterschiede stark macht? Die Programme fordern Distinktion statt Konformität, Überschreitung statt Regelbefolgung [...]. Doch auch die Verflüssigung von Positionen und ein Hinundherspringen zwischen pluralen Identitäten führen nicht aus dem Bann dieser Anrufung heraus: die nomadischen 'queeren o oder hybriden Subjekte, die als empathisch aufgeladene Gegenanrufungen poststrukturalistische Theorien - von Gilles Deleuze über Judith Butler bis Homi Bhabha - bevölkern, mögen zwar auch den in der nachdisziplinären Gesellschaft noch wirksamen Heterogenisierungsdruck mit einem Vexierspiel unscharfer oder wechselnder Identitätskonstruktionen unterlaufen, dem Flexibilisierungsimperativ einer radikalen Marktökonomie haben sie wenig entgegenzusetzen. “ ${ }^{494}$

Wo das Ich, so Saskia Wendel, »nicht mehr als dem Diskurs vorgängig verstanden«, sondern seiner Allmacht unterworfen und damit als »Spielball des Diskurses und seiner Macht« gedeutet wird, ${ }^{495}$ unterläuft dies neben dem frei-

491 | Butler, Psyche der Macht 2002, 19.

492 | Werner, Differenz als theologischer Begriff 2016, $101 \mathrm{f}$.

493 | Vgl. Werner, Differenz als theologischer Begriff 2016, 102-105. Ferner zum Subjektbegriff: Riedl, Ethik an den Grenzen der Souveränität 2017; Thiem, Unbecoming subjects 2008.

494 | Bröckling, Das unternehmerische Selbst 2007, 285; vgl. Baader, Gender/Geschlecht 2014, 656ff.; Baader, Diversity education 2013.

495 | Wendel, Gendersensible Theologie 2015, 83. 
heits- wie subjekttheoretisch denkbaren Widerstandspotential überdies die Prämissen von Butlers Philosophie der Freiheit selber. Freiheit wird relativiert. Selbst für Hans-Christoph Koller, der seinen Begriff transformatorischer Bildung auf Butlers Subjektivationstheorie gründet, bleibt »weitgehend offen, wie genau die melancholische Struktur der Subjektivität in Handlungsfähigkeit umschlagen und wie aus unabschließbarer Trauer ein veränderndes Handeln werden kann «.496 Eine lediglich performativ erzeugte Subjektivität sei pädagogisch zu schwach, um im Bereich der Förderpädagogik das Phänomen Behinderung anerkennungstheoretisch zu würdigen. Eine solche depotenzierte Subjektivität birgt die »Gefahr der Überbetonung des Konstruktionsaspekts von Behinderung « mit der Folge entsolidarisierender Effekte, die den Einsatz für veränderte Lebensbedingungen eher schwächen. ${ }^{497}$ Ähnlich argumentiert auch Rahel Jaeggi, die gerade angesichts von Entfremdungsprozessen auf einem Begriff des Selbst insistiert, das zwar nicht mehr in den Bahnen idealistischer Selbstvergewisserungen gedacht werden kann, aber an dem doch gegenüber poststrukturalistischen Verabschiedungen bei Butler wie bei Foucault festgehalten werden muss.

"Als Aneignungsvollzug gedacht ist das Selbst einerseits 'nicht Eines', sofern es aus einer Vielzahl zu integrierender Aspekte besteht. Da es sich in Erfahrungen konstituiert, die es mit sich und der Welt macht, ist es ein Selbst der Veränderung. Und sofern auch Aneignungsprozesse einen experimentell-kreativen Charakter haben, ist das Selbst unvordenklich. Als Träger solcher Aneignungsprozesse allerdings bleibt das Selbst andererseits ein Bezugspunkt, an dem sich das Gelingen oder Scheitern solcher Integrationsleistungen zeigt. " ${ }^{498}$

Die lediglich »auxiliarischen Leistungen« einer solchen subjektiven Identität sind demgegenüber zu blass. ${ }^{499}$

Ist damit bereits der Subjektbegriff problematisch, so verschärft sich dies noch auf dem Feld der Konstitution des Subjekts im Anruf des Anderen. Wie soll, so Rahel Jaeggi in ihrem Rekonstruktionsversuch eines nachidealistischen, ohne essentialistische Restbestände auskommenden Subjektbegriffs aus dem Erbe der Kritischen Theorie, der Einbruch des Anderen denkbar sein »ohne die Bezugsgröße dessen, der sich verändert«? ${ }^{500}$ Es muss doch jemanden geben, der diese »Erfahrungen machen kann«. Dabei geht es nicht um Kohärenz und Einheit »raus einem Guss<, sondern um die den Diskontinuitä-

496 | Koller, Bildung anders denken 2012, 68.

497 | Rösner, Auf's Spiel gesetzte Anerkennung 2012, 374.

498 | Jaeggi, Entfremdung 2016, 266.

499 | Konersmann, Die Unruhe der Welt 2015, 307.

500 | Jaeggi, Entfremdung 2016, 266. 
ten noch zugrunde liegende Fähigkeit, sich auf das, was man fühlt und tut, zu beziehen «. ${ }^{501}$ Wie Jacques Derrida, Stephan Strasser oder Paul Ricoeur gegen ein radikalisiertes Alteritätskonzept bei Levinas als einem zentralen Bezugspunkt Butlers eingewandt haben, steht ohne die Annahme eines vorreflexiven, vordialogischen Haltepunktes im Ich, ohne die Unterstellung von subjektiven Verstehensvoraussetzungen, die Kommunizierbarkeit von Andersheit und Subjekt auf dem Spiel. ${ }^{502}$ Eine radikale Fremdheit wäre nicht mehr erfahrbar, Gerechtigkeit als Handeln der Subjekte nicht mehr möglich. Eine radikale Äquivozität kann nicht verdeutlichen, wie der unbedingte Befehl des anderen das Ich erreichen, wie er gehört werden, ja warum ihm das Ich überhaupt gehorchen und sich immer auch zu sich selbst frei und verantwortlich verhalten kann. Braucht es nicht, so Ricoeur, »eine Dialogik, die die vorgebliche absolute Distanz zwischen dem getrennten Ich und dem belehrenden Anderen durch eine Beziehung überlagert «? ${ }^{503}$

Andererseits müsste jedoch deutlich werden, inwiefern das Subjekt selbst auf diese Alterität verwiesen ist, inwiefern es überhaupt verstehen und annehmen kann, was sich von Alterität her zusagen will. Wenn der Mensch überhaupt keinen Bezug dazu hat, wenn er Alterität, wenn er den Anderen nicht wenigstens in Ansätzen wahrnehmen und nichts von ihm verstehen könnte, wie sollte dann überhaupt der Andere für ihn Bedeutung haben? Zwar setzt sich darum auch Judith Butler von Levinas ab. Trotz ihrer Zustimmung zur Widerlegung des Vorrangs der Selbsterhaltung für das ethische Denken möchte sie auf einer gegenseitigen »Verflechtung zwischen jenem anderen Leben - all den anderen Leben - und meinem eigenen bestehen«. Denn »welchen Sinn >unser Leben auch haben mag, er rührt genau von dieser Sozialität her, von der Tatsache, dass wir immer schon, von Anfang an, von einer Welt der anderen abhängig sind, dass wir in und von einer sozialen Welt konstituiert werden «. ${ }^{504}$ Im Kontext einer in Kategorien der Macht reformulierten Genealogie der Bildung reformuliert Norbert Ricken dies als Suche nach einem dritten Moment,

"das die Relation von Gegebenheit und Aufgegebenheit aufsprengt: denn hängt das 'Eigene، immer auch am 'Anderen`, ohne dass dieses als Produkt des Anderen verstehbar würde, so ist es dem Selbst immer auch entzogen. Es ist vielleicht dieses Moment der 'Alterität des Selbst, das die Problematik situierter Subjektivität auch macht-

$\mathbf{5 0 1}$ | Jaeggi, Entfremdung 2016, 185.

502 | Vgl. Ricoeur, Das Selbst als ein Anderer 1996, 382-426; Strasser, Jenseits von Zeit und Sein 1978, 240; Derrida, Die Schrift und die Differenz 1972, 174-193.

503 | Ricoeur, Das Selbst als ein Anderer 1996, 408.

504 | Butler, Anmerkungen zu einer performativen Theorie der Versammlung 2016, 144. 
theoretisch so bedeutsam macht und die Dynamik sozialer Anerkennungspraktiken als 'Kämpfen des Anerkennens und Aberkennens، antreibt, indem es 'die in der Bewegung des Anerkennens aufscheinende Unausdeutbarkeit des Selbst، zum Focus dieser Kämpfe erklärt. “505

Damit laufen diese Prozesse der Subjektivierung und der Subjektkonstitution durch Alterität am Ende auf das Moment der Normativität zu. Gerade wenn diese Subjektivierungsprozesse machttheoretisch durchbuchstabiert werden, braucht es doch eine normative Perspektive. Von Butler und Foucault her wäre der machttheoretische Blick zu lernen, der die Formen des Wissens, Denkens, des Sprechens und Handelns reflexiv und kritisch bearbeiten hilft. Es geht in dieser Rationalität

"um nicht mehr und nicht weniger als die Form unserer Existenz - die Art und Weise, wie wir dazu geführt werden, uns selbst zu verhalten, mit anderen und mit uns selbst in Beziehung zu treten. Kein Diskurs regiert die Gesellschaft als ganze, und es ist auch nicht ganz richtig zu sagen, daß Diskurse regieren،. Vielmehr gibt es Foucault zufolge viele und manchmal auch miteinander konfligierende Diskurse, die in einer modernen gesellschaftlichen Ordnung in Umlauf sind, von denen jeder bestimmte Wissensgebiete, Identität und Handeln oder Exempel konstruiert, Diskurse der Sexualität, Bildung, Immigration, des Multikulturalismus, der Sicherheit, der Natur oder der Rechte.“ ${ }^{506}$

Wie aber soll man sich orientieren zwischen schlechten und guten Diskursen, zwischen gelungener und gescheiterter Öffentlichkeit, zwischen dehumanisierenden und humanen Positionen? Auch Judith Butler reformuliert einen normativ geladenen Universalitätsbegriff poststrukturalistisch so, dass sie von den Selbstkonstrukten der Subjekte im Kontext der Gerechtigkeitsfrage ausgeht. Jeder Gerechtigkeitsbegriff, auch wenn er Universalität beansprucht, sei aufgrund seines Konstruktionscharakters nicht in der Lage, alle Bedeutungsmöglichkeiten und Inklusionen des Gerechtigkeitsbegriffs auszuschöpfen. Begriffe sind nur in gebrochener Weise universal. Sie werden in ihrem Universalitätsanspruch angefochten und $\mathrm{zu}$ fortwährender Differenzierung genötigt durch die Subjekte, die dieser Begriff gerade ausschließt. Indem diese fordern, dass der Begriff auch sie einschließen möge, »machen sie den widersprüchlichen Charakter der bisherigen Formulierungen des Universalen« in performativer Weise augenfällig. ${ }^{507}$

Hier wird die Holistik des Diskurses porös auf Freiheit hin, aber im gleichen Maße doch das Problem offenkundig. Butler ringt um Kriterien, nach

$\mathbf{5 0 5}$ | Ricken, Die Ordnung der Bildung 2006, 122.

506 | Brown, Die schleichende Revolution 2015, $137 f$.

507 | Butler, Haß spricht 2006, 142. 
denen die Selbstkonstituierungsprozesse der Pegida-Bewegung von denen der Befreiungsbewegungen unterschieden werden können. Wie sollen Volk und Lynchmobs begründet auseinandergehalten werden? ${ }^{508}$ Sie bezieht normative Horizonte mit ein, indem sie differenziert. Nicht die Tatsache der Versammlung an sich ist schon verdienstvoll. Diese ist weder schlecht noch gut. »Der Wert der Körper auf der Straße hängt davon ab, wofür sie sich versammeln und wie die Versammlung abläuft. ${ }^{509}$ Doch wird letztlich »nicht klar ersichtlich«, wie diese Kriterien und ihr Kritikverständnis »normativ angemessen begründet werden «. ${ }^{510}$ Dies aber ist besonders problematisch angesichts der Tatsache, dass sich inzwischen auch die Neue Rechte jener performativen Handlungsformen des Politischen bemächtigt hat, wie sie die Linke der 1968-Ära kultiviert hatte. ${ }^{511}$

Ähnlich undifferenziert bleibt Butlers Prekariatsbegriff. Kann man »Frauen, Queers, Trans-Personen, Arme, anders Begabte, Staatenlose, aber auch religiöse und ethnische Minderheiten « auf eine Stufe stellen? ${ }^{512}$ Die hermeneutischen Auseinandersetzungen in der Intersektionalitäts- und Heterogenitätsdebatte machen doch auf die feinen begrifflichen Gefüge und Differenzen aufmerksam, die nicht zu berücksichtigen eine Verharmlosung vor allem von Ungleichheits- und Gerechtigkeitsproblemen gegenüber kulturellen Identitätsfragen darstellt. ${ }^{513}$

So bleibt am Ende, ungeschmälert der Verdienste für einen religionspädagogischen Öffentlichkeitsbegriff, der zweifache Problemüberhang einer Subjekt- und Normativitätsschwäche. Hier wäre weiterzudenken, indem explizit die Machtfrage und die Normativitätsfrage verbunden werden. Das Problem von »Normativität und Macht« wird damit zum zentralen Problem einer religionspädagogischen Öffentlichkeitstheorie, ${ }^{514}$ die zudem sensibel wird für die Orte und die körperlich-leibhaft vollzogenen Prozesse religiösen Lernens und religiöser Bildung. Öffentliche Religionspädagogik hätte sich um Heterotope zu kümmern, um Andersorte, von denen die Öffentlichkeit selbst dann noch zehren kann, wenn sie sie in ihrer sinnstiftenden wie irritierenden Bedeutung negiert.

508 | Vgl. Butler, Anmerkungen zu einer performativen Theorie der Versammlung 2016, 234-240.

509 | Butler, Anmerkungen zu einer performativen Theorie der Versammlung 2016, 164.

$\mathbf{5 1 0}$ | Ludwig, Kritische Theorie und Kapitalismus 2013, 80.

511 | Vgl. Wagner, Die Angstmacher 2017.

512 | Butler, Anmerkungen zu einer performativen Theorie der Versammlung 2016, 80.

513 | Vgl. Grümme, Heterogenität 2017, 63-97; Fraser, Honneth, Umverteilung oder Anerkennung 2003.

514 | Vgl. Forst, Normativität und Macht 2015. 


\section{Ertrag und Frageüberhang}

Wir haben einen langen Weg zurückgelegt, um religionspädagogisch maßgebliche Öffentlichkeitstheorien zu sichten. Dabei ging es nicht um den Gegenstand der Öffentlichkeit selber, es ging nicht darum, wie etwa die Differenz von >privat< und >öffentlichく, wie das Verhältnis der Teilöffentlichkeiten zueinander und zur Öffentlichkeit insgesamt, wie die zivilgesellschaftliche zur politischen Öffentlichkeit, wie die Einlassbedingungen und Teilhabemöglichkeiten der Subjekte an der Öffentlichkeit, wie deren Konstitutionsbedingungen oder auch das Verhältnis zwischen Parteien und zivilgesellschaftlichen Organisationen zu fassen sind. Ob Öffentlichkeit den direkten Kontakt der Teilnehmer, ob virtuelle, digitale oder andere technische Vermittlungen möglich oder erforderlich sind, ob Öffentlichkeit regional, national, transnational oder international zu organisieren ist, dies lag ebenso wenig im Zentrum wie die Frage nach dem Verhältnis zwischen Neutralität und dem Rang von kulturellen, religiösen, weltanschaulichen Positionierungen sowie zwischen den fein ausdifferenzierten Orten der diversen Formen von staatlicher Neutralität und zivilgesellschaftlicher Öffentlichkeit. Aus der Beschäftigung und kritischen Auseinandersetzung mit ausgewählten Konzeptionen sollte keine neue substantielle Öffentlichkeitstheorie entwickelt werden. Die Denkform stand im Mittelpunkt, nicht der Inhalt, auch wenn sich beide in der bereits thematisierten Logik nicht voneinander lösen lassen. ${ }^{515}$

So ging es um Spuren, um Elemente, um Hinweise, um Themen für einen Öffentlichkeitsbegriff, der dem Anliegen einer Öffentlichen Religionspädagogik im Kontext der Heterogenität Kraft, Sinn und Orientierung verschaffen kann. Vieles wurde aufgerufen, manches bereits aufeinander bezogen, in komparativer, kritischer, inspirierender, weiterführender Absicht. Daraus kann noch nicht direkt ein solcher Öffentlichkeitsbegriff konzipiert werden. Zuvor müssen die einzelnen Elemente der jeweiligen Öffentlichkeitstheorien geordnet, zueinander in Bezug gesetzt und systematisiert werden. Dies ist die Aufgabe dieses Kapitels. Dabei werden Elemente einer weiterführenden Denkform des Öffentlichkeitsbegriffs im Zentrum stehen. Da dies in religionspädagogischer Absicht erfolgt, wird neben diesen Akzenten auf der formalen Bestimmung doch zumindest mit dem Bereich der Religion und deren Status in der Öffentlichkeit ein materialer Aspekt berührt. Denn dies könnte relevant sein für die Positionierung von Orten religiösen Lernens und religiöser Bildung im Verhältnis zu anderen Lern- und Bildungsorten.

Nimmt man die verhandelten Theorien in den Blick und bezieht sie vergleichend wie kritisch aufeinander, so ergibt sich ein uneinheitliches Bild. Nicht alle behandeln alle Themen in der gleichen Intensität und Ausführlichkeit.

515 | Vgl. B 6. 
Und doch kristallisieren sich zentrale Elemente heraus, die integraler Bestandteil eines religionspädagogischen Öffentlichkeitsbegriffs sind.

Es bietet sich an, diese Elemente in einer diachronen Rückschau auf unseren Gedankengang zu gewinnen. Diese Elemente sind nicht als je schon bestimmte zu identifizieren. Sie sind Problemfelder, die in einer noch zu bestimmenden Ordnung konstelliert werden. Genealogie und Systematik werden so zusammengeführt.

Habermas, der dominante Referenzpunkt aller hier verhandelten religionspädagogischen Öffentlichkeitstheorien, liefert bereits wesentliche Bestandteile eines zu konzipierenden religionspädagogischen Öffentlichkeitsbegriffs. Aus seiner deliberativen Öffentlichkeitstheorie sind hierfür folgende Problemfelder herauszulösen:
1. Vernunft
2. Normativität
3. Verhältnis von Universalität und Partikularität
4. Religion in der Öffentlichkeit.

Diese Problemfelder lassen sich nun aus der Auseinandersetzung mit den erörterten Theorien genauer substantiieren. Diese Substantiierung kann allerdings nicht darin bestehen, hier bereits eine eigene begründete Positionierung vorzunehmen. Dafür sind die Divergenzen auf diesen Feldern zwischen diesen Ansätzen zu groß. Vielmehr gilt es ein Problembewusstsein zu schärfen, Spannungen hervorzurufen durch das Herstellen von Konstellationen, Probleme aufzuwerfen, Horizonte zu eröffnen.

In dieser Logik sollen nun die benannten Problemfelder nacheinander konkretisiert werden, stets im Wissen darum, dass diese nur heuristisch voneinander getrennt werden können. Auf diese Weise konturieren sich schließlich Struktur und Anlage der gesuchten öffentlichkeitstheoretischen Denkform.

\subsection{Vernunft}

Wie soll Vernunft strukturiert sein:

Handlungstheoretisch wie bei Habermas, mit dem enormen Gewinn, in kritischer Reformulierung des kantianischen Erbes eine postmetaphysische Letztbegründungstheorie zu liefern im Rückgang auf die in geschichtlich-interkommunikativer Praxis konstituierten Subjekte, mit dem Nachteil, dabei die Differenzen und Heterogenitäten der multiplen Lebensentwürfe in ihrer Relevanz für die Öffentlichkeit nicht hinreichend zu berücksichtigen?; Transzendental wie bei Gerhardt, mit dem Vorteil, Öffentlichkeit bereits im Subjekt zu verankern und eine universale Teilhabemöglichkeit begründen zu können, aber mit dem Nachteil einer kategorialen Unterscheidungs- und Be- 
gründungsschwäche?; Systemisch wie bei Luhmann, mit dem Vorteil einer klaren Trennung verschiedener Teilsysteme und der Würdigung ihrer jeweils spezifischen Logik, aber dem Nachteil eines prinzipiellen Subjektverlustes?; Hermeneutisch-pragmatisch wie bei Taylor, der die Vernunft im dichten Gewebe je schon evaluativ und sprachlich vollzogener Weltbeziehungen situiert mit dem Vorteil, die Subjekte in konstitutiven Wertbindungen zu beheimaten, in denen und aus denen sie je schon sinnstiftend und orientiert leben können, aber mit dem Nachteil, klare und übergreifende Wertorientierungen so nicht begründen zu können?; Performativ-poststrukturalistisch wie bei Butler, die als einzige mit besonderer Vehemenz die Eröffnung der vulnerablen Subjekte durch eine vorgängig wirksame Alterität betont und dabei auf die vorgängige Mitkonstituiertheit der Vernunft durch unreflex wirksame Mechanismen von Macht und hegemonialen Strukturen aufmerksam macht? Dies ruft die Vernunft selber um ihrer ideologiesensiblen Vernünftigkeit willen zu ihrer kritischen Selbstreflexivität auf, lässt aber dabei die Kraft und Würde der Subjekte verblassen.

\subsection{Normativität}

Welchen Rang und Gestalt soll Normativität haben:

Als Grundgestalt der Vernunft und damit auch der Öffentlichkeitstheorie wie bei Habermas, der eine starke Normativität vorlegt? Dies bietet begründete und überaus starke Unterscheidungs- und Legitimationskriterien im Raum der Öffentlichkeit, ohne auf metaphysisch-substantielle Begründungsfiguren zurückzugreifen. Das aber hat die nicht minder greifbare Schwäche, deskriptive Momente, Aspekte von Alterität und Differenz und damit auch jene selbstreflexiv-kritischen Elemente zurückzufahren, wie dies in poststrukturalistischen Theorien so wirkungsvoll eingebracht wird; als pragmatische Normativität wie bei Gerhardt, die um die Bedeutung normativer Begründungs- und Orientierungsleistungen für politische Systeme weiß, aber doch so niederschwellig ist, dass damit diese Leistungen wieder zu verblassen drohen?; als dezidiert antinormative, rein deskriptive Vernunft wie bei Luhmann, die sich werthaltiger Bewertungen enthält und dabei die Logik der einzelnen Teilsysteme detailliert und beobachtend freilegt, aber doch genau deshalb die übergreifende Logik etwa des Ökonomischen für andere Teilsysteme unterschätzt?; als schwache Normativität bei Taylor, der eine rein rational fundierte Letztbegründung ablehnt, aber doch um die Unverzichtbarkeit normativer Horizonte wegen ihrer orientierenden, evaluativen und sinnstiftenden Kraft weiß? Indem er diese aus starken Wertungen und falliblen Schlüssen heraus gewinnt, bettet er diese Normativität in Weltbeziehungen ein, was ihr aber doch die ihr zugeordneten Unterscheidungsfunktionen und Orientierungsleistungen letztlich nicht im angezielten Maße ermöglicht; als eine enthaltsam-selbstreflexive Normativi- 
tät bei Butler, die sich streng von universalistischen Normativitätskonzepten absetzt und dabei in der Sensibilität für die mit Normierungsmomenten der Normativität intrinsisch verbundenen Exklusionstendenzen auf der erforderlichen Selbstreflexivität der Vernunft besteht, dabei aber doch um die Bedeutung von normativen Orientierungen weiß? Die darin vollzogene normative Enthaltsamkeit ist gleichwohl zu stark zurückgefahren, um die Subjekte und deren Praxis in der Öffentlichkeit zu schützen und zu orientieren.

\subsection{Verhältnis von Universalität und Partikularität}

Wie soll das Verhältnis von Universalität und Partikularität gestaltet sein?

Als Dominanz des formal-prozeduralen Universalismus wie bei Habermas? Erst eine solche Vernunft kann im Kontext von Heterogenität den Zusammenhalt einer pluralen Öffentlichkeit sichern. Denn substantielle Visionen des guten Lebens, ethische Orientierungen, religiöse, agnostische, nicht-religiöse worldviews sind nicht für alle geltend $\mathrm{zu}$ machen. Sie sind nicht universalisierbar und bleiben notwendig partikular. Universalität ist nur durch formale Prozeduren zu gewährleisten, obschon diese als Basis von Öffentlichkeit wie von Moral und Gerechtigkeit die gelebte Verwurzelung in lebendigen, narrativ tradierten Weltbeziehungen braucht. Von dorther bekommt sie lebensweltliche Kraft und Dynamik, obschon diese Visionen des guten Lebens und partikularer gelebter Ethik dem formal begründeten Universalismus untergeordnet bleiben. Insofern werden diese universalisierbaren Orientierungsleistungen des formalen Prozeduralismus allerdings bezahlt mit der Schwächung lebensweltlicher Dynamiken und Beheimatungen; als Verweigerung einer universalitätsfähigen Zuschreibung der Teilsysteme bei Luhmann, die schlicht die Teilsysteme in der Konstellation von System und Umwelt nicht-hierarchisch nebeneinander setzt? Die messerscharfe analytische Klarheit wird allerdings erkauft mit der Unfähigkeit, das Verhältnis dieser Teilsysteme in ihrem Bezug zueinander hinreichend öffentlichkeitstheoretisch zu denken und etwa moralischen Fragen eine für die Öffentlichkeit geltende Relevanz zuzuerkennen; als Gegenwart des Universalen im Partikularen bei Gerhardt im Rahmen seiner transzendentalen Philosophie, der damit zwar die Öffentlichkeit bereits im individuellen Bewusstsein verankert, aber Gefahr läuft, idealistische Reminiszenzen zu riskieren?; als Verwurzelung des Universalen im Partikularen, wie bei Taylor, der aus kommunitaristischen Bahnen heraus die Inspirationskraft der Gemeinschaften und besonderen Traditionen, der Visionen des Guten für die Ethik und die erfahrungsgesättigten Narrationen gelebten Lebens erst in begrifflicher Schärfe, Kraft und Begründetheit ins Spiel der Öffentlichkeitstheorie bringen kann? Die erfahrungs- wie subjektlose Kälte der Systemtheorie im Ansatz überwindend, überschreitet dies zudem die Abstraktheit eines formalen Prozeduralismus, kann aber dennoch den partikularen Traditionen 
etwa von ethischer Orientierung nicht jenen Rang verschaffen, die sie selber anvisieren. Indem Taylor aus den erfahrungsstarken Verwurzelungen in tradierten wie gemeinschaftlichen Bezügen heraus denkt, kann er sie lediglich anzielen, aber nicht als Kriterium erreichen und öffentlichkeitstheoretisch fruchtbar machen; als eine gebrochen-negative Universalität wie bei Butler, die sich unirritierten holistischen Universalismen der Vernunft verweigert, indem sie vom vorgängigen Einbruch der Alterität und von der Ausgesetztheit der Subjekte her reflektiert und diese in performativen Prozessen beheimatet denkt? Universal kann eine Vernunft nur insofern sein, als sie ihre Vorstrukturierung durch die alles umgreifende Macht der Diskurse selbstkritisch bedenkt. Es ist also nur eine hoch gebrochene Universalität, die das Partikulare als wesentliche Momente der Öffentlichkeit anerkennen kann, dabei aber die darin implizit beanspruchten Formen von Begründungs-, Orientierungs- und Unterscheidungsleistungen nicht zu erreichen vermag.

\subsection{Religion in der Öffentlichkeit}

Anders als die bisher erörterten Problemfelder überschreitet dieses die Ebene der Denkformen. Es berührt bereits materiale Aspekte, obschon bei manchen der diskutierten Autoren die Religion gerade als verdichtetes Signum für eine bestimmte Vernunft bestimmt wird.

Wie wird also Religion gedacht?

Als eine für säkulare Vernunft opake Größe bei Habermas, die vernunfthaltig, aber nicht vollends vernunftfähig ist? Sie kann postmetaphysisch jene Defizite kompensieren helfen, die mit dem modernen Verlust an metaphysischen Weltbildern verbunden sind: ethische Orientierung, Kraft zu supererogatorischen Handlungen, Motivationen zum Engagement für Gesellschaft und Gemeinschaften, Kontingenzbewältigungspraxis. Gleichwohl ist sie als Verkörperung einer partikularen Vision des Guten nicht universalisierbar. Zwar steht sie in symmetrischen Übersetzungsverhältnissen mit säkularer Vernunft, doch bleibt sie ihr insofern nachgeordnet, als sie nicht auf allen Ebenen des demokratischen Gemeinwesens für diskursfähig gehalten wird. Nur säkulare Vernunft kann in moderner Pluralität das Forum demokratisch-staatlicher Öffentlichkeit und das Forum der Verständigung zwischen religiösen und nicht-religiösen Bürgern sein. Eine solche Würdigung der Religion, angesichts säkularer Welterklärungssysteme geradezu unerwartet, geht freilich mit einer Funktionalisierung und öffentlichkeitstheoretischen kognitiven Delegitimierung der Religion einher; als ebenbürtig eingeordnet neben Kultur, Wirtschaft, Wissenschaft bei Gerhardt in einer niederschwellig interpretierten Öffentlichkeit, was ihr zwar öffentlichen Einfluss zubilligt, aber doch ihre präzise innere Bestimmtheit vermissen lässt?; als Teilsystem in einer funktional ausdifferenzierten Wirklichkeit bei Luhmann, deren innere Logik in den Kate- 
gorien von Transzendenz und Immanenz präzise rekonstruiert, aber deren innere, aus den Lebensvollzügen der Subjekte heraus in Anspruch genommene, befreiende wie übergreifende Wahrheit in der schneidenden Architektur des Systems negiert wird?; als gleichberechtigt neben säkularer Vernunft und als in gleicher Weise diskursfähig wie bei Taylor, der allenfalls auf der Ebene des Staates einen Unterschied walten lässt? Die befreiende, stützende wie herausfordernde und in Anspruch nehmende Kraft der Religion wird damit gerade auf der Ebene der Öffentlichkeitstheorie als der Gesellschaft insgesamt zu Gute kommende Hoffnung und Kraft zur Geltung gebracht, ohne dabei jedoch hinreichend normative rationale Unterscheidungskriterien zu begründen; als Indikator für eine alteritätstheoretisch strukturierte Vernunft bei Butler, die sich vorauslaufend mit dem Anspruch von einer (für die Vernunft schlechthin nicht einzuholenden) Fremdheit konfrontiert und sich so erst zur ethischen Verantwortung gerufen sieht? Als solche bleibt sie ständiger Stachel der Kritik aller sich hermetisch abschließenden Öffentlichkeiten und politischen Systeme, wirkt als solche primär negativ, wobei allerdings deren Vermittlung und Verhältnisbestimmung mit anderen worldviews unklar bleibt.

Man könnte sicherlich diese Problemfelder differenzierter, detaillierter und umfassender konstruieren. Aber es ging hier mit deren Aufweis allein darum, ein Arsenal zu entwickeln, aus dem die Konzeption eines den kontextuellen Herausforderungen wie dem Profil der Religionspädagogik angemessenen Begriffs der Öffentlichkeit schöpfen kann. Die konstellative, spannungsvolle Struktur dieser jeweiligen Rekonstruktionen ist bewusst gewählt. ${ }^{516}$ Weder trägt sie Kompromisscharakter noch ist sie Resultat einer notwendig eingegangenen Schwäche, die sich einer eindeutigen Positionierung verweigerte. Sie ist inhaltlich bedingt wie methodisch begründet. Erst aus dieser spannungsvollen Konstellation erhält die Konturierung eines religionspädagogischen Öffentlichkeitsbegriffs ihre erforderliche Dynamik, die hiermit eröffnet ist.

516 | Zur Erkenntnistheorie der Konstellation bei Walter Benjamin und Theodor W. Adorno vgl. Mulsow, Stamm, Konstellationsforschung 2005. 


\section{Skizze eines religionspädagogischen Öffentlichkeitsbegriffs}

\section{AnLäUfe}

Öffentlichkeit religionspädagogisch $\mathrm{zu}$ denken stellt eines der zentralen Desiderate Öffentlicher Religionspädagogik dar. Öffentlichkeit muss gedacht werden, auch und gerade in der Religionspädagogik. Denn es muss doch vor allen vernünftig verantwortet werden, was religionspädagogisch getan wird, wie umgekehrt religionspädagogische Praxis theoretisch orientiert werden muss. Und nach Ausweis aller Ansätze Öffentlicher Religionspädagogik ist eines der zentralen Foren ihrer Artikulation, ihr Ziel und ihr Adressat - die Öffentlichkeit. Nur fragt sich, wie diese Verantwortung und Orientierung zu geschehen hat, mit welcher Vernunft, mit welcher wissenschaftstheoretischen Ausrichtung. Wie kann Öffentlichkeit religionspädagogisch so konzipiert werden, dass es den Axiomen Öffentlicher Religionspädagogik entspricht? Ohne diese hier im einzelnen zu wiederholen, lassen sich diese doch in drei Punkten bündeln:

\section{a. Kontextualität}

Öffentliche Religionspädagogik muss, will sie denn Öffentlichkeit als Forum wie als Adressat anvisieren, ihre Kontexte wahrnehmen, kritisch beurteilen und in Bezug darauf handlungsfähig werden. Was das Konzil als Bewährung von Theologie und Kirche angesichts der "Zeichen der Zeit« mit normativer Wucht allgemein eingeschärft hat, ${ }^{1}$ ist von der Öffentlichen Religionspädagogik auf ihre Weise einzulösen. Dieser Kontext ist als Kontext zunehmender Heterogenität zu qualifizieren. In ihm wird die konstruktiv-kritische Bearbeitung der Spannung zwischen Pluralität und Gerechtigkeit, Identität und Gleichheit

1 | Vgl. Böttigheimer, Bruckmann, Glaubensverantwortung 2012. 
zum Kriterium religionspädagogischer Kontextualität und damit zum Ausweis ihrer bestimmten Wahrheit. ${ }^{2}$

\section{b. Heterogenität der Öffentlichkeiten}

Öffentliche Religionspädagogik muss, will sie denn ihre Kontextualität und ihren eigene Öffentlichkeit realisieren, die Ausdifferenzierung verschiedener Öffentlichkeiten innerhalb des Feldes der Theologie wie innerhalb der Öffentlichkeit selber angemessen würdigen. Innertheologisch hatte David Tracy der Theologie zugemutet, sich um ihrer Wahrheitsfähigkeit auf dem Forum der drei verschiedenen Öffentlichkeiten der Gesellschaft, der Wissenschaft wie der Kirche zu begreifen, und hatte den drei Disziplinen der Fundamental-, der Systematischen und der Praktischen Theologie entsprechende Bereiche zugewiesen. ${ }^{3}$ So revolutionär dies für die Aufbrüche einer Öffentlichen Theologie seinerzeit war, wies dies doch damit die Theologie selber in hermeneutischer Hinsicht als »öffentlicher Diskurs« in der Postmoderne aus, ${ }^{4}$ so weiterführend auch die im Dialog mit der Öffentlichkeitstheorie von Habermas entwickelte öffentlichkeitstheoretische Unterscheidung zwischen einem technoökonomischen, politischen und kulturellen Bereich, ${ }^{5}$ so begrenzt scheint deren begriffliches Arsenal angesichts der in der Spätmoderne zunehmenden Ausdifferenzierung verschiedener, spannungsvoll zu einander stehender Öffentlichkeiten schon allein innerhalb der Gesellschaft. Und obschon empirische Studien eine Milieuverengung innerhalb der Kirchen haben nachweisen können, finden sich zunehmende Vielfalt und Diversität auch dort. ${ }^{6}$ Kurz: verschiedene Teilöffentlichkeiten, Gegenöffentlichkeiten, Kontrastöffentlichkeiten signalisieren die eskalierende Heterogenität der Öffentlichkeit selber. Minderheiten, Exkludierte, Marginalisierte müssen in der Öffentlichkeit zu ihrem Recht kommen.

Allerdings muss nicht unbedingt ein Gegensatz zwischen einer agonalen und einer kommunikativen Öffentlichkeit konstruiert werden. Wenn Hannah Arendt diese agonale Öffentlichkeit als Öffentlicher Streit um das Beste in Stellung bringt, ${ }^{7}$ so muss dies nicht grundsätzlich dem konsensualen Prinzip der

2 | Vgl. Grümme, Heterogenität 2017, 89-159.

3 | Vgl. Tracy, The Analogical Imagination 1981, 3-98; Tracy, Religion in the Public Realm 2014. Dazu Telser, Habermas und die Öffentliche Theologie 2017.

4 | Telser, Theologie als öffentlicher Diskurs 2016, 115. Vgl. Arnes, Ist Theologie Luxus 2000, $180 f f$.

5 | Vgl. Telser, Habermas und die Öffentliche Theologie 2017, 184-186.

6 | Vgl. Sellmann, Milieuverengung als Gottesverengung 2006; Ahrens, Wegner, Soziokulturelle Milieus und Kirche 2013; Wippermann, Sellmann, Milieus in Bewegung 2011. 7 | Vgl. Marchart, Das Agonale 2011. 
deliberativen Öffentlichkeit widersprechen. Auch dort regiert die streitende Suche nach dem besten Argument. Aber durch diese Heterogenität der Öffentlichkeiten wird zumindest der Blick frei für das, was Seyla Benhabib in ihrem kritischen Votum gegen Habermas' deliberative Öffentlichkeitstheorie die »Gefährdete Öffentlichkeit« nennt. ${ }^{8}$

\section{c. Heterogenitätsfähigkeit und Subjektorientierung}

Öffentliche Religionspädagogik muss diese Kontextualität und Heterogenität der Öffentlichkeiten als Forum und Ort begreifen, wo sie sich selber bewähren, sich artikulieren, sich bewahrheiten muss. Es gehört zu ihrem Selbstverständnis, dies im zentralen Maße durch Rückgriff auf jene Glaubensüberlieferung zu tun, aus der sie sich speist und die sie um der Subjekte willen diakonisch in den Öffentlichkeiten einspielt.

Heterogenitätsfähig ist Öffentliche Religionspädagogik demnach dann, wenn sie die identitätsstiftende, befreiende Botschaft des Glaubens so in den gegenwärtigen Kontexten zur Sprache bringt, dass die Subjekte daraus sinnvoll und gut leben können.

Aus diesen drei Axiomen kristallisieren sich nun die entscheidenden Kriterien eines religionspädagogischen Öffentlichkeitsbegriffs heraus, die ihre hermeneutische Potenz auf den oben skizzierten Problemfeldern zu erweisen haben.

\section{ZUSPITZUNG}

Die für die Öffentlichkeitstheorie entscheidende Frage ist die, wie die verschiedenen Öffentlichkeiten so ins Verhältnis gesetzt werden können, dass deren jeweilige Würde als Vollzugsort expressiver Artikulation subjektiver und kollektiver Identitäten sowie deren kritisch-produktiv inspirierende Kraft für die Öffentlichkeit insgesamt angemessen zum Ausdruck gebracht werden?

Christian Bauer hat in seinem fulminanten Entwurf einer Konstellativen Pastoraltheologie einer wissenschaftstheoretischen Grundierung in Konstellationen das Wort geredet. Im Rückgriff auf die Diskurstheorie Foucaults, die Semiotik Ecos und Peirces, die theologische Tradition des locus theologicus und die Theologie Chenus könne die Theologie den Herausforderungen der Spätmoderne nicht in einem normativen Gestus gerecht werden, der die unübersehbare Vielfalt der pastoraltheologischen Praxis wie die Pluralität der Tradition übersehe. Es gelte vielmehr, ein »konstellatives Denken mit zwei

8 | Vgl. Benhabib, Die gefährdete Öffentlichkeit 1997; Benhabib, Models of the Public Space 1992; Klingen, Gefährdete Öffentlichkeit 2008. 
grundlegenden Bezugsräumen« der Theorie der Praxis und der Praxis der Theorie anzulegen, »für dessen Feldforschungen bzw. Archivrecherchen mindestens drei Kontaktaufnahmen konstitutiv sind: die sextradiskursive zum Feld menschlicher Praktiken, (>loci in actu<), die sintradiskursive< zum Archiv anderer theologischer Diskurse (>loci proprii<) und die sinterdiskursive< zum Archiv anderer wissenschaftlicher Diskurse (>loci alieni<)«. Theologie ist damit auf das dynamische Ganze menschlichen Lebens, menschlicher Kultur wie auf die anderen Wissenschaften konstitutiv verwiesen.

Wissenschaftsmethodisch arbeitet diese Konstellative Theologie deshalb mit der spannungsvollen Zusammenführung von Deduktion und Induktion durch Abduktion. Denn in der Konstellation von heterogenen Räumen, von Heterotopen, von Nicht-Räumen könne Neues entstehen und Wahrheit wenigstens momentan aufscheinen. Sie bringt

"die jeweiligen Einstiegspunkte von Induktion und Deduktion, pastorale Einzelfälle bzw. dogmatische Allgemeingesetze, auf abduktive Weise in einen potenziell kreativen Kontrast, aus dem dann schließlich experimentelle ,Handlungsregeln، im Sinne des semiotischen Pragmatizismus von Charles S. Peirce gewonnen werden können: 'Es ist wahr, dass die verschiedenen Elemente der Hypothese zuvor in unserem Geist waren; aber die Idee, das zusammenzubringen, von dem wir nie geträumt hätten, es zusammenzubringen, lässt blitzartig die neue Vermutung in unserer Kontemplation aufleuchten. Abduktion verlässt den festen Grund zwingender Argumentation und begibt sich auf den wackeligen Boden einer entsprechenden Hypothese. Sie öffnet gewohnte Diskurse ad experimentum auf etwas Neues hin und führt hinaus ins Weite: heraus aus dem Diskursarchiv, hinein ins pastorale Praxisfeld - und umgekehrt. ${ }^{10}$

Diese Konstellative Pastoraltheologie ist öffentlichkeitstheoretisch hoch bedeutsam. Dreierlei ist an dieser Hermeneutik der Konstellation aus religionspädagogischer Sicht besonders zu würdigen: erstens die Radikalität, mit der die jeweiligen Subjekte gerade in ihrer Fremdheit in ihrer theologiegenerativen Kraft pastoraltheologisch anerkannt werden; zweitens die Fähigkeit, die verschiedenen Orte der Theologie miteinander ins Verhältnis zu setzen, das eben im Rückgang auf Adorno und Benjamin als das einer Konstellation charakterisiert wird; drittens die Plausibilität und Vehemenz, mit der die Kategorie des Raumes und damit die Bedeutung des spatial turn markiert wird. ${ }^{11}$

9 | Bauer, Denken in Konstellation 2015, $6 \mathrm{f}$.

10 | Bauer, Denken in Konstellation 2015, 11; vgl. Bauer, Konstellative Pastoraltheologie 2016.

11 | Vgl. zum spatial turn Dünne, Günzel, Raumtheorie 2006; Bachmann-Medick, Cultural Turns 2014. 
Öffentlichkeitstheoretisch gesehen bringt die Hermeneutik der Konstellation die jeweiligen Teilöffentlichkeiten gegenüber den etwaigen Dominanzoder gar Hegemonialansprüchen einer übergreifenden Öffentlichkeit zur Geltung. Der Fundamentalkritik an universalen Öffentlichkeitstheorien, wie sie Nancy Fraser gegenüber Habermas eingebracht hat und wohl auch gegenüber Gerhardt einbringen würde, wäre damit entsprochen. Differenzerfahrungen diverser Identitäten wären als öffentlichkeitsrelevant anerkannt. Die systemtheoretische Intention, die Öffentlichkeit von der jeweiligen Logik der Teilsysteme in der binären Codierung von Umwelt und System anzulegen, vor allem jedoch die Insistenz Judith Butlers auf der Uneinholbarkeit und Vorgängigkeit von Alterität wären öffentlichkeitstheoretisch eingelöst. Öffentlichkeit wäre nicht mehr in idealistischen Bahnen aus dem Gefüge der handelnden und sich verständigenden Subjekte heraus zu denken. Öffentlichkeit konstituiert sich stattdessen im stets volatilen konstellierenden Zusammenspiel heterogener Teilöffentlichkeiten. Das öffentlichkeitstheoretisch brisante Problem, wie die Subjekte in ihren lebensweltlichen Bindungen sowie die mitunter ja höchst konträren Teilöffentlichkeiten so kommunizieren können, dass sich diese im Rahmen des größeren Ganzen der Gesamtöffentlichkeit als sie selbst zur Geltung bringen können, wird hier sehr eindeutig zugunsten dieser Teilöffentlichkeiten angegangen. Die prekäre Spannung zwischen Einheit und Vielfalt wird eindeutig zugunsten der zweiten Alternative beantwortet.

Dies ist für eine an den Subjekten diakonisch ausgerichtete Öffentliche Religionspädagogik instruktiv, zumal sie mit dem Rückgang auf die Theologie der loci theologici die theologiegenerative Kraft der Subjekte ihrerseits fundamental veranschlagt. Indem Kinder und Jugendliche sich etwa im Religionsunterricht kritisch-produktiv wie erfahrungsbezogen mit der biblischen Überlieferung auseinandersetzen, lässt dies den Religionsunterricht zu einem locus theologicus werden. ${ }^{12}$ Der Gewinn dieser Form der Vermittlung von Differenz und Einheit liegt in der bleibenden Ausständigkeit von Alterität, die die Würde des Ausgeschlossenen, des Fremden, des Anderen in dessen Freiheit sichert.

Doch scheint diese Konstellationshermeneutik die Insistenz auf Alterität mit der tendenziellen Suspendierung der Wahrheitsfrage zu bezahlen, was sich öffentlichkeitstheoretisch als Schwächung kriterieller Unterscheidungen im Spiel der verschiedenen Öffentlichkeiten auswirkt. Wie soll Öffentlichkeit als gemeinsames Forum verschiedener Teilöffentlichkeit gedacht werden? Woher sollen, im Schema einer unendlichen Semiose gedacht, in dieser Konstellation diverser Öffentlichkeiten begründete Unterscheidungen kommen? Nicht

12 | Vgl. Grümme, Kinder im sensus fidei 2014. Grundlegend Mette, Sellmann, Religionsunterricht als Ort der Theologie 2012. 
einmal ein Begriff starker Wertungen, wie er bei Charles Taylor zur Grundlage seiner Öffentlichkeitstheorie gemacht wird, ist so zu erreichen.

\section{Alteritätstheoretische Vernunft}

Demgegenüber soll hier ein normativer Universalismus ins Spiel gebracht werden, der gleichwohl alteritätstheoretisch gebrochen und zugleich im Interesse einer alteritätstheoretischen Vernunft subjekttheoretisch grundiert wird. Insofern gegenüber dem in der Konstellativen Hermeneutik manifestierten postmodernen Pluralitätspathos wie der systemtheoretischen Differenzhermeneutik an verallgemeinerbaren Wahrheitsansprüchen öffentlichkeitstheoretisch festzuhalten ist, diese aber nicht mehr substanzmetaphysisch-objektivistisch oder mentalistisch, sondern in intersubjektiven Prozessen in einer noch zu bestimmenden Weise prozedural handlungstheoretisch zu denken sind, bietet sich zunächst Habermas Konzept für eine religionspädagogische Öffentlichkeitstheorie aus drei Gründen an: Es ist 1. universal und dabei zugleich integrativ und offen, rekurriert 2. jenseits idealistischer Engführungen eines Letztbegründungskonzeptes auf die Begründungsfrage und erweist 3. seine hermeneutische Anschlussfähigkeit hinsichtlich der adäquaten Buchstabierbarkeit biblischer Traditionen oder auch eines angemessenen Begriffs verantwortlicher Subjektivität in interkommunikativen Handlungszusammenhängen. ${ }^{13}$

Freilich bleibt die Anschlussfähigkeit dieser Theorie kommunikativen Handelns wegen ihrer aporetischen Tendenz angesichts der unschuldig Leidenden der Geschichte wie ihrer Schwierigkeit im Umgang mit Differenz und Macht gebrochen. Die kommunikative Vernunft müsste daher aufgesprengt werden durch eine vorgängige Irritation, durch eine Alterität. Sie hätte sich inmitten aller Orientierungsleistungen kommunikativer Vernunft den konkreten Anderen auszusetzen und sich damit um ihres Universalitätspathos willen zu öffnen für die normativen und orientierenden Gehalte, die mit dem Alteritätsgedanken verbunden sind. Dieser Alteritätsgedanke ist wesentlich ein praktisch, sprachlich-intersubjektiv vollzogener Gedanke. In dieser alteritätstheoretisch grundierten kommunikativen Praxis liegt die Kraft, im Vorgriff auf eine Vision des Lebens in Fülle das Gegebene zu verändern, kreativ Möglichkeiten $\mathrm{zu}$ erschließen und hegemoniale Tendenzen zu konterkarieren. Eine solche vom Anderen her eröffnete kommunikative Praxis, die auf ein intersubjektives, befreiendes, neue Perspektiven, ungeahnte Möglichkeiten realisierendes und dabei das Gegebene transformierendes und Systemimperative aufsprengendes

13 | Vgl. Habermas, Wahrheit und Rechtfertigung 1999; Arens, Fundamentale Theologie im Anspruch kommunikativer Rationalität 2002, 58. 
Handeln rekurriert, ist verwurzelt in sprachlich verfassten Kommunikationsprozessen, aus denen heraus Freiheit eröffnet, Identitäten anerkannt und gesellschaftliche Strukturen verändert werden können. ${ }^{14}$

Ohne dies hier im einzelnen zeigen zu können, wird hierin der öffentlichkeitstheoretische Ertrag erkennbar: Eine alteritätstheoretische Vernunft beansprucht die Wahrheitsfähigkeit und Kommunikabilität des Anderen durch Rekurs auf die Rationalität des Subjekts zu sichern, und verankert sich doch prinzipiell in einer Vernunft, die sich von zuvorkommender Alterität irritieren, befreien und eröffnen lassen kann. Sie will Theorie sein, indem sie unter transformatorischem Rückgriff auf die Traditionen transzendentalen Denkens die Konstitutionsbedingungen subjektiven Bewusstseins reflektiert. ${ }^{15}$ Die sprachtheoretische und handlungstheoretische Grundierung in intersubjektiver, sprachlich strukturierter Freiheit erlaubt es, die Alteritätstheorie in Kategorien von Geschichte und Gesellschaft zu denken und an einem Konzept universaler Vernunft festzuhalten. Dementsprechend besteht diese Vernunft dezidiert auf der Wechselseitigkeit von Subjekt und Objekt. Gerade die Wechselseitigkeit gewährleistet die relative Eigenständigkeit von Ich und Du, von Subjekt und Objekt, von Identität und Differenz. ${ }^{16}$

Andererseits kann angesichts der kritisch-herausfordernden, korrektivischen Wucht der uneinholbaren Fremdheit des Anderen Alterität nicht in Dialogik aufgehen. ${ }^{17}$ Erfahrung wird von Andersheit je vorgängig gestiftet, so sehr sie auch vom Ich erfahren und zugeeignet werden muss. Dialogik ist deshalb asymmetrisch zu grundieren. Die Vorordnung des Anderen im Dialog durchbricht die strenge Wechselseitigkeit der Dialogik. Die Dialogik wird aufgesprengt in eine Unabschließbarkeit hinein. Die Wechselseitigkeit des Dialogs wird unterhöhlt durch eine vorgängige Alterität, die die Dialogik ins Offene weitet. Damit bekommt sie eine Drift, eine Gefälle. Jede Gegenwart wird so noch einmal in Frage gestellt. Die Dialogik bekommt eine nicht umzukehrende, verharmlosende Richtung, die die Autorität und - ungeachtet aller Präsenz - doch uneinholbare Ferne des Anderen im Dialog verbürgt. Insofern diese Eröffnung deshalb als Gabe verstanden werden kann, dokumentiert dies die Anschlussfähigkeit der alteritätstheoretischen Denkform an die reflexive Erörterung religiöser oder christlicher Erfahrungen. ${ }^{18}$

Diese alteritätstheoretische Vernunft mit der asymmetrischen Tiefenstruktur des Dialogs lässt sich als eine heterogenitätsfähige Hermeneutik von Differenz verstehen, die Identität und Alterität, Einheit und Vielfalt, Universalität

14 | Vgl. C 1.

15 | Vgl. zu Begründungen Grümme, Vom Anderen eröffnete Erfahrung 2007, 235-282.

16 | Vgl. Sattler, Beziehungsdenken 1997, 266-299; Honneth, Das Ich im Wir 2010.

17 | Vgl. Casper, Religion der Erfahrung 2004, 193-205.

18 | Vgl. Grümme, Öffentliche Religionspädagogik 2015, 5-78. 
und Partikularität in einer spannungsvollen Dialektik miteinander vermittelt, ohne den einen Pol in dem anderen aufgehen zu lassen oder diese Dialektik begrifflich still zu stellen. Mit ihrem Votum für universale Wahrheitsansprüche wie für eine autonome, von Alterität herausgeforderte Freiheit ist sie differenzorientiert und würdigt darin zugleich die subjektgeleitete praktische Vernunft intersubjektiver Freiheit.

Dies aber liefert die gesuchte tragfähige Basis für einen Öffentlichkeitsbegriff. Die alteritätstheoretische Vernunft bietet, wo sie sprachpragmatisch grundiert wird, die Form, in der die diversen Öffentlichkeiten sinngeleitet und wahrheitsorientiert kommunizieren können.

Sie würdigt die uneinholbare Vorgängigkeit des Anderen, ohne dessen Kommunikabilität einzubüßen. Das zugrundeliegende Muster der asymmetrischen Dialogizität mit seiner handlungstheoretisch ausformulierten Intersubjektivität in den Kategorien kommunikativ strukturierter alteritätstheoretischer Vernunft ist differenzfähig und zugleich orientierungsstark. Sie könnte damit beispielsweise den überschießenden Anspruch der Religion formulieren, ohne die moderne funktionale Ausdifferenzierung diverser Teilsysteme zu unterlaufen. Insofern würdigt sie die Autonomie der Teilöffentlichkeiten, ohne diese zu verabsolutieren. Kommunikationstheoretisch gegründet, betont sie in ihrer handlungstheoretischen Akzentuierung die konstitutive Relevanz der Subjekte, ohne strukturelle Bedingungen zu übergehen.

Darin liegt auch ein kritischer Stachel gegenüber der theologisch wirkungsvollen Öffentlichkeitstheorie David Tracys. Diese arbeitet streng mit einer korrelativen Hermeneutik, um die verschiedenen Öffentlichkeiten miteinander ins Gespräch zu bringen. Dialogik ist deren Struktur. ${ }^{19}$ Demgegenüber insistiert die alteritätstheoretische Vernunft auf einer Korrelation mit asymmetrischer Tiefenschärfe. Sie hält an der Korrelation aus subjekttheoretischen wie offenbarungstheoretischen Gründen fest, grundiert sie aber alteritätstheoretisch. So konturiert sie diese zu einer Korrelation auf der Basis einer asymmetrischen Dialogizität. ${ }^{20}$ Dadurch kann sie besser als Tracy die kritische, irritierende wie produktive Kraft der jeweiligen Teilöffentlichkeiten im Rahmen gesamtgesellschaftlicher Öffentlichkeit zur Geltung bringen. Gegenöffentlichkeiten können sich erst im Rahmen einer solchen alteritätstheoretischen Hermeneutik öffentlich einbringen. Die agonale Struktur der Öffentlichkeit in ihrer heterogenen Tiefendimension wird markiert.

Indessen ist noch ein weiterer Gesichtspunkt zu vermerken: Verwurzelt in sprachlich vermittelten Vollzügen erfahrungsgesättigter, intersubjektiver Freiheit kann ein solcher alteritätstheoretisch geprägter, handlungsorientier-

19 | Vgl. Telser, Theologie als öffentlicher Diskurs 2016, 246-263.

20 | Vgl. Grümme, Öffentliche Religionspädagogik 2015, 35-75; ferner Wenzel, Offenbarung 2016, $125 \mathrm{ff}$. 
ter Vernunftbegriff seinerseits die Impulse aufnehmen, die von Butlers performativem Öffentlichkeitsbegriff eingebracht werden. In ganz besonderer Weise muss sich ein religionspädagogischer Öffentlichkeitsbegriff vor kognitiven Engführungen schützen. Elementare religiöse Praktiken, in denen der Glaube gelebt und bezeugt wird, reichen weiter, als je durch Verbalisierungen und Kognitivierungen zu erfassen wäre. Liturgie trägt, gerade in der pluralen Öffentlichkeit, Öffentlichkeitscharakter. ${ }^{21}$ Religiöses Lernen ist immer leibgebundenes Lernen, ${ }^{22}$ Embodiment ist eine religionspädagogische wie pädagogische Größe, ${ }^{23}$ der Körper auch ein religiös inszenierter Körper, in den religiöse Selbstverständigungsprozesse eingeschrieben und expressiv zum Ausdruck gebracht werden. ${ }^{24}$ Wallfahrten, Prozessionen, Pilgern, religiöse Flash-mobs: solche eklektisch aufgezählten Phänomene zeigen den konstitutiven Rang der Öffentlichkeit für religiöse leibbezogen-performative Praktiken. Was Performative Religionspädagogik vorwiegend innerreligionspädagogisch $\mathrm{zu}$ ihrem Anliegen gemacht hat, ${ }^{25}$ muss öffentlichkeitstheoretisch seinen Niederschlag finden. Gleichwohl weist die Alteritätstheoretische Vernunft diesen Praktiken ihren angemessenen Ort zu. Zwar basiert in Erfahrungen, die ihrerseits bereits eine Reflexion von affektiven Erlebnissen sind, so bleiben sie doch auf Vernunft hingeordnet. Es bedarf der Interdependenz von Kognition, Affektion und Pragmatik, um Verantwortung und moralische Selbstbestimmung öffentlichkeitstheoretisch denken zu können. ${ }^{26}$

\section{Aufgeklärte Selbstreflexivität und Normativität}

Eines der Verdienste des Poststrukturalismus liegt sicher in der Sensibilität, mit der dieser jene Mechanismen freigelegt hat, die in Sprache und Vernunft am Werke sind. Je schon sind, ob bewusst oder nicht, in Sprache, Denken und Praxis Mechanismen der Macht und Hegemonie wirksam, Mechanismen, die sich oft wider der eigenen Intention als Identifizierung, als Stigmatisierung und gar als Exklusion manifestieren. Dies wäre insbesondere von Foucaults'

21 | Vgl. Böntert, Objektive Feier 2011.

22 | Vgl. Buck, Bewegter Religionsunterricht 2004; Rendle, Ganzheitliche Methoden 2007.

23 | Vgl. Leonhard, Leiblich lernen 2006; Mendl, Religion zeigen 2016; Nöth, Guido, Körper 2005.

24 | Vgl. Wendel, Affektiv und inkarniert 2002; Waldenfels, Das leibliche Selbst 2000; Meyer-Drawe, Diskurse des Lernens 2008; Markschies, Gottes Körper 2016.

25 | Leonhard, Leiblich lernen 2006; Mendl, Religion 2016.

26 | Vgl. Grümme, Öffentliche Religionspädagogik 2015, 5-75. 
Diskursanalyse wie von Butlers Subjektivationstheorie zu lernen. ${ }^{27}$ Andererseits hat sich deren Subjektschwäche wie die weitgehende Entnormativierung als problematisch erwiesen, wie auch im gegenwärtigen Kontext der Kritischen Theorie eingewandt wird. Es braucht ein Subjekt der Kritik, es braucht übergreifende Normativität, um Strukturen und Praktiken der Entfremdung zu identifizieren, um Kritik zu üben und Gerechtigkeit für alle einzufordern. Seyla Benhabib wie Rahel Jaeggi haben aus Sicht der Feministischen Theorie wie der Kritischen Theorie gezeigt, dass ohne einen normativen Horizont und ein handlungsfähiges Subjekt Befreiung und Gerechtigkeit nicht zu denken sind. ${ }^{28}$

Für einen religionspädagogischen Begriff der Öffentlichkeit bleiben diese Einsichten wegweisend. In den Augen der Öffentlichen Religionspädagogik sind sowohl eine subjekttheoretische wie eine normativitätstheoretische Enthaltsamkeit problematisch. Gott, Offenbarung, Glaube, Reich Gottes sind ebenso subjektgeladene, normativitätsgesättigte Begriffe wie die der Pädagogik, der Bildung oder auch des Lernens. Es kommt allerdings darauf an, wie Subjekt und Normativität jenseits idealistischer Überverallgemeinerungen nachmetaphysisch zu denken sind.

Es ist hier nicht der Ort aufzuzeigen, inwiefern insbesondere eine alteritätstheoretische Vernunft einen Begriff verantwortlicher, intersubjektiver Freiheit zu denken in der Lage ist, der diesen stets prekären Herausforderungen wenigstens ansatzweise genügt. Ein solches Subjekt wäre ein in geschichtlichen, öffentlichen Prozessen und sozial-ökonomischen Strukturen je schon verstricktes vulnerables Subjekt, vorgängig herausgefordert durch Alterität, aber genau darin sich selber in Freiheit aufgegeben. ${ }^{29}$ Die alteritätstheoretische Vernunft kann so ihren Beitrag zur Öffentlichkeitstheorie auch subjekttheoretisch liefern, weil sie im Unterschied zum schwachen Subjektdenken Butlers durchaus ein kritisches Widerstandspotential gegen hegemoniale Tendenzen zu entbinden vermag.

Ohne einen normativen Horizont sind die biblischen Visionen von Erlösung, Befreiung, Gerechtigkeit nicht zu verstehen. Ohne normative Visionen, ohne Imaginationen des Möglichen über den Status Quo hinaus, ohne Perspektiven, die die pragmatischen Selbstverständlichkeiten je neu überschreiten, sind pädagogische und religionspädagogische Prozesse nicht einmal zu denken. Ohnehin öffentlichkeitstheoretisch problematisch, erweisen sich deshalb auch in theologischer wie religionspädagogischer Hinsicht Luhmanns System-

27 | Vgl. Honneth, Die zerrissene Welt des Sozialen 2013, 73-92; Joas, Knöbl, Sozialtheorie 2011, 623-635.

28 | Vgl. Jaeggi, Entfremdung 2016, 184-188; Benhabib, Selbst im Kontext 1995, 231-235.

29 | Vgl. Grümme, Vom Anderen eröffnete Erfahrung 2007, 235-305. 
theorie mit ihrem dezidiert entnormativierten, deskriptiven Gestus wie - mit Abstrichen - auch Taylors Kommunitarismus theologisch wie öffentlichkeitstheoretisch als defizitär: Luhmann, weil bei ihm dezidiert Subjekt und Normativität als Relikt der alteuropäischen Moderne entschieden hinter sich gelassen werden, Taylor, weil trotz dem Versuch ihrer Reformulierung dennoch jene normativen Ressourcen nicht erreicht werden, derer Öffentlichkeit, Subjekt wie Theologie und Religionspädagogik angesichts der Infragestellungen in der Spätmoderne bedürfen..$^{30}$ Die alteritätstheoretische Vernunft dagegen operiert wesentlich mit einem normativen Horizont, bricht ihn aber durch den Alteritätsgedanken.

Das Weiterführende gegenüber solchen Konzepten einer schwachen Normativität ist darin zu sehen, dass im Unterschied dazu die alteritätstheoretische Denkform universalisierbare Aussagen erlaubt. Sie reduziert sich nicht darauf, lediglich wechselnde Perspektiven auf Öffentlichkeit einzunehmen. Sie erlaubt es, Kritik der Öffentlichkeit und Normativität in einer von bleibender Fremdheit her eröffneten Vernunft dialektisch zusammenzuführen und das »Dilemma von Partikularität und Universalität« fundiert anzugehen. ${ }^{31}$ Normativität ist ein durch Alterität irritierter, in seiner totalisierenden Dynamik unterbrochener Gedanke. Insofern ist auch diese Normativität ihrerseits grundsätzlich kritisierbar, prinzipiell anfragbar. Sie ist nicht absolut, sondern steht mitten in dem kontextuell verorteten Ringen um Wahrheit. Religion als Unterbrechung zu denken, wie dies etwa J.B. Metz tut, ${ }^{32}$ zeigt die theologische Anschlussfähigkeit der alteritätstheoretischen Vernunft gerade in ihrem bestimmten normativen wie subjektorientierten Impetus. ${ }^{33}$ Sie ist offen auf eine Wahrheit, die sie sich schenken lassen muss, ${ }^{34}$ aber in autonomer, gleichwohl von Gott eröffneter Freiheit annehmen kann. ${ }^{35}$

Exemplarisch verdichtet sich das auf dem Feld der Anthropologie. Eine solche alteritätstheoretische Denkform kann das biblische Menschenbild »dadurch verständigungsfähig « machen, dass sie zeigt, »was sie für den Umgang mit konkreten gesellschaftlichen und individuellen Herausforderungen heute austrägt; dies aber eben nicht im Sinne einer Deduktion situativer Handlungs-

30 | Vgl. Heger, Wissenschaftstheorie 2017, 565-568. Grundlegend Nipkow, Bildung in einer pluralen Welt 1998; Grümme, Öffentliche Religionspädagogik 2015, 50-75.

31 | EKD, Maße des Menschlichen 2003, 48. Vgl. Englert, Braucht, wer von Bildung redet, ein Menschenbild 2004.

32 | Vgl. Metz, Glaube in Geschichte und Gesellschaft 1984, 150; ferner Wenzel, Offenbarung 2016, 5-75.

33 | Vgl. Grümme, Vom Anderen eröffnete Erfahrung 2007, 235-305; Grümme, Alteritätstheoretische Didaktik 2012.

34 | Kritisch zu Menke, Macht die Wahrheit frei 2017, 12-76.

35 | Zum Autonomiebegriff vgl. Menke, Macht die Wahrheit frei 2017, 34-43. 
orientierungen aus allgemeinen Prinzipien, sondern im Sinne einer Erinnerung aus Erfahrungen, welche die >Kirche< im Horizont des biblischen Menschenbildes gemacht hat«. Das biblische Menschenbild wird also nicht einfach als solches präsentiert oder gar als Antwort menschlicher Fragen angepriesen. »Sondern es wird von den Erfahrungen her zugänglich zu machen versucht, zu denen es Menschen verholfen hat; und zwar von Erfahrungen her, die, weil sie im Zusammenhang mit >weltgeschichtlichen Veränderungen< [...] stehen, von mehr als nur partikularer Bedeutung sind. $\ll^{36}$

Birgt bereits die Kommunikativ-deliberative Vernunft angesichts der Aporien in der Leidensfrage eine Tendenz zur Unvernunft, muss indessen die Alteritätstheoretische Vernunft ihrerseits in einem kritischen Sinne selbstreflexiv werden, um jener Dialektik inne zu werden, die diskursanalytisch selbst dem Differenzdenken attestiert wurde: In der Intention, Verschiedenheit $\mathrm{zu}$ würdigen und als nicht zu hintergehende Vielfalt anzuerkennen, Gegenöffentlichkeiten, Minderheiten, Marginalisierte zur Anerkennung und zugleich zu ihrem Recht zu verhelfen, unterliegen Differenzsemantiken und Differenzpädagogiken der Tendenz, dennoch zu benennen, zu identifizieren und festzulegen. Zwar kann die Alteritätstheorie durch den kategorialen Vorrang von Alterität den Hang der Vernunft zur »Synthesis des Heterogenen« bereits kritisch unterlaufen und damit im Ansatz dieses Dilemma der Vernunft zumindest kritisch analysieren und konstruktiv bearbeiten. ${ }^{37}$ Ihr Vorzug liegt darin, dies nicht durch elementare Einbußen bei der Orientierungs- und Begründungsfähigkeit und zugleich bei ihrer analytisch-kritischen Widerstandskraft gegen hegemoniale Strukturen erkaufen zu müssen, wie wir dies als das zentrale Defizit bei Butler und Foucault herauszuarbeiten hatten.

Um ihrer eigenen Dialektik inne zu werden, um auf die auch ihr wie jeder Vernunft inhärenten Mechanismen von Macht und Hegemonie aufmerksam zu machen, ohne in die normativitätstheoretischen Fallen des Poststrukturalismus zu tappen, bietet sich freilich die Anschärfung der alteritätstheoretischen Vernunft durch die Kritische Theorie an. Denn kritische Theorie macht auf »systematische Verzerrungen« in der eigenen Theoriebildung und auf die Versuchung aufmerksam, »sich auf subtile Weise von ihrer eigenen Kontextbezogenheit zu lösen und so sabsolut< (unschuldig) zu werden «. ${ }^{8}$ Nach Horkheimers berühmter Unterscheidung charakterisiert eine kritische Theorie im Vergleich zur traditionellen Theorie die axiomatische Verortung in befreiender Praxis. ${ }^{39}$

36 | Englert, Braucht, wer von Bildung redet, ein Menschenbild 2004, 151.

37 | Kokorschke, Hegel und wir 2015, 133.

38 | Telser, Theologie als öffentlicher Diskurs 2016, 240f. Vgl. zum folgenden auch Grümme, Heterogenität 2017, 91-97.

39 | Vgl. Horkheimer, Traditionelle und kritische Theorie 1937, 254. 
"Kritische Theorie nennen wir eine Verbindung philosophischer und sozialwissenschaftlicher Reflexion mit emanzipatorischem Interesse, die nach der historisch möglichen und normativ geforderten, rationalen Form einer allgemein gerechtfertigten gesellschaftlichen Ordnung fragt und zugleich danach, weshalb eine solche Ordnung angesichts der Herrschaftsverhältnisse in einer Gesellschaft (bzw. jenseits von ihr) nicht entsteht. Dies stimmt damit überein, wie Horkheimer ursprünglich ,die vom Interesse an vernünftigen Zuständen durchherrschte kritische Theorie der gegenwärtigen Gesellschaftı verstanden hat. " 40

Einer unter den gegenwärtigen Bedingungen reformulierten Kritischen Theorie geht es um die zentralen interdependenten Konstitutionsbedingungen und Vollzüge von Normativität und Macht, von einerseits normativ bestimmten Lebensvollzügen in Kultur, Religion, Geschichte, Ökonomie und Gesellschaft und andererseits von Macht und Hegemonie. So kann verstanden werden, inwiefern Normativität stets mit Macht einhergeht und umgekehrt Macht selber Normativität in Anspruch nimmt.

"Wir sind daran gewöhnt, die Begriffe `Normativitätı und 'Macht` als Gegensatzpaar zu verstehen: Ersterer ist durch rechtfertigende Gründe für unser Denken und Handeln gekennzeichnet, Letzterer durch deren Abwesenheit und die Herrschaft purer Faktizität. So scheint es jedenfalls. Aber genauer betrachtet, muss Normativität auch Macht entfalten, um uns bewegen zu können - und soziale Macht muss, um wirksam zu sein, die Normativität des gesellschaftlichen Lebens, unseres Denkens und Handelns, durchdringen, auch dann, wenn sie nicht gut begründet ist. . ${ }^{41}$

Durch den damit aufgehellten Zusammenhang von Normativität und Macht wird zweierlei deutlich:

Die Kritische Theorie ist in einem sehr grundlegenden Sinne für eine Öffentliche Religionspädagogik bedeutsam. Der Rekurs auf sie erlaubt es ihr, religiöse Bildungsprozesse inmitten ihrer materialen und kulturellen, ihrer sozialen und politischen, ökonomischen wie religiösen Rahmungen kritisch und konstruktiv reflektieren und entsprechend der ihr zugrunde liegenden Dialektik von Theorie und Praxis als einer praktischen Wissenschaft religiöse Bildungsprozesse normativ bestimmen zu können. ${ }^{42}$

Doch bezogen auf den Öffentlichkeitsbegriff ist es die dadurch gegebene Möglichkeit, die gegenseitige Durchdringung von hegemonialen, machtbezogenen Bedingungen und normativ bestimmten Formationen kritisch zu analysieren und konstruktiv zu bearbeiten. Wir werden noch sehen, wie Pers-

40 | Forst, Normativität und Macht 2015, 9 f.

41 | Forst, Normativität und Macht 2015, 7.

42 | Vgl. Grümme, Öffentliche Religionspädagogik 2015, 70-150. 
pektiven von Gerechtigkeit und Anerkennung, von Differenz und Gleichheit, von Macht und Verschiedenheit, von Ungleichheit und Unterschiedlichkeit aufeinander in gesellschaftskritischer und machtsensibler Dynamik auf dem komplexen Feld pädagogischer und religionspädagogischer Theorie-Praxiszusammenhänge kritisch korrelierbar und reformulierbar werden. ${ }^{43}$

An einen entsprechenden Begriff der Öffentlichkeit ergeht damit der Anspruch, Essentialisierungen und geschichtslose Ontologisierungen zu verhindern gerade in dem Versuch, jeweilige Vielfalt und Verschiedenheit zu würdigen. Das bedeutet eine integrale Verpflichtung zur selbstreflexiven Aufklärung seiner eigenen Konstruktionsmechanismen, wie dies allerdings die anderen hier erörterten Theorien der Öffentlichkeit weitestgehend vermissen lassen. Der Öffentlichkeitsbegriff muss selbstreflexiv die Struktur seiner eigenen Begrifflichkeit kritisch in den Blick nehmen. Insofern sind Alteritätstheorie, Diskursanalyse und Kritische Theorie im Horizont von Normativität und Macht öffentlichkeitstheoretisch streng zusammenzudenken.

\section{5. ÖFFentLichKeIt ZWISChEN UNIVERSALITÄT Und PartikUlarität}

Öffentlichkeitstheorien ringen im wesentlichen um die Lösung, wie Öffentlichkeit so gestaltet, strukturiert und ausgerichtet sein kann, dass alle an ihr in möglichst gerechter und gleicher Weise zum Wohle des Ganzen teilhaben und sie dabei ihre jeweilige Besonderheit voll entfalten und jeweils für die anderen einbringen können. Unterschiede müssen gewahrt und anerkannt werden, ohne dabei die Ungleichheit zwischen allen möglichen Beteiligten aus dem Blick zu verlieren. Ohne Partizipationsmöglichkeit aller, ohne Inklusion wäre ein Öffentlichkeitsbegriff nicht zu denken, der seinen Namen verdient. >Öffentlich bedeutet nach dem hier entwickelten Verständnis ja eine normativ bestimmte universale Ausrichtung an der potentiellen Teilhabe aller. Andererseits ist die Öffentlichkeit nicht allein aus der Perspektive potentieller Teilnehmer als Forum und Artikulationssphäre von integraler Relevanz. Nicht nur die jeweiligen Narrationen und Traditionen, nicht allein die Visionen guten Lebens, nicht nur die individuellen Lebenswelten und Sinnentwürfe wollen gehört, wollen artikuliert und damit (in wiederum jeweils zu bestimmender Weise und Intensität) öffentlich werden. Aus der Perspektive der Öffentlichkeit selber und deren Teilöffentlichkeiten bilden solche Traditionen und Visionen ihrerseits einen elementaren, weil motivierenden, vergewissernden, orientierenden und in erfahrungsgesättigter Weise sinnstiftenden Fundierungszusammenhang.

43 | Vgl. D 5. 
Allerdings ist das, was in dem Strukturwandel der Moderne zur Spätmoderne besonders prekär wird, der Wandel zu einer identitäts- und erfahrungsbegründeten Gesellschaft von »Singularitäten « und »Neogemeinschaften «, ${ }^{44}$ deren Bezug auf Gerechtigkeits- und Gleichheitsfragen einseitig zugunsten von erfahrungsgeleiteten Identitätsfragen vorgenommen wird. Die »Expansion des Besonderen ${ }^{45}$ die sich beispielsweise kulturtheoretisch in der ästhetischen Selbstkonstruktion der auf Authentizität und Kreativität abgestellten Subjekte, ökonomisch in der erlebnisbezogenen Aufladung von Konsumgütern und politisch in einer Ausrichtung an nationalen wie regionalen, das Besondere einer spezifischen Kultur und Tradition kultivierenden Gemeinschaften zeigt, geht mit der Abblendung der Perspektive des Allgemeinen einher. Dort, wo inzwischen eine etablierte obere Mittelschicht sich der Symbole der Unterschicht kulturell-ästhetisch bedient und dies bis in den eigenen Lebensstil kultiviert, rücken verallgemeinerbare Gleichheits- und Gerechtigkeitsaspekte in den Hintergrund. ${ }^{46}$ Die entscheidende Krise liegt demnach in der prekären Bestimmung der »sozialen Logik des Allgemeinen und des Besonderen «. ${ }^{47}$ Und diese Krise ist, wie oben bereits erwähnt, im wesentlichen eine »Krise der Öffentlichkeit«. ${ }^{48}$

Dies aber macht die Fragen der Partizipation wie der Exklusion ebenso zum öffentlichkeitsrelevanten Problem wie die konkrete Bestimmung von Universalität und Partikularität, von Gleichheit und Differenz, von Ungleichheit und Unterschiedlichkeit, von Gerechtigkeit und Anerkennung, von Visionen des Guten und der Gerechtigkeit. Es geht um das Ausloten von Möglichkeiten und Grenzen der Teilnahme von Traditionen an der Öffentlichkeit. Eine solche Frage wird unter spätmodernen Bedingungen besonders brisant, eröffnet es doch die lebensweltlich, pädagogisch wie gesellschaftlich hoch aktuelle Spannung zwischen Universalität und Partikularität, aber auch die zwischen Universalität und Toleranz.

Der hier vertretene Öffentlichkeitsbegriff geht im Gegensatz zu den diskutierten (und in ihrer Differenz zu einander noch deutlich stärker auszufaltenden) systemtheoretischen, postmodernen und poststrukturellen Konzepten sehr wohl von der Triftigkeit universalisierbarer, normativ bestimmter Horizonte aus. Umso mehr jedoch sind alle Traditionen grundsätzlich mit einem Universalisierungsvorbehalt versehen. Bestimmte Traditionen zum Maßstab und Lebenssinn gesellschaftlichen Zusammenlebens zu machen, die nicht von allen gleich und jeweils in besonderer Weise akzeptiert werden können,

44 | Reckwitz, Die Gesellschaft der Singularitäten 2017, 8-10.

45 | Reckwitz, Die Gesellschaft der Singularitäten 2017, 7.

46 | Vgl. Reckwitz, Die Gesellschaft der Singularitäten 2017, 273-370.

47 | Reckwitz, Die Gesellschaft der Singularitäten 2017, 27.

48 | Reckwitz, Die Gesellschaft der Singularitäten 2017, 436. Vgl. Teil B 4. 
wäre im spätmodernen Kontext der Heterogenität angesichts der Selbstbestimmung der Subjekte widersprüchlich. Universalisierungsfähig sind nur diejenigen Konzepte und Annahmen, die von allen zumindest potentiell in wechselseitiger, also reziproker und allgemeiner Weise frei und gleich gerechtfertigt werden können. ${ }^{49}$ »Es gibt ein Grund-Recht « auf gleiche, also allgemeine und reziproke Rechtfertigung. ${ }^{50}$ Im Lichte dieses normativ gefassten Maßstabs erscheinen in einer kritischen Gesellschaftsanalyse alle jene mehr oder weniger institutionalisierten Beziehungen und Strukturen, die »dem Maßstab reziproker und allgemeiner Rechtfertigung nicht gerecht werden und durch Formen der Exklusion, von Privilegien und Beherrschung « gekennzeichnet sind, als illegitim. ${ }^{51}$ Dies ist freilich in potentieller Perspektive gemeint, geht es doch darum, was in der Gesellschaft »reziprok und allgemein gelten dürfte, wenn die Normunterworfenen freie und gleiche Normautoren wären . $^{52}$ Und dies gilt in Reformulierung des kantischen Kategorischen Imperativs auch dann, wenn Personen dazu die Fähigkeiten fehlen. Dann »gälte es, sie als autonome Wesen zu respektieren, die niemals nur Objekt, sondern Subjekt der Rechtfertigung sind $\kappa^{53}$

Doch wo endet die Partizipationsmöglichkeit aller an der Öffentlichkeit? Wo hätte Toleranz ihre Grenzen? Ein angemessenes Verständnis von Toleranz reduziert sich keineswegs auf die wohlfeile Akzeptanz jedweder Position. Weiterführend ist eine »Toleranz im Konflikt«, deren Versprechen es ist, dass »ein Miteinander im Dissens möglich ist ${ }^{54}$ Toleranz wird bei Rainer Forst zum Prinzip gesellschaftlicher Selbstorganisation, ja sie wird zum Grundmoment der komplexen Dynamik zwischen Macht und Moral, zwischen Religion, Ethik und Politik. Deren Diskussion handelt »von der Fähigkeit und den Grenzen der praktischen Vernunft angesichts tiefgehender ethischer Konflikte und schließlich von der Unumgänglichkeit einer diesem Streit übergeordneten Konzeption der Moral, die von den umstrittenen Wertungen unabhängig (wenn auch nicht vollkommen losgelöst) ist«. ${ }^{55}$

Rainer Forst arbeitet in seiner Profilierung eines Toleranzbegriffs, der den Herausforderungen der Spätmoderne Stand halten kann, vier zentrale Elemente heraus: erstens ist Toleranz ein Konfliktbegriff, weil in ihm Konflikte zum Austrag kommen aus der Einsicht heraus, dass »den Gründen gegenseitiger

49 | Vgl. Forst, Das Recht auf Rechtfertigung 2007, $20 \mathrm{ff}$.

50 | Forst, Das Recht auf Rechtfertigung 2007, 283; vgl. Forst, Kritik der Rechtfertigungsverhältnisse 2011, 40.

51 | Forst, Kritik der Rechtfertigungsverhältnisse 2011, 20.

52 | Forst, Kritik der Rechtfertigungsverhältnisse 2011, 17.

53 | Forst, Kritik der Rechtfertigungsverhältnisse 2011, 16.

54 | Forst, Toleranz im Konflikt 2014, 12.

55 | Forst, Toleranz im Konflikt 2014, 23. 
Ablehnung Gründe gegenseitiger Akzeptanz gegenüberstehen, die erstere nicht aufheben «. ${ }^{56}$ Toleranz impliziert stets eine Komponente der Ablehnung einer Position wie eine Komponente der Akzeptanz, weil man die Positionen zwar für falsch hält, aber diese nicht so sehr verurteilt werden, dass sie schlechthin zu negieren sind; ${ }^{57}$ zweitens findet dieses Ringen um Toleranz inmitten der gesellschaftlichen Auseinandersetzungen statt; drittens stellt sie nicht nur eine Forderung, sondern den Gegenstand solcher Auseinandersetzungen dar und viertens spielen dabei ganz unterschiedliche Toleranzbegründungen eine zentrale Rolle. ${ }^{58}$ Toleranz lässt sich angesichts konkurrierender Wertvorstellungen und Religionen nur reflexiv begründen im Lichte diskursiv bestimmter Prinzipien von Reziprozität und Allgemeinheit. Grenzen und Reichweite von Toleranz sind demnach im öffentlichen Diskurs zu bestimmen. ${ }^{59}$ Dieser Diskurs, und dies ist nun entscheidend, ist auch für Forst deliberativ organisiert, wobei hier allerdings fraglich wird, ob er seinerseits die Schwierigkeiten von Habermas überwindet. Dafür scheint - wir werden darauf zurückkommen bei aller Sensibilität für den Alteritätsgedanken doch dessen diskursive Einhegung am Ende zu stark. ${ }^{60}$ Gleichwohl: Öffentlichkeit und Toleranz brauchen gerade um ihrer selbst willen einen universalisierbaren Beurteilungsmaßstab, der zugleich die einzelnen Lebensformen und Orientierungen auch in ihrer Andersheit und Alterität würdigt und anerkennt.

Ein konstellatives Denken in der Spur Christian Bauers scheint hierfür ebenso zu schwach zu sein wie Taylors Kommunitarismus, obschon er wie kaum ein zweiter der hier verhandelten Positionen auf die Unverzichtbarkeit lebensweltlicher Verwurzelungen gegenüber einem rein formalen Prozeduralismus der Öffentlichkeitstheorie insistiert. Instruktiv ist dagegen der Ansatz von Forst, Kontexte des Guten und formale Prozeduren des Gerechten im Rahmen einer sozialkonstruktivistischen Gerechtigkeitstheorie streng aufeinander zu beziehen. Die Relevanz konkreter Gemeinschaften ethischen Lebens, die intelligible Kraft bestimmter Sphären der Gerechtigkeit für die Bestimmung von Gerechtigkeit bleiben integraler Bestandteil, ohne in eine letztlich relativistisch-partikularistische Drift zu geraten. Je nach Kontext muss für Forst die Person ihr Handeln rechtfertigen. Der Mensch ist immer gleichzeitig auf unterschiedliche Weise ethisch, moralisch, rechtlich, politisch autonom, ist also nie nur ethische, moralische, rechtliche, politische Person. Ethische Fragen als Identitätsfragen nach einem guten Leben können und dürfen damit nicht in einer moralischen oder politischen Weise allgemeine Geltung bean-

56 | Forst, Toleranz im Konflikt 2014, 12.

57 | Vgl. Forst, Toleranz im Konflikt 2014, 30-35.

58 | Vgl. Forst, Toleranz im Konflikt 2014, 12-14.

59 | Vgl. Forst, Toleranz im Konflikt 2014, 588-600.

60 | Vgl. D 8. 
spruchen wie umgekehrt rechtliche Fragen etwa die ethische Selbstbestimmung determinieren können. Forst nimmt eine analytische Unterscheidung der jeweiligen Kontexte der Person vor und führt diese jeweiligen Kontexte durch eine übergreifende, von einem universalen Begriff praktischer Vernunft her bestimmte Theorie der Gerechtigkeit zusammen. Diese hält die Grenzen zwischen diesen Kontexten »dadurch aufrecht, dass sie ethische Identität, gleiche Rechte, politische Mitgliedschaft und moralischen Respekt nach allgemein gerechtfertigten Normen zur Geltung bringt«. ${ }^{61}$ Was also die Anerkennung von Personen als Staatsbürger, als Rechtspersonen, als ethische und moralische Subjekte angeht, bleibt dies den »Kontexten ethischer und politischer Gemeinschaften überlassen; $d a \beta$ sie als solche anerkannt werden müssen, ist eine Forderung der Gerechtigkeit «. ${ }^{62}$ Vor einer solchen Theorie der Gerechtigkeit müssen dann die einzelnen ethischen, moralischen, rechtlichen und politischen Normen gerechtfertigt werden. ${ }^{63}$ Die Komponente einer in Kategorien universaler Vernunft gedachte Moral ist nach dieser konstruktiv-kritischen Verhältnisbestimmung »normativ entscheidend, während die partikularistische Komponente wesentlich dabei ist, Verantwortung zu lokalisieren «. ${ }^{64}$

Eine religionspädagogische Öffentlichkeitstheorie kann dies aufgreifen, muss dies aber angesichts der Schwierigkeiten deliberativer Vernunft alteritätstheoretisch radikalisieren. Ein Alteritätstheoretisches Denken beansprucht, wie eben gezeigt, im Unterschied zur schwachen Vernunft, die Wahrheitsfähigkeit und Kommunikabilität des Anderen durch Rekurs auf die Rationalität des Subjekts zu sichern, und verankert sich doch prinzipiell in einer Vernunft, die sich von zuvorkommender Alterität irritieren, befreien und eröffnen lässt. ${ }^{65}$ In diesem Sinne ist es gegen eine radikalisierte Systemtheorie, gegen fideistische wie gegen rationalistische Annahmen für sie eine

"zwingende Annahme, einen integrierenden Rahmen verschiedener Sprachspiele und Weltdeutungssysteme zu postulieren [...]. So wird sowohl ein material ausgestaltetes und in diesem Sinne schwer universalisierbares, weil unzeitgemäß substantielles Konzept ausgeschlossen als auch eine Aufspaltung verschiedener Weltdeutungssysteme in inkommensurable Sphären vermieden, die keinerlei kritischen Vergleich, Übersetzungsleistungen oder Dialog ermöglicht, weil sprachspielexterne Kriterien der diskursiven Bewertung dieser Sphären fehlen." 66

61 | Forst, Kontexte 1994, 361.

62 | Forst, Kontexte 1994, 362.

63 | Forst, Kontexte 1994, 436.

64 | Forst, Das Recht auf Rechtfertigung 2007, 258.

65 | Vgl. Grümme, Vom Anderen eröffnete Erfahrung 2007, 235-282.

66 | Breul, Religiöse Epistemologie 2016, 185; vgl. Breul, Religion in der politischen Öffentlichkeit 2015. 
Lediglich ein »Experimentieren mit Begriffen«, um die Fähigkeit zu erwerben, »auf die eigenen Erfahrungen reflektierend zu reagieren«, ist ihr am Ende doch zu wenig. ${ }^{67}$ Auf diese Weise kann eine alteritätstheoretische Vernunft Universalität und Partikularität, Einheit und Vielfalt jeweils in sich selbst und in ihrem Verhältnis zueinander würdigen. Alteritätstheoretisches Denken ist differenzorientiert und würdigt darin zugleich die subjektgeleitete praktische Vernunft intersubjektiver Freiheit. Weil es den Anspruch auf universalisierbare Züge von Rationalität nicht aufzugeben bereit ist, trägt ein solches Denken dem Heterogenen in seiner genannten anspruchsvollen Komplexität Rechnung. ${ }^{68}$ Es bietet, wo es sprachpragmatisch grundiert wird, die Form, in der die Teilsysteme und deren Rationalitäten sinngeleitet und wahrheitsorientiert kommunizieren können. Es könnte damit, wie bereits angedeutet, beispielsweise den überschießenden Anspruch der Religion formulieren inmitten der Logik der funktionalen Ausdifferenzierung diverser Teilsysteme. Eine solche Hermeneutik ist modernitätsfähig.

Wegen ihrer Verwurzelung in praktisch-theoretischen Prozessen sprachlich vollzogener Erfahrung unterläuft sie die Begrenzungen einer reinen Beobachterperspektive. Sie kann Normativität und Vielfalt, Differenz und Gleichheit angemessen ins Verhältnis setzen. Sie bleibt wahrheitsfähig genau darin, wenn sie die Vielfalt achtet. Sie würdigt Vielfalt, ohne diese einfach nebeneinander zu setzen. Die kategoriale Divergenz von Unterschieden und Ungleichheiten wird so ebenso denkbar wie eine Relativierungstendenz vermieden wird, die undifferenziert unterschiedliche Formen von Differenz und Anerkennung auf eine Stufe stellt. ${ }^{69}$ Es gibt, wie gezeigt wurde, eine verkennende, eine herabwürdigende Fehlform von Anerkennung, die alteritätstheoretisch konterkariert wird. Normalitätsdiskurse, die einerseits klassifizieren und deklassieren, andererseits aber doch orientierendes, auf pädagogische Zielstellungen hinführendes Potential besitzen, wären so kritisch-konstruktiv für einen religionspädagogischen Öffentlichkeitsbegriff reformulierbar.

\section{Religion als Bewährungsprobe}

Wie in einem Brennglas verdichten sich die Diskussionen um den Rang von Traditionen und Narrativen in der Öffentlichkeit auf dem Feld der Religion. Hier hat man in nuce jene prekäre Herausforderung vor sich, wie denn eine begrenzte Vision guten Lebens mit den anderen Traditionen so koexistieren

67 | Hampe, Die Lehren der Philosophie 2016, 63.

68 | Vgl. Grümme, Auf Sand gebaut 2004, 266-279.

69 | Zu Aporien etwa, wenn Veganismus und sexuelle Differenz mit sozialer Ungleichheit verwechselt oder identifiziert werden: Grümme, Heterogenität 2017, 50-105. 
kann, dass alle jeweils zu ihrem Recht kommen und zugleich das gemeinsame Ganze nicht nur nicht gefährdet, sondern gar gestärkt wird. Kurz: die für den Öffentlichkeitsbegriff signifikante Spannung zwischen Universalität und Partikularität wird hier besonders brisant. Besonders brisant ist dies deshalb, weil mit der Religion nun ein world view ins Spiel kommt, der mit Unbedingtheit aufgeladen und deshalb mit vergleichsweise radikalem Geltungsanspruch auftritt. Wenn sich ein militanter Neuer Atheismus inzwischen seinerseits mit ähnlicher Vehemenz artikuliert, so spricht dies nicht gegen diese These, sondern markiert nur die Tatsache, dass dieser unter der Hand selber zur Religion geworden ist.

Nun zeigen unsere Rekonstruktionen der verschiedenen Öffentlichkeitstheorien teilweise ganz überraschende Ergebnisse hinsichtlich der Verortung der Religion in der öffentlichen Sphäre. Andererseits ergeben sich zugleich unerwartete Koalitionen. Dass die systemtheoretische Logik auf eine Depolitisierung und damit in einer bestimmten Weise auf eine Privatisierung hinausläuft, wird bereits dadurch deutlich, dass Religion in ihrer binären Codierung von Immanenz und Transzendenz nach dem Muster von System und Umwelt schlicht neben die anderen Teilsysteme gestellt wird. Zwar wird ihr immerhin noch eine funktionale Bedeutung als Kontingenzsicherung attestiert; aber deren übergreifender Wahrheitsanspruch als einer comprehensive doctrine wird strukturell negiert. ${ }^{70}$

Anders bei Habermas. Dieser sieht in der Religion gerade als comprehensive doctrine wesentliche Ressourcen für eine spätmoderne Gesellschaft, deren Kraftquellen aus formal-prozeduraler Rationalität allein nicht ausreichen, um eine lebendige, kohärente, dynamische und gerechte Gesellschaft zu gestalten. Um wirksam zu werden, ist hierfür freilich eine Übersetzung in eine verallgemeinerbare, von allen verstehbare Sprache die Voraussetzung. Auf der Ebene der Politik und ihrer Institutionen, insbesondere der Parlamente, sind alle religiösen Bezüge zu streichen. Was nicht übersetzbar ist, bleibt der vorinstitutionellen Ebene der Öffentlichkeit vorbehalten. ${ }^{71}$

Anders Taylor, der Religion ebenso für diskursfähig hält wie nicht-religiöse word views und philosophische Überzeugungen. Doch zumindest auf der Ebene der politischen Institutionen fordert er eine von allen gleichermaßen zugängliche und verstehbare Amtssprache. ${ }^{72}$ Trotz aller Unterschiede kommen er und Habermas in der Unverzichtbarkeit einer Sphäre der Öffentlichkeit überein, die neutral bzw. frei von einseitigen Dominanzen gehalten werden muss, wobei die Übersetzung, insbesondere bei Habermas, hierfür eine zentrale Bedeutung hat.

70 | Vgl. C 3.

71 | Vgl. C 1.

72 | Vgl. C 4. 
Anders bei Butler. In besonderer Intensität meldet sie massive grundsätzliche Zweifel an der Übersetzbarkeit von Religion an. Doch geht es ihr dabei weniger um einen opaken Kern, der in seiner welterschließenden Kraft nur für die Gläubigen einsehbar und lebbar ist. Ihr geht es darum, durch diese Unübersetzbarkeit die Perspektiven der Öffentlichkeitstheorie diametral zu verändern. Religion fungiert als Index für Alterität, für Unterbrechung, für Fremdheit, die erst ethische Verantwortung konstituiert. Nicht die Arbeit an konsensueller Übereinstimmung zur diskursiven Lösung von gesellschaftlichen und politischen Fragen wie bei Habermas und - mit Abstrichen bei Taylor -, sondern der Bruch systematisierender Vernunft durch Alterität prägt diese Perspektive. ${ }^{73}$ Insofern ist es nur konsequent, dass Religion als sie selber in der Öffentlichkeit vertreten sein kann und als sie selber die gesellschaftlichen wie die politischen Debatten vorantreibt.

Allerdings mag man sich fragen, ob diese eindeutige Ausrichtung Butlers an den diversen religiösen Identitäten dem Postulat von Gleichheit und Gerechtigkeit standhält. Nicht schon die Tatsache der öffentlichen Präsenz jedweder religiösen Überzeugung kann Zielhorizont öffentlichkeitstheoretischer Debatten sein. Solange die Frage religiöser Identität nicht mit der von struktureller Gleichheit und Gerechtigkeit verbunden ist, so lange Identität und Gleichheit nicht strikt aufeinander bezogen sind, so lange bleibt eine solche Position problematisch. Die Tatsache an sich, dass jede Religion die gleiche Möglichkeit und das gleiche Recht auf alle Formen der Öffentlichkeit hat, verbürgt doch noch nicht Gerechtigkeit. Es könnte doch sein, dass religiöse Symbole aus Zwang getragen werden. Hier begründete Unterscheidungskriterien zwischen den Religionen sowie zwischen den diversen religiösen Praktiken zu liefern bleibt das radikale Alteritätsdenken Butlers schuldig, ein Defizit, dass Butler allerdings trotz der geradezu konträren Anlage des Denkens mit Taylor teilt. Andererseits scheint Habermas in der Tradition der liberalen Trennung von Staat und Religion die Relevanz religiöser Ressourcen für Öffentlichkeit und Politik doch zu unterschätzen. Mit seiner Forderung an eine wechselseitige Übersetzungspflicht von Religiösen und Nicht-Religiösen zeigt er zwar überzeugend das Ungenügen eines Laizismus auf, der sich selber zu einem eigenen world view verselbstständigt und damit performativ die eigene Neutralitätsforderung an die Adresse des Staates und der politischen Institutionen konterkariert. Doch hält Habermas strikt an der Exklusion der Religion aus der Sphäre der Politik fest.

Demgegenüber nehmen in der gegenwärtigen Politischen Theorie Überlegungen zunehmend an Fahrt auf, die diese diastatische Trennung von Glauben und Wissen sowie Öffentlichkeit und Privatheit innerhalb liberaler Konzeptionen überwinden wollen. Zumeist argumentieren sie erkenntnistheoretisch

73 | Vgl. Butler u.a., Abschlussdiskussion 2012, 162-168. 
oder pragmatisch. Beide Wege seien wegen ihres exemplarischen Charakters kurz umrissen:

So hält erkenntnistheoretisch Martin Breul zwar an der Nichtverallgemeinerbarkeit religiöser Überzeugungen fest, weshalb diese nicht als allgemeine universalisierbare Basis gesellschaftlichen Zusammenlebens fungieren können. Doch ist es gerade die kognitive Verfasstheit der Religionen, die ein Unterscheidungskriterium zwischen Religionen und etwa der Astrologie ermöglicht und zugleich die Basis für deren gesellschaftliche Diskursfähigkeit liefert. Breul formuliert einen »Moderaten Exklusivismus«, der »einerseits auf der Notwendigkeit der Rechtfertigungsneutralität« besteht (exklusives Element), daraus aber »keine Privatisierungsforderung ableitet, sondern religiösen Überzeugungen durch die Möglichkeit ihrer kognitiven Zugänglichkeit und der damit verbundenen intersubjektiven Nachvollziehbarkeit eine Vielzahl von wichtigen und in einer postsäkularen Gesellschaft unverzichtbaren Rollen in öffentlichen Diskursen zuschreibt (moderierendes Element) «.74 Hintergrund ist die massive Infragestellung des »epistemischen Ghettos«, in das Rawls und Habermas religiöse Überzeugungen abschieben, die einer »prädiskursiven Diskriminierung « religiöser Gründe « gleichkomme. ${ }^{75}$ Denn sie übersehen die rationale Erreichbarkeit und damit die argumentative Triftigkeit religiöser Überzeugungen, die intersubjektiven wie diskursiven Rechtfertigungen »zugänglich sein können «. ${ }^{76}$

So überzeugend dieser epistemologische Aufweis der Rationalität des Glaubens ist, so sehr damit die Trennung zwischen Glauben und Wissen als Hintergrund der Unterscheidung von >öffentlich bleibt ein solcher Zugang dennoch eindimensional. In seiner kognitiven Engführung kann er Religion als ganzmenschliche Lebenspraxis nur ansatzweise erfassen.

Deshalb verstehen Pragmatische Argumentationslinien hingegen Religionen als »sprachliche und symbolische Ausdrucksformen, die das Verhältnis von Transzendenz und Immanenz im Sinne eines wissenden Nichtwissens thematisieren und damit eine soziale Praxis konstituieren, die einen umfassenden Anspruch an die religiösen Menschen stellen «.77 Mit einer solchen Zuschreibung, die der Religion kognitive wie lebensweltliche Würde attestiert ${ }^{78}$ ist die Möglichkeit rational-diskursiver Unterscheidungen innerhalb der Religionen sowie zwischen ihnen und esoterischen Positionen gegeben. Überdies ist zudem die Basis für eine rationale Ausweisbarkeit von Religion

74 | Breul, Religion in der politischen Öffentlichkeit 2015, 249.

75 | Breul, Religiöse Epistemologie 2016, 183.

76 | Breul, Religiöse Epistemologie 2016, 185.

77 | Reder, Religion in säkularer Gesellschaft 2013, 348.

78 | Vgl. Seibert, "An ihren Früchten werdet ihr sie erkennen" 2017, 169-171. 
in der Öffentlichkeit gelegt. Doch zugleich ist eine kognitive Reduktion überschritten, insofern Religionen als ganzmenschliche Praxis begriffen werden, die als solche öffentlichkeitsrelevant sind. So gesehen bilden Religionen einen wichtigen, gleichberechtigten Bestandteil öffentlicher Diskurse. Sie müssen sich an die demokratische Rechtsordnung gesellschaftlicher Prozesse halten. Als solche

"können sie einen wichtigen Teil zum Gelingen moderner Demokratien beitragen. Deliberative Verfahren [...] werden nicht gefährdet, wenn sie religiöse Argumente als solche beachten, sondern erst, wenn einzelne Gruppierungen - seien sie religiös oder säkular einen Absolutheitsanspruch im politischen Raum erheben. Wichtig ist daher ein offener und fairer Umgang der verschiedenen Praktiken miteinander und weniger die Frage, ob religiöse Semantiken in der Öffentlichkeit zugelassen werden oder nicht. «99

Religionen haben als Ganze öffentliche Bedeutung, nicht nur ihr diskursiver Teil. Aber es wird in deliberativen Verfahren entschieden, inwieweit sie öffentlichkeitswirksam und von politischem Einfluss sein sollen und können.

\section{7. Öffentliche Religion}

In diesem Raum diskursiver Öffentlichkeit kristallisiert sich damit eine Öffentliche Religion heraus. ${ }^{80} \mathrm{In}$ ihm treten unterschiedliche Weltanschauungen, Religionen und Politik in eine diskursive Auseinandersetzung um grundlegende Orientierungen, Werthaltungen und Praktiken. Diese Öffentliche Religion macht ernst mit der eben angespielten politiktheoretischen, kulturwissenschaftlichen und historischen Analyse, dass im strengen Sinne der weltanschaulich neutrale Verfassungsstaat in seinen Beschlüssen, seinem Handeln und seinen Regelungen »tatsächlich niemals weltanschaulich neutral« ist, sondern auf der »Rivalität der Weltanschauungen basier ${ } \ll \cdot{ }^{8}$ Hans Joas kommt am Ende seiner langen Analysen der Begriffe von Modernisierung, Funktionaler Differenzierung, Säkularisierung und Entzauberung zu dem Ergebnis, dass die Vorstellung der Religion als einer Wertsphäre oder einem Funktionssystem neben anderen bereits »säkularistisch« sei.

79 | Reder, Öffentlichkeit und Liberalismus 2016, $254 f$.

80 | Vgl. Gabriel, Gottesglaube 2008, 266ff. Zum folgenden in Überarbeitung Grümme, Religionsunterricht und Politik 2009, 32-34.

81 | Hochgeschwender, Amerikanische Religion 2007, 200; vgl. Casanova, Public Religions 1994; Taylor, Ein säkulares Zeitalter 2009. 
"Religion hat Spezifika, aber diese liegen nicht in einer kulturellen Spezialisierung aufs Religiöse. Ihr Verhältnis zur Kultur insgesamt ist nicht das einer Kultursphäre zur anderen. Gläubige und ihre sozialen Organisationen erheben Ansprüche auf die Gestaltung aller Kultursphären und Funktionssysteme, wenn sie ihren Glauben ernst nehmen. Dies ist kein Plädoyer für religiösen Fundamentalismus oder Integralismus, da es unbestreitbar eine religiöse Lerngeschichte des Respekts vor anderen Wertsystemen und Glaubensformen sowie der Einsicht in die jeweils spezifische Funktionslogik von gesellschaftlichen 'Teilsystemen o oder kulturellen ,Wertsphären، gibt. Aber das Pathos universalistischer Religion und übrigens auch universalistischen säkularen Denkens fügt sich nicht ein in das Weltbild eines fortschreitenden Prozesses funktionaler Differenzierung. Ausmaß, Grad und Richtung dieses Prozesses sind selbst an den Idealen der Lebensführung und Weltgestaltung, religiösen und säkularen, zu messen. " 82

Eine agonistische Ausrichtung des Gemeinwohls, die freiheitsfördernde Gesetze und Institutionen hervorbringt, lässt auch religiöse Äußerungen zu, überantwortet sie jedoch auch der Kritik, wenn sie autoritär zu werden drohen.

"In direkter Analogie zur politischen Autorität sind auch autoritäre religiöse Verordnungen, Gesetze und Institutionen Abarten von Autorität, die aufgrund ihrer freiheitsbeeinträchtigenden Wirkungen kritisiert werden müssen. Und weil aus der Perspektive der ethischen Freiheit religiöse Glaubenssätze, Traditionen, Rituale und Lebensweisen auch für Nicht-Gläubige und Anders-Gläubige ein wichtiges semantisches Potential haben, muss diese Kritik nicht nur in der jeweiligen Glaubensgemeinschaft, sondern im öffentliche Diskurs stattfinden, zu dem prinzipiell jeder Mensch zugelassen werden soll.".83

Der christliche Glaube gehört demnach in den öffentlichen Raum. Er selber drängt darauf, in kritisch-transformatorischer wie befreiender Weise öffentlich zu werden. Er kann dazu beitragen, dass Fragen nach Sinn, nach Gerechtigkeit, nach dem vergangenen Leiden, nach der Wahrheit und Legitimität von Weltanschauungen nicht aus der Öffentlichkeit herausgedrängt werden. ${ }^{84}$ Gleichwohl kann dies nur nach den normativen Spielregeln diskursiver Vernunft geschehen. Allein hier, allein also auf der prozeduralen Ebene, liegt die Neutralität des Verfassungsstaates. ${ }^{85}$ In diesem Diskurs ist dann auch die Wahrheit des Glaubens einzubringen und dort »diskursiv gut paulinisch zu prüfen. Sie kann hier gegebenenfalls ihre argumentative Überzeugungs- und

82 | Joas, Die Macht des Heiligen 2017, $416 f$.

83 | Cooke, Nicht zugänglich 2017, 210.

84 | Vgl. Kühnlein, Politische Theologie 2017, 200.

85 | Vgl. Hochgeschwender, Amerikanische Religion 2007, 201. 
ihre performative Veränderungskraft aufzeigen. ${ }^{86}$ Jedoch gehen, wie auch Michael Walzer betont, von einer solchen Öffentlichkeit der Religion wiederum zivilisierende Wirkungen auf die Religion und die Gläubigen aus.

"It is also important to say that when religious citizens join democratic debates, they must join in every aspect of those debates. That means: they must listen and respond to criticism of their own positions, including criticism of their theology, if theology provides the basis of those positions. In the political arena, theology and ideology have similar standing. The claim to know God's word brings no special authority in democratic politics." 87

Eine solche Öffentliche Religion gehört in diesem spezifischen Sinne in die diskursive Öffentlichkeit. Ohne die Modernisierungsprozesse zu unterlaufen, gehen von ihr dann durchaus Impulse für die Politik aus. Beispielsweise könnte sie gegenüber einem universalen Machbarkeitswahn wie gegenüber einem pragmatischen Defätismus immer zugleich das »Nicht-Politische der Politik« einklagen, ${ }^{88}$ ein Gedanke, der in der gegenwärtigen Debatte um das Politische in der Politik von nicht zu unterschätzender Bedeutung ist. ${ }^{89}$ Sie könnte in der Zivilgesellschaft, dem Motor der Demokratie, als Impulsgeberin für eine Politisierung des Privaten und für eine Renormierung der Öffentlichkeit wirken und die Gesellschaft zwingen, sich kritisch wie reflexiv mit den eigenen normativen Grundlagen zu beschäftigen. ${ }^{90}$

Die Sozialphilosophin Agnes Heller schärft diesen Charakter der öffentlichen Religion im Kontext der funktionalen Differenzierung der Moderne dadurch an, dass sie ihn einträgt in den Horizont biblischen Bilderverbots.

„Politische Institutionen können durchaus auch ohne Gott funktionieren und auch ohne Wissenschaft, allein mit Hilfe menschlicher Entscheidungen, menschlichen Denkens und menschlichen Willens. Mehr noch, sie funktionieren so sogar am besten. Gleichzeitig ist es der Religion und der Kunst, nachdem sie sich von inrer Verpflichtung, der Politik zu dienen, befreit haben, ermöglicht, sich in ihren eigenen Sphären einzuschließen und den Luxus ihrer Autonomie zu genießen. Eine solche Entwicklung wäre ein schöner Ausgang unserer Geschichte. Aber dieser Ausgang ist bei weitem nicht garantiert. Die Zukunft der Modernität ist unbekannt; es ist noch nicht gesichert, ob sie überleben wird,

86 | Arens, Gottesverständigung 2007, 54.

87 | Walzer, Political Theology 2017, 339.

88 | Höhn, Postsäkular 2007, 19.

89 | Vgl. Laclau, Mouffe, Hegemonie und radikale Demokratie 2012; Marchart, Die politische Differenz 2010; Mouffe, Das demokratische Paradox 2013; Mouffe, Über das Politische 2007.

90 | Vgl. Klingen, Gefährdete Öffentlichkeit 2008, $178 f$. 
und noch unsicherer, ob sie, sollte sie überleben, eine Nische für das gute Leben bewahren kann. Darum muss das Gespenst des Messianischen heraufbeschwört werden, aber nur als Gespenst. [...]. Der leere Stuhl wartet auf den Messias. Wenn jemand diesen Stuhl besetzt, kann man sicher sein: es handelt sich um den pervertierten oder verlogenen Messias. Wenn jemand den Stuhl wegnimmt, dann ist die Vorführung zu Ende und der Geist wird die Gemeinde verlassen. Die Politik kann diesen unbesetzten Stuhl nicht gebrauchen; aber solange man den Stuhl belässt, wo er ist, genau dort im Zentrum des Raumes, wo er in seiner warnenden, vielleicht sogar pathetischen Leere fixiert bleibt, müssen die politischen Handlungsträger sein Dasein immer noch in Rechnung stellen. Zumindest steht es innen frei, sein Dasein in Rechnung zu stellen. Alles Übrige ist Pragmatismus. ${ }^{91}$

Einerseits wird von Agnes Heller her die berechtigte relative Autonomie der einzelnen Wirklichkeitsbereiche verständlich. Jedoch kann Politik unter einer messianischen Perspektive mehr als Technik sein und sich aus dem Bann instrumenteller Vernunft befreien. So markiert dies andererseits die Abhängigkeit der Politik von messianischer Hoffnung. Dies wäre echte Politik als einer Kunst des Möglichen im Unterschied zu einer Politik, die das System unverändert ließe, weil die Parameter dessen, was als wirklich und was als möglich anzusehen ist, für irreversibel ausgegeben werden. ${ }^{92}{ }^{2}$ Deshalb fällt insbesondere den Religionen heutzutage eine große Verantwortung zu. Sie haben die Aufgabe, dafür Sorge zu tragen, dass die Politik sich nicht auf die Erhaltung der vorgegebenen Ordnung begrenzt und in der Illusion einer reinen Immanenz lebt. Die Gesellschaft erfährt durch Religionen und die in ihnen erinnerten Hoffnungen eine Konfrontation mit etwas, das sie selbst nicht produziert. « $^{93}$ Korreliert mit der monotheistischen Tradition, gewinnt Politik Spielräume und subjektkonstitutive Kraft:

"Sowohl die Demokratie als auch ein Monotheismus zielen weniger auf Volkwerdung, denn auf Subjektwerdung. Wenn Demokratie definiert werden kann als die institutionalisierte Form des öffentlichen Umgangs mit Ungewissheit‘ (H. Dubiel), dann dient der Monotheismus nicht dazu, dieser Ungewissheit Herr zu werden. Im Gegenteil: Er radikalisiert die Ungewissheit. Ungewissheit kann nämlich neue Handlungsspielräume entstehen lassen. Der biblische Monotheismus ist ein einziger Aufruf gegen Verwurzelungen, ein Aufruf zu produktiver Heimatlosigkeit.." 94

91 | Heller, Politik nach dem Tod Gottes 1997, 87.

92 | Vgl. Manemann, Rettende Erinnerung 2005, 78.

93 | Manemann, Über Freunde und Feinde 2008, 85. Vgl. auch Peters, Theologie und Politik 2008, 89f.

94 | Manemann, Über Freunde und Feinde 2008, 81. Aus dekonstruktivistischer Sicht vgl. Zilleßen, Religion, Kultur, Ethik 2001. 
Zugleich wird aber in gleicher Schärfe erkennbar, dass der messianische Überschuss genau dann verloren geht, wenn Politik den Messianismus in Besitz nimmt. Jürgen Manemann, bestrebt die christliche Hoffnung im Geist apokalyptischer Tradition zuzuspitzen, spricht vom Messianischen als absoluter Überraschung. Nur wenn messianische Erwartung und memoria passionis zusammenkommen, ist eine »messianische Politik« vor Selbstverabsolutierung und zugleich die Religion vor einem neuen Integralismus gefeit. ${ }^{95}$

\section{Konsequenzen}

Der hier entwickelte religionspädagogische Öffentlichkeitsbegriff kann sich diesem Konzept der Öffentlichen Religion anschließen - und besteht doch auf weiterführenden Perspektiven. Die Pflicht einer rationalen Ausweisbarkeit religiöser Praktiken bleibt für ihn integrales Moment in der spannungsvollen wie dynamischen Bestimmung von Universalität und Partikularität. Gerade wenn die Religionen als Quelle, als Zielhorizont und als dynamisierende Kraft öffentlicher und politischer Selbstverständigungsprozesse verstanden werden, gilt es, einen Rahmen zu finden, in dem dies in gerechter wie verallgemeinerbarer Weise geschehen kann. Die Rechtfertigungspraxis gesellschaftlicher und politischer Prozesse nach den Maximen der allgemeinen, gleichen und wechselseitigen Partizipation aller, und damit die demokratische Rechtsordnung, wie wir dies mit Rainer Forst rekonstruiert haben ${ }^{96}$ stellen die Schwelle dar, die Religionen mit ihrem jeweiligen Wahrheitsanspruch nicht unterbieten dürfen, ohne öffentlichkeitstheoretisch illegitim zu werden.

Allerdings ist die in der diskursiven Öffentlichkeit unterstellte Vernunft anzufragen, ob sie wirklich der radikalen Praxis der Religion angemessen ist. Muss nicht jede deliberative Vernunft sich von Fremdheit und der zuvorkommenden Herausforderung durch Alterität irritieren lassen, einer Alterität, die im Rahmen der jüdischen oder christlichen Tradition angesichts des unauslotbaren Geheimnisses Gottes nochmals radikalisiert wird? Im kantianischen Sozialkonstruktivismus von Rainer Forst, geprägt von der deliberativen Vernunftkonzeption Habermas', scheint dies nicht hinreichend gegeben. Ist wirklich durch die rechtfertigenden Gründe alles einholbar? Werden nicht die konkreten Anderen in ihrem je spezifischen lebensweltlichen Kontext überspielt? Seyla Benhabib erinnert dies an einen geheimen Platonismus: »A fully transparent and justified basic structure reminds one of a Platonic utopia

95 | Manemann, Über Freunde und Feinde 2008, 85; Vgl. Manemann, Das Politische 2008, 116-118.

96 | Vgl. D 5. 
rather than critical theory's emphasis on the longing for the wholly other. ${ }^{97}$ Vor dem Hintergrund der Philosophie von Levinas erscheint Forsts Reziprozitätsschema deshalb problematisch, weil es den Anderen in seiner ethischen Provokation für das Selbst untergräbt:

"Stressing the asymmetrical moment also warns of the dangers of irresponsibility that come with the facile adoption of a third-person perspective. While we need norms ensuring that your motivation to do the right thing is not swamped by others failing to do their fair share, we should also expect us as individuals to understand that our freedom is tied to responsibility, a responsibility that exceeds what the community asks us to do." 198

Öffentlichkeitstheoretisch wird das Problem aus theologischer wie postkolonialer aus Sicht noch dramatisiert. Können Phänomene der Weisheiten indigener Völker in ihrer autochthonen Fremdheit, können deren Riten und Kulte letztlich als irrational abgetan und als allenfalls im Privaten relevante Ressourcen individuellen Lebens marginalisiert werden? Das mag für westliche Adaptionen schamanistischer, neopaganer oder esoterischer Praktiken sinnvoll sein. Doch in seiner generellen Delegitimierung hieße dies, in der unseligen Tradition kolonialen Denkens eine »Abschließung des Geistes« zu vollziehen. ${ }^{99}$ Brauchen nicht die säkulare Öffentlichkeit wie die Kirche religiöse Überlieferungen als Inspiration, als Irritation, als Quelle für die »Pflege der Natur und die Sorge für die schwächsten Brüder und Schwestern«?100 Norbert Mette macht dies in seiner Kompilation der Theologie von Papst Franziskus eindrucksvoll deutlich. Für Papst Franziskus sei es notwendig, » auf die verschiedenen kulturellen Reichtümer der Völker, auf Kunst und Poesie, auf das innerliche Leben und auf die Spiritualität zurückzugreifen< (LS 63). Kein Wissenschaftszweig und keine Form der Weisheit dürfen beiseite gelassen werden werden, >auch nicht die religiöse mit ihrer eigenen Sprache $\triangleleft «^{101}$ So gesehen hängen die Anerkennung indigener Volker mit ihren Praktiken und Riten und eine veränderte Hermeneutik aufs engste zusammen. Wir haben »die Dinge anders zu interpretieren, indem wir jedes Volk, seine Kultur, seine Sprache wertschätzen ${ }^{102}$ Und doch braucht es begründete, rational ausweisbare Unterscheidungen, um die Subjekte zu schützen und Gerechtigkeit zu

97 | Benhabib, The Uses and Abuses 2015, 789.

98 | Fritsch, Rational Justification 2015, 817.

99 | Membe, Kritik der schwarzen Vernunft 2014, 28. Vgl. 151-194.

100 | Mette, Nicht gleichgültig bleiben 2017, 49.

101 | Mette, Nicht gleichgültig bleiben 2017, 49.

102 | Mette, Nicht gleichgültig bleiben 2017, 107. 
ermöglichen. Diese Unterscheidungen können aber nur verallgemeinerbarer Natur sein.

Angesichts der Triftigkeit deliberativer Verfahren, aber nicht minder angesichts der erkennbaren Grenzen dieser kantianisch-deliberativen Vernunft wird darum abermals die Bedeutung der hier vertretenen alteritätstheoretischen Denkform eklatant sichtbar. Sie ist im besonderen Maße geeignet, die Eigenlogik religiöser Überzeugungen in der Sphäre der Öffentlichkeit zur Sprache zu bringen und dabei zugleich rationale, universal ausweisbare Unterscheidungskriterien zu liefern. Die begriffliche Anerkennung der Heterogenität der Öffentlichkeit, die Zusammenführung von Identitäts- und Gleichheitsfragen und damit zugleich die begriffliche Würdigung dessen, worauf Benhabib mit ihrem Begriff »Gefährdete Öffentlichkeit« aufmerksam gemacht hat, können alteritätstheoretisch in fruchtbarer Weise gedacht werden. ${ }^{103}$ Damit wird nun ein Blick auf unsere Ausgangsfrage möglich. 



\section{E. Fazit und Ausblick. Religionspädagogische Implikationen}

\section{KontUREN EINES ALteritätSTHEORETISCh StRUKTURIERTEN ÖFFENTLICHKEITSBEGRIFFS}

Die vorgetragenen Überlegungen haben zum Ziel, eines der zentralen wie eines der am meisten übersehenen Desiderate Öffentlicher Religionspädagogik zu eruieren und zu bearbeiten: Das Desiderat eines Öffentlichkeitsbegriffs als Basis, Strukturprinzip und normative Orientierung der Öffentlichen Religionspädagogik. Sie, die so verheißungsvoll wie provokativ die Religionspädagogik aus ihrem Dornröschenschlaf kirchlicher oder schulisch-institutionell abgesicherter Selbstversicherungsdiskurse herausruft, sie, deren Potential religionspädagogisch noch lange nicht ausgelotet ist, sie droht ihre eigenen Maximen zu unterlaufen, solange diese hermeneutische Selbstklärung nicht erfolgt. Methodisch angelegt in den zwei Schritten der kritischen Analyse und der Konstruktion, wurde ein Öffentlichkeitsbegriff als Teil einer Metatheorie Öffentlicher Religionspädagogik gesucht, der dreierlei im gleichen Maße gerecht wird: 1. den Anforderungen des spätmodernen Kontextes, 2. dem Profil religionspädagogischer Selbstkonzeptualisierung und 3. den sinnverheißenden, befreienden wie herausfordernden Traditionen christlicher Religion.

Dieses Desiderat wurde deutlich angesichts der Auseinandersetzung mit drei prominenten Positionen Öffentlicher Religionspädagogik.

Im Diskurs mit Judith Könemann zeigte sich mit politikwissenschaftlichem Akzent das Profil zivilgesellschaftlicher Öffentlichkeit als dem intermediären Raum zwischen Privatheit und Staat, in dem Religionspädagogik wie die Kirchen mit jeweils eigenem Profil ihren Öffentlichkeitscharakter artikulieren. Doch diese beeindruckende hermeneutische und analytische Bearbeitung der public sphere als Feld religionspädagogischen und kirchlichen Selbstvollzugs drang bis zur begrifflichen Klärung des Öffentlichkeitsbegriffs selber nicht vor. ${ }^{1}$ 
Noch deutlicher wurde dieses Desiderat in der Beschäftigung mit der Öffentlichen Religionspädagogik Manfred Pirners. Ihm gelingt ein überzeugender Aufweis der Anschlussfähigkeit religionspädagogischer Praxis und Theoriebildung an die Debatten dominierender sozialphilosophischer Selbstverständigungsprozesse. Doch deren Kategorien selber wurden nicht hinterfragt, ein Manko, was Ansatz und Struktur Öffentlicher Religionspädagogik selber affiziert. ${ }^{2}$

In dem elaboriertesten Entwurf Öffentlicher Religionspädagogik bei Bernd Schröder wurde der Verdienst markiert, Theologie und Religionspädagogik in grundlegender Weise einen öffentlichen Charakter zuzuschreiben. Öffentlichkeit wird dort als Adressat, als Ziel, als Gegenstand, als Forum religionspädagogischer Praxis und Theorie konzipiert. Religionspädagogik »als öffentliche Angelegenheit zu entfalten ${ }^{3}{ }^{3}$ heißt, diese in rezeptiver, konstruktiver und konstitutiver Hinsicht auf Öffentlichkeit zu beziehen und als öffentliche Religionspädagogik zu artikulieren. So sehr dies das Defizit des mainstream gegenwärtiger Religionspädagogik offenlegt, so sehr lässt dies die Reflektiertheit des Öffentlichkeitsbegriffs als Grundlage von Öffentlichkeit vermissen. ${ }^{4}$

Aus dieser Diskussionslage kristallisierte sich damit das Desiderat einer begrifflichen Klärung des Öffentlichkeitsbegriffs heraus. Diesen ungeklärt gelassen zu haben, droht Intention, Anlage und Durchführung der jeweiligen Öffentlichen Religionspädagogik zu konterkarieren. Als die gravierendsten, jeweils höchst spannungsvoll konstituierten Problemfelder wurden das der Vernunft, das Verhältnis zwischen Normativität und Macht als Frage nach den hegemonialen Strukturen öffentlicher Religionspädagogik, die Frage nach Universalität und Partikularität sowie die nach der Stellung der Religion in der Öffentlichkeit herausgearbeitet.

Auf diesen Problemfeldern wurde dann das Potential einer alteritätstheoretischen Denkform ausgelotet, die einen entsprechenden Öffentlichkeitsbegriff konturieren kann. Dieser Öffentlichkeitsbegriff operiert mit einer alteritätstheoretisch strukturierten Vernunft, die normativ und universal angelegt ist und dadurch Öffentlichkeit denken kann, ohne die konstitutiven Leistungen der Subjekte und partikulären Traditionen zu marginalisieren. Im Gegenteil: In einer Umkehrung der Perspektive avanciert die Öffentlichkeit geradezu zum Feld der Artikulation der jeweiligen Tradition, ihres eigenen Wahrheitserweises und zugleich ihrer konstruktiv-kritischen Auseinandersetzung mit anderen Traditionen. So wird es möglich, Religion in der Öffentlichkeit zu denken und ihren kritisch-konstruktiven Wahrheitsanspruch, ihren prophetischkritischen Impuls wie ihre tröstenden, befreienden Erfahrungsräume in der

2 | Vgl. B 5.2.

3 | Schröder, Öffentliche Religionspädagogik 2013, 111.

4 | Vgl. B 5.3. 
Öffentlichkeit hörbar zu machen, ohne zu ungebührlichen Verabsolutierungen zu kommen. Die hier vorausgesetzte Alteritätstheorie kann den Öffentlichkeitscharakter der Religion im Dienste der Subjekte wie des Gemeinwohls entfalten, indem sie diese mitten in das Ringen um das gemeinsame Gute hineinstellt. Sie ermöglicht es, einen normativen Horizont gesellschaftlicher Selbstverständigungsprozesse der Bürgerinnen und Bürger als citoyens zu denken, der den Legitimitätsrahmen der Religionen konstituiert und ihnen genau darin zur Entfaltung verhilft. Die Konstellation mit poststrukturalistischen und kritisch-theoretischen Denktraditionen ermöglicht es der alteritätstheoretischen Vernunft, ihre eigene Dialektik kritisch-konstruktiv zu bearbeiten, die darin liegt, hegemoniale Strukturen wider der eigenen Intention $\mathrm{zu}$ reproduzieren.

Bezogen auf die markierten Desiderate gegenwärtiger Öffentlicher Religionspädagogik liegt in diesem Aufweis eines Öffentlichkeitsbegriffs sicherlich der am meisten weiterführende Impuls. Alteritätstheorie kann gerade dadurch, dass sie sich ungebrochenen Universalismen verweigert, dass sich sich prinzipiell von Alterität irritieren, dekonstruieren und herausfordern lässt, aber dies auch reflexiv weiß, sich in analytisch-selbstreflexiver Weise dieser eigenen dialektischen Selbstkonstitution stellen und diese kritisch-konstruktiv bearbeiten.

Die Grundlinien eines religionspädagogisch weiterführenden Öffentlichkeitsbegriffs liegen somit vor. Mit ihnen kann die Öffentliche Religionspädagogik weiterarbeiten. Wollte man freilich dessen Implikationen detailliert und nuanciert in seiner potentiellen Komplexität entfalten, hieße das, einen eigenen strukturellen Entwurf Öffentlicher Religionspädagogik zu entwickeln. Von einer zu erarbeitenden Metatheorie auf grundlagentheoretischer Ebene war bereits die Rede. Aber ebenfalls auf den anderen Ebenen wissenschaftstheoretischer Arbeit, der Kairologie und der Praxeologie, wäre dies durchzuführen. ${ }^{5}$ Dies aber ist hier nicht mehr möglich. Hier kann es allenfalls um einen kurzen, thetischen wie schlaglichtartigen Aufriss religionspädagogischer Implikationen gehen.

\section{ReLIGIONSPÄDAGOGISCHE ÖFFENTLICHKEITEN}

Um diese Implikationen zu systematisieren, bietet es sich an, unter kreativer Aufnahme dieser Unterscheidung von Grundlagentheorie, Kairologie und Praxeologie im Anschluss an die Pädagogische Schultheorie von Helmut Fend

5 | Vgl. hierzu Englert, Wissenschaftstheorie der Religionspädagogik 1995; neuerdings Heger, Wissenschaftstheorie 2017. 
drei Ebenen zu unterscheiden: die Makroebene, die Mesoebene und die Mikroebene. $^{6}$

\subsection{Makroebene: Religionspädagogik in den diversen öffentlichkeiten}

Auf der Makroebene ist der Ort der Religionspädagogik in der Öffentlichkeit zu reflektieren. Nach dem Muster der Öffentlichen Religion ist die Religionspädagogik aufgerufen, sich in der Öffentlichkeit Gehör zu verschaffen. Es geht um Kritik, es geht um konstruktiven, weiterführenden Beitrag insbesondere auf den affinen Feldern von Bildung, von Gerechtigkeit, von gesellschaftlichem Engagement. Hier hat sie ihre Tradition der Gotteshoffnung als einer Tradition der Freiheit und Gerechtigkeit, eines Lebens in Fülle für alle, als befreiende wie kritische Botschaft einzubringen.

Dabei muss sie sich selber mit verschiedenen Formen von Öffentlichkeit kritisch wie konstruktiv auseinandersetzen:

Mit einer transnationalen Öffentlichkeit: In Zeiten der Globalisierung einerseits und Renationalisierungstendenzen andererseits kommt es für die Religionspädagogik darauf an, als Glied einer Teilöffentlichkeit, die selber aus kirchlichen Bindungen heraus transnational strukturiert ist, Perspektiven zu entwickeln, die eine solche transnationale Öffentlichkeit in Verantwortung für alle und unter Partizipation aller entwickeln helfen können. Die eingangs genannten Konzepte Globalisierter Religionspädagogik sind ein Ansatz dazu. ${ }^{7}$

Mit einer nationalen gesellschaftlichen Öffentlichkeit, die in ihrer Dynamik längst den zivilgesellschaftlichen Bereich analoger Selbstverständigungsprozesse in die Sphären von Medialität und Virtualität überstiegen hat, deren Partizipationsmöglichkeiten jedoch angesichts sich verschärfender sozial-ökonomischer Segregationen sowie der eskalierenden Deflationierung von Wahrheitsansprüchen und verlässlicher Information durch fake news immer prekärer zu werden drohen; wenn hier beispielsweise von Gesellschaft, Politik und Wirtschaft Ansprüche an lebenslanges Lernen, an Wertevermittlung, an Kontingenzbewältigung an die Adresse der Religionspädagogik ergehen, müsste diese ihren kritisch-konstruktiven Impuls auch zur kritischen Selbstreflexion nutzen, ob diese Form der öffentlichen Inanspruchnahme nicht mehr zur gesellschaftlich-ökonomischen Affirmation als zu ihrer ureigenen diakonischen Ausrichtung an autonomer Freiheit und Gerechtigkeit dient.

Mit einer Kirchlichen Öffentlichkeit, die einerseits einen integralen Zielund Adressatenhorizont religionspädagogischer Arbeit darstellt, andererseits dabei aber nicht immer deutlich wird, inwieweit die Logik kirchlich-institu-

6 | Fend, Neue Theorie der Schule 2008.

7 | Vgl. Simojoki, Globalisierte Religion 2012. 
tioneller Selbstreproduktion den Maximen der Autonomie und Subjektorientierung der Religionspädagogik und deren eigener Logik entsprechen können.

Mit einer transtheologischen Wissenschaftlichen Öffentlichkeit, die einerseits mit zunehmender positivistischer und naturalistischer Ausrichtung inzwischen der Theologie den Wissenschaftscharakter bestreitet, ihn andererseits jedoch auf der Ebene der Wissenschaftspolitik etwa in Gestalt des Wissenschaftsrates mit Nachdruck einfordert.

Mit einer innertheologischen Wissenschaft, die den zentralen Ort und - neben der Pädagogik - die entscheidende Referenzwissenschaft der Religionspädagogik bildet, die andererseits nicht frei ist von jenen längst überholt geglaubten Funktionalisierungseffekten, die der Religionspädagogik vornehmlich die Praxis zur didaktisierenden Vermittlung jener Inhalte überlässt, die von der Systematischen und Exegetischen Sektion zuvor erarbeitet wurden.

\subsection{Mesoebene: Religionspädagogik in der Vielzahl ihrer Disziplinen}

Auf dieser Ebene hat sich Religionspädagogik mit ihren eigenen, diversen, teilweise differenten Öffentlichkeiten auseinanderzusetzen. Forciert durch die Ansprüche der kirchlichen Öffentlichkeit werden dabei nicht selten die Grenzen verwischt und die relativen Eigenlogiken insbesondere der Katechese und des Religionsunterrichts unterminiert, um die Herausforderungen zunehmender Heterogenität zu bewältigen.

Religionspädagogik hat sich konstruktiv mit der Verhältnisbestimmung ihrer einzelnen Bereiche auseinanderzusetzen und im Zusammenspiel der drei Ebenen der Makro-, Meso- und Mikroebene deren Relation so zu gestalten, dass deren Eigenlogik wie ihre Gesamtverantwortung für die Bezeugung und Tradierung des Glaubens in subjektorientierter Weise möglich, verantwortbar und sichtbar wird. Katechese, Kinder- und Jugendpastoral, Elementarbildung, Religionsunterricht, Erwachsenbildung, Altenbildung sind im Sinne des hier erarbeiteten Öffentlichkeitsbegriffs Teilöffentlichkeiten, die in agonal-diskursiver Weise ihr Profil entwickeln. Das Profil einer jeden Teilöffentlichkeit ist freilich auf der Mikroebene zu entfalten.

\subsection{Mikroebene: Religionsunterricht}

Auf der Mikroebene hat jeder Teil der Religionspädagogik jeweils eine übergreifende Öffentlichkeit, in der sie sich selber profiliert, ausweist und von der sie angefragt wird. Zugleich aber muss dieser Teilbereich sich selber so konstruieren und gestalten, dass er allen drei Ebenen der verschiedenen Öffentlichkeiten entsprechen, d.h. deren jeweilige Ansprüche und Möglichkeiten kritisch wie konstruktiv bearbeiten kann. 
Da inzwischen der Religionsunterricht zu dem prominenten Ort der Religionspädagogik avanciert ist, weil hier aufgrund grundgesetzlicher und schulpolitscher Regelungen, aber auch, weil er nach wie vor ein beliebtes Unterrichtsfach darstellt, ${ }^{8}$ die meisten der Heranwachsenden erreicht werden, wird die Mikroebene exemplarisch aus dessen Perspektive heraus bedacht. Dabei soll zunächst eine Perspektive auf Öffentlichkeit nach außen und anschließend eine Perspektive nach innen beleuchtet werden.

\subsubsection{Außerreligionsunterrichtliche Öffentlichkeit}

Der Religionsunterricht ist sowohl auf die Schule, auf die anderen Fächer, auf die Fächergruppe in der Schule, aber auch auf innerschulische Lernorte wie die Schulpastoral, die religionspädagogisch qualifizierte Gestaltung des Ganztags und außerschulische Lernorte bis zur Kooperation mit der Pfarrgemeinde verwiesen. Diese bilden das Forum seiner äußeren Öffentlichkeit.

Der Religionsunterricht verhält sich zum Fächerkanon wie die Öffentliche Religion zu anderen Wirklichkeitsbereichen. Die öffentliche Religion unterläuft die Ausdifferenzierung der Moderne nicht, die sich ja nach Ausweis des Allgemeinbildungskonzepts Dietrich Benners ihrerseits im Fächerkanon der Schule niederschlägt. ${ }^{9}$ Als solcher bringt der Religionsunterricht den universalen Anspruch der christlichen Botschaft diskursiv in die Schulöffentlichkeit ein. Es wäre ein vermessener und dem eigenen Profil gerade widerstreitender Anspruch, einen wahrheitstheoretischen, bildungstheoretischen oder pädagogischen Dominanzanspruch des Religionsunterrichts abzuleiten. Dieser artikuliert seinen Beitrag zum Bildungsauftrag der Schule kritisch-konstruktiv und lässt sich seinerseits von den anderen Fächern anfragen und inspirieren. Er steht somit in fächerübergreifender wie fächerbindender Kooperation mit allen anderen Fächern. ${ }^{10}$

Mit anderen Schulfächern hat ein solcher Religionsunterricht den methodischen Zugang bei performativen Akten, bei Schülerorientierung, Handlungsorientierung, bei der Ganzheitlichkeit des Lernens oder auch den Anspruch gemeinsam, die Fixierung auf Alltagstheorien durch die Konfrontation mit Orientierungswissen aufzusprengen und die Lernenden zum Wechsel ihrer Konzepte zu veranlassen. ${ }^{11}$

8 | Vgl. Mendl, Religionsdidaktik Kompakt 2011, 23-33; Bucher, Religionsunterricht zwischen Lernfach und Lebenshilfe 2000.

9 | Vgl. Benner, Bildung und Religion 2014, 15-48.

10 | Vgl. Dieterich, Fächerübergreifenderer Unterricht 2008, 17-27; Moegling, Kompetenzaufbau 2010; Pirner, Schulte, Religionsdidaktik im Dialog 2009; Schreiner, Das Verhältnis des Religionsunterrichts 2012.

11 | Vgl. Hunze, Ein seltenes Gespräch 2007, 278; Liessmann, Bildung als Provokation 2017, 7-81. 
Mit dem Gottesgedanken bringt ein solcher Religionsunterricht sein inhaltliches Spezifikum in die innerschulische Öffentlichkeit ein. Er hält damit den »Sinn für das, was fehlt und sanders sein könnte« in der Schule offen und wirkt sich auch normativ in dessen formaler Anlage als Sprachschule der Freiheit und einem Bildungsverständnis aus, ${ }^{12}$ das keinen verloren gibt. Dies wirkt sich im unterrichtlichen Umgang miteinander aus, nimmt ideologiekritisch institutionelle Zwänge und überbordende Leistungserwartungen in der Schule in den Blick und liefert über den Unterricht hinaus einen Beitrag dazu, die Schule als Lebenshaus für alle bewohnbar zu machen. Gleichwohl weiß dieser Religionsunterricht um die »Begrenztheit des schulischen Wirkungsraumes und die Bedeutung nichtschulischer Bildungsinstitutionen « aufgrund der strukturellen Eigenarten und zeitlichen Begrenztheit schulischen Lernens. ${ }^{13}$

Im Rahmen des Konzepts der Fächergruppe Ethik, evangelischer Religionsunterricht und katholischer, islamischer, jüdischer Religionsunterricht weckt ein öffentlichkeitssensibler Religionsunterricht analytisch und normativ die Aufmerksamkeit für die politischen Implikationen des jeweiligen Faches. Die Relevanz des Politischen für ethisches und soziales Lernen könnte durch diesen Religionsunterricht als dauernder »Stachel im Fleisch« markiert werden. ${ }^{14}$

Der Dialog mit den naturwissenschaftlichen Fächern konzentriert sich zur Zeit vornehmlich auf die Verhältnisbestimmung von Evolution, Schöpfung, Kreationismus und intelligent design. Angesichts der gegenwärtigen Brisanz ist das durchaus legitim. Sensibel für die politischen wie öffentlichen Dimensionen akzentuiert der Religionsunterricht verdeckte ideologische und politische Aspekte. Ohne sie, ohne etwa den Bezug auf die starken Interessen mächtiger Gruppen und Organisationen in den USA oder in Westeuropa zu lenken, bliebe die Behandlung des Themas abstrakt. Inhaltlich bringt der Religionsunterricht kritisches Potential ein gegenüber den innerhalb der Naturwissenschaften vertretenen Reduktionismen wie dem Naturalismus und den dort zu findenden Perfektibilitätsidealen, die sich bei genauerer Betrachtung als zutiefst inhuman erweisen. Die Auseinandersetzung mit dem naturwissenschaftlichen Menschenbild sowie mit utilitaristischen Tendenzen gewinnt durch die politisch-systemische Sphäre erst eine den Herausforderungen angemessene Tiefenschärfe. Aber er nimmt sich selber aus dieser ideologiekriti-

12 | Habermas, Ach, Europa 2008, 84; vgl. Reder, Schmidt, Ein Bewusstsein von dem, was fehlt 2008.

13 | Drilling, Moral und Demokratieentwicklung 2007, 263; Grümme, Bildungsgerechtigkeit 2014, 153-159.

14 | Vgl. Kahrs, Öffentliche Bildung 2009; Schlag, Horizonte demokratischer Bildung 2010. 
schen Reflexion nicht aus. Die kritische Dynamik des Öffentlichkeitsbegriffs macht ihn wahrnehmungsstark für die eigenen hegemonialen Aspekte.

Die innere Nähe eines solchen öffentlichkeitssensiblen, politisch dimensionierten Religionsunterrichts $\mathrm{zu}$ sozialwissenschaftlich-historischen Fächern liegt auf der Hand. In der Kooperation mit diesen Fächern bringt der Religionsunterricht mit der Erlösungshoffnung die Zusage einer geschenkten, zuvorkommenden, erlösenden Freiheit ein, die in gesellschaftlich-politischer Interaktion praktisch und damit wahr werden will. Dies schenkt Sinn und Hoffnung, dies ermöglicht supererogatorische Handlungen sowie den anamnetischen Blick auf das Marginale und Verlorene. Gegenüber dem latent den Geschichtsunterricht, den Politikunterricht oder auch den Sozialkundeunterricht beeinflussenden Fortschrittsdenken bringt dies eine weiterführende, kritische Perspektive ein. ${ }^{15}$

\subsubsection{Innerreligionsunterrichtliche öffentlichkeit}

All dies verlangt aber dem Religionsunterricht selber die Realisierung einer solchen öffentlichkeitsfähigen Gestalt ab. Dies ist die öffentlichkeitsrelevante Perspektive nach innen.

Dazu muss der Religionsunterricht seine öffentliche und damit seine politische Dimension kultivieren. Doch anstatt hier einer voreiligen, bildungspolitisch wie historisch verhängnisvollen Politisierung das Wort zu reden, ist das korrelative, kritisch-konstruktive Zueinander seiner verschiedenen Dimensionen zu sichern. »Der Religion sind die Wirklichkeit als Ganze erhellende sinnstiftende kognitive und ethisch orientierende, soziale und ästhetische Seiten eigen. Sie sind daher auch religiöser Bildung gleichursprünglich inhärent. Die ethische, soziale und politische Seite religionspädagogisch grundsätzlich festzuhalten, entspricht insbesondere den Sachstrukturen unserer biblischchristlichen Gesamtüberlieferung. $\ll^{16}$ Die politische Dimension anerkennt die anderen Dimensionen religiösen Lernens im Religionsunterricht vor allem ästhetisch-expressiver, kognitiver, affektiver und pragmatischer Art in ihrer relativen Autonomie. Sie steht aber aus bildungstheoretischen Gründen in kritisch-korrelativer Vernetzung mit ihnen, wie eine alteritätstheoretisch grundierte Bildungstheorie begründen und aufzeigen kann. ${ }^{17}$ Ästhetisch-kulturhermeneutische, kognitiv-reflexive wie strukturell-politische Dimensionen religiöser Bildung werden in nicht-hierarchischer Weise kritisch wie produktiv aufeinander bezogen. Immer sind die anderen Dimensionen mitgedacht. Eine Konzentration auf eine Dimension würde eine methodische Abstraktion von

15 | Vgl. Grümme, Sander, Von der "Vergegnung" 2009.

16 | Nipkow, Zur Bildungspolitik 2003, 246; vgl. Biehl, Art.: Religionsdidaktische Konzeptionen 2002, 445.

17 | Vgl. Grümme, Religionsunterricht und Politik 2009, 148-155. 
diesem korrelativen Verhältnis der drei Dimensionen darstellen. Damit wird einerseits der Eigenständigkeit verschiedener Wirklichkeitsbereiche und Wirklichkeitszugänge Rechnung getragen, wie es der funktionalen Differenzierung der Moderne entspricht. Andererseits würde dadurch markiert, dass wir es mit dieser Eigenständigkeit mit einer relativen Eigenständigkeit zu tun haben, die eine additive oder separierende Zuschreibung der Dimensionen unterläuft.

Der Ertrag für eine Öffentliche Religionspädagogik liegt in mehreren Bereichen. Beispielsweise schließen sich ästhetische oder symbolpädagogische Elemente unter der Konfrontation mit politischen Kategorien reflexiv auf für die politischen Instrumentalisierungszusammenhänge, in denen sie stehen. Kulturhermeneutik wird kritisch wie produktiv mit Kriterien konfrontiert, die dieser erst eine trennscharfe »Unterscheidung der Geister« erlaubt. Sie vermag damit nicht nur faktisch, sondern eben vor allem intentional ihre ideologiekritische Potenz in gesellschaftlich-strukturellen Kategorien zu entfalten. Eigentlich kann erst eine kritisch-produktive Korrelation die Wahrheit kulturhermeneutischer oder symbolpädagogischer Ansätze in der Religionspädagogik vor ästhetisierenden Reduktionismen bewahren. Sie kann so die lebensweltliche Wahrheit auch gegen kulturindustrielle Übergriffe einklagen, die sich beispielsweise in den populärkulturellen Symbolisierungen artikuliert. Kognitive Prozesse erhalten durch Korrelation mit Elementen von Wahrnehmung eine Erfahrungsgrundlage und damit eine stärkere lebensweltliche Verwurzelung. Der Aspekt von Orientierung und Beheimatung, der in den heterogenen Lebenskontexten religionspädagogisch immer wichtiger wird, wird durch gesellschaftliche Kategorien vor einem individualistischen Reduktionismus geschützt.

Gibt erst die Verbindung von Mystagogie und Politik dem religiösen Lernen Tiefenschärfe, so markiert dies sein kritisches Profil und seine weiterführende Dynamik gegenüber den in der Religionspädagogik derzeit dominierenden performativ-kulturalistischen Ansätzen. Dazu gehört auch die Anschärfung der religionsdidaktisch dominanten Kategorie des sozialen Lernens etwa in der Compassionpädagogik, dem Diakonischem Lernen oder im Vorbildlernen durch politische Kategorien, wie sie im Umfeld der Kritischen Politischen Bildung entwickelt werden. ${ }^{18}$

Um die Bedeutung von politischen Kategorien für eine Öffentliche Religionspädagogik noch deutlicher zu machen, sei die Differenz zwischen Sozialem und Politischem Lernen skizziert. Soziales Lernen versucht Kinder zu Solidarität und vernünftiger Selbst- und Mitbestimmung anzuleiten. Es zielt auf Bereitschaft und Fähigkeit zur Kommunikation, zu Kooperation, zu Solidarität und einem verantwortlichen Konfliktlösungsverhalten, zu einer stabilen Ich-

18 | Vgl. Wohnig, Zum Verhältnis von sozialem und politischem Lernen 2017, 23-113; Lösch, Thimmel, Kritische politische Bildung 2011. 
Identität, sozialen Empfindsamkeit, Perspektivenübernahme, sie visiert Toleranz, Kritikfähigkeit und angemessenen Umgang mit Regeln an. ${ }^{19}$ Soziales Lernen ist ethisch, interkommunikativ ausgerichtet. Personale, soziale Kompetenzen in Bezug auf das Ich, die peer-group, die Familie, die Gemeinschaft stehen im Zentrum.

Politisches Lernen hingegen zielt auf politische Mündigkeit. Es bewegt sich im Lichte der Kategorien, Konzepte und Begriffe von politischen Institutionen der Entscheidung, der Kontrolle und der Herrschaftsexekution, es geht in ihm um Macht, Rechtsordnung, Ideologie und Manipulation, Herrschaft und Interesse, um Sinn und Funktion politischer Institutionen, um die normative Ausrichtung des Politischen. Es geht um Loyalität und Kritik, um Unterstützung und Transformation. ${ }^{20}$ Gegenüber der face-to-face-Interaktion ist also politisches Lernen systemisch, strukturell ausgerichtet und bezieht sich auf gesamtgesellschaftliche und politische Kontexte.

Diese Unterscheidung von Politischem und Sozialem Lernen ist für eine Öffentliche Religionspädagogik zentral. Gewiss sind die Grenzen fließend, sicherlich sind beide Formen konstruktiv aufeinander hingeordnet. ${ }^{21}$ Doch zeigt sich exemplarisch auf dem Feld Diakonischen Lernens der Überschuss des Politischen. Das diakonische Lernen, dem es vor allem um eine Änderung der Seh- und Denkgewohnheiten der Schülerinnen und Schüler geht, situiert sich durchaus im Rahmen einer Option für die Armen und Leidenden, bleibt aber letztlich »eine spezielle Art sozialen Lernens«, das inhaltlich durch das helfende und versöhnende Handeln Jesu qualifiziert wird. ${ }^{22}$ Fraglich ist nur, inwiefern dies dem politischen Charakter der biblischen Botschaft selber gerecht wird. Denn die Reduktion aufs Soziale unterläuft deren grundstürzende, transformatorische, kritisch-befreiende Pointe, die auch die gesellschaftlichökonomischen Strukturen kritisch reflektiert.

Damit wird die eigentliche Brisanz für die Öffentliche Religionspädagogik markiert. Indem diese sich von dem hier entwickelten Öffentlichkeitsbegriff zu denken und zu handeln gibt, werden soziale Kategorien stets mit politischen Kategorien korreliert. Nicht wird das Soziale immer schon ins Politische hinein übersteigert oder - umgekehrt - das Politische ohne das Soziale gedacht. Die festgehaltene Interdependenz zwischen der sozialen und politischen Ebene verdankt sich der Einsicht in die unüberholbare Bedeutung lebensweltlicher Erfahrungen gegenüber rein strukturell-institutionellen Vernetzungen, wie

19 | Vgl. Herdegen, Soziales und politisches Lernen 1999, 34f; Massing, Politische Bildung in der Grundschule 2007, $20 \mathrm{ff}$.

20 | Vgl. Massing, Politische Bildung in der Grundschule 2007, 31ff.; Siehe B 2.

21 | Vgl. Wohnig, Zum Verhältnis von sozialem und politischem Lernen 2017, 357-358.

22 | Schmidt, Diakonisches Lernen 2004, 9. Vgl. Langenhorst, Lernchance Solidarität 2000. 
sie Hannah Arendt, Jürgen Habermas oder Charles Taylor auf ihre jeweilige Weise betonen. Aber erst durch politisch-strukturelle Kategorien werden intersubjektive, partizipatorische Lernerfahrungen $\mathrm{zu}$ Wegen eines auch politisch kompetenten, praktischen Urteilsvermögens. ${ }^{23}$

Bezogen auf die Methodik und Didaktik des Religionsunterrichts machen damit politische Kategorien phänomenologische Wahrnehmungsprozesse von Fremdheit und Alterität sensibel für gesellschaftlich-strukturelle Wirkungsund Begründungszusammenhänge persönlicher Verantwortung. Umgekehrt bringen ästhetische Aspekte gegenüber einer strukturell-gesellschaftstheoretischen Annäherung Momente von Verlangsamung, Non-Funktionalität und Spiritualität ein. Die unverlierbare Erkenntnis performativer Religionspädagogik, dass Verstehen Praxis voraussetzt, wird durch den mehrdimensionalen Praxisbegriff vertieft. Christliche Praxis vorwiegend auf liturgische Elemente zu beziehen, hieße das Christentum in seinem komplexen Praxisbegriff ebenso $\mathrm{zu}$ reduzieren wie umgekehrt eine rein sozialmoralische Zugangsweise kulturhermeneutische und kognitiv-reflexive Momente außer Betracht ließe. Christentum als praktische Lebensform zu erschließen bedeutet auch, praktische Lebensvollzüge anzubahnen - in den Grenzen schulisch-institutionellen Lernens.

Durch den hier entwickelten Öffentlichkeitsbegriff wird aber der Performativitätsgedanke wesentlich geweitet. Performative Religionspädagogik, angesichts der Heterogenität der Schülerschaft und zunehmender Säkularisierungserfahrungen als probates Instrument religiösen Lernens angesehen, gewinnen durch solche politisch-öffentlichkeitsbezogenen Perspektiven an Tiefe, an Möglichkeiten expressiven Ausdrucks und zugleich an Sensibilität für hegemoniale Ordnungen und Machtfragen. Die Einsicht, die Bourdieu gegenüber der Sprechakttheorie geltend gemacht hat, wird religionspädagogisch folgenreich: »Wird eine Bezeichnung von etwas als etwas von einer autorisierten Sprecherin oder einem autorisierten Sprecher vorgenommen, zeitigt dies soziale Folgen. Sprechakte bilden daher nicht die Wirklichkeit ab, sondern greifen in die soziale Welt selbst ein und beteiligen sich auf diese Weise an der Aushandlung neuer Ordnungen. ${ }^{24}$ Die Auseinandersetzung mit Butlers performativer Öffentlichkeitstheorie hat das unausgeschöpfte Potential für leibbezogenes, ganzheitliches religiöses Lernen aufgezeigt, das hierdurch ihr kritisches wie emanzipatorisches Potential bis in außerschulische Horizonte hinein entfalten kann.

Die Kategorie des Raumes als Referenzpunkt religiöser Lernprozesse, wie dies bereits im spatial turn der Kulturwissenschaften und in Ansätzen der

23 | Vgl. Sander, Politik entdecken 2008, 160-164; Schlag, Horizonte demokratischer Bildung 2010, 496-537; Grümme, Religionsunterricht und Politik 2009, 40-43.180-182.

24 | Rieger-Ladich, Ordnung stiften 2017, 38. 
Systematischen Theologie bedacht wird, ist gerade aus solchen öffentlichkeitsrelevanten Gründen zu bedenken. Eine religionspädagogische Topologie, die über die Ansätze einer Rezeption der locus theologicus-Hermeneutik hinausginge, die fremde Orte, ungewöhnliche Plätze und abgeschiedene Regionen als religiöse Lernorte qualifizierte, wäre von der Öffentlichen Religionspädagogik weiter zu verfolgen. Hierzu gehören dann auch die Urbanitätskategorien, die Pastoral und Theologie in den Mega-Cities der Welt positionieren und sich auf die Suche nach Heterotopien als inspirierenden wie irritierenden Orten von Religion und Glauben machen. ${ }^{25}$

Die Implikationen dieses alteritätstheoretischen Öffentlichkeitsbegriffs reichen bis auf die Ebene der Wissenschaftstheorie. Eine kritisch-produktive Korrelierung der Dimensionen religionsunterrichtlichen Lernens, wie sie hier vorgeschlagen wird, impliziert die Vernetzung der maßgeblichen wissenschaftstheoretischen Ansätze. In einer beeindruckenden wissenschaftstheoretischen Grundlagenreflexion wurde jüngst diese Vernetzung von Wahrnehmungswissenschaften, Semiotik, Handlungswissenschaften, Empirische Wissenschaften, Ideologiekritik und Anwendungswissenschaften als eine im Muster jeweilig zu wählender Perspektiven präzise konturiert. ${ }^{26}$ Dieser wissenschaftstheoretischen Hermeneutik könnte der hier entfaltete Öffentlichkeitsbegriffs folgen, wenn diese Perspektivenfrage noch schärfer in den Kategorien der Öffentlichkeit und des zugrunde gelegten Öffentlichkeitsbegriffs entfaltet würde. Ansonsten droht diese Perspektivenvielfalt angesichts der hegemonialen Unterströmungen gegenwärtiger Verhältnisse ihre normative Kraft und inhaltliche Bestimmung einzubüßen.

\section{Religion als conversation stopper? Horizonte}

Nimmt man nun diese Perspektive des Religionsunterrichts abschließend als Ganzes in den Blick, wird etwas deutlich, was man sich religionspädagogisch in seiner Dramatik und Brisanz bislang nicht hinreichend klar macht: Der Religionsunterricht findet in sich selber bereits, nein, besser: konstituiert sich je schon als ein Abbild heterogener Öffentlichkeit. Nicht nur weisen die zunehmende Zahl von Flüchtlingen mit deren teilweise traumatisierter Religion, nicht nur weisen die wachsende Zahl an Nons, an nicht-konfessionell oder

25 | Vgl. Kaupp, Raumkonzepte in der Theologie 2016; Bauer, Konstellative Pastoraltheologie 2016. Die Vorordnung der Kategorie des Raumes vor der der Zeit ist in den postcolonial studies, in interkulturellen Forschungen wie auch befreiungstheologisch wichtig: Eckholt, An die Peripherie gehen 2015, 66-75; Sievernich, Wenzel, Aufbruch in die Urbanität 2013.

26 | Vgl. Heger, Wissenschaftstheorie 2017, 465-565. 
religiös Gebundenen, auf die Wirksamkeit makrosoziologischer Faktoren im Klassenzimmer hin. Es sind zudem die wachsenden gesellschaftlichen, sozialen und ökonomischen Differenzen in deren intersektionaler Verschärfung, die den Religionsunterricht zu einem Ort von zunehmender Heterogenität machen und damit wohl zu dem entscheidenden Bewährungsfeld religionspädagogischer Heterogenitätsfähigkeit werden lassen. Religionsunterricht kann nicht mehr im Paradigma der Pluralitätsfähigkeit angelegt sein, wenn er die Komplexität der gegenwärtigen Lebens- und Lernwelten nicht verfehlen will. Die Heterogenitätsforschung in der Religionspädagogik hat klar herausgestellt, dass die Fixierung auf rein religiöse und kulturelle Fragen zu kurz greift. Aspekte von sozialer Schichtung, von lebensweltlichen Segregationen spielen auf der Seite der Lehrenden wie der Lernenden stets mit hinein. Diese Interdependenz von Identitäts- und Gleichheitsfragen kann bis in die konkreten methodischen und didaktischen Arrangements des Religionsunterrichts hinein nachgewiesen werden. ${ }^{27}$

Auf diese komplexe wie heterogene Lage mit sich intensivierenden Übersetzungsforderungen an die Adresse der Religionslehrerinnen und Religionslehrer zu antworten, ist einerseits sach- und vor allem subjektgemäß. Lehrkräfte müssen von zwei Seiten her sinnstiftend und existenzerhellend übersetzen: von Seiten der Tradition und von Seiten der Lernenden. Andererseits wird dies trotz aller säkularisierenden Effekte religionsdidaktischer Arrangements der komplexen wie vielschichtigen Gegenwart des Religiösen im Religionsunterricht nicht gerecht. Ohne in die Fallen einer Rekatechesierung zu tappen, vor der selbst imponierende Ansätze performativer Religionspädagogik nicht in jeder Hinsicht geschützt zu sein scheinen, ist doch Religion im Klassenraum präsent, wie versteckt und wie herabtemperiert zu religiösen Selbstkonstruktionen der Subjekte auch immer. Hier treffen, wenngleich im diachronen Verlauf sicher mit wachsendem Gefälle in Richtung der Nons, die Schülerinnen und Schüler mit ihren jeweils ganz unterschiedlichen world views, ihren Glaubensüberzeugungen und religiösen Haltungen aufeinander. Auf diese Weise gewinnt der Religionsunterricht in zunehmenden Maße die Qualität einer Repräsentanz gesellschaftlicher Öffentlichkeit. Religionsunterricht trägt Öffentlichkeitscharakter. Obschon in pädagogisch normativer Sicht die Schule »Moratorium des Lebensernstes « sein soll, ${ }^{28}$ obschon didaktische Arrangements dezidiert aus diesem Verständnis eines gesellschaftlichen Schonraums heraus operieren, ist Schule schon lange nicht mehr ein solcher gesellschaftlich, sozial, kulturell und religiös exemter Ort. Wahrscheinlich ist diese

27 | Vgl. Grümme, School matters 2016; grundlegend Grümme, Bildungsgerechtigkeit 2014; Grümme, Heterogenität 2017, 245-285; Bohl u.a., Umgang mit Heterogenität in Schule und Unterricht 2017, 257-307.

28 | Dressler, Bildung-Religion-Kompetenz 2004, 263. 
Haltung ohnehin mehr Ideologie als Sachverhaltsfeststellung. Denn »indem die Organisationen des Bildungssystems diesem Moratorium eine materielle Gestalt verleihen, indem sie diese Gegenwelt auf symbolische Weise verkörpern, etablieren sie unweigerlich neue Ordnungen «. ${ }^{29}$ Eine solche kritische Dekonstruktion des Moratoriumbegriffs bedeutet religionsdidaktisch für den Religionsunterricht: Alle, die Nicht-Religiösen, religiös Gelangweilten und Interessierten, die Religiösen, die Gläubigen wie die religiös Gleichgültigen aus einer Teilnehmerperspektive heraus in dieser kleinen Öffentlichkeit diskursiv und im demokratischen Rahmen agonal zu Wort kommen und zugleich erfahrungsbezogen-affektiv wie leiblich vor-kommen zu lassen, dies didaktisch $\mathrm{zu}$ arrangieren und kritisch zu reflektieren, ist vor diesem Hintergrund ein wesentlicher, unverzichtbarer Bestandteil Öffentlicher Religionspädagogik. Denn in dieser bestimmten Form der Teilöffentlichkeit in der Schule liegt wohl eines der entscheidenden Unterscheidungsmerkmale zu derjenigen anderen Schulfächer. Religion muss, so gesehen, kein conversation stopper sein, wie Richard Rorty meint. ${ }^{30}$ Aber damit ist erst die Suche nach der Zukunftsfähigkeit seiner Gestaltung zwischen konfessioneller Ausrichtung und Offenheit für alle eröffnet. ${ }^{31}$

Damit wird insgesamt deutlich: Schülerinnen und Schüler motiviert, fähig und handlungsstark werden zu lassen, um sich selber in den unterschiedlichen Öffentlichkeiten zu engagieren, sich einzubringen und ihrerseits von dort her Impulse zu erfahren - hierzu könnte eine Öffentliche Religionspädagogik beitragen. Allerdings würde erst eine Öffentliche Religionspädagogik, die sich von dem hier entwickelten Öffentlichkeitsbegriff inspirieren lässt, jene Kraft, jenes Profil und jene Orientierung bekommen, die ihr bislang noch zu fehlen scheinen.

Das aber lenkt Blick zurück auf den Anfang. Wenn Religionspädagogik öffentlich wird, dann wird sie dies in einem politischen Sinne. Diese Einsicht in die Interdependenz struktureller, selbstreflexiver wie handlungstheoretischer Momente der Öffentlichkeit erfordert eine begriffliche Anschärfung und kontextualisierende Präzisierung der Kategorien. Bestärkt durch die Verortung der public theology in liberal-theologischen Traditionen unterhalb der politisch-strukturellen Ebene, ${ }^{32}$ verweist ein solcher Öffentlichkeitsbegriff die Öffentliche Religionspädagogik vorrangig auf die Politische Theologie als her-

29 | Rieger-Ladich, Ordnung stiften 2017, $34 \mathrm{f}$.

30 | Vgl. Rorty, Philosophy and Social Hope 1999, 169.

31 | Vgl. Kenngott u.a., Konfessionell 2015; Schröder, Religionsunterricht 2014; PohlPatalong, Konfessioneller Religionsunterricht 2016; Pohl-Patalong, Konfessioneller Religionsunterricht II 2017.

32 | Vgl. Höhne, Öffentliche Theologie 2015, $125 f$. 
meneutischen Referenzpunkt. Daran müsste deren noch zu schreibende Realisierung Maß nehmen. 



\section{Literatur}

Ahrens, Petra-Angela, Wegner, Gerhard, Soziokulturelle Milieus und Kirche. Lebensstile - Sozialstrukturen - kirchliche Angebote, Stuttgart 2013 Alexander, Hanan, Reimagining Liberal Education. Affiliation and Inquiry in Democrating Schooling, New York 2015 (E-Book)

Amos, Karin, Meseth, Wolfgang, Proske, Matthias, Öffentliche Erziehung revisited - Eine Einleitung; in: Amos, Karin, Meseth, Wolfgang, Proske, Matthias (Hg.), Öffentliche Erziehung revisited. Erziehung, Politik und Gesellschaft im Diskurs, Wiesbaden 2011, 9-32

Arendt, Hannah, Macht und Gewalt, München Zürich 1970

Arendt, Hannah, Über die Revolution, München 1963

Arendt, Hannah, Vita activa. Oder Vom tätigen Leben, München Zürich 1981

Arens, Edmund, Fundamentale Theologie im Anspruch kommunikativer Rationalität; in: Neuner, Peter (Hg.), Glaubenswissenschaft? Theologie im Spannungsfeld von Glaube, Rationalität und Öffentlichkeit (Quaestiones Disputatae 195), Freiburg i.Br. 2002, 57-76

Arens, Edmund, Gottesverständigung. Eine kommunikative Religionstheologie, Freiburg i.Br. 2007

Arens, Edmund, Ist Theologie Luxus? Ein Plädoyer für öffentliche Gottesrede; in: Arens, Edmund, Hoping Helmut (Hg.), Wieviel Theologie verträgt die Öffentlichkeit?, Freiburg i.Br. 2000, 171-194

Arens, Edmund, Kritisch, kirchlich, kommunikativ. Fundamentaltheologie als Öffentliche Theologie; in: Böttigheimer, Christoph, Bruckmann, Florian (Hg.), Glaubensverantwortung im Horizont der »Zeichen der Zeit« (Quaestiones Disputatae 248), Freiburg i.Br. 2012, 432-453

Arens, Edmund, Religion als Kommunikation. Religionstheoretische Konzeptionen und religionspädagogische Konsequenzen; in: Schreijäck, Thomas (Hg.), Christwerden im Kulturwandel. Analysen, Themen und Optionen für Religionspädagogik und Praktische Theologie, Freiburg i.Br. u.a. 2001 Arens, Edmund, Vom Schrei zur Verständigung. Politische Theologie als öffentliche Theologie; in: Polednitschek, Thomas, Rainer, Michael J., Zamora, José Antonio (Hg.), Theologisch-politische Vergewisserungen. Ein 
Arbeitsbuch aus dem Schüler- und Freundeskreis von Johann Baptist Metz, Berlin 2009, 129-138

Arens, Edmund, Hoping Helmut (Hg.), Wieviel Theologie verträgt die Öffentlichkeit?, Freiburg i.Br. 2000

Arens, Edmund, Manemann, Jürgen, Wie sollen wir zusammen leben? Zur

Diskussion über den Kommunitarismus; in: Jahrbuch Politische Theologie 1 (1996) 155-187

Asen, Robert, Seeking the »Counter « in Counterpublics; in: Communication Theory 4 (2000) 424-446

Aulenbacher, Brigitte, Dörre, Klaus, Michael Burawoys Soziologie - eine kapitalismus- und wissenschaftskritische Herausforderung; in: Burawoy, Michael (Hg.), Public Sociology. Öffentliche Soziologie gegen Marktfundamentalismus und globale Ungleichheit, Weinheim Basel 2015, 9-22

Austin, John L., Zur Theorie der Sprechakte. How to do things with Words, Stuttgart 1972

Baader, Meike Sophia, Diversity education. Zugänge, Perspektiven, Beispiele, Frankfurt a.M. 2013

Baader, Meike Sophia, Gender/Geschlecht; in: Wulf, Christoph, Zirfas, Jörg (Hg.), Handbuch Pädagogische Anthropologie, Wiesbaden 2014, 651-661

Bachmann-Medick, Doris, Cultural Turns. Neuorientierungen in den Kulturwissenschaften, Reinbek bei Hamburg 2014

Bauer, Christian, Denken in Konstellation? Pastoraltheologie als kontrastiver Mischdiskurs; in: Pastoraltheologische Informationen 2 (2015) 5-12

Bauer, Christian, Konstellative Pastoraltheologie. Erkundungen zwischen Diskursarchiven und Praxisfeldern, Stuttgart 2016

Beck, Ulrich, Der eigene Gott. Von der Friedensfähigkeit und dem Gewaltpotential der Religionen, Leipzig Frankfurt a.M. 2008

Bedford-Strohm, Heinrich, Bildung und Gerechtigkeit; in: Bednorz, Lars, Kühl-Freudenstein, Olaf, Kunzert, Magdalena (Hg.), Religion braucht Bildung - Bildung braucht Religion, Würzburg 2009, 39-52

Bedford-Strohm, Heinrich, Kirche in der Zivilgesellschaft; in: Weth, Rudolf (Hg.), Was hat die Kirche heute zu sagen? Auftrag und Freiheit der Kirche in pluralistischer Gesellschaft, Neukirchen-Vluyn 1998, 92-108

Bedford-Strohm, Heinrich, Öffentliche Theologie als Befreiungstheologie einer demokratischen Gesellschaft; in: Theologische Ethik der Gegenwart, Tübingen 2009, 167-182

Bedford-Strohm, Heinrich, Öffentliche Theologie in der Zivilgesellschaft; in: Gabriel, Ingeborg (Hg.), Politik und Theologie in Europa. Perspektiven ökumenischer Sozialethik, Mainz 2008, 340-366

Bedford-Strohm, Heinrich, Poverty and Public Theology. Advocacy of the Church in Pluralistic Society; in: International Journal of Public Theology 2 (2008) 144-162 
Bedford-Strohm, Heinrich, Vorrang für die Armen. Öffentliche Theologie als Befreiungstheologie für eine demokratische Gesellschaft; in: Nüssel, Friederike (Hg.), Theologische Ethik der Gegenwart. Ein Überblick über zentrale Ansätze und Themen, Tübingen 2009, 167-182

Bedford-Strohm, Heinrich, Nolte, Paul, Sachau, Rüdiger (Hg.), Kommunikative Freiheit. Interdisziplinäre Diskurse mit Wolfgang Huber, Leipzig 2014

Bedorf, Thomas, Verkennende Anerkennung. Über Identität und Politik, Berlin 2010

Bell, Catherine, Ritual Theory, Ritual Practice, Oxford $199^{2}$

Benhabib, Seyla, Die gefährdete Öffentlichkeit; in: Transit 13 (1997) 26-41

Benhabib, Seyla, Modelle des »öffentlichen Raums«. Hannah Arendt, die liberale Tradition und Jürgen Habermas; in: Benhabib, Seyla (Hg.), Selbst im Kontext. Kommunikative Ethik im Spannungsfeld von Feminismus, Kommunitarismus und Postmoderne, Frankfurt a.M. 1995, 96-130

Benhabib, Seyla, Models of the Public Space: Hannah Arendt, the Liberal Tradition and Jürgen Habermas; in: Calhoun, Craig (Hg.), Habermas and the Public Sphere, Massachusetts 1992, 73-98

Benhabib, Seyla, Selbst im Kontext. Kommunikative Ethik im Spannungsfeld von Feminismus, Kommunitarismus und Postmoderne, Frankfurt a.M. 1995

Benhabib, Seyla, The Uses and Abuses of Kantian Rigorism. On Rainer Forst's Moral and Political Philosophy; in: Political Theory 6 (2015) 777-792

Benner, Dietrich, Bildung und Religion. Nur einem bildsamen Wesen kann ein Gott sich offenbaren, Paderborn 2014

Biehl, Peter, Art.: Religionsdidaktische Konzeptionen; in: Bitter, Gottfried u.a. (Hg.), Neues Handbuch religionspädagogischer Grundbegriffe, München 2002

Binder, Ulrich, Oelkers, Jürgen (Hg.), Der neue Strukturwandel von Öffentlichkeit. Reflexionen in pädagogischer Perspektive, Weinheim, Basel 2017

Böckenförde, Ernst Wolfgang, Was heißt heute eigentlich >politisch«; in: Jahrbuch für Politische Theologie 2 (1995) 2-5

Böntert, Stefan, Objektive Feier und subjektiver Glaube? Beiträge zum Verhältnis von Liturgie und Spiritualität, Regensburg 2011

Böttigheimer, Christoph, Bruckmann, Florian (Hg.), Glaubensverantwortung im Horizont der »Zeichen der Zeit«, Freiburg i.Br. 2012

Bohl, Thorsten, Budde, Jürgen, Rieger-Ladich, Markus (Hg.), Umgang mit Heterogenität in Schule und Unterricht. Grundlagentheoretische Beiträge und didaktische Reflexionen, Bad Heilbrunn 2017

Bohmann, James, Expanding dialogue. The Internet, the public sphere and prospects for transnational democracy; in: Sociological Review 1 (2004) 131- 
Breul, Martin, Religiöse Epistemologie und öffentliche Religion. Zum erkenntnistheoretischen Status religiöser Überzeugungen; in: Könemann, Judith, Wendel, Saskia (Hg.), Religion, Öffentlichkeit, Moderne. Transdisziplinäre Perspektiven, Bielefeld 2016, 173-188

Breul, Martin, Religion in der politischen Öffentlichkeit. Zum Verhältnis von religiösen Überzeugungen und öffentlicher Rechtfertigung, Paderborn 2015

Bröckling, Ulrich, Das unternehmerische Selbst. Soziologie einer Subjektivierungsform, Frankfurt a.M. 2007

Bröckling, Ulrich, Gute Hirten führen sanft. Über Menschenregierungskünste, Berlin 2017

Brown, Wendy, Die schleichende Revolution. Wie der Neoliberalismus die Demokratie zerstört, Berlin 2015

Brüggen, Friedhelm, Art. Öffentlichkeit; in: Benner, Dietrich, Oelkers, Jürgen (Hg.), Historisches Wörterbuch der Pädagogik, Weinheim Basel 2010, 724749

Brumlik, Micha, Brunkhorst, Hauke (Hg.), Gemeinschaft und Gerechtigkeit, Frankfurt a.M. 1993

Brunkhorst, Hauke, Art.: Systemtheorie; in: Lenzen, Dieter (Hg.), Pädagogische Grundbegriffe, Reinbek bei Hamburg 2007 , 1480-1509

Brunkhorst, Hauke, Kreide, Regine, Lafont, Christina (Hg.), Habermas Handbuch, Stuttgart 2009

Bucher, Anton, Religionsunterricht zwischen Lernfach und Lebenshilfe. Eine empirische Untersuchung zum katholischen Religionsunterricht in der Bundesrepublik Deutschland, Stuttgart, Berlin 2000

Buck, Elisabeth, Bewegter Religionsunterricht, Göttingen 2004

Budde, Jürgen, Die Rede von der Heterogenität in der Schulpädagogik. Diskursanalytische Perspektiven; in: Forum Qualitative Sozialforschung. Forum Qualitative Social Research 2 (2012)

Budde, Jürgen, Einleitung; in: Budde, Jürgen, Unscharfe Einsätze. (Re-)Produktion von Heterogenität im schulischen Feld, Wiesbaden 2013, 7-28

Büttner, Gerhard, Scheunpflug, Anette, Eine Einleitung in das Buch; in: Büttner, Gerhard u.a. (Hg.), Zwischen Erziehung und Religion. Religionspädagogische Perspektiven nach Niklas Luhmann, Berlin 2007, 9-14

Burawoy, Michael (Hg.), Public Sociology. Öffentliche Soziologie gegen Marktfundamentalismus und globale Ungleichheit, Weinheim Basel 2015

Butler, Judith, Anmerkungen zu einer performativen Theorie der Versammlung, Berlin 2016

Butler, Judith, Die Macht der Geschlechternormen und die Grenzen des Menschlichen, Frankfurt a.M. 2009

Butler, Judith, Gefährdetes Leben. Politische Essays, Berlin 2005 
Butler, Judith, Haß spricht. Zur Politik des Performativen, Frankfurt a.M. 2006

Butler, Judith, Ist das Judentum zionistisch; in: Mendieta, Eduardo, VanAntwerpen, Jonathan (Hg.), Religion und Öffentlichkeit, Berlin 2012, 102-133

Butler, Judith, Kritik der ethischen Gewalt. Erweiterte Ausgabe, Frankfurt a.M. 2007

Butler, Judith, Psyche der Macht. Das Subjekt der Unterwerfung, Frankfurt a.M. 2002

Butler, Judith, Raster des Krieges. Warum wir nicht jedes Leid beklagen, Frankfurt a.M. 2010

Butler, Judith, Was ist Kritik? Ein Essay über Foucaults Tugend; in: Jaeggi, Rahel, Wesche, Tilo (Hg.), Was ist Kritik?, Frankfurt a.M. 2013, 221-246

Butler, Judith, Habermas, Jürgen, Taylor, Charles, West, Cornel, Abschlussdiskussion; in: Mendieta, Eduardo, VanAntwerpen, Jonathan (Hg.), Religion und Öffentlichkeit, Berlin 2012, 159-169

Cady, Linell E., H. Richard Niebuhr and the Task of a Public Theology; in: Thiemann, Ronald F. (Hg.), The Legacy of H. Richard Niebuhr, Minneapolis 1991, 119-126

Calhoun, Craig (Hg.), Habermas and the Public Sphere, Massachusetts 1992

Calhoun, Craig, Nachwort: Die vielen Mächte der Religion; in: Mendieta, Eduardo, VanAntwerpen, Jonathan (Hg.), Religion und Öffentlichkeit, Berlin 2012, 170-195

Casanova, José, Die religiöse Lage in Europa; in: Joas, Hans, Wiegandt, Klaus (Hg.), Säkularisierung und die Weltreligionen, Frankfurt a.M. 2007, 322357

Casanova, José, Public Religions in the Modern World, Chicago 1994

Casper, Bernhard, Religion der Erfahrung. Einführung in das Denken Franz Rosenzweigs, Paderborn 2004

Chung, Paul S., Public Theology in an Age of World Christianity. God's Mission as World-Event, New York 2010

Cooke, Maeve, Nicht zugänglich! Nicht verständlich! Nicht akzeptabel! Sind religiöse Wahrheitsansprüche ein Problem für den liberaldemokratischen Rechtsstaat?; in: Viertbauer, Klaus, Gruber, Franz (Hg.), Habermas und die Religion, Darmstadt 2017, 197-210

Dalferth, Ingolf U., Öffentlichkeit, Universität und Theologie; in: Arens, Edmund, Hoping Helmut (Hg.), Wieviel Theologie verträgt die Öffentlichkeit?, Freiburg i.Br. 2000, 38-72

D'Costa Gavin, Theology in the Public Square. Church, Academy and Nation, Oxford 2005

Dederich, Markus, Bildungsgerechtigkeit und Inklusion - Ein Problemaufriss; in: Meyer, Thomas, Vorholt, Udo (Hg.), Bildungsgerechtigkeit als politische Aufgabe, Bochum Freiburg 2011, 40-56 
Derrida, Jaques, Die Schrift und die Differenz, Frankfurt a.M. 1972

Dewey, John, Die Öffentlichkeit und ihre Probleme, Bodenheim 1996

Dierksmeier, Claus, Qualitative Freiheit. Selbstbestimmung in weltbürgerlicher Verantwortung, Bielefeld 2016

Dieterich, Veit-Jakobus, Fächerübergreifender Unterricht; in: Theo-Web 1 (2008) 17-27

Doak, Mary, Reclaiming Narrative for Public Theology, London 2004

Domsgen, Michael, Chancen und Grenzen einer Religionspädagogik in systemischer Perspektive. Eine Zwischenbilanz; in: Domsgen, Michael (Hg.), Religionspädagogik in Systemischer Perspektive. Chancen und Grenzen, Leipzig 2009, 141-154

Domsgen, Michael, Grundlagen und Ziele einer systemischen Religionspädagogik. Einführende Thesen; in: Domsgen, Michael (Hg.), Religionspädagogik in Systemischer Perspektive. Chancen und Grenzen, Leipzig 2009, 7-26

Domsgen, Michael, Religionsunterricht vom lernenden Subjekt aus profilieren und die prägende Kraft der Lernorte berücksichtigen. Religionsdidaktik mit systemischen Perspektiven; in: Grümme, Bernhard u.a. (Hg.), Religionsunterricht neu denken. Innovative Ansätze und Perspektiven der Religionsdidaktik, Stuttgart 2012, 198-209

Domsgen, Michael, Systemische Perspektiven als Rahmen einer neuen Verhältnisbestimmung von schulischer und außerschulischer Religionspädagogik; in: Theo-Web 9 (2010) 9-22

Dressler, Bernhard, Bildung - Religion - Kompetenz; in: Zeitschrift für Pädagogik und Theologie 56 (2004) 258-263

Dreyfus, Hubert L., Taylor, Charles, Die Wiedergewinnung des Realismus, Berlin 2016

Drilling, Matthias, Moral und Demokratieentwicklung. Perspektiven einer Synthese von schulischen und nichtschulischen Bildungsangeboten; in: Bierdermann, Horst, Oser, Fritz, Quesel, Carsten (Hg.), Vom Gelingen und Scheitern Politischer Bildung, Zürich 2007, 259-270

Dünne, Jörg, Günzel, Stephan (Hg.), Raumtheorie. Grundlagentexte aus Philosophie und Kulturwissenschaften, Frankfurt a.M. 2006

Eckholt, Margit, An die Peripherie gehen. In den Spuren des armen Jesus. Vom Zweiten Vatikanum zu Papst Franziskus, Ostfildern 2015

EKD, Maße des Menschlichen: Evangelische Perspektiven zur Bildung in der Wissens- und Lerngesellschaft. Eine Denkschrift der Evangelischen Kirche in Deutschland, Gütersloh 2003

Emmerich, Markus, Hormel, Ulrike, Heterogenität - Diversity - Intersektionalität. Zur Logik sozialer Unterscheidungen in pädagogischen Semantiken der Differenz, Wiesbaden 2013 
Englert, Rudolf, Braucht, wer von Bildung redet, ein Menschenbild? Ein Blick auf die EKD-Denkschrift »Maße des Menschlichen«; in: Jahrbuch der Religionspädagogik 20 (2004) 147-154

Englert, Rudolf, Wissenschaftstheorie der Religionspädagogik; in: Ziebertz, Hans-Georg, Simon, Werner (Hg.), Bilanz der Religionspädagogik, Düsseldorf 1995, 147-174

Eribon, Didier, Rückkehr nach Reims, Berlin 2017

Fassin, Didier, Das Leben. Eine kritische Gebrauchsanweisung, Berlin 2017

Fend, Helmut, Neue Theorie der Schule. Einführung in das Verstehen von Bildungssystemen, Wiesbaden 2008

Fenton, Natalie, Downey, John, Counter Public sphere and global modernity; in: Javnost - The Public. Community media in transition 1 (2003) 15-32

Forst, Rainer, Das Recht auf Rechtfertigung. Elemente einer konstruktivistischen Theorie der Gerechtigkeit, Frankfurt a.M. Berlin 2007

Forst, Rainer, Kontexte der Gerechtigkeit. Politische Philosophie jenseits von Liberalismus und Kommunitarismus, Frankfurt a.M. 1994

Forst, Rainer, Kritik der Rechtfertigungsverhältnisse. Perspektiven einer kritischen Theorie der Politik, Berlin 2011

Forst, Rainer, Normativität und Macht. Zur Analyse sozialer Rechtfertigungsordnungen, Berlin 2015

Forst, Rainer, Politische Freiheit; in: Schink, Philipp (Hg.), Freiheit. Zeitgenössische Texte zu einer philosophischen Kontroverse, Berlin 2017, 397-421

Forst, Rainer, Toleranz im Konflikt. Geschichte, Gehalt und Gegenwart eines umstrittenen Begriffs, Frankfurt a.M. 2014

Foucault, Michel, Das Subjekt und die Macht; in: Dreyfus, Hubert L., Rabinow, Paul (Hg.), Michel Foucault. Jenseits von Strukturalismus und Hermeneutik, Frankfurt a.M. 1987, 243-261

Foucault, Michel, Die Heterotopien. Der utopische Körper. Zwei Radiovorträge, zweisprachige Ausgabe, übersetzt von Michael Bischoff. Mit einem Nachwort von Daniel Defert, Frankfurt a.M. 2005

Foucault, Michel, Die Ordnung der Dinge. Eine Archäologie der Humanwissenschaften, Frankfurt a.M. 1990

Foucault, Michel, Die Ordnung des Diskurses, Frankfurt a.M. 1991

Foucault, Michel, Schriften III, Frankfurt a.M. 2003

Foucault, Michel, Schriften IV, Frankfurt a.M. 2005

Fraser, Nancy, Neue Überlegungen zur Öffentlichkeit. Ein Beitrag zur Kritik der real existierenden Demokratie; in: Fraser, Nancy (Hg.), Die halbierte Gerechtigkeit. Schlüsselbegriffe des postindustriellen Sozialstaats, Frankfurt a.M. 2001, 107-150

Fraser, Nancy, Öffentlichkeit neu denken. Ein Beitrag zur Kritik real existierender Demokratie; in: Scheich, Elvira (Hg.), Vermittelte Weiblichkeit. Feministische Wissenschafts- und Gesellschaftstheorie, Hamburg 1996, 151-182 
Fraser, Nancy, Honneth, Axel (Hg.), Umverteilung oder Anerkennung? Eine politisch-philosophische Kontroverse, Frankfurt a.M. 2003

Fresacher, Bernhard, Kommunikation. Verheißungen und Grenzen eines theologischen Leitbegriffs, Freiburg i.Br. 2006

Fritsch, Matthias, Rational Justification and Vulnerability. On the »All-Affected « Principle in Rainer Forst's Right to Justification; in: Political Theory 6 (2015) 805-821

Füllsack, Manfred, Die Habermas-Luhmann-Debatte; in: Kneer, Georg, Moebius, Stephan (Hg.), Soziologische Kontroversen. Beiträge zu einer anderen Geschichte der Wissenschaft vom Sozialen, Berlin 2010, 154-181

Füssel, Marian, Zur Aktualität von Michel Certeau. Einführung in sein Werk, Wiesbaden 2018

Gabriel, Karl, Gottesglaube, Theologie und Öffentlichkeit; in: Kläden, Tobias, Könemann, Judith, Stoltmann, Dagmar (Hg.), Kommunikation des Evangeliums (FS für Udo F. Schmälzle), Münster 2008, 259-272

Gärtner, Claudia, Religionsunterricht - ein Auslaufmodell? Begründungen und Grundlagen religiöser Bildung in der Schule, Paderborn 2015

Gehring, Petra, Lob der nicht privaten Vernunft. Volker Gerhardt über Bewusstsein und Öffentlichkeit; in: Deutsche Zeitschrift für Philosophie 2 (2013) 313-330

Gerhards, Jürgen, Öffentlichkeit; in: Jarren, Otfried, Sarcinelli, Ulrich, Saxer, Ulrich (Hg.), Politische Kommunikation in der demokratischen Gesellschaft, Opladen 1998, 268-274

Gerhards, Jürgen, Politische Öffentlichkeit. Ein system- und akteurtheoretischer Bestimmungsversuch; in: Neidhardt, Friedhelm (Hg.), Öffentlichkeit, öffentliche Meinung, soziale Bewegungen, Opladen 1994, 77-105

Gerhards, Jürgen, Neidhardt, Friedhelm, Strukturen und Funktionen moderner Öffentlichkeit. Fragestellungen und Ansätze, Berlin 1990

Gerhardt, Volker, Der Sinn des Sinns. Versuch über das Göttliche, München 2014

Gerhardt, Volker, Die Öffentlichkeit Gottes; in: Könemann Judith, Wendel, Saskia (Hg.), Religion, Öffentlichkeit, Moderne. Transdisziplinäre Perspektiven, Bielefeld 2016, 307-323

Gerhardt, Volker, Glauben und Wissen. Ein notwendiger Zusammenhang, Stuttgart 2016

Gerhardt, Volker, Immanuel Kants Entwurf »Zum ewigen Frieden«. Eine Theorie der Politik, Darmstadt 1995

Gerhardt, Volker, Öffentlichkeit. Die politische Form des Bewusstseins, München 2012

Geuss, Raymond, Privatheit. Eine Genealogie, Frankfurt a.M. 2002 
Goldstein, Jürgen, Perspektiven des politischen Denkens. Sechs Portraits, Hannah Arendt, Dolf Sternberger, John Rawls, Jürgen Habermas, Alasdair MacIntyre, Charles Taylor, Göttingen 2012

Goldstein, Jürgen, Säkularisierung als Vorsehung. Charles Taylors Erzählung der Moderne; in: Kühnlein, Michael, Lutz-Bachmann, Matthias (Hg.), Unerfüllte Moderne? Neue Perspektiven auf das Werk von Charles Taylor, Ber$\operatorname{lin} 2011,623-650$

Graf, Friedrich Wilhelm, Die Wiederkehr der Götter. Religion in der modernen Kultur, München 2004

Graham, Elaine, Rowlands, Anna (Hg.), Pathways to the Public Square. Practical Theology in an Age of Pluralism. International Academy of Practical Theology, Manchester 2003

Große Kracht, Hermann-Joseph, Kirche in ziviler Gesellschaft. Studien zur Konfliktgeschichte von katholischer Kirche und demokratischer Öffentlichkeit, Paderborn u.a. 1997

Grümme, Bernhard, Alteritätstheoretische Didaktik; in: Grümme, Bernhard, Lenhard, Hartmut, Pirner, Manfred L. (Hg.), Religionsunterricht neu denken. Innovative Ansätze und Perspektiven der Religionsdidaktik. Ein Arbeitsbuch für Studierende und Lehrer/innen, Stuttgart 2012, 119-132

Grümme, Bernhard, Auf Sand gebaut? Zur Bedeutung der Denkformen in der Debatte um Reflexionsdefizite in der Religionspädagogik; in: Theologie der Gegenwart 4 (2004) 266-279

Grümme, Bernhard, Bildungsgerechtigkeit. Eine religionspädagogische Herausforderung, Stuttgart 2014

Grümme, Bernhard, Heterogenität in der Religionspädagogik. Grundlagen und konkrete Bausteine, Freiburg i.Br. 2017

Grümme, Bernhard, Kinder im sensus fidei. Ein Versuch, ihren ekklesiologischen Ort zu bestimmen; in: Knapp, Markus, Söding, Thomas (Hg.), Glaube in Gemeinschaft. Autorität und Rezeption in der Kirche, Freiburg i.Br. 2014, 228-240

Grümme, Bernhard, Menschen bilden? Eine religionspädagogische Anthropologie, Freiburg i.Br. 2012

Grümme, Bernhard, Öffentliche Religionspädagogik. Religiöse Bildung in pluralen Lebenswelten, Stuttgart 2015

Grümme, Bernhard, Religionsunterricht und Politik. Bestandsaufnahme Grundsatzüberlegungen - Perspektiven für eine politische Dimension des RU, Stuttgart 2009

Grümme, Bernhard, School matters. Zur Relevanz von Schule und unterrichtlichem Handeln für einen bildungsgerechten Religionsunterricht; in: Grümme, Bernhard, Schlag, Thomas (Hg.), Gerechter Religionsunterricht. Religionspädagogische, pädagogische und sozialethische Orientierungen, Stuttgart 2016, 125-138 
Grümme, Bernhard, Sich aufs Spiel setzen. Zum Ansatz einer Öffentlichen Religionspädagogik; in: Religionspädagogische Beiträge 71 (2014) 87-97

Grümme, Bernhard, Vom Anderen eröffnete Erfahrung. Zur Neubestimmung des Erfahrungsbegriffs in der Religionsdidaktik, Freiburg i.Br. 2007

Grümme, Bernhard, Sander, Wolfgang, Von der »Vergegnung« (Martin Buber) zum Dialog? Das Verhältnis von Religionsdidaktik und Politikdidaktik; in: Pirner, Manfred, Schulte, Andrea (Hg.), Religionsdidaktik im Dialog (Studien zur Religionspädagogik und Praktischer Theologie, Bd. 2), Jena 2009, 171-193

Grümme, Bernhard, Schlag, Thomas (Hg.), Gerechter Religionsunterricht. Religionspädagogische, pädagogische und sozialethische Orientierungen, Stuttgart 2016

Günther, Klaus, Wingert, Lutz (Hg.), Die Öffentlichkeit der Vernunft und die Vernunft der Öffentlichkeit: Festschrift für Jürgen Habermas, Frankfurt a.M. 2001

Habermas, Jürgen, Ach, Europa. Kleine politische Schriften XI, Frankfurt a.M. 2008

Habermas, Jürgen, Der Strukturwandel der Öffentlichkeit. Untersuchungen zu einer Kategorie der bürgerlichen Gesellschaft, Frankfurt a.M. 1990

Habermas, Jürgen, Die Dialektik der Säkularisierung; in: Blätter für deutsche und internationale Politik 4 (2008) 33-46

Habermas, Jürgen, Die Einbeziehung des Anderen. Studien zur politischen Theorie, Frankfurt a.M. 1996

Habermas, Jürgen, Die postnationale Konstellation. Politische Essays, Frankfurt a.M. 1998

Habermas, Jürgen, Die Zukunft der menschlichen Natur. Auf dem Weg zur liberalen Eugenik?, Frankfurt a.M. 2005

Habermas, Jürgen, Ein Bewusstsein von dem, was fehlt; in: Reder, Michael, Schmidt, Josef (Hg.), Ein Bewusstsein von dem, was fehlt. Eine Diskussion mit Jürgen Habermas, Frankfurt a.M. 2008, 26-36

Habermas, Jürgen, Eine Replik; in: Reder, Michael, Schmidt, Josef (Hg.), Ein Bewusstsein von dem, was fehlt. Eine Diskussion mit Jürgen Habermas, Frankfurt a.M. 2008, 94-107

Habermas, Jürgen, Erläuterungen zur Diskursethik, Frankfurt a.M. 1991

Habermas, Jürgen, Faktizität und Geltung. Beiträge zur Diskurstheorie des

Rechts und des demokratischen Rechtsstaats, Frankfurt a.M. 1992

Habermas, Jürgen, Glauben und Wissen, Frankfurt a.M. 2001

Habermas, Jürgen, Kritik der Vernunft. Philosophische Texte, Band 5, Frankfurt a.M. 2009

Habermas, Jürgen, Nachmetaphysisches Denken II. Aufsätze und Repliken, Berlin 2012 
Habermas, Jürgen, Strukturwandel der Öffentlichkeit. Untersuchungen zu einer Kategorie der bürgerlichen Gesellschaft, Frankfurt a.M. 1990

Habermas, Jürgen, Texte und Kontexte, Frankfurt a.M. 1991

Habermas, Jürgen, Theorie des kommunikativen Handelns, Frankfurt a.M. 1981

Habermas, Jürgen, Wahrheit und Rechtfertigung. Philosophische Aufsätze, Frankfurt a.M. 1999

Habermas, Jürgen, Wieviel Religion verträgt der liberale. Staat? Über die schrille Polyfonie der Meinungen und ihre Filterung; in: Neue Züricher Zeitung, 04.08.2012, Nr. 179 (2012), S. 63-64.

Habermas, Jürgen, Zur Verfassung Europas. Ein Essay, Berlin 2011

Habermas, Jürgen, Zwischen Naturalismus und Religion. Philosophische Aufsätze, Frankfurt a.M. 2005

Habermas, Jürgen, Taylor, Charles, Diskussion; in: Mendieta, Eduardo, Van Antwerpen, Jonathan (Hg.), Religion und Öffentlichkeit, Berlin 2012, 89101

Hampe, Michael, Die Lehren der Philosophie. Eine Kritik. Erweiterte Ausgabe, Berlin 2016

Heger, Johannes, Wissenschaftstheorie als Perspektivenfrage?! Eine kritische Diskussion wissenschaftstheoretischer Ansätze der Religionspädagogik, Paderborn 2017

Heller, Agnes, Politik nach dem Tod Gottes; in: Jahrbuch Politische Theologie 2 (1997) 67-87

Herdegen, Peter, Soziales und politisches Lernen in der Grundschule. Grundlagen - Ziele - Handlungsfelder. Ein Lern- und Arbeitsbuch, Donauwörth 1999

Heuer, Wolfgang, Heiter, Bernd, Rosenmüller, Stefanie (Hg.), Arendt Handbuch. Leben - Werk - Wirkung, Stuttgart 2011

Higton, Mike, Christ, Providence \& History. Hans W. Frei's Public Theology, London 2004

Hochgeschwender, Michael, Amerikanische Religion. Evangelikalismus, Pfingstlertum und Fundamentalismus, Frankfurt a.M. Leipzig 2007

Höhn, Hans-Joachim, Postsäkular. Gesellschaft im Umbruch - Religion im Wandel, Paderborn 2007

Höhne, Florian, Öffentliche Theologie. Begriffsgeschichte und Grundfragen, Leipzig 2015

Höhne, Florian, Oorschot, Frederike van (Hg.), Grundtexte Öffentliche Theologie, Leipzig 2015

Hoff, Gregor Maria, Die Vernunft der Ordnungen, die Ordnungen der Vernunft. Die differenztheoretischen Spiegel der Fundamentaltheologie; in: Kruck, Günter, Valentin, Joachim (Hg.), Rationalitätstypen in der Theologie, Freiburg i.Br. 2017, 77-94 
Honneth, Axel, Das Ich im Wir. Studien zur Anerkennungstheorie, Berlin 2010

Honneth, Axel, Das Recht der Freiheit. Grundriß einer demokratischen Sittlichkeit, Berlin 2011

Honneth, Axel, Die zerrissene Welt des Sozialen. Sozialphilosophische Aufsätze, Frankfurt a.M. 2003

Honneth, Axel, Verdinglichung. Eine anerkennungstheoretische Studie, mit Kommentaren von Judith Butler, Raymond Geuss und Jonathan Lear und einer Erwiderung von Axel Honneth, Berlin 2015

Honneth, Axel, Saar, Martin, Geschichte der Gegenwart. Michel Foucaults Philosophie der Kritik; in: Michel Foucault, Die Hauptwerke. Mit einem Nachwort von Axel Honneth und Martin Saar, Frankfurt a.M. 2013, 16511682

Horkheimer, Max, Traditionelle und kritische Theorie; in: Zeitschrift für Sozialforschung 6 (1937) 245-294

Horster, Detlef, Jürgen Habermas. Eine Einführung, Darmstadt 2010

Huber, Wolfgang, Vorwort; in: Birch, Bruce C., Rasmussen, Larry L. (Hg.), Bibel und Ethik im christlichen Leben, Gütersloh 1993, 9-12

Hunze, Guido, Ein seltenes Gespräch. Was haben sich Naturwissenschaft und Religionspädagogik wissenschaftstheoretisch zu sagen; in: Boschki, Reinhold, Gronover, Matthias (Hg.), Junge Wissenschaftstheorie der Religionspädagogik, Münster 2007, 268-282

Imhof, Kurt, Die Krise der Öffentlichkeit. Kommunikation und Medien als Faktoren des sozialen Wandels, Frankfurt New York 2011

Imhof, Kurt, Theorie der Öffentlichkeit als Theorie der Moderne; in: Winter, Carsten, Hepp, Andreas, Krotz, Friedrich (Hg.), Theorien der Kommunikations- und Medienwissenschaft. Grundlegende Diskussionen, Forschungsfelder und Theorieentwicklungen, Wiesbaden 2008, 65-89

Jaeggi, Rahel, Entfremdung. Zur Aktualität eines sozialphilosophischen Problems. Mit einem neuen Nachwort, Berlin 2016

Jergus, Kerstin, Krüger, Jens Oliver, Schenk, Sabrina, Heterogenität - Zur Konjunktur eines pädagogischen Konzepts? Analysen der Kontingenz, Generativität und Performativität pädagogischer Artikulationen; in: Koller, HansChristoph u.a. (Hg.), Heterogenität. Zur Konjunktur eines pädagogischen Konzepts, Paderborn 2014, 149-168

Jergus, Kerstin, Schumann, Ira, Thompson, Christiane, Autorität und Autorisierung. Analysen zur Performativität des Pädagogischen; in: Ricken, Norbert, Balzer, Nicole (Hg.), Judith Butler. Pädagogische Lektüren, Wiesbaden 2012, 207-224

Joas, Hans, Braucht der Mensch Religion? Über Erfahrungen der Selbsttranszendenz, Freiburg i.Br. 2004

Joas, Hans, Die Entstehung der Werte, Frankfurt a.M. 1999 
Joas, Hans, Die Macht des Heiligen. Eine Alternative zur Geschichte von der Entzauberung, Berlin 2017

Joas, Hans, Glaube als Option. Zukunftsmöglichkeiten des Christentums, Freiburg i.Br. 2012

Joas, Hans, Knöbl, Wolfgang (Hg.), Sozialtheorie. Zwanzig einführende Vorlesungen, Frankfurt a.M. 2011

John, Ottmar, Diskursethik und Leidenserfahrungen. Die Auseinandersetzung mit dem Religionsbegriff des späten Habermas aus der Perspektive der politischen Theologie; in: Viertbauer, Klaus, Gruber, Franz (Hg.), Habermas und die Religion, Darmstadt 2017, 145-181

Kahrs, Christian, Öffentliche Bildung privater Religion. Plädoyer für einen »Fachbereich Religion « - obligatorisch für alle, Freiburg i.Br. 2009

Kant, Immanuel, Kritik der reinen Vernunft, Bd. 1, 2, hg. v. Weischedel, W. (Werkausgabe Bd. III, Bd. IV), Frankfurt a.M. 1990

Kaupp, Angela (Hg.), Raumkonzepte in der Theologie. Interdisziplinäre und interkulturelle Zugänge, Ostfildern 2016

Kellner, Douglas, Habermas, the Public Sphere, and Democracy. A Critical Intervention; in: Hahn, Lewis Edwin (Hg.), Perspectives on Habermas, Peru (Illinois) 2000, 259-288

Kenngott, Eva-Maria, Englert, Rudolf, Knauth, Thorsten (Hg.), Konfessionell - interreligiös - religionskundlich. Unterrichtsmodelle in der Diskussion, Stuttgart 2015

Kern, Bruno, »Es rettet uns kein höh'res Wesen«? Zur Religionskritik von Karl Marx - ein solidarisches Streitgespräch, Ostfildern 2017

Klingen, Henning, »Gefährdete Öffentlichkeit«. Zu einer Leerstelle politischtheologischer Gesellschaftskritik; in: Jahrbuch Politische Theologie 5 (2008) 156-181

Klingen, Henning, Gefährdete Öffentlichkeit. Zur Verhältnisbestimmung von Politischer Theologie und medialer Öffentlichkeit, Berlin 2008

Klöcker, Katharina, Freiheit im Fadenkreuz. Terrorbekämpfung als christlichethische Herausforderung, Freiburg i.Br. 2017

Knapp, Markus, Gott in säkularer Gesellschaft. Zum Gottesverständnis in Charles Taylors Philosophie der Religion; in: Kühnlein, Michael, LutzBachmann, Matthias (Hg.), Unerfüllte Moderne? Neue Perspektiven auf das Werk von Charles Taylor, Berlin 2011, 650-680

Knapp, Markus, Vernunft, Freiheit, Religion. Zur Kontroverse zwischen Charles Taylor und Jürgen Habermas; in: Kühnlein, Michael (Hg.), Kommunitarismus und Religion, Berlin 2010, 287-302

Knauth, Thorsten, Jochimsen, Maren A. (Hg.), Einschließungen und Ausgrenzungen. Zur Intersektionalität von Religion, Geschlecht und sozialem Status für religiöse Bildung, Münster 2017 
Könemann, Judith, Bildungsgerechtigkeit - (k)ein Thema religiöser Bildung? Normative Orientierungen in der Religionspädagogik; in: Könemann, Judith, Mette, Norbert (Hg.), Bildung und Gerechtigkeit. Warum religiöse Bildung politisch sein muss, Ostfildern 2013, 37-51

Könemann, Judith, Art.: Politische Religionspädagogik; in: Das wissenschaftlich-religionspädagogische Lexikon (www.wirelex.de), 2016 (Zugriffsdatum: 14.01.2018)

Könemann, Judith, Theologie, Kirche und Öffentlichkeit; in: Könemann, Judith, Wendel, Saskia (Hg.), Religion, Öffentlichkeit, Moderne. Transdisziplinäre Perspektiven, Bielefeld 2016, 129-152

Könemann, Judith, Mette, Norbert (Hg.), Bildung und Gerechtigkeit. Warum religiöse Bildung politisch sein muss, Ostfildern 2013

Kohl, Bernhard, Die Anerkennung des Verletzbaren. Eine Rekonstruktion der negativen Hermeneutik der Gottebenbildlichkeit aus den Anerkennungstheorien Judith Butlers und Axel Honneths und der Theologie Edward Schillebeeckx', Würzburg 2017

Kojima, Tomoko, Die Öffentlichkeiten der Erziehung. Eine historisch vergleichende Untersuchung, Wiesbaden 2015

Kokorschke, Albrecht, Hegel und wir, Berlin 2015

Koller, Hans-Christoph, Bildung anders denken. Einführung in die Theorie transformatorischer Bildungsprozesse, Stuttgart 2012

Konersmann, Ralf, Die Unruhe der Welt, Frankfurt a.M. 2015

Kreutzer, Ansgar, Politische Theologie für heute. Aktualisierungen und Konkretionen eines theologischen Programms, Freiburg i.Br. 2017

Krieger, Gerhard (Hg.), Zur Zukunft der Theologie in Kirche, Universität und Gesellschaft, Freiburg i.Br. 2017

Kühnlein, Michael (Hg.), Exodus, Exilpolitik und Revolution. Zur Politischen Theologie Michael Walzers, Tübingen 2017

Kühnlein, Michael, Immanente Ausdeutung und religiöse Option. Zur Expressivität des säkularen Zeitalters; in: Schmidt, Thomas M., Pitschmann, Annette (Hg.), Religion und Säkularisierung. Ein interdisziplinäres Handbuch, Stuttgart, Weimar 2014, 127-139

Kühnlein, Michael, Politische Theologie im Paradigmenwechsel. Zur Legitimitätsanalytik von Carl Schmitt und Michael Walzer; in: Kühnlein, Michael (Hg.), Exodus, Exilpolitik und Revolution. Zur Politischen Theologie Michael Walzers, Tübingen 2017, 195-218

Kühnlein, Michael, Lutz-Bachmann, Matthias (Hg.), Unerfüllte Moderne? Neue Perspektiven auf das Werk von Charles Taylor, Berlin 2011

Kühnlein, Michael, Lutz-Bachmann, Matthias (Hg.), Vermisste Tugend? Zur Philosophie Alasdair MacIntyres, Wiesbaden 2015

Laclau, Ernesto, Mouffe, Chantal, Hegemonie und radikale Demokratie. Zur Dekonstruktion des Marxismus, Wien 2012 
Ladwig, Bernd, Moderne politische Theorie, Schwalbach 2013

Langenhorst, Georg, Lernchance Solidarität. Diakonisches Lernen im Religionsunterricht; in: Religionspädagogische Beiträge 45 (2000) 103-113

Langthaler, Rudolf, Nagl-Docekal, Herta (Hg.), Glauben und Wissen. Ein Symposium mit Jürgen Habermas, Wien 2007

Laubach, Thomas, Sautermeister, Jochen, Klöcker, Katharina (Hg.), Gender Herausforderung für die christliche Ethik, Freiburg i.Br. 2017

Lenzen, Dieter (Hg.), Irritationen des Erziehungssystems. Pädagogische Resonanzen auf Niklas Luhmann, Frankfurt a.M. 2004

Leonhard, Silke, Leiblich lernen und lehren. Ein religionsdidaktischer Diskurs, Stuttgart 2006

Liedhegener, Antonius, Religion in Zivilgesellschaft. Öffentlichkeit und Politik in demokratischen politischen Systemen: Sechs Fallbeispiele und ein heuristisches Modell der empirischen politischen Theorie; in: Könemann, Judith, Wendel, Saskia (Hg.), Religion, Öffentlichkeit, Moderne. Transdisziplinäre Perspektiven, Bielefeld 2016, 93-128

Liedhegener, Antonius, Werkner, Ines-Jaqueline, Religion zwischen Zivilgesellschaft und politischem System. Befunde - Positionen - Perspektiven, Wiesbaden 2011

Liessmann, Konrad Paul, Bildung als Provokation, Wien 2017

Lilla, Mark, The once and future Liberal. After identity politics, New York 2017 Lösch, Bettina, Thimmel, Andreas (Hg.), Kritische politische Bildung. Ein Handbuch, Bonn 2011

Ludwig, Christian, Kritische Theorie und Kapitalismus. Die jüngere Kritische Theorie auf dem Weg zu einer Gesellschaftstheorie, Wiesbaden 2013

Lübbe, Hermann, Religion nach der Aufklärung, München 2004

Luhmann, Niklas, Die Gesellschaft der Gesellschaft, Frankfurt a.M. 1998

Luhmann, Niklas, Die Realität der Massenmedien, Opladen 1996

Luhmann, Niklas, Die Religion der Gesellschaft, Frankfurt a.M. 2002

Luhmann, Niklas, Die Wissenschaft der Gesellschaft, Frankfurt a.M. 1990

Luhmann, Niklas, Ökologische Kommunikation, Opladen 1986

Luhmann, Niklas, Politische Planung. Aufsätze zur Soziologie von Politik und Verwaltung, Wiesbaden 1971

Luhmann, Niklas, Soziale Systeme. Grundriß einer allgemeinen Theorie, Frankfurt a.M. 1984

Maclure, Jocely, Taylor, Charles (Hg.), Laizität und Gewissensfreiheit, Berlin 2011

Manemann, Jürgen, Das Politische in der Neuen Politischen Theologie; in: Jahrbuch Politische Theologie 5 (2008) 94-119

Manemann, Jürgen, Rettende Erinnerung an die Zukunft. Essay über die christliche Verschärfung, Mainz 2005 
Manemann, Jürgen, Über Freunde und Feinde. Brüderlichkeit Gottes, Kevelaer 2008

Manemann, Jürgen, Wacker, Bernd (Hg.), Politische Theologie - gegengelesen (Jahrbuch Politische Theologie 5), Berlin u.a. 2008

Marchart, Oliver, Das Agonale; in: Heuer, Wolfgang, Heiter, Bernd, Rosenmüller, Stefanie (Hg.), Arendt Handbuch. Leben - Werk - Wirkung, Stuttgart 2011, 263-264

Marchart, Oliver, Die politische Differenz. Zum Denken des Politischen bei Nancy, Lefort, Badiou, Laclau und Agamben, Berlin 2010

Marcinkowski, Frank, Politische Öffentlichkeit. Systemtheoretische Grundlagen und politikwissenschaftliche Konsequenzen; in: Hellmann, Kai-Uwe, Schmalz-Bruns, Reiner (Hg.), Theorie der Politik. Niklas Luhmanns politische Soziologie, Frankfurt a.M. 2002, 85-108

Markschies, Christoph, Gottes Körper. Jüdische, christliche und pagane Gottesvorstellungen in der Antike, München 2016

Marx, Reinhard, Zierer, Klaus, Glaube und Bildung. Ein Dialog zwischen Theologie und Erziehungswissenschaft, Paderborn 2013

Massing, Peter, Politische Bildung in der Grundschule - Überblick, Kritik, Perspektiven; in: Richter, Dagmar (Hg.), Politische Bildung von Anfang an, Bonn 2007, 18-35

McDermott, Gerald, One Holy and Happy Society. The Public Theology of Jonathan Edwards, Pennsylvania 1992

McKee, Alan, The Public Sphere: An Introduction, Cambridge 2005

Membe, Achille, Kritik der schwarzen Vernunft, Berlin 2014

Mendieta, Eduardo, VanAntwerpen, Jonathan, Einleitung: Die öffentliche Macht der Religion; in: Mendieta, Eduardo, VanAntwerpen, Jonathan (Hg.), Religion und Öffentlichkeit, Berlin 2012, 9-27

Mendl, Hans, Religion zeigen - Religion erleben - Religion verstehen. Ein Studienbuch zum performativen Religionsunterricht, Stuttgart 2016

Mendl, Hans, Religionsdidaktik Kompakt. Für Studium, Prüfung und Beruf, München 2011

Menke, Karl-Heinz, Macht die Wahrheit frei oder die Freiheit wahr? Eine Streitschrift, Regensburg 2017

Mette, Norbert, Nicht gleichgültig bleiben. Die soziale Botschaft von Papst Franziskus, Ostfildern 2017

Mette, Norbert, Sellmann, Matthias (Hg.), Religionsunterricht als Ort der Theologie, Freiburg i.Br. 2012

Metz, Johann Baptist, Glaube in Geschichte und Gesellschaft, Mainz 1984

Metz, Johann Baptist, Memoria passionis. Ein provozierendes Gedächtnis in pluralistischer Gesellschaft, Freiburg i.Br. 2006 
Metz, Johan Baptist, Monotheismus und Demokratie. Über Religion und Politik auf dem Boden der Moderne; in: Jahrbuch Politische Theologie 1 (1996) $39-52$

Metz, Johann Baptist, Zum Begriff der neuen Politischen Theologie 1967-1997, Mainz 1997

Meyer, Katrin, Theorien der Intersektionalität zur Einführung, Hamburg 2017 Meyer, Thomas, Was ist Politik? Second Edition, Wiesbaden 2010

Meyer-Drawe, Käte, Diskurse des Lernens, München 2008

Meyer-Wilmes, Hedwig, Ist Öffentlichkeit öffentlich? Kritische Anmerkungen zum Öffentlichkeitsbegriff aus feministisch-theologischer Sicht; in: Arens, Edmund, Hoping Helmut (Hg.), Wieviel Theologie verträgt die Öffentlichkeit?, Freiburg i.Br. 2000, 113-127

Miggelbrink, Ralf, Öffentliche Theologie. Neues zur Ortsbestimmung von Religion und Theologie; in: Theologische Revue 107 (2011) 443-455

Moegling, Klaus, Kompetenzaufbau im fächerübergreifenden Unterricht. Förderung vernetzten Denkens und komplexen Handelns, Immenhausen 2010

Moltmann, Jürgen, Gott im Projekt der modernen Welt. Beiträge zur öffentlichen Relevanz der Theologie, Gütersloh 1997

Mouffe, Chantal, Das demokratische Paradox. Aus dem Englischen von Oliver Marchart, Wien 2013

Mouffe, Chantal, Über das Politische. Wider die kosmopolitische Illusion, Frankfurt a.M. 2007

Müller, Hans-Peter, Pierre Bourdieu. Eine systematische Einführung, Berlin 2014

Müller-Doohm, Stefan, Jürgen Habermas. Eine Biographie, Berlin 2014

Mulsow, Martin, Stamm, Marcelo (Hg.), Konstellationsforschung, Frankfurt a.M. 2005

Nanz, Patrizia, Öffentlichkeit; in: Brunkhorst, Hauke, Lafont, Cristina, Kreide, Regine (Hg.), Habermas-Handbuch, Stuttgart 2009

Nassehi, Armin, Die letzte Stunde der Wahrheit, Hamburg 2017

Nassehi, Armin, Gesellschaft der Gegenwarten. Studien zur Theorie der modernen Gesellschaft II, Berlin 2011

Neidhardt, Friedhelm, Öffentlichkeit, öffentliche Meinung, soziale Bewegungen; in: Neidhardt, Friedhelm (Hg.), Öffentlichkeit, öffentliche Meinung, soziale Bewegungen, Opladen 1994, 7-41

Negt, Oskar, Kluge, Alexander, Öffentlichkeit und Erfahrung. Zur Organisationsanalyse von bürgerlicher und proletarischer Öffentlichkeit, Frankfurt 1977

Nipkow, Karl Ernst, Bildung in einer pluralen Welt, 2 Bde., Gütersloh 1998

Nipkow, Karl Ernst, Zur Bildungspolitik der evangelischen Kirche. Eine historisch-systematische Studie; in: Biehl, Peter, Nipkow, Karl Ernst (Hg.), 
Bildung und Bildungspolitik in theologischer Perspektive, Münster 2003, 153-251

Nöth, Winfried, Ipsen, Guido (Hg.), Körper - Verkörperung - Entkörperung. Body - Embodiment - Disembodiment, Kassel 2005

Oelkers, Jürgen, Öffentliche Bildung ohne Öffentlichkeit? Zum Verhältnis von Allgemeinbildung, neuen Medien und den Bürgern; in: Binder, Ulrich, Oelkers, Jürgen (Hg.), Der neue Strukturwandel von Öffentlichkeit. Reflexionen in pädagogischer Perspektive, Weinheim Basel 2017, 90-117

Oelkers, Jürgen, Tenorth, Heinz-Elmar (Hg.), Pädagogik, Erziehungswissenschaft und Systemtheorie, Weinheim, Basel 1987

Paul, Eugen, Geschichte der christlichen Erziehung. Antike und Mittelalter Bd. 1, Freiburg i.Br. 1993

Paul, Eugen, Geschichte der christlichen Erziehung. Barock und Aufklärung Bd. 2, Freiburg i.Br. 1995

Peters, Bernhard, Der Sinn von Öffentlichkeit. Mit einem Vorwort von Jürgen Habermas, Frankfurt a.M. 2007

Peters, Tiemo Rainer, Theologie und Politik in den Widersprüchen der Säkularisierung; in: Jahrbuch Politische Theologie 5 (2008) 80-93

Peukert, Helmut, Die Frage nach der Allgemeinbildung als Frage nach dem Verhältnis von Bildung und Vernunft; in: Pleines, Jürgen-Eckhardt (Hg.), Das Problem des Allgemeinen in der Bildungstheorie, Würzburg 1987, 6988

Peukert, Helmut, Erziehungswissenschaft - Religionswissenschaft - Theologie - Religionspädagogik; in: Groß, Engelbert (Hg.), Erziehungswissenschaft, Religion und Religionspädagogik, Münster 2004, 51-91

Pinker, Susan, Das Geschlechterparadox. Über begabte Mädchen, schwierige Jungs und den wahren Unterschied zwischen Männern und Frauen, Bonn 2009

Pirker, Viera, fluide und fragil. Identität als Grundoption zeitsensibler Pastoralpsychologie, Ostfildern 2013

Pirker, Viera, Wer hat dem wird gegeben? Zur bildungspolitischen Problematik der Ressourcen- (Un-)Gerechtigkeit in einer identitätsbildenden Religionspädagogik; in: Könemann, Judith, Mette, Norbert (Hg.), Bildung und Gerechtigkeit. Warum religiöse Bildung politisch sein muss, Ostfildern $2013,67-83$

Pirner, Manfred, Die blinden Flecken interreligiöser Kompetenzbildung. Bestandsaufnahme und Konsequenzen für ein Modell von interreligiöser und interweltanschaulicher Kompetenz im Horizont Öffentlicher Religionspädagogik; in: Heller, Thomas u.a. (Hg.), Festschrift für Michael Wermke, 2018 (im Erscheinen)

Pirner, Manfred, Öffentliche Religionspädagogik. Neue Perspektiven für komplementäres Lernen von religiösen und nicht religiösen Schülerinnen und 
Schülern im Religionsunterricht. GPM-Arbeitshilfe für den ev. Religionsunterricht an Gymnasien (Jahresband 2015), 62-81

Pirner, Manfred, Öffentliche Religionspädagogik im globalen Horizont. Perspektiven für evangelische Schulen; in: Scheunpflug, Annette, Simojoki, Henrik (Hg.), (Schadeberg-Vorlesungen) 2018 (im Erscheinen)

Pirner, Manfred, Religion und öffentliche Vernunft. Impulse aus der Diskussion um die Grundlagen liberaler Gesellschaften für eine Öffentliche Religionspädagogik; in: Zeitschrift für Pädagogik und Theologie 4 (2015) 310-318

Pirner, Manfred, Re-präsentation und Übersetzung als zentrale Aufgaben einer Öffentlichen Theologie und Religionspädagogik; in: Evangelische Theologie 6 (2015) 446-458

Pirner, Manfred, Übersetzung. Zur Bedeutung einer fundamentaltheologischen Kategorie für kirchliche Bildungsverantwortung; in: Meier, Gernot (Hg.), Reflexive Religionspädagogik. Impulse für die kirchliche Bildungsarbeit in Schule und Gemeinde, Stuttgart 2012, 79-88

Pirner, Manfred. L., Lähnemann, Johannes, Haussmann, Werner, Schwarz, Susanne (eds.), Public Theology, Religious Diversity and Interreligious Learning (Volume I/II), London New York 2018

Pirner, Manfred, Schulte, Andrea (Hg.), Religionsdidaktik im Dialog (Studien zur Religionspädagogik und Praktischer Theologie, Bd. 2), Jena 2009

Platzbecker, Paul, Religiöse Bildung als Freiheitsgeschehen. Konturen einer religionspädagogischen Grundlagentheorie, Stuttgart 2013

Pohl-Patalong, Uta u.a. (Hg.), Konfessioneller Religionsunterricht in religiöser Vielfalt. Eine empirische Studie zum evangelischen Religionsunterricht in Schleswig-Holstein, Stuttgart 2016

Pohl-Patalong, Uta u.a. (Hg.), Konfessioneller Religionsunterricht in religiöser Vielfalt II. Perspektiven von Schülerinnen und Schülern, Stuttgart 2017

Polke, Christian, Öffentliche Religion in der Demokratie. Eine Untersuchung zur weltanschaulichen Neutralität des Staates, Leipzig 2009

Pollack, Detlef, Art.: Säkularisierung; in: Das wissenschaftlich-religionspädagogische Lexikon (www.wirelex.de) 2016 (Zugriffsdatum: 05.02.2018)

Pröpper, Thomas, Evangelium und freie Vernunft. Konturen einer theologischen Hermeneutik, Freiburg i.Br. 2001

Rawls, John, Political Liberalism, New York 1993

Reckwitz, Andreas, Die Gesellschaft der Singularitäten. Zum Strukturwandel der Moderne, Berlin 2017

Reder, Michael, Liberal, deliberativ oder dekonstruktivistisch? Rorty, Habermas und Derrida über das Verhältnis von Religion und Gesellschaft; in: Viertbauer, Klaus, Gruber, Franz (Hg.), Habermas und die Religion, Darmstadt 2017, 125-142 
Reder, Michael, Öffentlichkeit und Liberalismus. Eine pragmatistische Neubestimmung anhand des Verhältnisses von Öffentlichkeit und Religion; in: Könemann, Judith, Wendel, Saskia (Hg.), Religion, Öffentlichkeit, Moderne. Transdisziplinäre Perspektiven, Bielefeld 2016, 227-256

Reder, Michael, Religion in säkularer Gesellschaft. Über die neue Aufmerksamkeit für Religion in der politischen Philosophie, Freiburg i.Br. München 2013

Reder, Michael, Schmidt, Josef (Hg.), Ein Bewusstsein von dem, was fehlt. Eine Diskussion mit Jürgen Habermas, Frankfurt a.M. 2008

Rendle, Ludwig (Hg.), Ganzheitliche Methoden im Religionsunterricht, München 2007

Renn, Joachim, Straub, Jürgen, Shimada, Shingo (Hg.), Übersetzung als Medium des Kulturverstehens und sozialer Integration, Frankfurt a.M. New York 2002

Renn, Joachim, Straub, Jürgen, Shimada, Shingo, Vorwort der Herausgeber; in: Renn, Joachim, Straub, Jürgen, Shimada, Shingo (Hg.), Übersetzung als Medium des Kulturverstehens und sozialer Integration, Frankfurt a.M., New York 2002, 7-12

Renner, Tobias, Postsäkulare Gesellschaft und Religion. Zum Spätwerk Jürgen Habermas, Freiburg i.Br. 2017

Ricoeur, Paul, Das Selbst als ein Anderer, München 1996

Riedl, Anna Maria, Ethik an den Grenzen der Souveränität. Christliche Sozialethik im Dialog mit Judith Butler unter Berücksichtigung des Kindeswohlbegriffs, Paderborn 2017

Riegel, Ulrich, Art.: Pluralisierung; in: Das wissenschaftlich-religionspädagogische Lexikon (www.wirelex.de) 2016 (Zugriffsdatum: 14.01.2018)

Riegel, Ulrich, Rezension zu Bernhard Grümme, Öffentliche Religionspädagogik; in: Theologische Revue 5 (2016) 339-341

Rieger-Ladich, Markus, Ordnung stiften, Differenzen markieren. Machttheoretische Überlegungen zur Rede von Heterogenität; in: Bohl, Thorsten, Budde, Jürgen, Rieger-Ladich, Markus (Hg.), Umgang mit Heterogenität in Schule und Unterricht, Stuttgart 2017, 27-42

Riescher, Gisela, Demokratische Freiheit und die Sicherheit des Leviathan; in: Gisela Riescher (Hg.), Sicherheit und Freiheit statt Terror und Angst. Perspektiven einer demokratischen Sicherheit, Baden-Baden 2010, 11-24

Ricken, Norbert, Bildsamkeit und Sozialität. Überlegungen zur Neufassung eines Topos pädagogischer Anthropologie; in: Ricken, Norbert, Balzer, Nicole (Hg.), Judith Butler. Pädagogische Lektüren, Wiesbaden 2012, 329-352

Ricken, Norbert, Die Ordnung der Bildung. Beiträge zu einer Genealogie der Bildung, Wiesbaden 2006

Ricken, Norbert, Balzer, Nicole (Hg.), Judith Butler. Pädagogische Lektüren, Wiesbaden 2012 
Rösner, Hans-Uwe, Auf's Spiel gesetzte Anerkennung. Judith Butlers Bedeutung für eine kulturwissenschaftlich orientierte Heilpädagogik; in: Ricken, Norbert, Balzer, Nicole (Hg.), Judith Butler. Pädagogische Lektüren, Wiesbaden 2012, 373-398

Rorty, Richard, Philosophy and Social Hope, London 1999

Rosa, Hartmut, Art.: Kommunitarismus; in: Düwell, Marcus, Hübenthal, Christoph, Werner, Micha H. (Hg.), Handbuch Ethik, Stuttgart 2011, 218231

Rosa, Hartmut, Gelingendes Leben in der Beschleunigungsgesellschaft. Resonante Weltbeziehungen als Schlüssel zur Überwindung der Eskalationsdynamik der Moderne; in: Kläden, Tobias, Schüßler, Michael (Hg.), $\mathrm{Zu}$ schnell für Gott? Theologische Kontroversen zu Beschleunigung und Resonanz, Freiburg i.Br. 2017, 18-51

Rosa, Hartmut, Identität und kulturelle Praxis. Politische Philosophie nach Charles Taylor, Frankfurt a.M., New York 1998

Rosa, Hartmut, Is There Anybody Out There? Stumme und resonante Weltbeziehungen - Charles Taylors monomanischer Analysefokus; in: Kühnlein, Michael, Lutz-Bachmann, Matthias (Hg.), Unerfüllte Moderne? Neue Perspektiven auf das Werk von Charles Taylor, Berlin 2011, 15-43

Rosa, Hartmut, Resonanz. Eine Soziologie der Weltbeziehungen, Berlin 2016

Rosa, Hartmut, Weltbeziehungen im Zeitalter der Beschleunigungen. Umrisse einer neuen Gesellschaftskritik, Berlin 2012

Rose, Nadine, »Alle unterschiedlich!«. Heterogenität als neue Normalität; in: Koller, Hans-Christoph u.a. (Hg.), Heterogenität. Zur Konjunktur eines pädagogischen Konzepts, Paderborn 2014

Rothgangel, Martin, Religionspädagogik im Dialog I. Disziplinäre und interdisziplinäre Grenzgänge, Stuttgart 2014

Rudolph, Enno, Rousseau absconditus. Zur Kritik der Taylorschen Liberalismuskritik; in: Kühnlein, Michael, Lutz-Bachmann, Matthias (Hg.), Unerfüllte Moderne? Neue Perspektiven auf das Werk von Charles Taylor, Berlin 2011, 107-116

Salvatore, Armando, The Public Sphere. Liberal Modernity, Catolicism, Islam, New York 2007

Sandel, Michael, Liberalism and the Limits of Justice, Cambridge 1982

Sander, Hans-Joachim, Einführung in die Gotteslehre, Darmstadt 2016

Sander, Hans-Joachim, Macht; in: Büchner, Christine, Spalle, Gerrit (Hg.), Auf den Punkt gebracht. Grundbegriffe der Theologie, Ostfildern 2017, 145-157

Sander, Wolfgang, Politik entdecken - Freiheit leben. Didaktische Grundlagen politischer Bildung, Schwalbach/Ts. 2008

Sander, Wolfgang, Politik in der Schule. Kleine Geschichte der politischen Bildung in Deutschland, Marburg 2004 
Sander, Wolfgang, Politische Bildung als fächerübergreifende Aufgabe in der Schule; in: Sander, Wolfgang (Hg.), Handbuch politische Bildung 2005, 254-264

Sander, Wolfgang, Politische Bildung im Religionsunterricht. Eine Untersuchung zur politischen Dimension der Religionspädagogik, Stuttgart 1980

Sander, Wolfgang, Politische Bildung in den Fächern der Schule. Beiträge zur politischen Bildung als Unterrichtsprinzip, Stuttgart 1985

Sattler, Dorothea, Beziehungsdenken in der Erlösungslehre. Bedeutung und Grenzen, Freiburg i.Br. 1997

Scheunpflug, Annette, Mette, Norbert, Anregungen aus Sicht einer systemtheoretischen Erziehungswissenschaft für das Verständnis eines Religionsunterrichts; in: Büttner, Gerhard u.a. (Hg.), Zwischen Erziehung und Religion. Religionspädagogische Perspektiven nach Niklas Luhmann, Berlin 2007, 41-54

Schieder, Rolf, Sind Religionen gefährlich? Religionspolitische Perspektiven für das 21. Jahrhundert, Berlin 2011

Schieder, Rolf, Vom erwählten Volk zum Volk, was wählt. Michael Walzers negative politische Theologie; in: Kühnlein, Michael (Hg.), Exodus, Exilpolitik und Revolution. Zur Politischen Theologie Michael Walzers, Tübingen 2017, 121-146

Schieder, Rolf, Wieviel Religion verträgt Deutschland, Frankfurt a.M. 2001

Schieder, Rolf, Meyer-Magister, Hendrik, Neue Rollen der Religion; in: Aus Politik und Zeitgeschichte 24/63 (2013) 28-34

Schiewe, Jürgen, Öffentlichkeit als Begriff; in: Schiewe, Jürgen (Hg.), Öffentlichkeit. Entstehung und Wandel in Deutschland. Paderborn 2004, 19-61

Schink, Philipp (Hg.), Freiheit. Zeitgenössische Texte zu einer philosophischen Kontroverse, Berlin 2017

Schlag, Thomas, Horizonte demokratischer Bildung. Evangelische Religionspädagogik in politischer Perspektive, Freiburg i.Br. 2010

Schlag, Thomas, Öffentliche Kirche. Grunddimensionen einer praktisch-theologischen Kirchentheorie, Theologische Studien Bd. 5, Zürich 2012

Schluß, Henning, Religiöse Bildung im öffentlichen Interesse. Analysen zum Verhältnis von Pädagogik und Religionen, Wiesbaden 2010

Schmidinger, Heinrich, Zichy, Michael (Hg.), Tod des Subjekts? Poststrukturalismus und christliches Denken, Innsbruck 2005

Schmidt, Heinz, Diakonisches Lernen. Grundlagen, Kontexte, Motive und Themen; in: Hanisch, Helmut, Schmidt, Heinz (Hg.), Diakonische Bildung. Theorie und Empirie, Heidelberg 2004, 9-15

Schmidt, Thomas M., Pitschmann, Annette (Hg.), Religion und Säkularisierung. Ein interdisziplinäres Handbuch, Stuttgart 2014

Schnädelbach, Herbert, Vernunft, Stuttgart 2007 
Schreiner, Martin, Das Verhältnis des Religionsunterrichts zu anderen Fächern; in: Rothgangel, Martin, Adam, Gottfried, Lachmann, Rainer (Hg.), Religionspädagogisches Kompendium, Göttingen 2012, 191-206

Schröder, Bernd, Öffentliche Religionspädagogik. Perspektiven einer theologischen Disziplin; in: Zeitschrift für Theologie und Kirche 110 (2013) 109-132

Schröder, Bernd, Religionspädagogik, Tübingen 2012

Schröder, Bernd (Hg.), Religionsunterricht - wohin? Modelle seiner Organisation und didaktischen Struktur, Neukirchen-Vluyn 2014

Schröder, Bernd, Theologische Bildung im öffentlichen Raum; in: Schlag, Thomas, Suhner, Jasmina (Hg.), Theologie als Herausforderung religiöser Bildung. Bildungstheoretische Orientierungen zur Theologizität der Religionspädagogik, Stuttgart 2017, 151-178

Schüssler Fiorenza, Francis u.a. (Hg.), Politische Theologie. Neuere Geschichte und Potenziale, Neukirchen-Vluyn 2011

Schweiker, Wolfgang, Prinzip Inklusion. Grundlagen einer interdisziplinären Metatheorie in religionspädagogischer Perspektive, Göttingen 2017

Schweitzer, Friedrich, Bildung, Neukirchen-Vluyn 2014

Schweitzer, Friedrich, Das lernende Subjekt - zwischen Konstruktion und Biographie. Überlegungen zu Sinn und Grenzen systemischer Ansätze in der Religionspädagogik; in: Domsgen, Michael (Hg.), Religionspädagogik in Systemischer Perspektive. Chancen und Grenzen, Leipzig 2009, 93-112

Schweitzer, Friedrich, Mehr als eine Privatangelegenheit! Perspektiven einer Religionspädagogik in der Zivilgesellschaft; in: Bitter, Gottfried, BlasbergKuhnke, Martina (Hg.), Religion und Bildung in Kirche und Gesellschaft. Für Norbert Mette, Würzburg 2011, 164-173

Schweitzer, Friedrich, Rezension zu Bernhard Grümme, Öffentliche Religionspädagogik; in: Theologische Literaturzeitung 9 (2016) 993-995

Schweitzer, Friedrich, Zivilgesellschaft - Schule - Religion. Welchen Religionsunterricht braucht eine zivilgesellschaftliche Demokratie?; in: Schweitzer, Friedrich, Scheilke, Christoph T. (Hg.), Religion, Ethik, Schule. Bildungspolitische Perspektiven in der pluralen Gesellschaft, Münster 1999, 195-307

Seibert, Christoph, »An ihren Früchten werdet ihr sie erkennen«. Überlegungen zu einem pragmatistischen Rationalitätsverständnis und seiner theologischen Bedeutsamkeit; in: Kruck, Günter, Valentin, Joachim (Hg.), Rationalitätstypen in der Theologie, Freiburg i.Br. 2017, 149-175

Sellmann, Matthias, Milieuverengung als Gottesverengung; in: Lebendige Seelsorge 4 (2006) 284-289

Sennett, Richard, Der Verfall des öffentlichen Lebens. Die Tyrannei der Intimität, Frankfurt a.M. 1998

Sennett, Richard, The Fall of Public Man, Cambridge 1977

Sievernich, Michael, Wenzel, Knut (Hg.), Aufbruch in die Urbanität. Theologische Reflexionen kirchlichen Handelns in der Stadt, Freiburg i.Br. 2013 
Simojoki, Henrik, Globalisierte Religion. Ausgangspunkte, Maßstäbe und Perspektiven religiöser Bildung in der Weltgesellschaft, Tübingen 2012

Sinner, Rudolf, Öffentliche Theologie. Neue Ansätze in globaler Perspektive; in: Evangelische Theologie 05/71 (2011) 324-340

Smith, James K.A., How (not) to be secular. Reading Charles Taylor, Cambridge 2014

Sobrino, Jon, Kritik an den heutigen Demokratien und Wege zu ihrer Humanisierung von der biblischen Tradition her; in: Concilium 4 (2007) 439-453

Stackhouse, Max L., Public Theology and Political Economy. Christian Stewardship in Modern Society, Grand Rapids 1987

Steinkamp, Hermann, Lange Schatten der Pastoralmacht. Theologischkritische Rückfragen, Münster 2015

Storrar, William F., Morton, Andrew R. (Hg.), Public Theology for the 21st Century. Essays in Honour of Duncan B. Forrester, London 2004

Strasser, Stephan, Jenseits von Zeit und Sein. Eine Einführung in Emmanuel Levinas' Philosophie, Paris 1978

Striet, Magnus, Sich selbst als geworden beschreiben wollen. Theologie und Soziologie; in: Goertz, Stephan Striet, Magnus (Hg.), »Nicht außerhalb der Welt«. Theologie und Soziologie, Freiburg i.Br. 2014, 13-32

Taylor, Charles, Das Unbehagen an der Moderne, Frankfurt a.M. 1995

Taylor, Charles, Die Formen des Religiösen in der Gegenwart, Frankfurt a.M. 2002

Taylor, Charles, Dilemmas and Connections, Cambridge 2011

Taylor, Charles, Ein säkulares Zeitalter, Frankfurt a.M. 2009

Taylor, Charles, Für eine grundlegende Neubestimmung des Säkularismus; in: Mendieta, Eduardo, VanAntwerpen, Jonathan (Hg.), Religion und Öffentlichkeit, Berlin 2012, 53-88

Taylor, Charles, Modern Social Imaginaries, Durham, London 2004

Taylor, Charles, Multikulturalismus und die Politik der Anerkennung, Frankfurt a.M. 2009

Taylor, Charles, Negative Freiheit? Zur Kritik des neuzeitlichen Individualismus, Frankfurt a.M. 1992

Taylor, Charles, Quellen des Selbst. Die Entstehung der neuzeitlichen Identität, Frankfurt a.M. 1996

Taylor, Charles, Replik; in: Kühnlein, Michael, Lutz-Bachmann, Matthias (Hg.), Unerfüllte Moderne? Neue Perspektiven auf das Werk von Charles Taylor, Berlin 2011, 821-861

Taylor, Charles, The Language Animal. The full shape of the Human Linguistic Capacity, Cambridge 2016

Telser, Andreas, Habermas und die Öffentliche Theologie; in: Viertbauer, Klaus, Gruber, Franz (Hg.), Habermas und die Religion, Darmstadt 2017, $182-196$ 
Telser, Andreas, Theologie als öffentlicher Diskurs. Zur Relevanz der Systematischen Theologie David Tracys, Innsbruck, Wien 2016

Themenheft Öffentliche Religionspädagogik jenseits kirchlicher Bildungsverantwortung, Theo-Web 1 (2016)

Themenheft Religionspädagogik und Öffentlichkeit, Zeitschrift für Pädagogik und Theologie 4 (2015)

Theological Roundtable, Theology in the Public Sphere in the Twenty-First Century; in: Horizons 43 (2016), 351-373

Thiem, Annika, Unbecoming subjects. Judith Butler, Moral Philosophy and critical responsibility, New York 2008

Tracy, David, Religion in the Public Realm: Three Forms of Publicness; in: Barbierie, William A. (Hg.), At the Limits of the Secular. Reflections on Faith and Public Life, Grand Rapids 2014, 29-50

Tracy, David, The Analogical Imagination. Christian Theology and the Culture of Pluralism, London 1981

Turner, Charles, Habermas' Öffentlichkeit. A reception history; in: Critical Review of International Social and Political Philosophy 2 (2009) 225-241

Uhl, Florian, Vom Ritual zur Sprache - Von der Sprache zum Ritual. Jürgen Habermas< Beitrag zur Religionsphilosophie; in: Viertbauer, Klaus, Gruber, Franz (Hg.), Habermas und die Religion, Darmstadt 2017, 256-270

Viertbauer, Klaus, Gruber, Franz (Hg.), Habermas und die Religion, Darmstadt 2017

Villagrán, Gonzalo, The Future of Catholic Public Theology. Mediating the Church and the World in Pluralistic Societies; in: Ahern, Kevin (Hg.), Visions of Hope. Emerging Theologians and the Future of the Church, Mariknoll 2013, 151-166

Vögele, Wolfgang, Zivilreligion in der Bundesrepublik Deutschland, Gütersloh 1994

Wagner, Thomas, Die Angstmacher. 1968 und die Neuen Rechten, Berlin 2017

Waldenfels, Bernhard, Das leibliche Selbst. Vorlesungen zur Phänomenologie des Leibes, Frankfurt a.M. 2000

Walzer, Michael, Political Theology. Response; in: Kühnlein, Michael (Hg.), Exodus, Exilpolitik und Revolution. Zur Politischen Theologie Michael Walzers, Tübingen 2017, 331-339

Walzer, Michael, The Politics of Michel Foucault; in: Hoy, David C. (Hg.), Foucault. A Critical Reader, Cambridge u.a. 1986, 51-68

Webb, Willie James, The Way Out of Darkness. Vital Public Theology, Bloomington 2007

Weber, Anne, Zwischen Kampf um Anerkennung, lebensweltlichen Krisenphänomenen und herrschaftsfreier Verständigung. Eine Befundanalyse im Horizont theologischer Wissenschaftstheorie; in: Dürnberger, Martin u.a. 
(Hg.), Stile der Theologie. Einheit und Vielfalt katholischer Systematik in der Gegenwart, Regensburg 2017, 109-120

Weber, Bernd, Aspekte zu einer Sozialgeschichte des (evangelischen und katholischen) Religionsunterrichts; in: Mannzmann, Anneliese (Hg.), Geschichte der Unterrichtsfächer II. Geschichte, Politische Bildung, Geographie, Religion, Philosophie, Pädagogik, München 1983, 108-176

Wendel, Saskia, Affektiv und inkarniert. Ansätze Deutscher Mystik als subjekttheoretische Herausforderung, Regensburg 2002

Wendel, Saskia, >Als Mann und Frau schuf er sie<. Auf dem Weg zu einer genderbewussten theologischen Anthropologie; in: Herder Korrespondenz $6_{3}$ (2009) 160-164

Wendel, Saskia, Gendersensible Theologie - ein hölzernes Eisen?; in: Lebendige Seelsorge 2 (2015), 82-87

Wendel, Saskia, Sexualethik und Genderperspektive; in: Hilpert, Konrad (Hg.), Zukunftshorizonte katholischer Sexualethik (Quaestiones Disputatae 241), Freiburg i.Br. 2011, 36-56

Wenzel, Knut, Offenbarung Text Subjekt. Grundlegungen der Fundamentaltheologie, Freiburg i.Br. 2016

Werner, Gunda, »Ins Wort fällt mir die Zeit« - Judith Butlers Subjekttheorie als Herausforderung pastoraler Praxis; in: Henkelmann, Andreas, Sonntag, Gisela (Hg.), Zeiten der pastoralen Wende? Studien zu Rezeption des zweiten Vatikanums - Deutschland und die USA im Vergleich, Münster 2015, 41-73

Werner, Gunda, Differenz als theologischer Begriff - subjekttheoretische Überlegungen und theologische Materialproben; in: Alkier, Stefan, Schneider, Michael, Wiese, Christian (Hg.), Diversität - Differenz - Dialogizität. Religion in pluralen Kontexten, Berlin 2016, 91-115

Wildt, Michael, Volk, Volksgemeinschaft, AfD, Hamburg 2017

Wilfred, Felix, Das Christentum und der globale demokratische Prozess; in: Concilium 4 (2007) 474-491

Wimmer, Jeffrey, (Gegen-)Öffentlichkeit in der Mediengesellschaft. Analyse eines medialen Spannungsverhältnisses, Wiesbaden 2007

Wippermann, Carsten, Sellmann, Matthias, Milieus in Bewegung - Werte, Sinn, Religion und Ästhetik in Deutschland. Forschungsergebnisse für die pastorale und soziale Praxis, Würzburg 2011

Wohnig, Alexander, Zum Verhältnis von sozialem und politischem Lernen. Eine Analyse von Praxisbeispielen politischer Bildung, Wiesbaden 2017

Wollbold, Andreas, Religionsunterricht in der Bürgergesellschaft; in: Trierer theologische Zeitschrift 109 (2000), 270-282

Zilleßen, Dietrich, Religion, Kultur, Ethik. Eine Politik schwieriger Beziehungen; in: Zilleßen, Dietrich (Hg.), Religion, Politik, Kultur. Diskussionen im religionspädagogischen Kontext, Münster 2001, 27-42 
Zirfas, Jörg, Pädagogik und Anthropologie. Eine Einführung, Stuttgart 2004 Zoll, Patrick, Volker Gerhardts öffentliche Theologie. Kritische Anmerkungen aus theistischer Perspektive; in: Könemann, Judith, Wendel, Saskia (Hg.), Religion, Öffentlichkeit, Moderne. Transdisziplinäre Perspektiven, Bielefeld 2016, 325-345 



\section{Internetquellen}

Berlin Institute for Public Theology, Mission Statement

https://www.theologie.hu-berlin.de/de/professuren/institute/bipt (3.8.2017, 17:09 Uhr)

Forschungsstelle für Öffentliche Religionspädagogik an der Universität Erlangen-Nürnberg www.rupre.uni-erlangen.org (19.8.2017, 16:31 Uhr)

Research Unit for Public Religion and Education

www.rupre.uni-erlangen.org (19.8.2017, $16.36 \mathrm{Uhr})$

Wissenschaftsrat, Empfehlungen zur Weiterentwicklung von Theologien und religionsbezogenen Wissenschaften an deutschen Hochschulen

https://www.wissenschaftsrat.de/download/archiv/9678-10.pdf (3.8.2017, 17:16 Uhr) 



\section{Namensregister}

Adorno, Theodor W. $143,148,149$, 170, 174

Ahrens, Petra-Angela 172

Alexander, Hanan 125-131

Althusser, Louis 146,172

Amos, Karin 11

Arendt, Hannah $\quad$ 64-65, 80, 133, 146, 151-155, 172, 211

Arens, Edmund $22,44,49,50,55$, $71,114,176,195$

Asen, Robert 62

Aulenbacher, Brigitte 9

Austin, John L. 146-148

Baader, Meike Sophia 160

Bachmann-Medick, Doris 174

Balzer, Nicole 136

Bauer, Christian 173-176, 187, 212

Beck, Ulrich 55

Bedford-Strohm, Heinrich 22, 23, 26

Bedorf, Thomas 141

Bell, Catherin 69

Benhabib, Seyla 62, 64, 173, 180, 197-199

Benjamin, Walter 70, 170, 174

Benner, Dietrich 11, 206

Berlin, Isaiah 110, 126

Biehl, Peter 208

Binder, Ulrich 10, 52

Böckenförde, Ernst Wolfgang 31,57

Böntert, Stefan 179

Böttigheimer, Christoph 171
Bohl, Thorsten 20, 213

Bohmann, James 62

Bourdieu, Pierre $37,49,98,146$, 149, 211

Breul, Martin 55, 59, 69, 188, 192

Bröckling, Ulrich 135,160

Brown, Wendy 163

Bruckmann, Florian 171

Brüggen, Friedhelm 10

Brumlik, Micha 114, 120

Brunkhorst, Hauke 97, 98, 114, 120

Bucher, Anton 206

Buck, Elisabeth 179

Budde, Jürgen 134, 137

Büttner, Gerhard 100

Burawoy, Michael 9, 10

Butler, Judith $25,71,72,85,133-164$, 166-170, 175, 179-182, 190-192, 211

Cady, Linell E. 22

Calhoun, Craig $\quad 51,158$

Casanova, José 24, 108, 193

Casper, Bernhard 177

Chung, Paul S. 21

Cooke, Maeve 69,70,194

Dalferth, Ingolf U. 52, 63

D'Costa, Gavin 23

Dederich, Markus 24

Derrida, Jaques $146,149,162$

Dewey, John 47, 51, 126

Dierksmeier, Claus $\quad 61,110$ 
Dieterich, Veit-Jakobus 206

Doak, Mary 23

Dörre, Klaus 9

Domsgen, Michael 89, 99, 101

Downey, John 62

Dressler, Bernhard 213

Dreyfus, Hubert L. 106, 112

Drilling, Matthias 207

Dünne, Jörg 174

Eckholt, Margit 212

Emmerich, Markus 134

Englert, Rudolf 21, 181, 182, 203

Eribon, Didier 159

Fassin, Didier 137

Fend, Helmut $88,100,204$

Fenton, Natalie 62

Forst, Rainer $24,51,60,66,72,111$, $131,132,137,138,164,183,186-188$, 197-198

Foucault, Michel 26, 38, 71-73, 112, $133-140,142-148,159,161,163,173$, 179, 182

Fraser, Nancy $\quad 62-63,72,120,164,175$

Fresacher, Bernhard 96

Fritsch, Matthias 198

Füllsack, Manfred 90, 93

Füssel, Marian 149

Gabriel, Karl 193

Gärtner, Claudia 15

Gehring, Petra 76

Gerhards, Jürgen $\quad 64,65,93,95$

Gerhardt, Volker 24, 28, 32, 40, 64, $65,68,74-88,94,100,101,133,158$, 166-170, 175

Geuss, Raymond 150

Goldstein, Jürgen 104, 107, 109, 110, 116,132

Graf, Friedrich Wilhelm 56

Graham, Elaine 23
Große Kracht, Hermann-Joseph 22

Gruber, Franz 55

Grümme, Bernhard 13-15, 19-25, $29,30,38,43-45,71,85-89,136$, 139, 164, 172, 175-183, 188, 189, 193 , 207-213

Günther, Klaus 48

Günzel, Stephan 174

Habermas, Jürgen $32-36,38-40,43$, $45,47-74,78,81,83,85,90-93$, $102-105,114,116,119-124,129-133$, $143,145,151,157,166-170,172,173-$ 176, 190-192, 197, 207, 211

Hampe, Michael 189

Hattie, John 16

Haussmann, Werner 21, 22

Heger, Johannes 181, 203, 212

Heller, Agnes 195,196

Herdegen, Peter 210

Heuer, Wolfgang 151

Hochgeschwender, Michael 57, 193, 194

Höhn, Hans-Joachim 195

Höhne, Florian 21-23, 214

Hoff, Gregor Maria 139

Honneth, Axel 51, 53, 65, 78, 104, $107,1112,113,120,133,138,145,164$, 177,180

Horkheimer, Max 182,183

Hormel, Ulrike 134

Horster, Detlef 53

Huber, Wolfgang 22

Hunze, Guido 206

Imhof, Kurt $\quad 28$

Jaeggi, Rahel 107, 161, 162, 180 James, William 109, 126 Jergus, Kerstin 137, 150 Joas, Hans 55, 67, 89, 91-93, 97, 108, $112,114,119,180,193,194$ 
Jochimsen, Maren A. 134

John, Ottmar 68, 71

Kahrs, Christian 207

Kant, Immanuel $44,49,50,57,64$, $66,67,80-81,103,105,112,114,123$, $126,186,197,199$

Kaupp, Angela 159, 212

Kellner, Douglas 51

Kenngott, Eva-Maria 214

Kern, Bruno 152

Klingen, Henning $120,173,195$

Klöcker, Katharina $\quad 28,87$

Kluge, Alexander 28

Knapp, Markus 105, 107, 119-123, 132

Knauth, Thorsten 134

Knöbl, Wolfgang 89-93, 97, 114, 180

Könemann, Judith $20,25,30-34,37$, 43, 201

Kohl, Bernhard 142

Kojima, Tomoko 10, 62, 93-96

Kokorschke, Albrecht 182

Koller, Hans-Christoph $\quad$ 141, 161

Konersmann, Ralf 134,161

Kreutzer, Ansgar 9-11, 37, 60

Krieger, Gerhard 12

Kühnlein, Michael 107, 108, 112, 129, 159,194

Laclau, Ernesto 195

Ladwig, Bernd 91

Lähnemann, Johannes 13, 21, 22

Langenhorst, Georg 210

Langthaler, Rudolf 55

Laubach, Thomas 136

Lenzen, Dieter 97

Leonhard, Silke 179

Levinas, Emmanuel 162,198

Liedhegener, Antonius 22, 31

Liessmann, Konrad Paul 40, 64, 206

Lilla, Mark 159
Lösch, Bettina 209

Ludwig, Christian 144,164

Lübbe, Hermann $\quad 55,56,109$,

Luhmann, Niklas 88-101, 133,151, 158, 167-170, 180-181

Lutz-Bachmann, Matthias 112, 120

Maclure, Jocely $\quad 114,115,124,125$

Manemann, Jürgen 11, 55, 70, 114, 196, 197

Marchart, Oliver 172, 195

Marcinkowski, Frank 93, 96

Markschies, Christoph 179

Marx, Karl 103, 107, 124, 152

Marx, Reinhard 25

Massing, Peter 210

McDermott, Gerald 23

McKee, Alan 28

Mead, George Herbert $\quad 50,67$

Membe, Achille 198

Mendieta, Eduardo 158

Mendl, Hans 179, 206

Menke, Karl-Heinz $\quad 181$

Mette, Norbert 20, 70, 99, 100, 175, 198

Metz, Johann Baptist $11,37,70,181$

Meyer, Katrin 134

Meyer, Thomas 31, 32

Meyer-Drawe, Käte 179

Meyer-Wilmes, Hedwig 53, 62

Miggelbrink, Ralf 22

Moegling, Klaus 206

Moltmann, Jürgen 22

Morton, Andrew R. 23

Mouffe, Chantal 195

Müller, Hans-Peter 49, 98

Müller-Doohm, Stefan 91

Mulsow, Martin 170

Nagl-Docekal, Herta 55

Nanz, Patrizia 49, 63

Nassehi, Armin 68, 92, 97-99 
Neidhardt, Friedhelm 65, 93, 95

Negt, Oskar 28

Nipkow, Karl Ernst $\quad 181,208$

Nöth, Winfried 179

Oelkers, Jürgen 10,11, 52, 97

Oorschot, Frederike van 21

Parsons, Talcott 89

Paul, Eugen 13, 18

Peirce, Charles S. 173-174

Peters, Bernhard 54,59, 83

Peters, Tiemo Rainer 196

Peukert, Helmut 24, 70, 71

Pinker, Susan ${ }_{13} 6$

Pirker, Viera 25, 139

Pirner, Manfred 13, 19, 21, 27, 34-39, 43, 60, 68, 202, 206

Pitschmann, Annette 56,59

Platzbecker, Paul 139

Pohl-Patalong, Uta 214

Polke, Christian 22

Pollack, Detlef 108

Pröpper, Thomas 45

Rawls, John $35,36,38,60,61,67$, 114, 121-124, 129, 151, 192

Reckwitz, Andreas 27, 28, 159, 185

Reder, Michael 56, 58, 67-71, 192, 193, 207

Rendle, Ludwig 179

Renn, Joachim 68

Renner, Tobias 54, 59, 68, 69

Ricoeur, Paul 162

Riedl, Anna Maria 160

Riegel, Ulrich 15, 30

Rieger-Ladich, Markus 211, 214

Riescher, Gisela 28

Ricken, Norbert $135,136,145,162,163$

Rösner, Hans-Uwe 145,161

Rorty, Richard 124, 214
Rosa, Hartmut $\quad 107,109,112,114,115$, 131

Rose, Nadine 134

Rothgangel, Martin 90,100

Rowlands, Anna 23

Rudolph, Enno 121, 124

Saar, Martin 133,138

Salvatore, Armando 64

Sandel, Michael 115

Sander, Hans-Joachim 72

Sander, Wolfgang 13, 18, 31, 208, 211

Sattler, Dorothea 177

Scheunpflug, Annette 99,100

Schieder, Rolf 56,57,138

Schiewe, Jürgen 28

Schink, Philipp 110

Schlag, Thomas 13, 19, 20, 21, 207, 211

Schluß, Henning 21

Schmidinger, Heinrich 136, 137

Schmidt, Heinz 210

Schmidt, Josef $56,58,71,207$

Schmidt, Thomas M. 56,69

Schnädelbach, Herbert 98

Schreiner, Martin 206

Schröder, Bernd 13, 21, 39-43, 48, 63, 202, 214

Schüssler Fiorenza, Francis 11

Schulte, Andrea 206

Schwarz, Susanne 13, 21, 22,

Schweiker, Wolfgang 43

Schweitzer, Friedrich 21, 29, 30, 101, 135,138

Seibert, Christoph 192

Sellmann, Matthias 172,175

Sennett, Richard 49, 64

Sievernich, Michael 212

Simojoki, Henrik 20, 204

Sinner, Rudolf 22

Smith, James K.A. 108

Sobrino, Jon 70 
Stackhouse, Max L. 26

Stamm, Marcelo 170

Steinkamp, Hermann 135

Storrar, William F. 23

Strasser, Stephan 162

Striet, Magnus 99

Taylor, Charles $\quad 28,59,69,97,102-$ $133,158,166-170,172,176,181,187$, 190-193, 211

Telser, Andreas $\quad 33,70,172,178,182$

Tenorth, Heinz-Elmar 97

Thiem, Annika 160

Thimmel, Andreas 209

Tracy, David 29, 33, 172, 178

Uhl, Florian 69

VanAntwerpen, Jonathan 158

Viertbauer, Klaus 55

Villagrán, Gonzalo 22

Vögele, Wolfgang 22, 23, 56

Wacker, Bernd 11, 55

Wagner, Thomas 164

Waldenfels, Bernhard 179

Walzer, Michael 129, 138, 195

Webb, Willie James 23

Weber, Anne 73

Weber, Bernd 13

Weber, Max 49, 55, 105, 108

Wegner, Gerhard 172

Wendel, Saskia 136, 160

Wenzel, Knut $178,181,212$

Werkner, Ines-Jaqueline $\mathbf{2 2}$

Werner, Gunda 139,160

Wildt, Michael 155

Wilfred, Felix 62

Wimmer, Jeffrey 62

Wingert, Lutz 48

Wippermann, Carsten 172

Wohnig, Alexander 209, 210
Wollbold, Andreas 21

Zichy, Michael 136,137

Zierer, Klaus 25

Zilleßen, Dietrich 196

Zirfas, Jörg ${ }_{136}$

Zoll, Patrick 75 
